\title{
Triggering and motion of landslides
}

\author{
EDUARDO E. ALONSO*
}

\begin{abstract}
The paper analyses the dynamic behaviour of a class of landslides characterised by a well-defined failure surface where shear strains accumulate. The subject goes beyond the common concepts of safety factor and static analysis, and discusses procedures to identify the velocity and runout, once stability is lost. Three initial case histories serve to highlight the relevance of predicting the motion after failure. These cases and a few others discussed in the paper help to connect the theoretical developments with their relevance in practice. The following landslides receive attention in the paper: Pampaneira, Cortes, Aznalcóllar, Vallcebre, Selborne, Vajont and Canelles. Existing publications describe all of them in some detail. These landslides illustrate the following phenomena: creeping motion, first-time failures, rapid sliding and the transition from slow to very rapid motion. These phenomena are present in the concept and organisation of the paper. Simple geometries (planar, double block) facilitate the description of the basic physics but are also capable of delivering useful solutions and deep understanding. In a second stage, the simple sliding cases evolve into continuum analysis. The material point method (MPM) offered the possibilities of approaching arbitrary geometries and removed a main limiting assumption of simple cases, namely the 'a priori' knowledge of the failure mechanism and its subsequent propagation. Two well-documented cases of progressive failure in brittle, high-plasticity, overconsolidated clays (Aznalcóllar and Selborne) provided useful data to check the capabilities of the MPM analysis to predict correctly the internal development of shearing surfaces and the observed runout. The method also provides information regarding the transition from an essentially 'static' behaviour to an accelerated displacement. A sensitivity analysis, inspired by the Selborne case, resulted in an interesting relationship between runout and soil brittleness. Rate effects on friction angle explain the creeping behaviour of landslides. Changing velocities of Vallcebre slide under a time history of pore water pressures provided a validation exercise for a simple modelling approach. However, friction laws do not easily explain the sudden acceleration observed in landslides such as Vajont. Previous work to explain the rapid acceleration and fast motion observed in some landslides rely on heat-induced pore pressurisation of the sliding surface. Further work introducing a double wedge for Vajont landslide stressed the relevance of shear band thickness and, in particular, the soil permeability. A generalisation of the involved thermo-hydro-mechanical (THM) formulation, by way of MPM, met the difficulty of solving the inconsistent results deriving from the mesh-size control of the shear band thickness. The solution was to embed shear bands, with a reasonable thickness, in the material points describing the soil matrix. This approach successfully reproduced the known Vajont after-failure motion. The model provided estimations of the internal shearing of the sliding rock mass, the temperature increase of the sliding surface and its transient excess pore pressures. A final section describes the close relationship between the creeping motion of a landslide and its eventual evolution towards a rapid phenomenon. A simple planar slide provided a set of dimensionless parameters governing the interaction. Strain rate effects on friction explained the creeping part of the problem. The paper describes a generalised approach to arbitrary geometries by means of MPM formulation. Canelles landslide was useful to discuss the merits and limitations of predictions based on the absence or presence of creeping and THM physics of the formulation and their possible combinations.
\end{abstract}

KEYWORDS: creep; dynamics; failure; friction; landslides; numerical modelling

\section{INTRODUCTION}

Classical methods (limit equilibrium) of slope stability provide a numerical scale (the safety factor) to the proximity of failure. However, failure events are often unavoidable, especially in natural environments. In fact, 'failed' slopes are a common occurrence in valley slopes and the question of the

Manuscript received 13 February 2020; revised manuscript accepted 30 July 2020. Published online ahead of print 2 October 2020. Discussion on this paper closes on 1 May 2021, for further details see p. ii.

* Department of Civil and Environmental Engineering, Division of Geotechnical Engineering and Geosciences, Polytechnic University of Catalonia (UPC), Barcelona, Spain

(Orcid:0000-0003-2472-3951). expected evolution of the slope becomes the critical question. In other circumstances, posing the question of the consequences of instability is appropriate. In a related field of civil engineering, dam engineering, the consequences of structural failure are an integral part of standard designs.

Triggering causes of slope failure and the subsequent motion of the failed mass look like separate aspects, requiring specific analysis and even material properties. However, it turns out that the two phenomena are closely linked and this paper will provide a discussion on this relationship for some classes of landslides.

Predicting the motion of unstable soil or rock masses has an obvious connection with the issues of risk and expected damage. In addition, it provides quantitative procedures to design protection structures or other procedures (barriers, excavations) to avoid or minimise the consequences of failure. 
Establishing a joint consideration of triggering and motion has an added advantage. It allows linking of the 'static' geotechnical description of soil or rock properties with the subsequent dynamic stage. In some of the computational procedures to predict the evolution of flow-type instabilities, this link is often difficult to establish because the analysis of the motion relies on fluid-mechanics methods, which essentially depend on the viscosity of the moving mass, a property unrelated to common constitutive parameters in geotechnical practice.

However, this is not a fundamental criticism but a confirmation of the difficulty of finding unified frameworks to integrate triggering and motion of landslides, especially for failures that evolve into flows. State parameters, which are useful to describe 'static' properties (before the triggering stage), may evolve into different state parameters for a proper description of the motion stage.

This lecture does not cover all of the categories of landslide phenomena, but a family of landslides phenomena described in some classifications, notably the well-known classification of Varnes (1978) and the recent review of Hungr et al. (2014). Essentially, this lecture will be concerned with slides in a strict sense. The motions analysed here are masses of relatively undisturbed soil or rock sliding on well-defined surfaces or shear bands. Often, these shear bands develop in a weaker clay stratum if one imagines a sequence of layers of varying stiffness and strength. This is also the case of slides in homogeneous soil profiles because of the natural development of localisation of shear deformations in bands (Vardoulakis, 2006). Descriptions accepted for this wide class of motions, in terms of the kinematics of the motion, are rotational sliding, translational sliding and lateral spreading. In terms of the material involved, it is common to refer to rock or soil slumps, block slides, debris slides, earth slides and rock or soil spreads (Hungr et al., 2014).

Two previous Rankine lecturers addressed specifically slope stability. Skempton (1964), the fourth Rankine lecturer, interpreted a few case records of instability in several soils, but mainly in overconsolidated, brittle, high-plasticity, fissured London Clay. He calculated, by limit equilibrium methods, average values, $\bar{\tau}$, of the drained mobilised shear strength at failure. At that time (1964), the relevance of residual friction to explain the long-term behaviour of clay slopes began to be recognised. He defined a dimensionless normalised 'residual factor'

$$
R_{\mathrm{f}}=\frac{\tau_{\text {peak }}-\bar{\tau}}{\tau_{\text {peak }}-\tau_{\text {res }}}\left(0 \leq R_{\mathrm{f}} \leq 1\right)
$$

The high $R_{\mathrm{f}}$ values determined in most cases analysed (the exception was an unweathered, non-fissured, low-plasticity boulder clay) was attributed to the presence of fissures and microcracks. In the years to follow, the pioneering contribution of Skempton - namely the process of progressive failure - was explained by changes in effective stress associated with pore water pressure equilibration after the initial excavation-induced changes (Vaughan \& Walbancke, 1973). It turned out that a proper analysis of progressive failure requires a coupled hydro-mechanical approach and a strain-softening constitutive model. Finite-element analyses are suitable for this purpose. Potts \& Zdravkovic (2001a) provide a good account of progressive failure of cut slopes in London Clay. Here, progressive failure in brittle soils is also discussed, paying attention to the dynamics of the unstable mass, once the slope becomes unstable.

Leroueil (2001), the 39th Rankine lecturer, contributed a comprehensive review of the necessary geotechnical aspects to understand landslides. He states in the closure of his paper, 'Slopes seem to be the most complex problems that geotechnical engineers face'. If not the most complex, it is certainly a multifaceted problem and his lecture is a good example. Leroueil combines a detailed description of soil properties at element scale and a review of slope behaviour at large scale. He describes in some detail the relevance of strain rate effects to explain soil strength and creeping motion. Strain rate effects will also be present in some sections below. Leroueil's lecture presents also the post-failure motion of landslides. The concept of energy dissipation helps to define the physics of the motion. The paper presents a few case records of landslide triggering and subsequent motion. Overall, Leroueil's contribution is a thorough critical discussion of all the relevant aspects present in the understanding of landslides.

In the recent past, the amount of publications on landslide analysis has increased rapidly. One good reason is the wide range of disciplines interested in the subject and, in particular, geology and engineering geology, rock mechanics, soil mechanics and geotechnical engineering. This paper concentrates on basic physical phenomena explaining and providing predictive tools. The approach follows two lines of argumentation: geometrically simple cases are first analysed. They even bring the possibility of deriving analytical solutions, which are always a solid reference to interpret the outcome of the analysis. In a subsequent stage, concepts and procedures are generalised to arbitrary geometries. This is a necessary step for engineering applications.

The second section of the paper includes the description of three case records to illustrate the significance of predicting the evolution of landslides and the post-failure motion. The third section discusses first failures in brittle soils. The analysis of the triggering and post-failure motion of two cases, Aznalcóllar dam failure and the Selborne experiment, provides an interesting discussion and serves to validate the computational tool developed. The fourth section describes slow-moving landslides from the perspective offered by strain rate effects on drained strength. The fifth section deals with fast or very fast landslides. This is a fascinating subject, which has attracted the interest of a large number of relevant geotechnical engineers ever since the catastrophic failure of Vajont in 1965. This phenomenal landslide will be revisited, simplifying at first the geometry and, in a second part, getting closer to field conditions. The sixth section discusses the transition from slow-moving (creeping) landslides to a generalised failure, associated with a significant increase in landslide velocity.

The material point method (MPM) was the numerical tool used in the simulation of several case histories discussed in the paper. The MPM is one of the available computational methods to deal with large displacements and deformations in a dynamic framework. MPM defines the body (in the present case, the volume of soil or rock experiencing deformations, velocities and displacements) by a number of material points, which carry with them all the properties of interest (mass, stress, pore pressure, deformation and constitutive and state parameters). A computational mesh, which remains unchanged during the analysis, serves to perform calculations (derivatives, integrations).

In the case shown in Fig. 1, the material point represents an unsaturated soil having three phases (Yerro et al., 2015). The material points move through the computational mesh in a manner sketched in Fig. 2. In a first stage, the information carried by material points is transferred to the nodes of the mesh, where the dynamic equations of motion are solved.

Figure 2(b) shows the displacement vectors for a given time increment at time $t$. This information goes back to material points to update soil variables and, in particular, displacements (Fig. 2(c)). The fourth step (Fig. 2(d)) shows the 


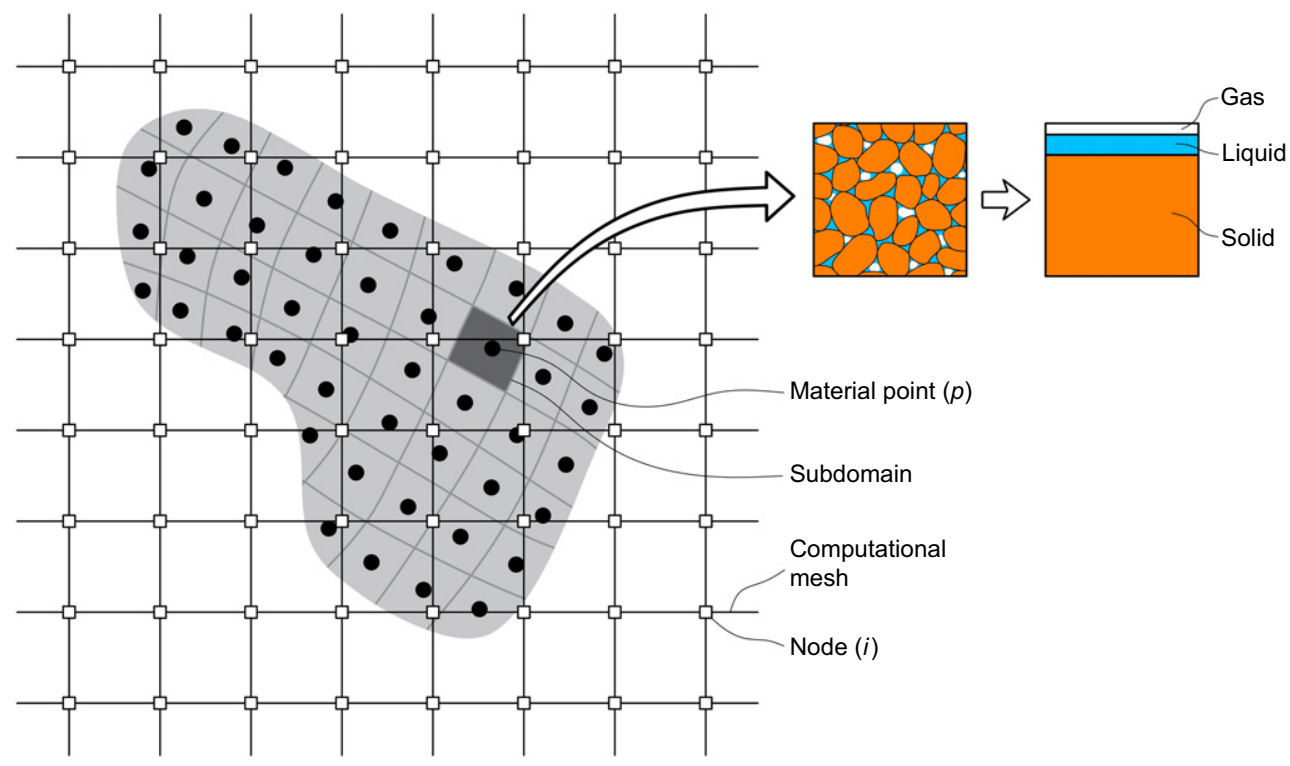

Fig. 1. Illustration of main components of the MPM for a slope stability problem (Yerro et al., 2015)

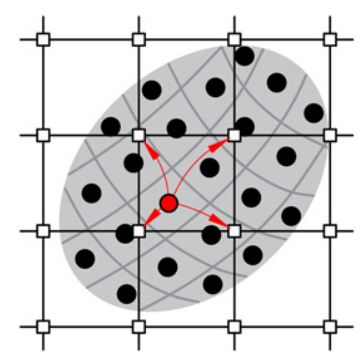

(a)

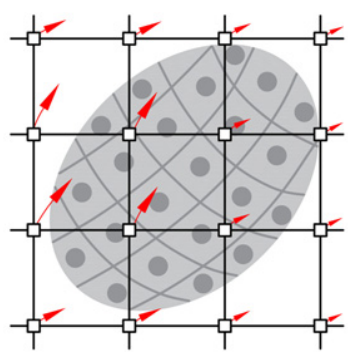

(b)

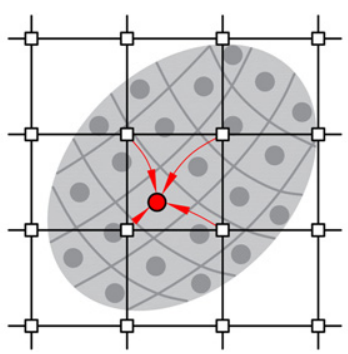

(c)

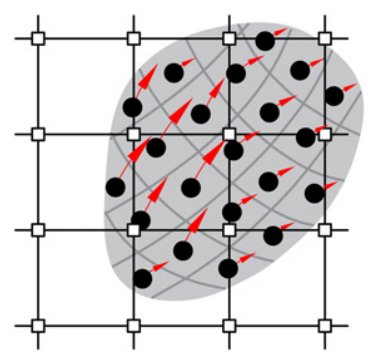

(d)

Fig. 2. The computational sequence in MPM (Fern \& Soga, 2016)

displacement of material points and the new position and deformed geometry of the moving body.

MPM is a continuum method of analysis and it shares some features with the finite-element method (interpolation shape functions, assembly of nodal equations). This facilitates the programming of the method. MPM is just one of the Eulerian-Lagrangian methods developed in the past decade to incorporate large displacements in geotechnical applications. Soga et al. (2016) review the available methods and highlight other advantages and limitations. A recently published book (Fern et al., 2019) provides the theory and numerical details, and describes the application of MPM to a variety of geotechnical situations.

Two MPM computer codes were used to analyse the case histories discussed below: Geopart and Anura3D. Geopart is a two-dimensional (2D) MPM code for saturated soil which solves the equilibrium and balance equations written in the so-called ' $(\bar{u}, p)$ ' formulation. The primary variables are the soil displacements, $\bar{u}$, and the pore water pressure, $p(\mathrm{Li} \&$ Zienkiewicz, 1992). This approach does not consider the relative accelerations of fluid with respect to solid.

Zabala et al. (2004) described Geopart, which was one of the first times that MPM could deal with coupled problems in saturated soils. New features (rate effects, thermal interactions), added later to the code, improved the Geopart code used here.

Anura3D is the result of a joint effort by the MPM research community. The web page (Anura3D, 2020) provides information about the community and the software developed. Anura3D uses a velocity formulation. In this case, the formulation includes relative accelerations of fluid with respect to the solid in the balance and equilibrium equations, formulated in this case in terms of the velocities of solids and fluids.

\section{THREE CASE RECORDS}

Pampaneira creeping landslide

Pampaneira is a large and ancient creeping landslide, located in Granada province, Spain. The toe erosive action of the Poqueira River is probably a continuous trigger of the motion. Fig. 3 shows a longitudinal profile. The unstable volume is estimated to be in the order of 3 to $4 \cdot 10^{6} \mathrm{~m}^{3}$. The rock substratum is made of highly fractured Paleozoic schists. Two faults, shown in the figure, cross the landslide.

Colluvial soils cover the upper levels of the landslide. In the lower part, thicker clay deposits lie on top of the schists. A village (Pampaneira) occupies the lower third of the slide. The average slope angle is $26^{\circ}$. However, the upper half is steeper $\left(30^{\circ}\right)$ than the lower half $\left(20^{\circ}\right)$. A steel penstock, built in 1953, approximately follows the dip direction of the valley slope. The tube was anchored to the valley slope surface by a few concrete blocks ('fixed points') and 'sliding' supports which, unlike the 'fixed' points, could follow the slope displacements without inducing tensile or compressive stresses on the tube.

The penstock diameter changes from $1.5 \mathrm{~m}$ at the water inlet, located close to the crest of the slide, to $1.2 \mathrm{~m}$ at the connection with the power station on the left bank of the Poqueira River. During its operating life (1953 until 


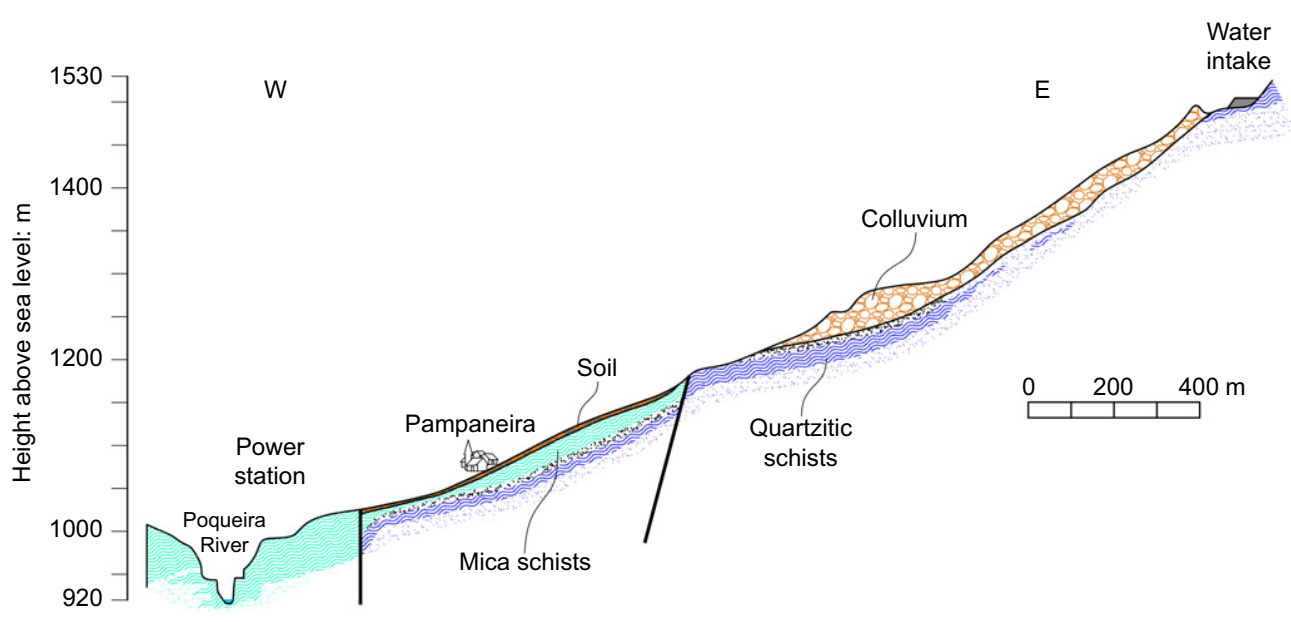

Fig. 3. Representative cross-section of Pampaneira creeping slope
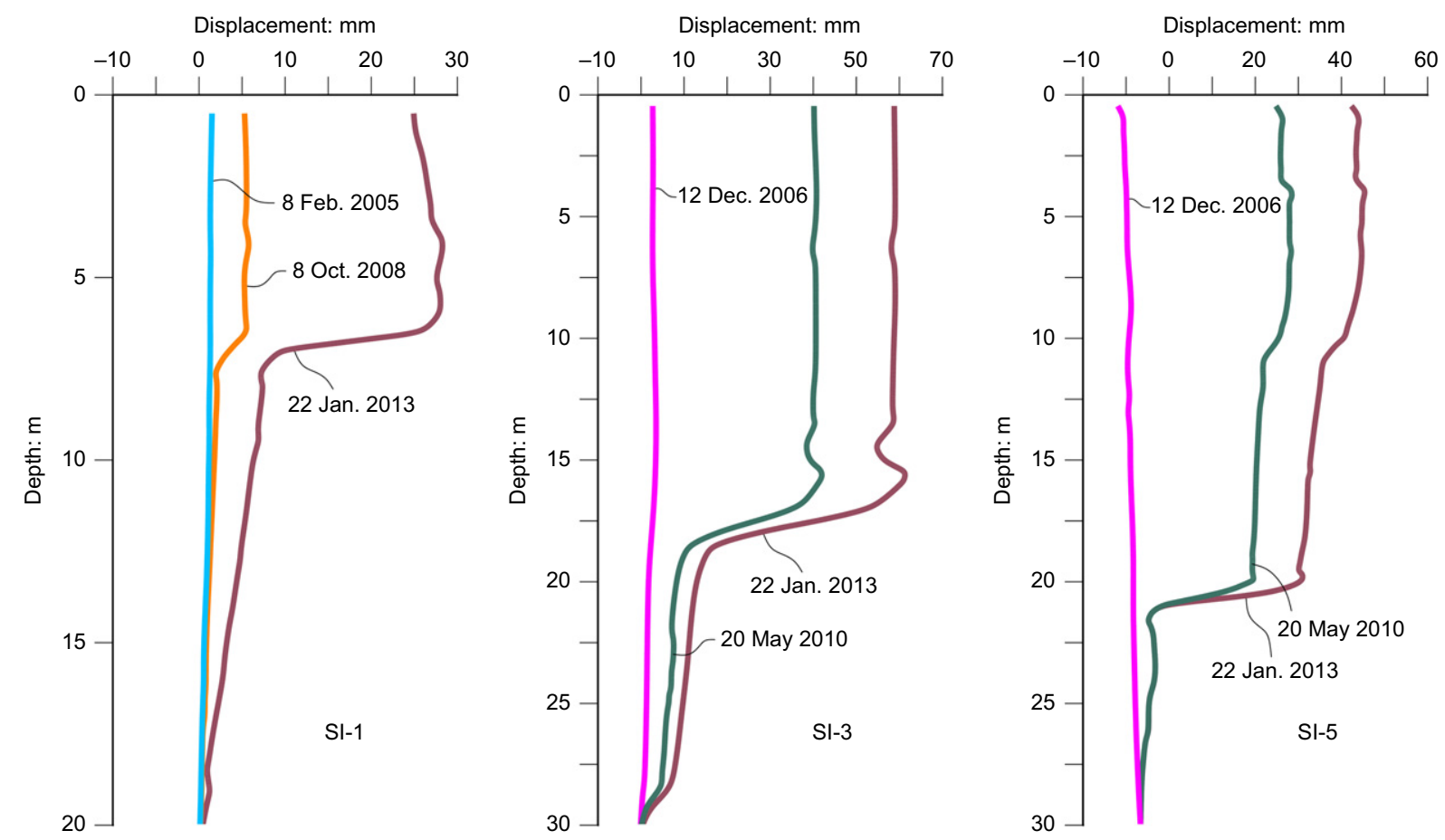

Fig. 4. Displacements measured, at the indicated dates, in three inclinometers

the present) the tube has suffered a few incidents and modifications (transformation of fixed points into sliding supports; installation of telescopic joints; repair of buckled sections) to mitigate the effects of the slope motion. The penstock has a length of $1250 \mathrm{~m}$.

The pipeline internal water pressure near Pampaneira village is $3-3.5 \mathrm{MPa}$. A tube failure and an uncontrolled high flow rate under pressure are risks for the village.

Eight inclinometers provided information on slope displacements during a 10 year period (1998-2008). Fig. 4 shows recorded displacements during this period in inclinometers SI-1, SI-3 and SI-5 (position given in Fig. 5). All the inclinometer records indicate that the creeping motion originates in deep sliding surfaces, which are easily identified in the plots. The sliding surface follows some clay-rich schist levels in the upper part of the slope and the contact between surface altered schists or colluvial soils and the underlying schist substratum. However, the precise geometry of the moving mass is insufficiently known.
Figure 5 shows the surface displacement vectors identified by inclinometers, plotted along the penstock position. Slope displacements may induce longitudinal stresses on the pipeline but also shear loading and bending moments. The slope creep rate estimated from inclinometer data in the period 1998-2008 is very small.

According to the Cruden \& Varnes (1996) classification of landslide velocities, Pampaneira landslide falls in the category of 'extremely slow' motions. The recommended action for this range of velocities, according to Varnes (1978) is 'nil'. However, the penstock known history of incidents and the aforementioned potential risk of flooding in case of pipe failure indicate that corrective actions are required.

There are also observations, which indicate that, in periods of high rainfall intensity, some portions of the unstable mass may accelerate and reach 'moderate' displacement velocities. Fig. 6 shows this effect for an early age of the penstock operation. The plot shows the downhill displacement records of a sliding support and its relationship with rainfall. 


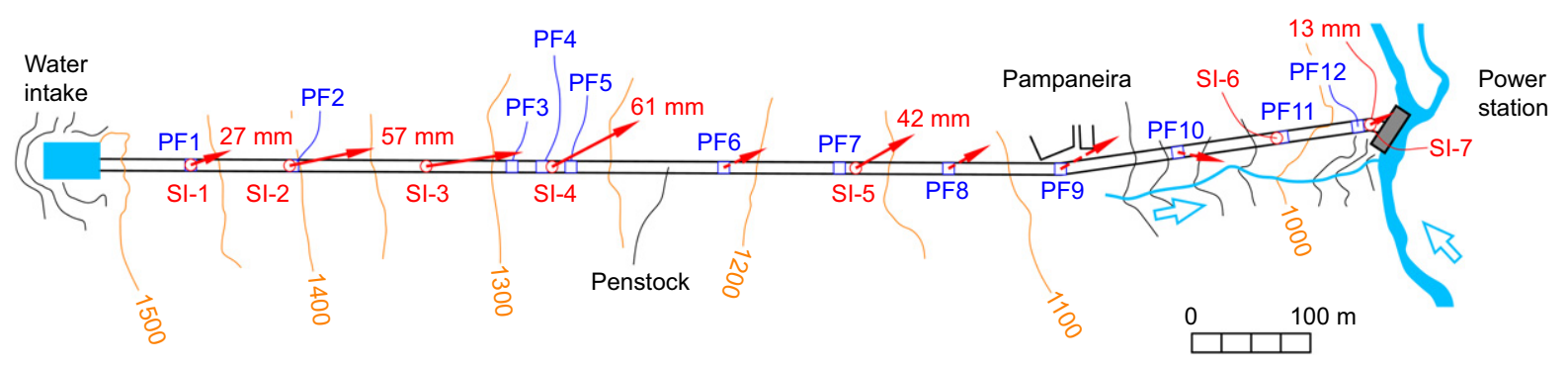

Fig. 5. Measured surface displacements in inclinometers (SI-i) in the period 2003-2012. The position of fixed points of the penstock are indicated (PFi)

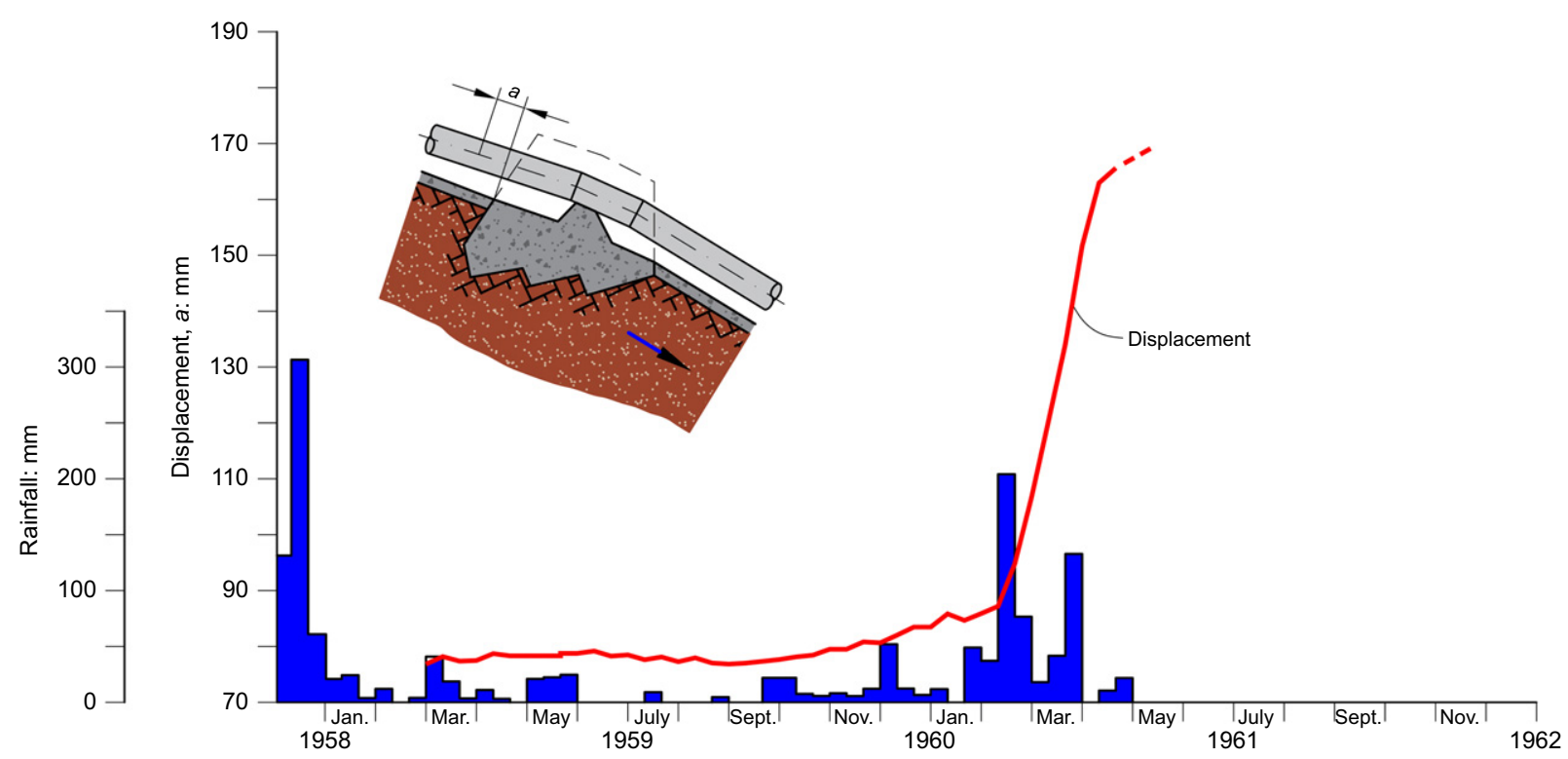

Fig. 6. Correlation between rainfall intensity and displacement of a simple support of the penstock

The owner of the hydroelectric station maintained continuous attention to the integrity of the penstock and the evolution of landslide displacements. There are some specific recent questions in view of the accumulated experience, field observations and the intention of maintaining the hydroelectric station in operation, as listed below.

(a) Is there a risk of the slow, creeping motion evolving into a catastrophic failure of the slope?

(b) Could the operation of the energy plant be reasonably maintained during the next 30 years?

(c) What are the recommended protective actions?

Question $(c)$ is outside the scope of this paper. However, the first two questions address one of the main topics discussed here, namely the nature of creeping landslide motion and its evolution towards a generalised failure, which involves a substantial acceleration of the moving mass.

\section{Cortes de Pallás landslide}

The operation of Cofrentes nuclear power plant in the province of Valencia, in the valley of the Júcar River, led to the construction of Cortes arch dam, downstream from the location of Cofrentes. Cortes dam provided a regulated water reservoir for the cooling of the power plant. A quarry excavated upstream of the dam provided the rock aggregates for the concrete of the dam. Fig. 7 illustrates the original profile of the river valley, the quarry excavation in the lower part of the valley and the regularly layered Mesozoic limestone providing the aggregates.
The figure shows also the position of a $2 \mathrm{~m}$ thick 'marl' layer, found at depth, concordant with the limestone layering. Quarry excavation triggered a landslide slowly moving towards the river. Fig. 8 shows records of surface displacement monitored by deep inclinometers. Inclinometer profiles clearly indicated the presence of a sliding surface within the marl layer.

The 'marl' was described as a low-plasticity $\left(w_{\mathrm{L}}=20-28 \%\right.$; $\left.w_{\mathrm{P}}=13-14 \%\right)$, low-porosity $(n=0 \cdot 25)$ and high-consistency $(w=16 \%)$ detrital soil. Clay minerals amounted to $10-40 \%$ of the mineral content. Dolomite in a large proportion (55-90\%) completed the marl mineral content. The marl also includes traces of quartz and calcite.

The induced landslide, about $5 \times 10^{6} \mathrm{~m}^{3}$ in volume, generated two major concerns: $(a)$ it was very close to the left Cortes dam abutment and $(b)$ a rapid landslide invading the reservoir would create a tsunami and a possible dam overtopping. The failure of Vajont in Italy was present in the technical discussions to assess the situation. Fig. 7 shows the maximum reservoir level. This level was a certain situation because of the operational requirements of the nuclear power station.

Alonso et al. (1993) describe the Cortes landslide. A standard back-analysis, using limit equilibrium methods, indicated that the operating friction angle on the sliding surface (before any reservoir water impounding) was in the range $16 \cdot 5-17 \cdot 7^{\circ}$. This range originates in the assumption made on the position of the water level: either at the top of the marl layer or at the bottom ( $2 \mathrm{~m}$ difference in water level). However, no water table was found in borings: the limestone 


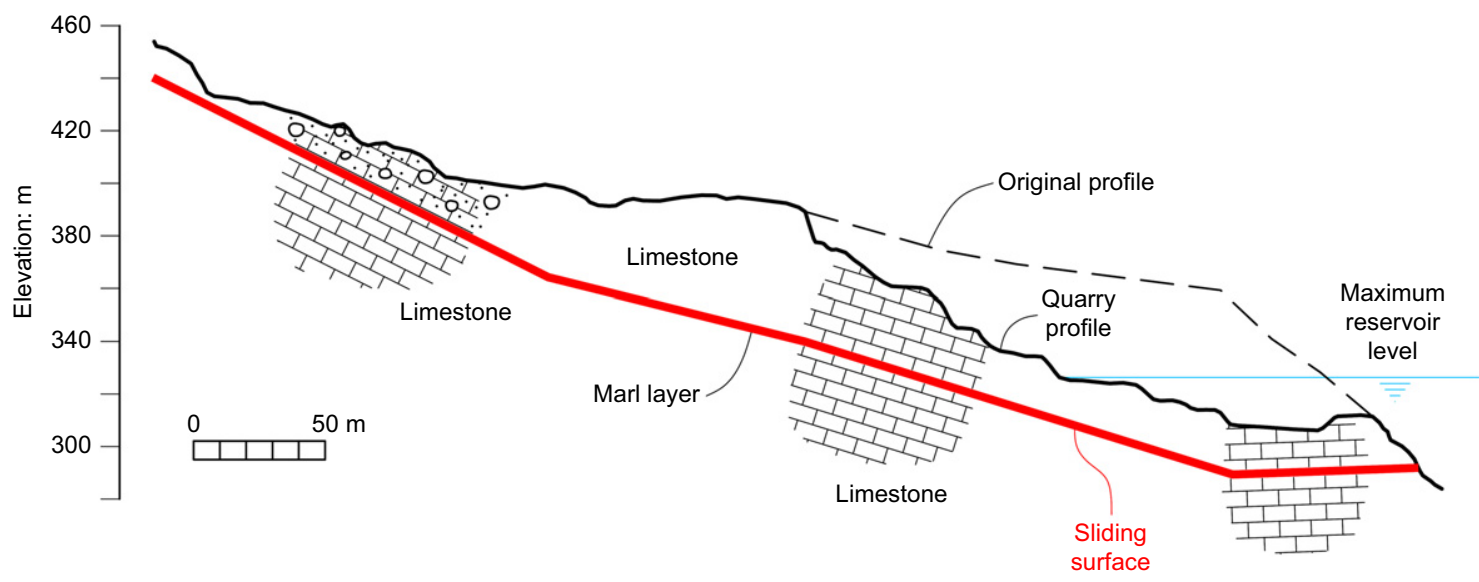

Fig. 7. Representative cross-section of Cortes slide

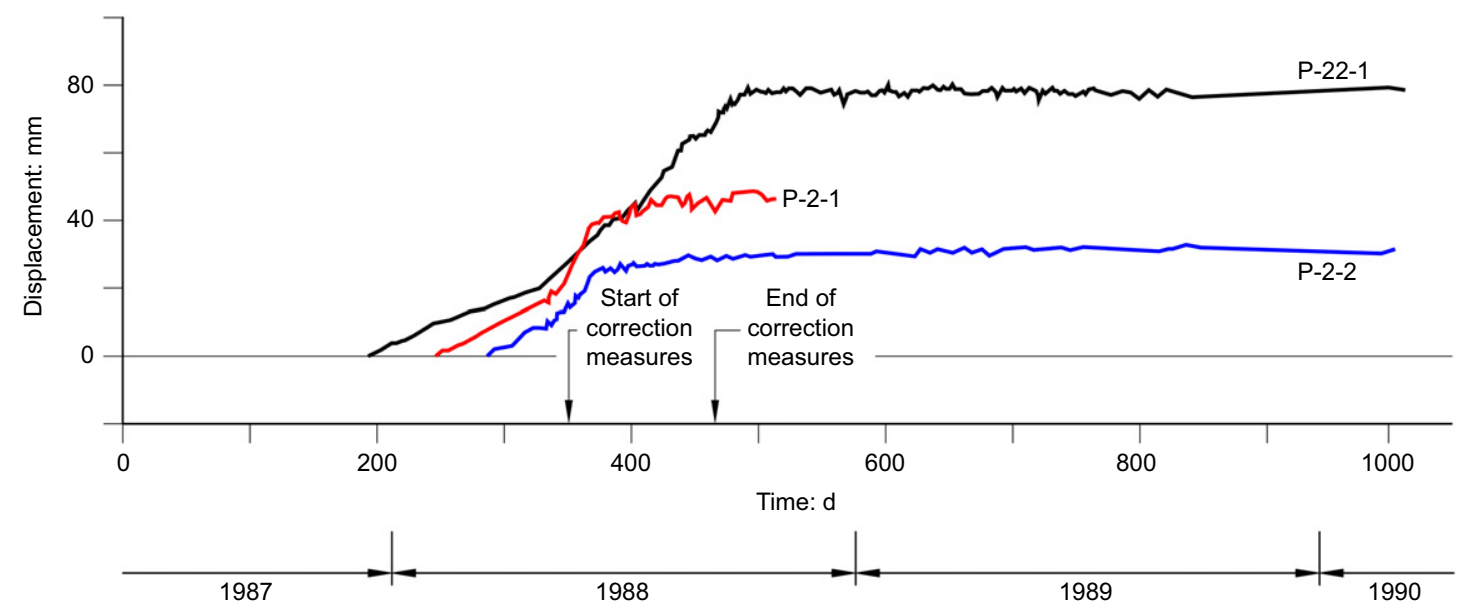

Fig. 8. Evolution of surface displacements at the position of three inclinometers

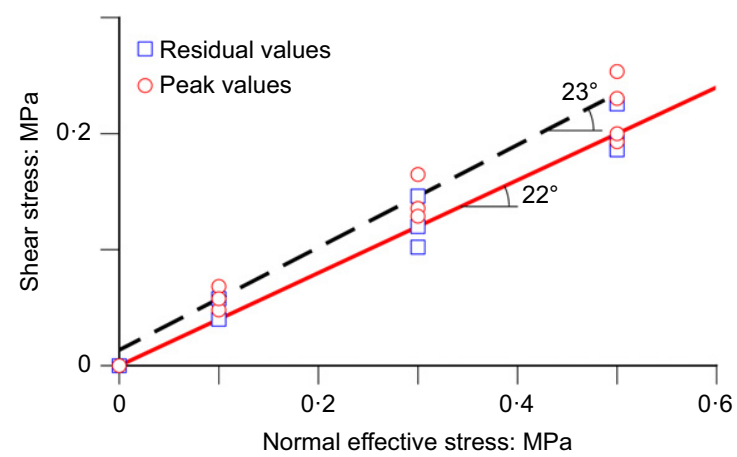

(a)

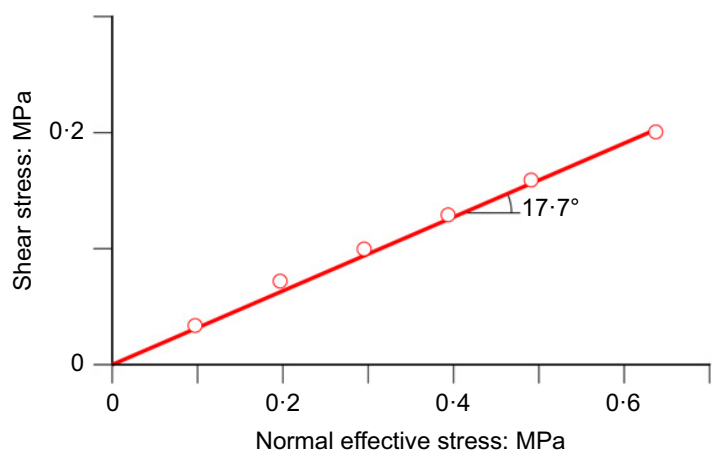

(b)

Fig. 9. (a) Results of drained direct shear tests on samples of the marl layer; (b) strength envelope determined by a direct shear test on the actual sliding surface

layers above and below the marl layer were highly pervious. The limestone above the marl layer was fragmented and powdery.

Removing the weight from the upper part and placing the excavated material into the quarry led to the stabilisation of the landslide. Fig. 8 shows the effect of this stabilisation procedure. The displacement rates, after a period of acceleration immediately after the start of operations, decreased with time and eventually became negligible. The maximum recorded displacement rates before stabilisation were $1 \mathrm{~mm} /$ day. Note also in Fig. 8 that the rate of displacements was continuously increasing before the corrective measures became effective.

The main concern in 1987-1988 of the responsible engineers - namely, the risk of a rapid landslide failure could not be answered at that time. A rapid stabilisation was the practical and wise decision.

This solution (stabilisation) is not always possible in very large landslides or in rugged topography. This case, as well as Vajont, motivated the research reported in this paper.

Cortes landslide teaches other lessons, connected to the origin and history of the landslide. These lessons are also 
relevant for the discussion of the loss of strength in sliding surfaces, a topic raised below. Drained shear box testing, including reversals, on samples recovered from the marl layer, resulted in peak and residual friction angles of $23^{\circ}$ and $22^{\circ}$, respectively. Fig. 9 shows the measured strength envelopes. The excavation of the upper part of the slide uncovered the sliding surface: a planar grey-greenish surface showing pronounced striations in the direction of the sliding motion (Fig. 10) (the grooves shown in the picture are the result of rainfall-induced erosion).

Figure 11 shows a vertical section of the sliding band (the material on top) and the marl itself (the lower part), of brownish colour. The uncovered sliding surface was also tested in the shear box by carefully aligning the box shearing plane and the sliding band. Samples were saturated before testing under drained conditions. Fig. 9 shows the strength envelope. The measured drained friction was $17 \cdot 7^{\circ}$, which matches the back-analysed friction of the entire slide. Scanning electron microscope observations of the marl (Fig. 12) show the nature of this material: it is a mixture of

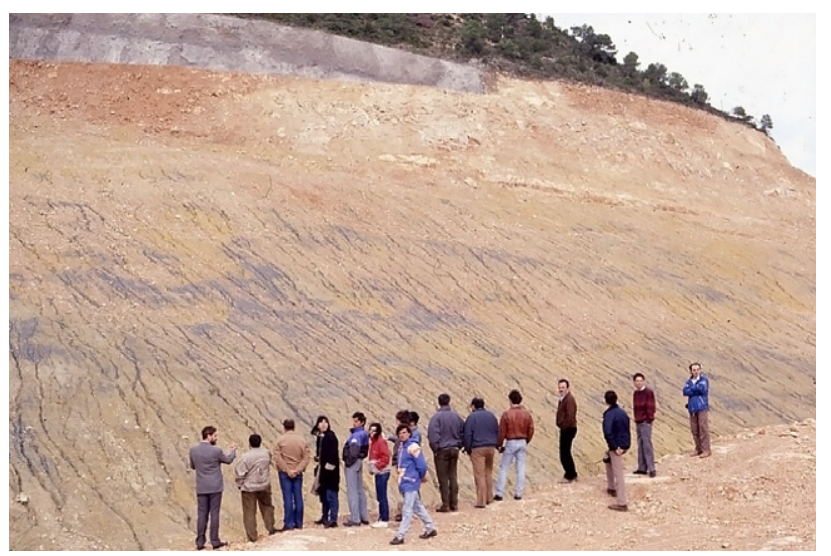

Fig. 10. The sliding surface of the upper part of Cortes slide after stabilising operations

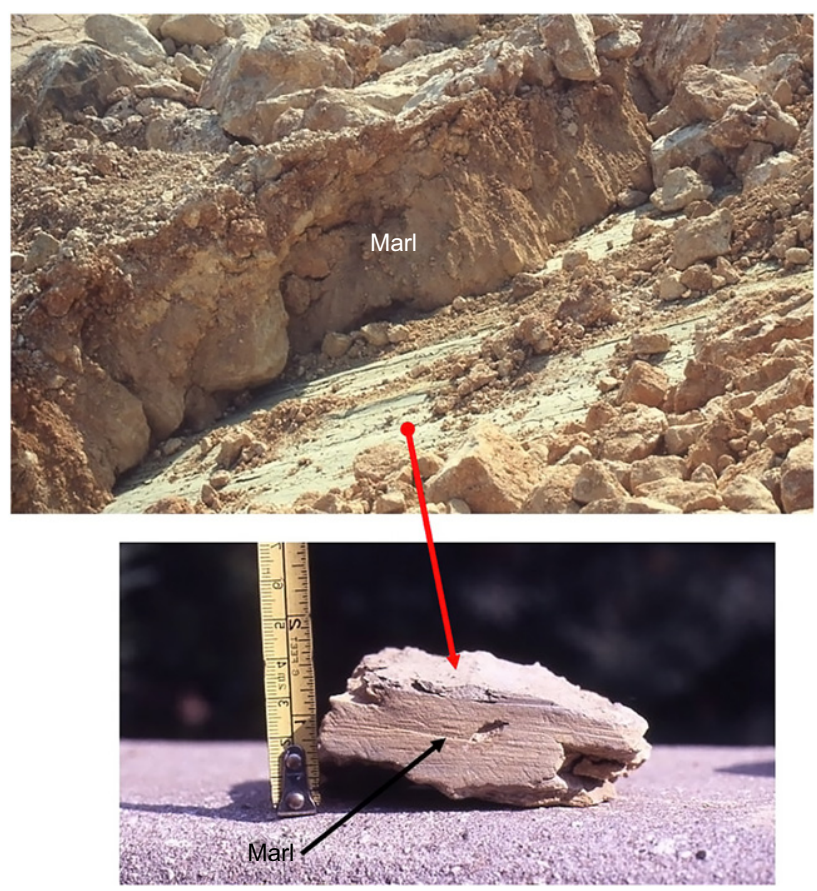

Fig. 11. The 'marl' layer and the uncovered sliding surface and a detail of the thin sliding band and the marl layer below rhombic dolomite crystals and clay platelets. This granular microstructure, which exhibits clay coatings of the dolomite crystals, facilitates the internal shearing. The measured drained friction angle $\left(22-23^{\circ}\right)$ is $5^{\circ}$ above the friction angle of the sliding surface itself.

The mineralogy of the shear band was investigated by carefully removing soil powder, scraping the sliding surface with a knife and determining the materials present by X-ray diffraction. Fig. 13 shows a comparison of the mineralogy of the marl and the soil in the shear band. Both diffractograms exhibit a similar 'signature'. However, there is a major difference: the massive dolomite peak of the marl is almost absent in the shear band.

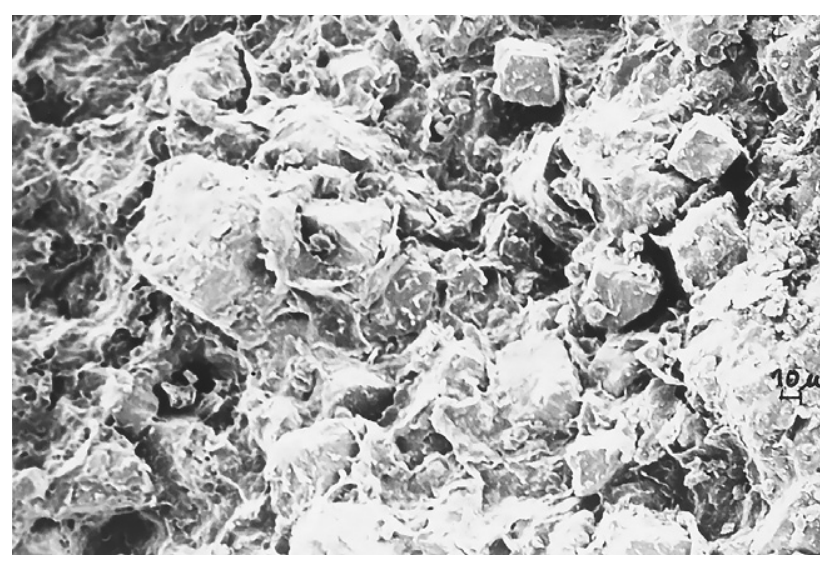

Fig. 12. Scanning electron microphotograph of the 'marl' material. Kaolinite and illite platelets surround dolomite crystals

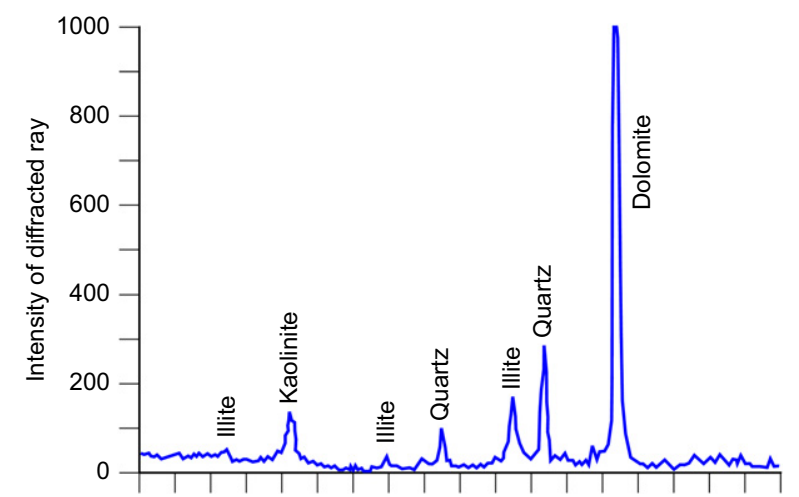

(a)

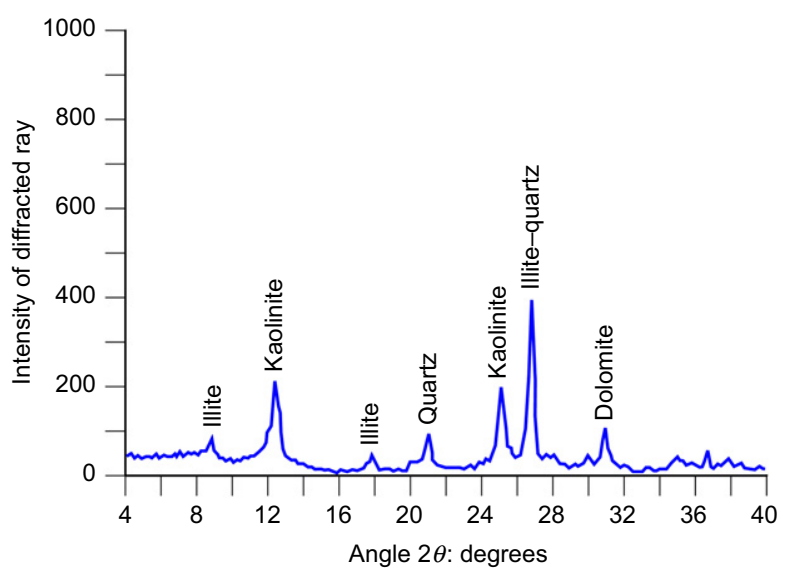

(b)

Fig. 13. X-ray diffractograms of (a) the 'marl' layer; (b) the shear band 


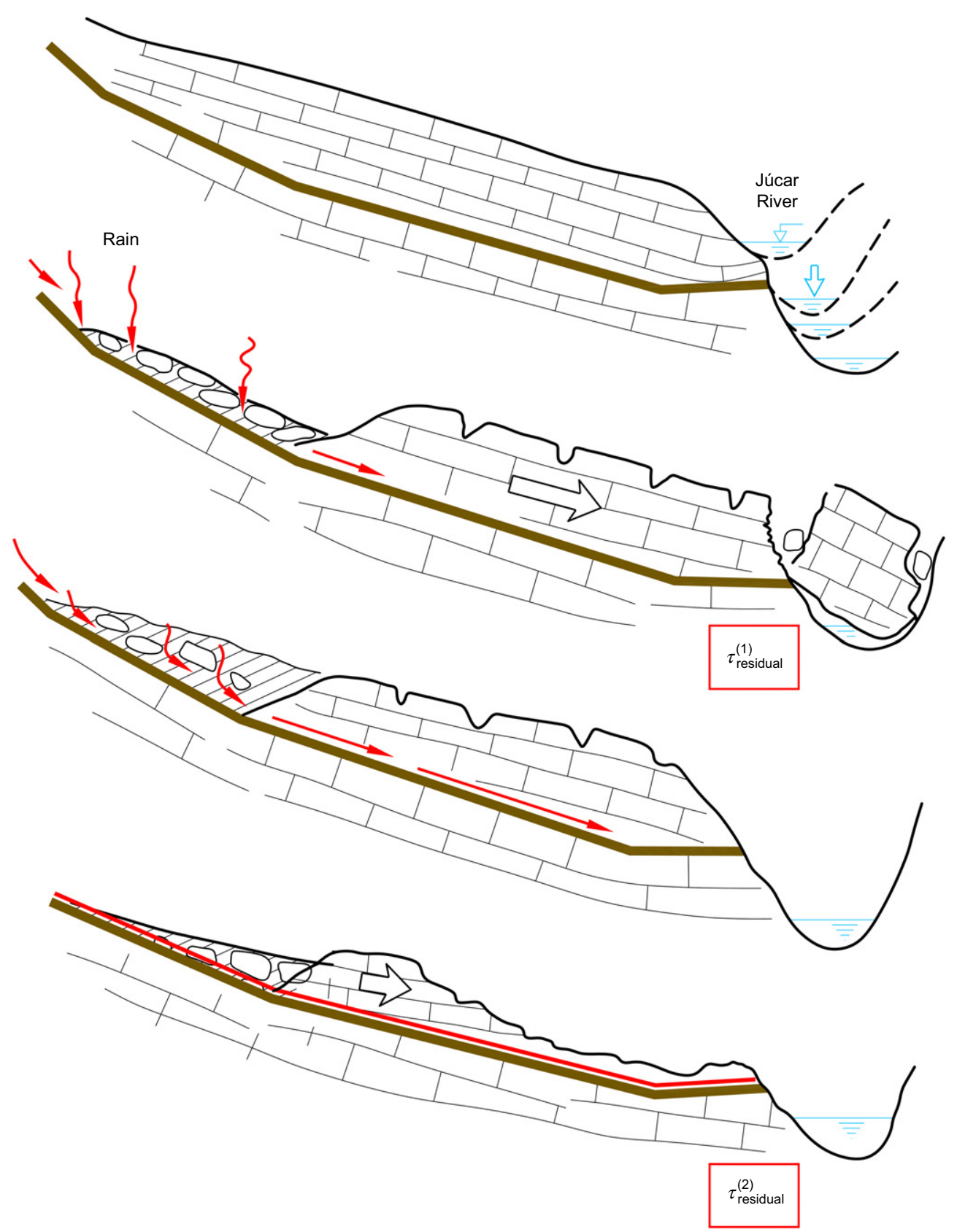

Fig. 14. Hypothetical reconstruction of Cortes landslide. The initial residual strength operating in the marl layer after the first failure $\left(\tau_{\text {residual }}^{(1)}\right)$ because of the large shearing deformations, reduces in time to $\tau_{\text {residual }}^{(2)}$ because of dissolution by infiltration water of carbonate minerals located in the shear band. However, heat generated in the sliding surface during the first failure may also explain significant reduction of the residual strength if carbonate minerals are decomposed

It emerged, during stabilising operations, that Cortes landslide was the reactivation of an ancient landslide. A clear indication was the nature of the excavated material in the upper part of the landslide: it was a random mixture of dolomite blocks and soils. This colluvium filled the upper part of the landslide, as sketched in Fig. 7.

The interpretation was that an original landslide, which probably dammed the Júcar River, opened a large void, filled later by debris and colluvial soils. The quarry excavation reactivated the original landslide. Fig. 14 shows a hypothetical sequence of events. This figure introduces an interesting aspect of Cortes landslide, namely, the nature and origin of the thin clay layer where the sliding surface is located. It is difficult to explain a sedimentary episode leading to a very thin clay layer in a geologic environment dominated by crystallised dolomite. The second alternative is to interpret the thin clay layer as a transformation of the parent 'marl'.
Fig. 14 illustrates a possible mechanism. The Júcar River cuts the original Cretaceous syncline. Eventually, a landslide develops because of the presence of the weak argillaceous dolomite layer shown in the sketches. This initial sliding surface brings the available strength of the sliding surface to a residual value, $\tau_{\text {residual }}^{(1)}$. The movement left a gap at the rear of the landslide, which was later infilled by colluvial material, originally identified in the field exploration and later removed to stabilise the slope. This gap allowed preferential access of rainwater to the upper surface of the marl layer where the sliding discontinuity is located.

The partially exposed 'marl' layer is probably a preferential path for atmospheric waters. Given the high permeability of the fractured limestone, and the imperviousness of the marl layer, it is likely that the water has flowed downwards along the limestone-marl interface. Rainwater is slightly acidic $(\mathrm{pH} \cong 5.7)$, and may dissolve carbonate minerals before 
reaching a geochemical equilibrium with the surrounding materials. In this way, water flowing along the old sliding surface may have slowly removed the magnesium carbonate from the marl, leaving only clay minerals and quartz. The similarities between the diffractograms shown in Fig. 13, other than in dolomite content, are significant in this regard.

This hypothetical scenario has interesting practical implications. A geochemical process, associated with a slide-induced change in the hydrogeological conditions, has changed the mineralogical nature of the sliding surface and, hence, its mechanical characteristics. The subsequent reactivation of the landslide, induced by the quarry operations, led to a new shear strength along the sliding surface, which was considerably lower than the residual strength resulting from the first slide movement. It is indicated as $\tau_{\text {residual }}^{(2)}$. This difference can be quantified as $4-5^{\circ}$ of internal friction in this case.

However, there is an alternative explanation closely related to physical phenomena discussed in detail below: the ancient landslide resulted in a significant frictional work, which was concentrated in the sliding surface. This work dissipates in heat. Carbonate rock minerals, dolomite in this case, may decompose - if the temperature reached in the shearing surface is high enough - into carbon dioxide $\left(\mathrm{CO}_{2}\right)$, which escapes in gaseous phase, and soluble calcium or magnesium oxides. Percolating waters carried the latter away.

The two hypothetical scenarios are compatible to some extent. The result is an evolution of the available shearing strength of the sliding surface.

\section{Aznalcóllar slide}

The Aznalcóllar accident is also known as a tailings dam failure. However, the dam itself, a $27 \mathrm{~m}$ high rockfill structure, did not experience a sliding failure. The actual failure is a shearing failure through the dam foundation, which carried forward the dam in a rigid body type of motion.

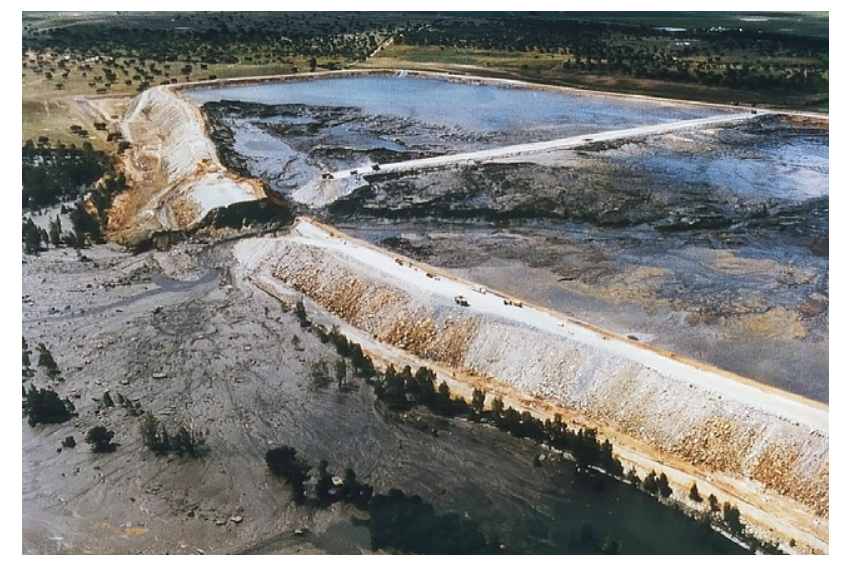

Fig. 15. Failure of Aznalcóllar perimeter dam
The dam created a large tailings pond of finely crushed pyrite mineral. Tailings were deposited by a spigotting procedure and remained saturated and under a thin water layer.

The dam was built in a forward scheme, starting in an initial small embankment, which increased in size by periodic enlarging and heightening. The upstream dam slope maintained its original position and inclination. Dam construction and the storage of tailings started in 1977. Failure took place 21 years later, without any warning, on 25 April 1998. During this period the dam height and, in parallel, the volume of tailings increased in a continuous manner even if the speed of dam heightening was not uniform.

The tailings pond and the perimeter dam rest on overconsolidated, brittle, marine, high-plasticity clays, which are very homogeneous, and deposited in sub-horizontal layers (dip values in the order of $2-3^{\circ}$ ). Sedimentation planes are the main structural features of the clay. Alonso \& Gens (2006a) and Gens \& Alonso (2006) describe the failure, field observations and material properties and discuss the failure mechanism. Fig. 15 is a photograph taken shortly after the failure.

Aznalcóllar was a clear case of first failure induced by a progressive failure mechanism. A section $500 \mathrm{~m}$ long of the dam moved forward $45-50 \mathrm{~m}$ in the manner indicated in Fig. 16, which is a representative cross-section once the dam and the accompanying foundation clay came to rest. The figure shows the geometry of the identified shearing surfaces. The large number of borings drilled (shown in the figure) and additional observations in trenches enabled a precise reconstruction of the failure mechanism and internal geometry.

Indirect evidence provided initial information of the development of a mechanism of progressive failure of the Guadalquivir blue clay. The two main reasons were: (a) the calculated safety factor, years before the dam failure (for a reliable estimation of pore water pressures and a back-analysed average friction) was found to be below one and $(b)$ very high estimated friction ratios below the advancing dam toe, at the position of the sliding surface (Gens \& Alonso, 2006). Later, a fully coupled hydromechanical modelling of dam and pond construction for a strain-softening brittle clay foundation led to a convincing explanation of the progressive failure mechanism and a remarkable agreement with the observed geometry of the failure surface (Zabala \& Alonso, 2011).

A first-time failure in brittle materials leads to an accelerated motion of the unstable mass. This topic receives more attention below. Probably, the downstream acceleration of the dam and a slab of the foundation soil induced the sliding of a large wedge of tailings lying over a mantle of the red clay, which extended on the upstream slope of the dam to render it impervious to tailings water. The unstable tailings wedge slid towards the tailings pond and fell into the big opening trough created by the downstream dam

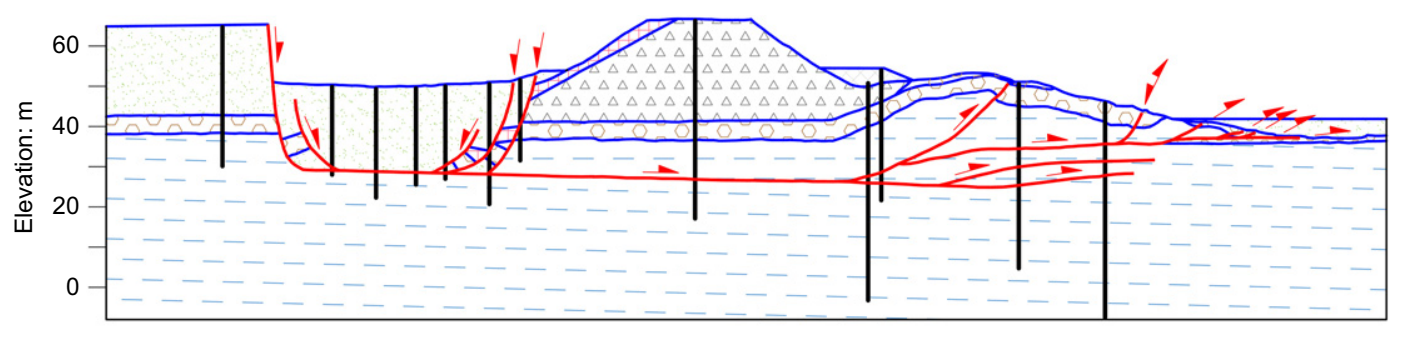

0 $40 \mathrm{~m}$

Fig. 16. Central cross-section of Aznalcóllar slide, after runout 
displacement (Fig. 16). This violent collapse of the tailings lying above of the upstream slope of the rockfill dam is believed to be the cause of tailings liquefaction.

Figure 17 shows a photograph taken from the dam crest, looking towards the pond, a few hours after failure. The widespread occurrence of silt/sand volcanos on the surface of the tailings is an incontestable indication of tailings liquefaction. This liquefaction explains the overall dam forward displacement (40-50 $\mathrm{m}$ in the central part of the landslide).

Figure 15 shows the position of the breach opened in the rockfill dam. At this point two dam sections ('northern' and 'southern') met at a relative angle of $19^{\circ}$. The northern section remained stable and the southern one became unstable. Gens \& Alonso (2006) explain this behaviour by three-dimensional effects of the direction and dip of the sedimentation planes of the foundation blue clay.

Figure 18 sketches the breach geometry. The failure plane separating the two sub-vertical walls of the breach follow the direction of the dominating family of vertical discontinuities of the clay foundation. The measured eastern displacement of the slide at this point $(\bar{d}=20 \mathrm{~m})$ implies a breach opening of around $14 \mathrm{~m}$. The breach opening is a direct consequence of the forward runout of the landslide. However, the breach opening controls the flood rate of liquefied tailings escaping from the pond. In Aznalcóllar

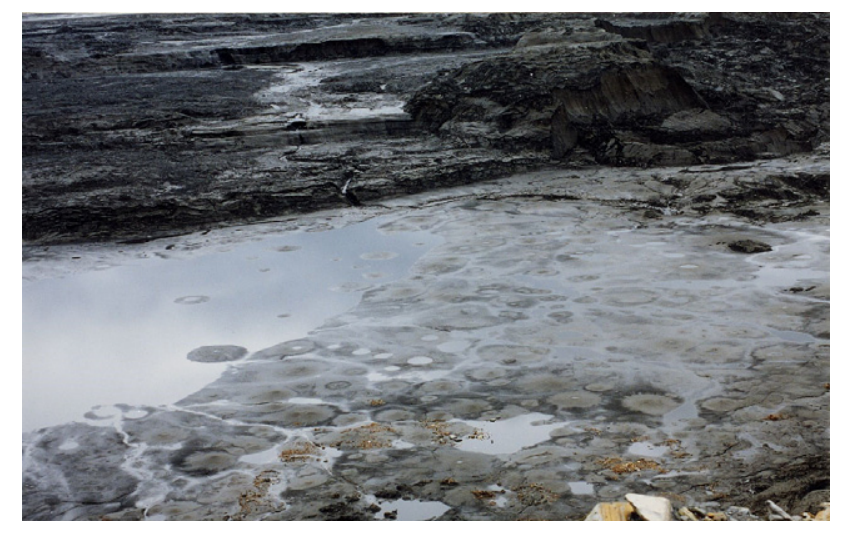

Fig. 17. Mud volcanoes observed a few hours after the failure on the surface of the depressed basin, upstream of the slid dam (courtesy of J. M. Rodríguez Ortiz)
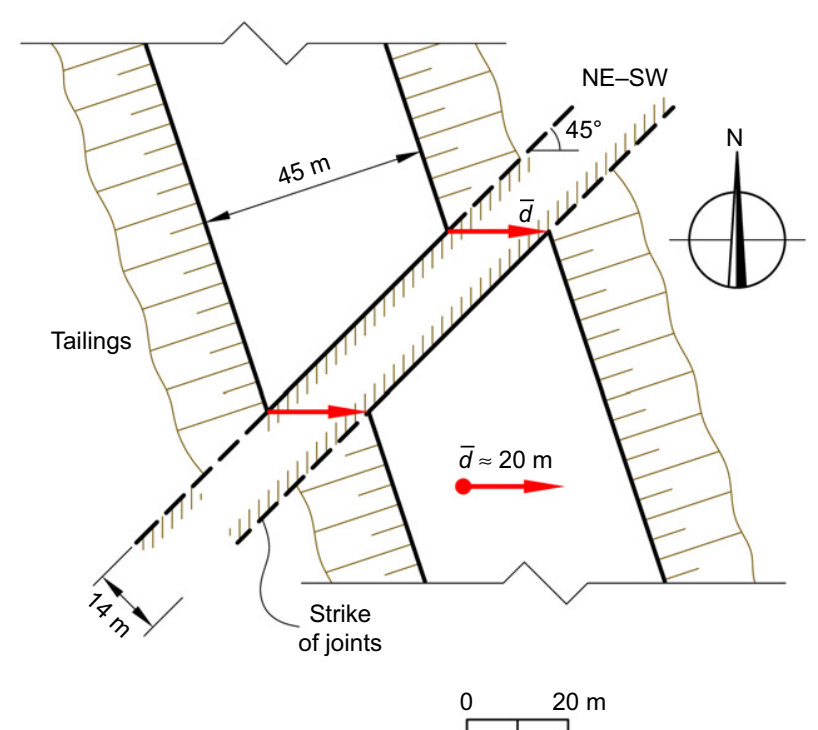

Fig. 18. Aznalcóllar dam slide. Geometry of the rupture breach failure, the intensity of uncontrolled tailings flow was a direct consequence of the landslide runout.

Summarising a few key aspects raised by the three case records outlined, the following questions should be resolved within a risk scenario associated with landslides

(a) the expected evolution, in terms of velocity and runout, of a creeping landslide (Pampaneira, Cortes)

(b) the risk of a very rapid landslide once it becomes unstable by a change in external disturbing actions loading, excavation, pore water pressures changes (Cortes)

(c) the expected acceleration velocity and runout of a first failure in brittle soils such as overconsolidated high plasticity clays (Aznalcóllar).

Further review of case histories will certainly add some qualifications to the questions above, but, in essence, the challenge is

(a) to predict the transition from creeping or non-observable motion (in the case of first-time failures) towards a new stage characterised by a significant velocity increase

(b) to predict the runout; in this process, significant geometry changes are expected.

Existing geotechnical codes of practice, in particular Eurocode 7 (BSI, 2004), do not help much in this context. There is probably a good reason for it, given in Section 1.1 of Eurocode 7 (overall stability), subsection 11.6 (serviceability limit state design), paragraph (3) (BSI, 2004: p. 121).

Since the analytical and numerical methods available at present do not usually provide reliable predictions of the deformation of a natural slope, the occurrence of serviceability limit states should be avoided by one of the following:

a) Limiting the mobilized shear strength or b) Observing the movements and specifying actions to reduce or stop them, if necessary'.

Unfortunately, the case records described and many others, especially in natural landslides, indicate that the suggested remedial actions are not feasible. On the other hand, accepting the possibility of a failure event makes sense in a scenario of risk analysis.

\section{FIRST-TIME FAILURES}

The landslide classification, described in Hungr et al. (2014), pays attention to the material involved and to the morphology features of the unstable soil or rock mass. However, from a geotechnical perspective it is useful to distinguish between first-time or reactivation failures. First-time failures very often imply, in practice, the need to address the effect of progressive failure. Except for the case of soft soils, which is not considered in this paper, soils, soft rocks, rock matrix, hard rock masses and natural joints often exhibit a strainsoftening behaviour when subjected to shear stress. The consequence of material brittleness is the development of progressive failure mechanisms in any situation leading to instability.

Skempton (1964) provided early examples of progressive failures of soils in London Clay. Aznalcóllar dam failure, described before, and Carsington and other British dam failures (Potts et al., 1990; Dounias et al., 1996) are examples. Alonso (2000) provides other case records. 
Shear strain localisation is a general feature of cohesivefrictional materials. Brittle materials enhance localisation. The result is the development of sliding surfaces (or fractures), which are usually very thin features, especially in clay-rich soils and rocks. Standard finite-element techniques lead to non-objective results in the sense that the outcome of the analysis was mesh dependent. A number of 'regularisation' techniques are available (Bazant \& Jirásek, 2002). They imply the introduction of a length scale to the analysis. In the case records discussed in this section, a smeared crack approach (Soga et al., 2016) will be followed. However, the grain size distribution and soil microstructure (Desrues \& Viggiani, 2004) controls the shear band thickness, which is, therefore, a material property. In addition, it is a very small value, in absolute terms, if compared with computational elements or cell size. The implications of this remark will be discussed later, when describing the thermohydro-mechanical (THM) analysis of landslides.

The presence of progressive failure implies a major departure from the calculation procedures and hypothesis made in limit equilibrium methods. Soil/rock stiffness is now required information. The geometry and development of the failure is a consequence of the constitutive behaviour of the soil, the loading or excavation sequence, the development in time of pore water pressures and the initial stress state. The sliding surface is a part of the solution. A good example in this regard is Aznalcóllar dam failure, described below. It turns out that the soil brittleness controls the post-failure behaviour, an aspect also discussed below.

Slope stability is typically a stress-controlled phenomenon. External loading/unloading and pore pressures changes belong to this class of actions. In contrast, fault generation and reactivation are strain-controlled phenomena, driven by tectonic activity.

Figure 19(a) illustrates the reaction of a stress-controlled triaxial test on a strain-softening material (Sibille, 2016). The 'test' was a distinct-element method (DEM) simulation of dry, granular material. The strain-controlled test shows a distinct peak strength followed by a moderate strain-softening response. The stress-controlled test does not provide any information regarding the strain-softening behaviour beyond the peak stress. However, it shows in a clear manner the nature of stress-controlled failure (Fig. 19(b)).

When peak strength is reached at the time $t=t_{\text {peak }}$ the axial deformation increases at a fast rate. There is also a burst of kinematic energy. The sample remains conceptually in equilibrium provided dynamic forces (or kinematic energy) are included in the equilibrium formulation. This behaviour at the small scale of samples (or representative volume) is repeated also at a large scale, when the slope failure is analysed.

Two case histories will illustrate the dynamics of first-time failures: Aznalcóllar dam failure and the Selborne slope failure experiment (Cooper, 1996).

\section{Aznalcóllar dam failure}

Figure 16 shows that the sliding surface was almost entirely located in the brittle Guadalquivir clay. The sub-vertical plane limiting upstream the motion was located in tailings, which did not offer any significant resistance against the forward motion of the slide. In the downstream part, the thin (4 m) alluvial deposit of sand offered a small shearing resistance.

Drained direct shear tests on intact clay samples revealed the brittle nature of the clay. Fig. 20 summarises the experiments performed. The plot shows the average envelope $\left(c^{\prime}=64 \mathrm{kPa} ; \phi^{\prime}=24^{\circ}\right)$ of the measured peak strengths (Alonso \& Gens (2006a) provide the details) and the points representing the sudden drop of strength after peak values. These points correspond to relative shear displacements of about $1 \mathrm{~mm}$. A zero effective cohesion and a friction angle close to the peak value characterise the average envelope immediately after peak. Friction decreases steadily as shearing displacements accumulate.

Residual friction was measured in ring shear tests and in shearing tests on natural discontinuities found in large clay blocks displaced by the mudflow that followed the dam breach. A residual friction angle of $11^{\circ}$ represents the available data.

The basal planar sliding surface shown in Fig. 16 was a consequence of the progressive failure developing in the clay foundation (Zabala \& Alonso, 2011). The Geopart MPM program helped to reproduce the history of dam construction and tailings impoundment until the onset of failure. The analysis covered the period 1978-1998.

Figure 21 shows the limits of the computational mesh and the materials involved: tailings, dam, alluvial deposit overlying the clay and the foundation clay. Note that the computational mesh (uniform quadrilateral cells $1 \mathrm{~m} \times 1 \mathrm{~m}$ ) discretise the expected empty space occupied by the dam after failure. The figure also shows the evolution of the dam geometry and the level of tailings during the 20 year long construction period.

The elastoplastic strain-softening Mohr-Coulomb model was characterised by the following evolution of

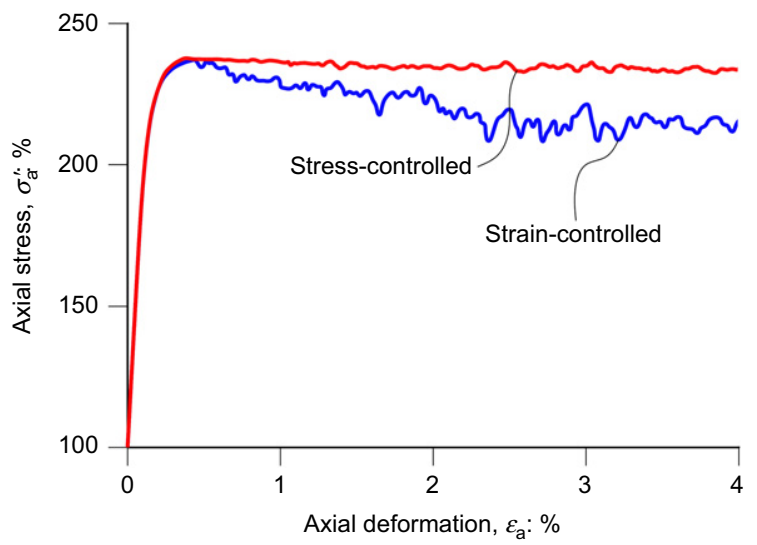

(a)

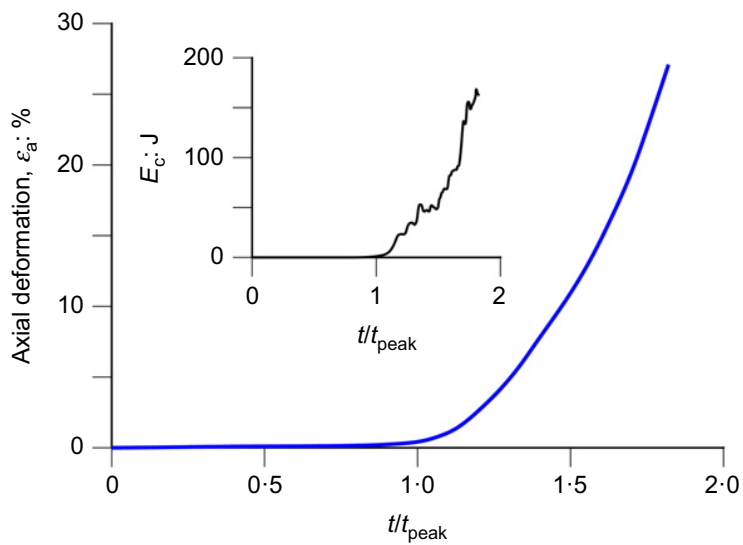

(b)

Fig. 19. DEM simulation of a triaxial test: (a) stress-strain results when axial stress or axial deformation is imposed; (b) calculated time development of axial strain and kinetic energy for the stress-controlled numerical test (after Sibille, 2016) 
the friction angle with the irreversible equivalent plastic strain, $\varepsilon_{\mathrm{eq}}^{\mathrm{p}}$

$$
\phi^{\prime}=\phi_{\text {res }}^{\prime}+\left(\phi_{\text {peak }}^{\prime}-\phi_{\text {res }}^{\prime}\right) \mathrm{e}^{-\eta \varepsilon_{\text {eq }}^{\mathrm{p}}}
$$

where $\phi_{\text {peak }}^{\prime}$ and $\phi_{\text {res }}^{\prime}$ are the peak and residual effective friction angles, and $\eta$ is a constant parameter. $\varepsilon_{\mathrm{eq}}^{\mathrm{p}}$ is defined as

$$
\varepsilon_{\mathrm{eq}}^{\mathrm{p}}=\left(2 / 3 \boldsymbol{e}^{\mathrm{p}}: \boldsymbol{e}^{\mathrm{p}}\right)^{1 / 2}
$$

where $\boldsymbol{e}^{\mathrm{p}}$ is the deviatoric plastic strain tensor.

Reducing cohesion to zero immediately after peak conditions simulates the sharp strength decrease.

A 'smeared crack' approach (Rots et al., 1985) allowed the regularisation of the solution. The plastic work dissipated in a mesh element was made equal to the energy dissipated in the sliding surface. The implication is that plastic softening modulus depends on mesh size. The strength of the smeared crack or sliding surface was assumed to be a function of the relative displacement of both sides of the discontinuity. Fig. 22 shows the relationship adopted in the analysis. $\eta=$ 100 and a constant mesh size $(1 \mathrm{~m} \times 1 \mathrm{~m})$ leads to the shear stress-relative displacement shown in Fig. 22.

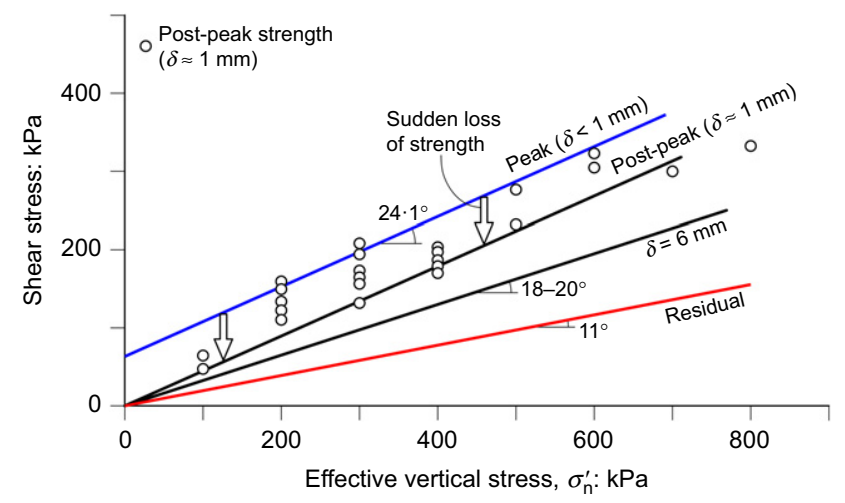

Fig. 20. Failure envelopes of Guadalquivir blue clay at the location of Aznalcóllar dam
The drained analysis performed required a coupled flowdeformation model. Fig. 23 shows the development of the failure surface. Shear strains began to localise at the downstream side of the advancing rockfill dam when it reached a height of around $21 \mathrm{~m}$. The initial crack progressed in two opposite directions and resulted in a horizontal failure surface, $14 \mathrm{~m}$ below the natural soil surface. The upstream side of the crack changed sharply in inclination at the upstream foot of the dam before shearing the tailings deposit. The downstream side of the failure surface daylighted near the downstream toe of the dam.

This geometry is remarkably similar to the real one. Fig. 24 is a reconstruction of the initial sliding surface, obtained by 'reversing', in the upstream direction, the post-failure geometry of the landslide (Moya, 2000).

The development, position and shape of the failure surface was the result of following factors.

(a) The downstream construction of the dam, which favoured a 'travelling' overstressing, in the downstream direction, of points in the brittle clay located in the vertical of the downstream toe of the dam. Other construction procedures, for instance the construction of the dam in a single step, do not induce any plastic shearing cracking in the clay. However, a downstream stage construction when a uniform drained friction of $17^{\circ}$ characterises the clay strength, leads to rotational failure, far from the real situation. Alonso \& Zabala (2012) discuss these cases.

(b) The upward flow caused by excess pore water pressures towards the granular alluvial mantle covering the impervious clays. Pore water pressures induced by the heavy pyritic tailings $\left(\gamma_{\mathrm{sat}}=31 \mathrm{kN} / \mathrm{m}^{3}\right)$ are high and prevent any water inflow from the tailings deposit towards the clay substratum. Pore pressures in the clay behave essentially as the pore pressures in a one-sided drainage oedometer test. A pore pressure gradient towards the upper drainage boundary developed in a clay band, approximately $12 \mathrm{~m}$ thick, at the time of failure. Below, the clay maintains almost unchanged the short-term pore pressures due to its very low
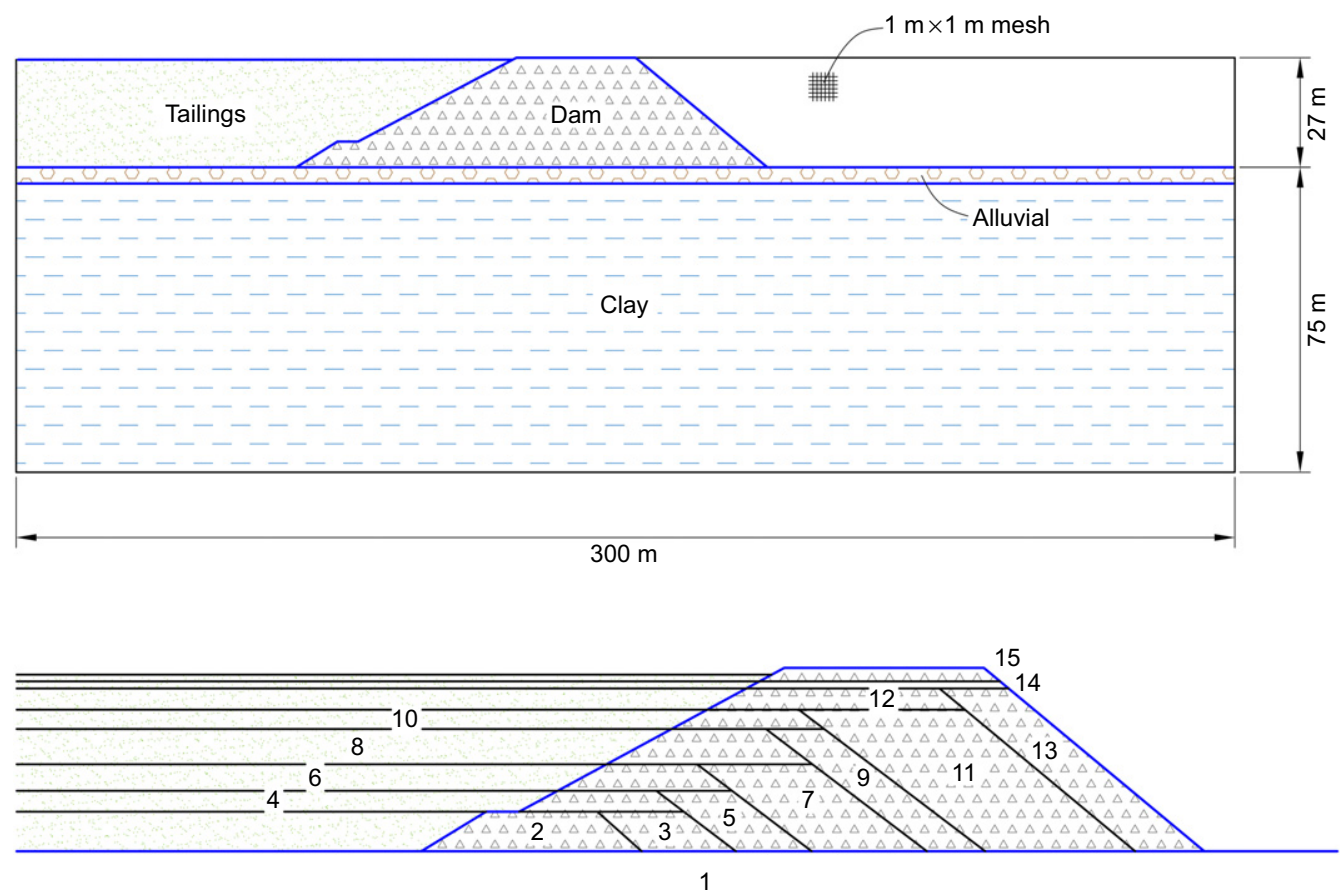

Fig. 21. Geometry of the model and construction sequence of Aznalcóllar dam 


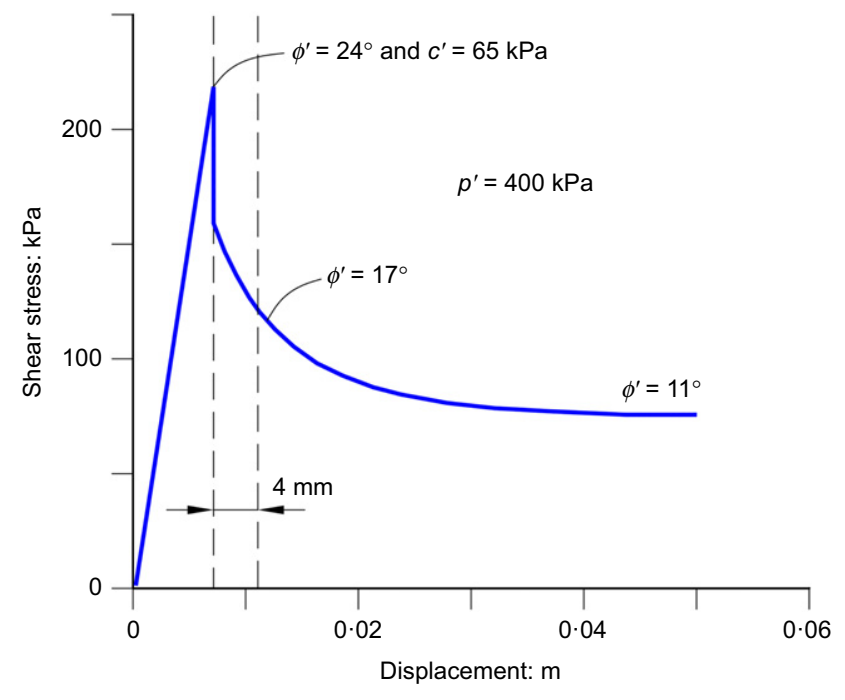

Fig. 22. Shear stress-relative displacements function for a clay particle in $1 \mathrm{~m} \times 1 \mathrm{~m}$ cell
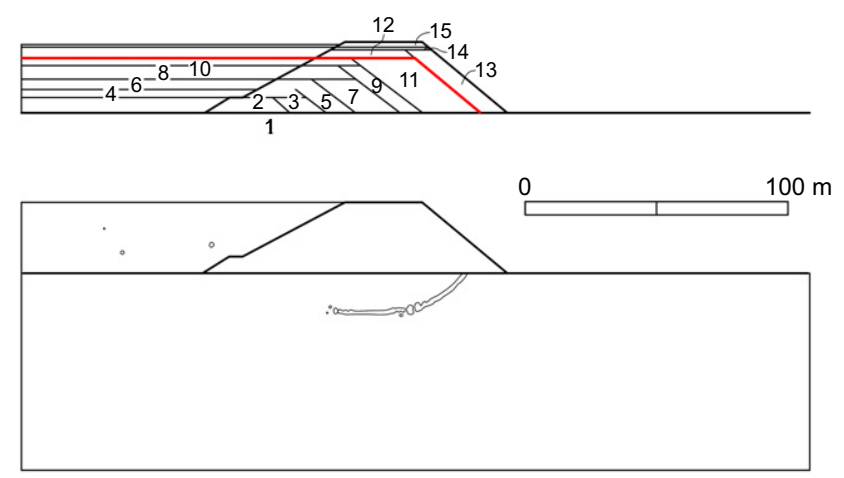

(a)

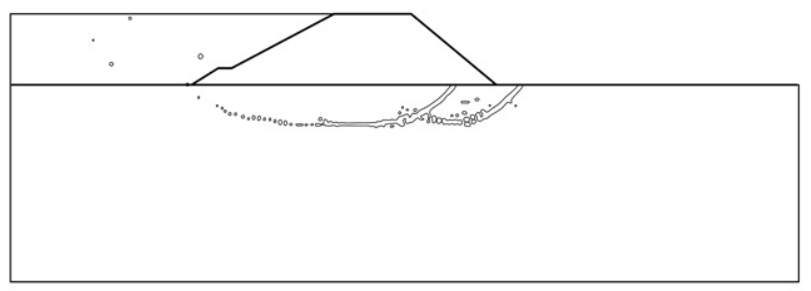

(b)

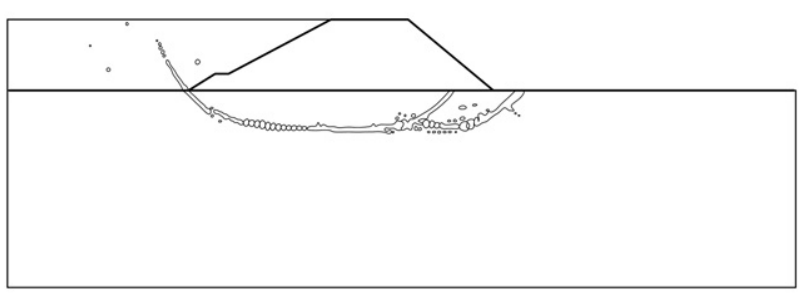

(c)

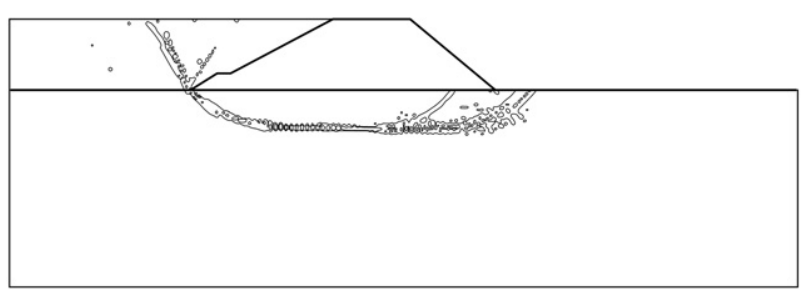

(d)

Fig. 23. Sequence of contours of equal equivalent plastic strain, $1 \%$ and $5 \% . c_{\mathrm{v}}=0 \cdot 001 \mathrm{~cm}^{2} / \mathrm{seg}, K_{0}=1$ : (a) end of stage 12 (see Fig. 21); (b) intermediate time in stage 13; (c) intermediate time in stage 14; (d) intermediate time in stage 15

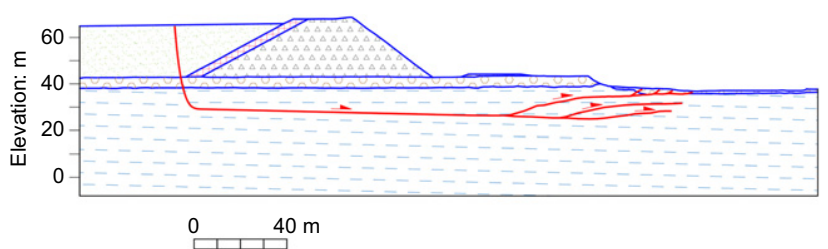

Fig. 24. Interpretation of initial rupture surfaces of Aznalcóllar landslide (after Moya, 2000)

permeability. The shearing band developed at a critical depth determined by the intense shear to effective vertical stress ratios. This is a feature of the stress distribution motivated by the embankment loading geometry and the high excess pore pressures.

(c) The $K_{0}$ coefficient of the clay foundation was not measured. Guadalquivir blue clays are late Tertiary deposits, which did not experience significant tectonic activity, and $K_{0}$ is not expected to be high. A value $K_{0}=0.5$ was assumed in an initial tentative calculation. The predicted shear band geometry was far from field observations (Zabala \& Alonso, 2011). Increasing its value to $K_{0}=1$ resulted in the good match of field observations described before.

(d) The pore water pressure distribution. The initial state was a hydrostatic distribution of pore pressures, assuming a phreatic level at the soil surface. The construction sequence of the dam and the tailings level, during the 20 year operation of the pond, was followed in the calculation. Fifteen steps of instantaneous loading, followed by periods of excess pore pressure dissipation, reproduced quite accurately the history of construction.

(e) The low dip angle $\left(\sim 2^{\circ}\right)$ of sedimentation planes in the blue clay. Even if the progressive failure mechanism described leads to an essentially horizontal basal sliding surface, the accurate levelling of the dam after failure indicated that the failure surface had a dip of $2^{\circ}$. Therefore, it was most likely following a sedimentation plane. Sedimentation planes were hardly seen in cores recovered in borings. The blue clay was remarkably homogeneous. Shear tests on planes at different orientations could not identify a consistent strength anisotropy (Alonso \& Gens, 2006a). Nevertheless, some minor reduction in shear strength of the sedimentation planes is a necessary scenario to explain the observed dip angle of the failure surface.

The dam forward displacement calculated in the MPM analysis described in Zabala \& Alonso (2011) was about $4 \mathrm{~m}$. The resistance offered by a passive wedge developing downstream was capable of halting the motion. However, the forward displacement in the central part of the landslide was in the order of 45-50 m. Alonso \& Gens (2006b) attributed this runout to the liquefaction of tailings once the motion started.

The program Geopart used in the analysis was not capable of modelling static liquefaction. Ghasemi et al. (2018), Di Carluccio et al. (2019) and Giridharan et al. (2019) describe recent developments in this regard. The simplified analysis described in Alonso \& Gens (2006b) indicated that the runout was a consequence of the increasing volume of the large gap opening upstream when the dam and an accompanying slab of foundation clay moved forward. Fig. 25 shows the failure mechanism analysed in Alonso \& Gens (2006b). The plot indicates the simplified geometry for a given displacement, the approximation adopted for the passive wedge and the level of liquefied tailings occupying 


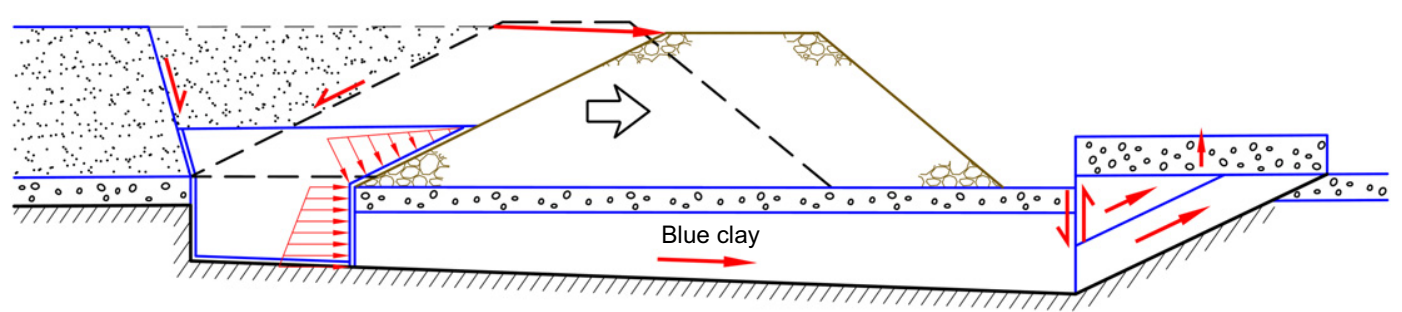

Fig. 25. Free body diagram of Aznalcóllar sliding mechanism (after Alonso \& Gens, 2006b)

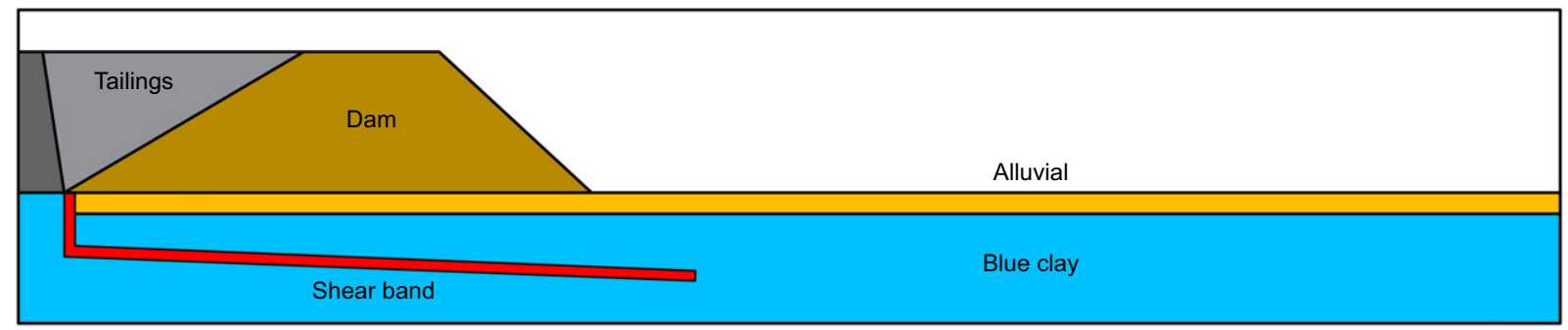

(a)

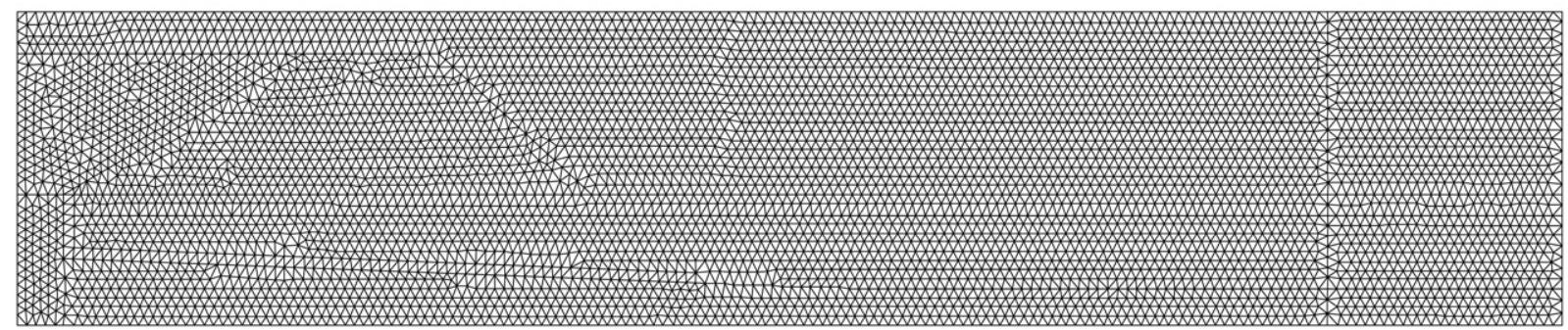

(b)

Fig. 26. (a) MPM model of Aznalcóllar dam immediately before failure and (b) MPM computational mesh

the upstream opening gap. Also plotted is the tailings pressure against the upstream boundary of the landslide. The calculated velocity and displacement of this model is compared below with a more advanced approach.

Recently, the Anura3D MPM program allowed the slide motion to be revisited. The analysis starts when a shear band, identified in the analysis of Zabala \& Alonso (2011), has fully developed (Fig. 26(a)). The analysis performed did not reproduce the entire construction history of the dam, the failure triggering and the resulting motion. The focus was placed on examining the post-failure dynamics and therefore the starting situation was to assume that the failure surface had already developed.

A residual friction angle of $11^{\circ}$ characterises the band. The calculated pore water pressures in previous analysis defined the initial state. A coupled flow-deformation analysis allowed the calculation of pore water pressures during the subsequent motion.

The motion started when the tailings wedge located on top of the upstream dam slope liquefied. This liquefaction was the triggering of the motion. The density of liquefied tailings was probably close to $3 \cdot 1 \mathrm{~g} / \mathrm{cm}^{3}$ (the saturated density of the tailings).

Figure 26(b) shows the computational mesh. The MPM plane strain model was a 'slice' of unit thickness $(1 \mathrm{~m})$ discretised by means of tetrahedral elements. The mesh includes a large area of empty space on the downstream side of the dam to accommodate the expected dam displacement. In this case, the field observations and the previous simple calculation reported in Alonso \& Gens (2006b) provided an approximate estimation of the maximum displacements $(50 \mathrm{~m})$. The calculation domain extends $200 \mathrm{~m}$ downstream of the dam toe to cover broadly the maximum run-out.

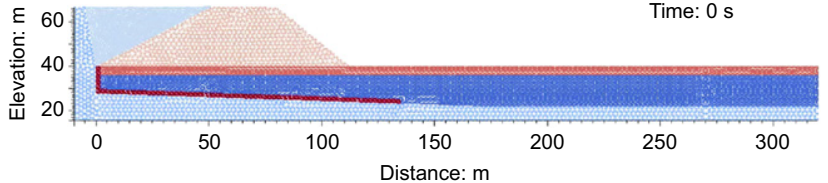

(a)

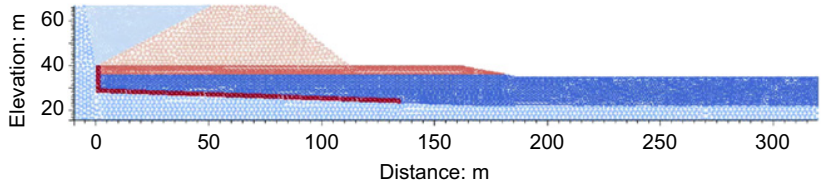

(b)

Fig. 27. Two cases analysed for Aznalcóllar failure: (a) long alluvial terrace and (b) short alluvial terrace

The granular alluvium stratum provided some confinement to the clay stratum. Two situations, which reproduce two actual cross-sections, a long alluvial terrace (Fig. 27(a)) and a short one (Fig. 27(b)), were analysed.

Figure 28 shows the calculated plastic shear strains $3 \mathrm{~s}$ after the start of the motion. At that time increment, the dam and the foundation soil over the failure surface has moved forward $3 \mathrm{~m}$. Shear bands develop on the boundaries of liquefied tailings. The calculated critical basal shear surface starts at the upstream toe of the dam and plunges into the clay to reach the pre-defined shear band. On the opposite end, a pattern of shear bands extends upwards and downstream of the initial failure surface. The shorter alluvial mantle (Fig. 28(b)) results in a rapid development of a sub-horizontal shear band lengthening the initial one. In both cases, longer or shorter alluvial cover, a passive zone develops close to the dam toe. 
Ten seconds later the effect of the length of the alluvial cover is better identified (Fig. 29).

Figure 30 compares the calculated shear bands at the end of the motion (for a long alluvial terrace) with the visual identification of failure surfaces. The calculated internal shearing was reasonably representative of observations.

Figure 31 shows a comparison of the approximate 'rigid body' model and the MPM calculation. The comparison focuses on the time histories of dam displacement and velocities, as well as the height of liquefied tailings above the ground level. The label 'analytical' identifies the simplified model. The term analytical does not imply a correct benchmark solution; it is just another approximation. In fact, it

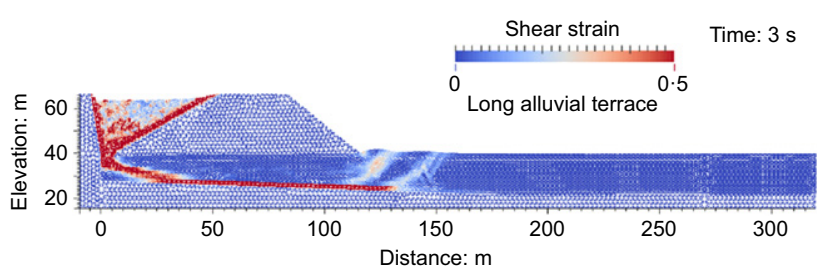

(a)

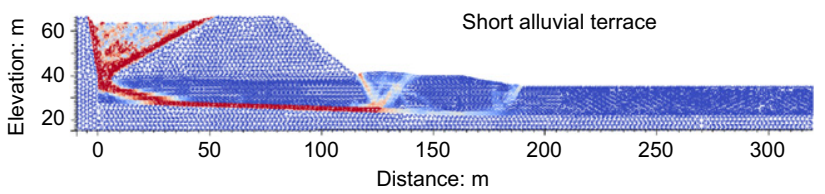

(b)

Fig. 28. Calculated plastic shear strains $3 \mathrm{~s}$ after the initiation of dynamic failure: (a) long alluvial terrace and (b) short alluvial terrace

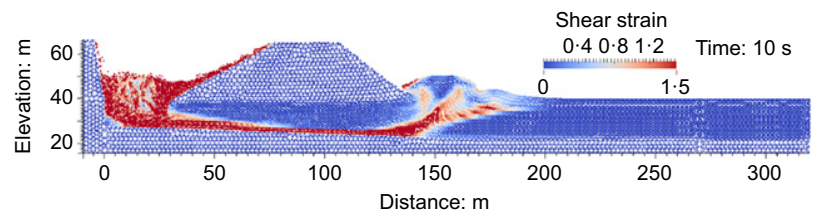

(a)

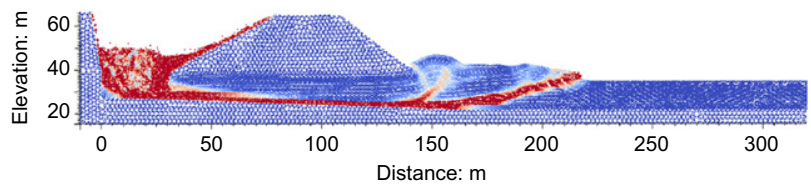

(b)

Fig. 29. Calculated plastic shear strains $10 \mathrm{~s}$ after the initiation of dynamic failure: (a) long alluvial terrace and (b) short alluvial terrace

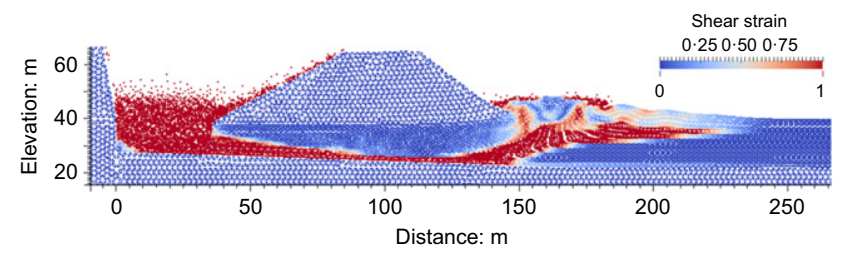

(a)

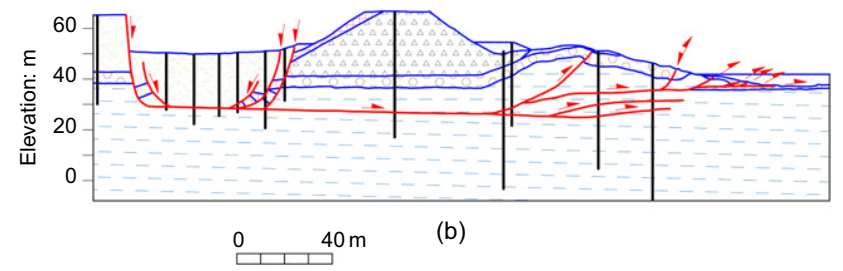

Fig. 30. A comparison of (a) the calculated deformed geometry and (b) shearing bands observed in the field required a significant amount of the hypothesis described in the paper by Alonso \& Gens (2006b). However, the reasonable correspondence between two widely different models, which try to capture the essential features of the post-failure dynamics of the landslide, provide a mutual support to the two approaches. Obviously, the MPM modelling provides additional significant information (i.e. the internal clay shearing), which was close to observations.

\section{Selborne failure experiment}

The aim of the experiment was the investigation of the development of progressive failure in a slope excavated in brittle clays. Cooper (1996) and Cooper et al. (1998) describe the experiment and its interpretation. For Leroueil (2001), the Selborne experiment was the first time that the development of progressive failure towards a generalised failure was observed. Injecting water in 20 recharge wells for about 6 months triggered the failure.

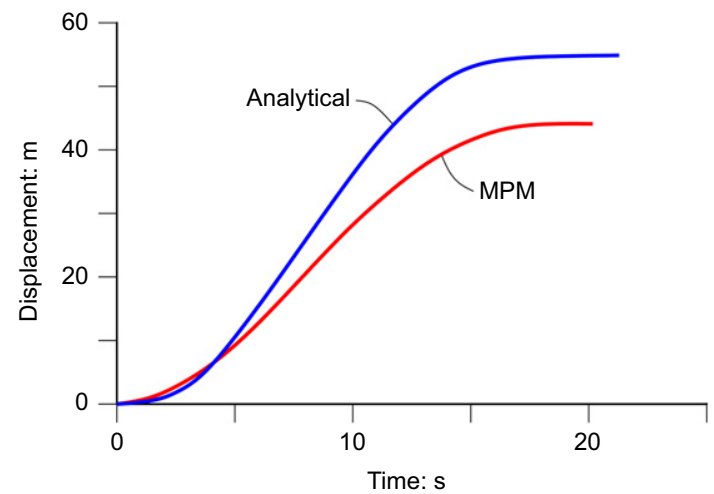

(a)

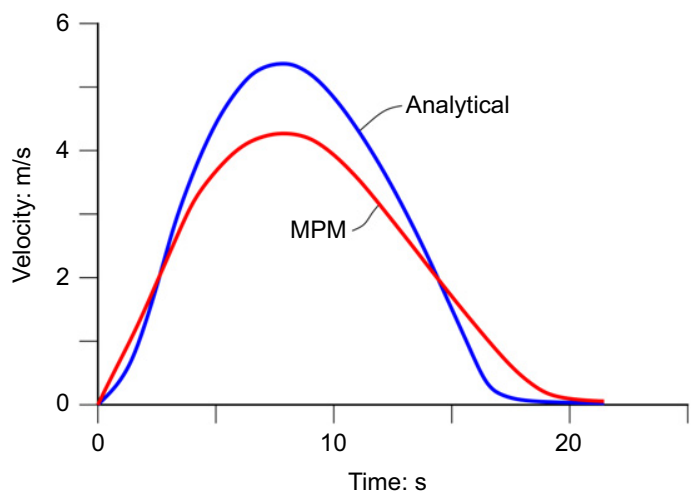

(b)

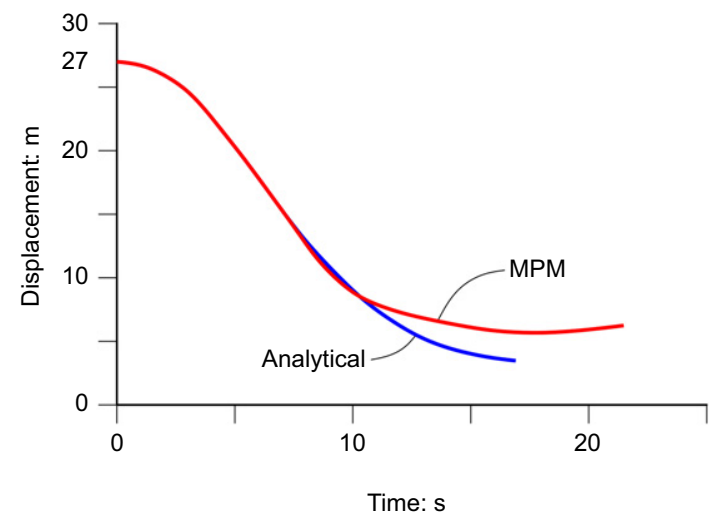

(c)

Fig. 31. Aznalcóllar landslide: (a) calculated time development of displacements; (b) velocity; (c) elevation of tailings surface upstream of the dam. Comparison between the analytical model (Alonso \& Gens, 2006b) and MPM results 
The slope $(2 \mathrm{H}: 1 \mathrm{~V})$ was excavated in overconsolidated Gault clay and it was instrumented by piezometers, inclinometers, extensometers and surface markers. Available information to validate an analysis of the failure are the time histories of pore water pressure, horizontal displacements in inclinometers and the geometry of the sliding surface.

Grant (1996) also reported the post-failure displacements of a few points located on the slope surface. This information is of special interest for the validation of post-failure runout. The geotechnical properties of the Gault clay profile (an upper level of weathered clay followed by unweathered clays down to a sandstone substratum) were determined in laboratory experiments described in the paper by Cooper et al. (1998). The analysis reported here maintains the published peak and residual drained strength parameters.

Figure 32 shows the geometry of the slope and the two layers of Gault clay overlying the sandstone substratum. The figure also indicates the region affected by the water injection. Fig. 32(b) shows the MPM computational mesh made up of tetrahedra, and the distribution of material points for the weathered and unweathered clay levels. The mesh was refined in the slope volume likely affected by the failure mechanism.

In the analysis, the water pressure increments were applied to the lower boundary of the discretisation mesh in the position shown in the figure.

A strain-softening drained Mohr-Coulomb material described the shearing behaviour of the two Gault clay levels. Table 1 indicates the strength parameters (peak and residual) for them.
Mesh conditioning followed the 'smeared crack approach' mentioned above. A parameter controlling the strainsoftening rate $\eta=400$ was adopted in calculations for the selected fine mesh area.

The explicit integration algorithm is conditionally stable. Adopting a low permeability requires very low time increments and exceedingly large computational times. The soil permeability was increased with the purpose of reducing calculation times to affordable values. The boundary water pressure increased linearly during $10 \mathrm{~s}$ to $110 \mathrm{kPa}$, to become constant thereafter. Calculated and measured time histories are represented in terms of a normalised dimensionless time parameter, $t^{*}=t / t_{\text {failure }}$.

Table 1. Selborne material parameters (based on Cooper et al., 1998)

\begin{tabular}{|c|c|c|}
\hline & $\begin{array}{l}\text { Weathered } \\
\text { Gault clay }\end{array}$ & $\begin{array}{l}\text { Unweathered } \\
\text { Gault clay }\end{array}$ \\
\hline Porosity & $0 \cdot 3$ & $0 \cdot 3$ \\
\hline Permeability: m/s & $10^{-3}$ & $10^{-3}$ \\
\hline Saturated density: $\mathrm{kg} / \mathrm{m}^{3}$ & 2700 & 2700 \\
\hline Young's modulus: kPa & 20000 & 20000 \\
\hline Poisson's coefficient & $0 \cdot 33$ & $0 \cdot 33$ \\
\hline $\begin{array}{l}\text { Effective cohesion: } \\
\text { peak/residual: } \mathrm{kPa}\end{array}$ & $13 / 4 \cdot 7$ & $25 / 1$ \\
\hline $\begin{array}{l}\text { Effective friction angle: } \\
\text { peak/residual: degrees }\end{array}$ & $24 \cdot 5 / 13 \cdot 5$ & $26 / 15$ \\
\hline Strain softening rate parameter, $\eta$ & 400 & 400 \\
\hline
\end{tabular}

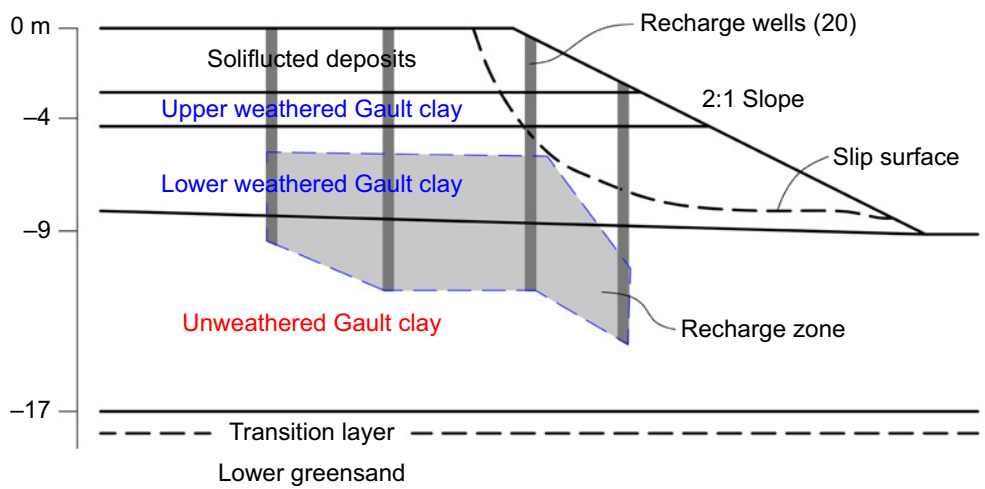

(a)

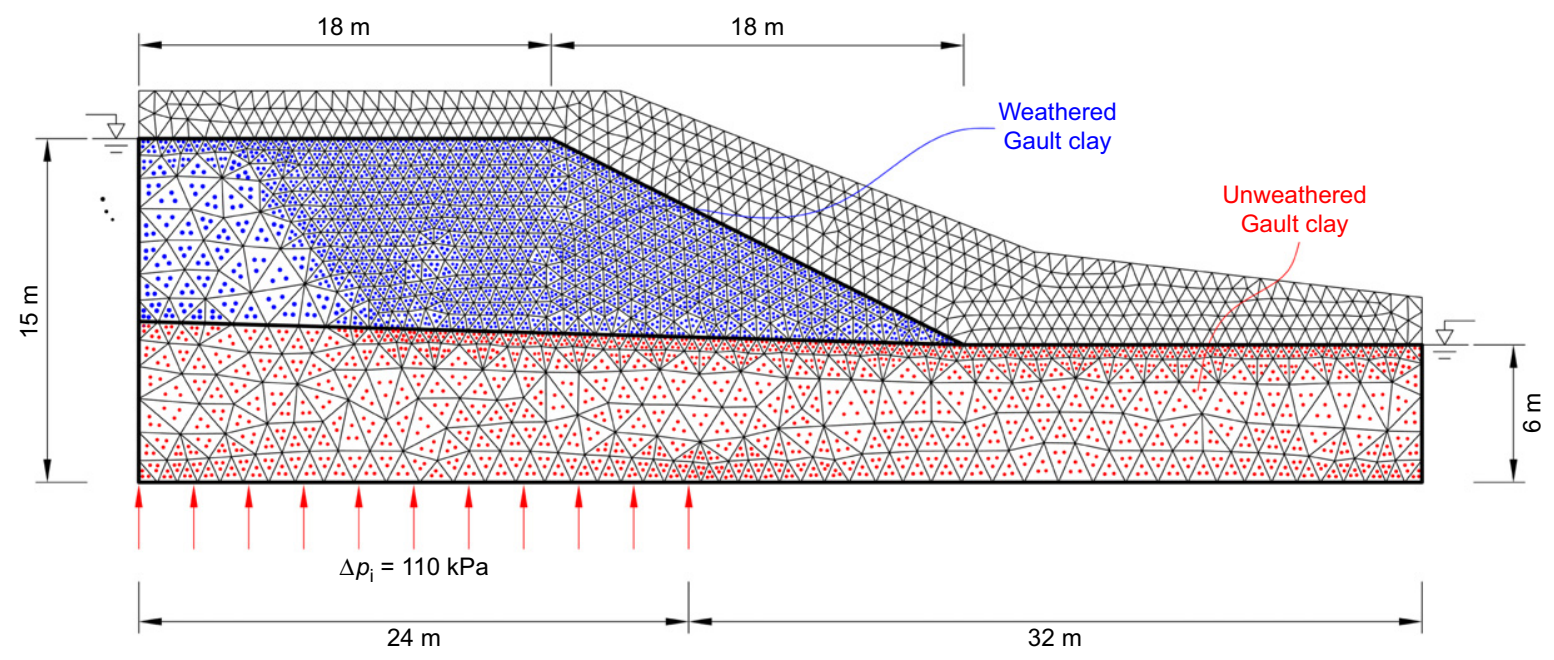

(b)

Fig. 32. (a) Representative cross-section of Selborne experiment after Cooper et al. (1998) and (b) MPM computational mesh 


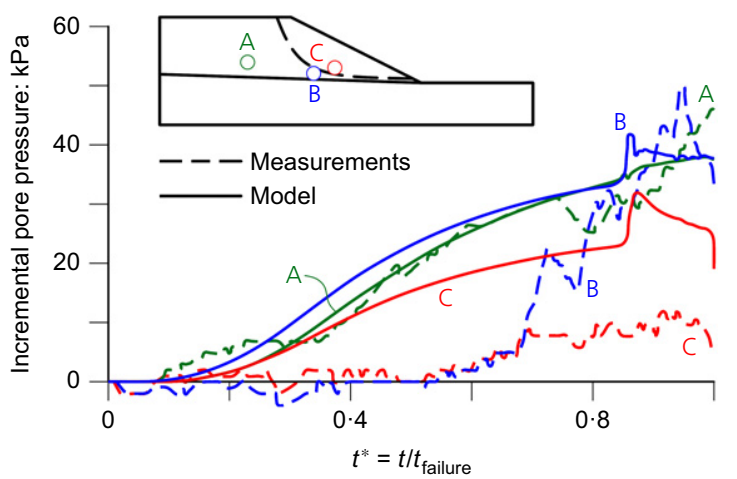

Fig. 33. Measured increments of pore water pressure and model calculations
For times $t^{*}<1$ the slope develops (in a 'static' manner) small internal deformations and progressive failure phenomena. At $t^{*}=1$ the slope fails in a catastrophic manner. For $t^{*}>1$ the dynamic motion develops. For any time, including repose times after runout, flow and deformations continue until reaching a final equilibrium. Table 1 shows all the parameters used in the calculation.

Field performance and model results

Figure 33 shows a comparison of pore pressure increments, measured and calculated, in the three indicated points. The approximation is reasonable in piezometers $\mathrm{B}$ and $\mathrm{C}$. Soil extension explains the fall in pore pressure near failure $\left(t^{*} \simeq 1\right)$. Cooper (1996) interpreted inclinometer data in the

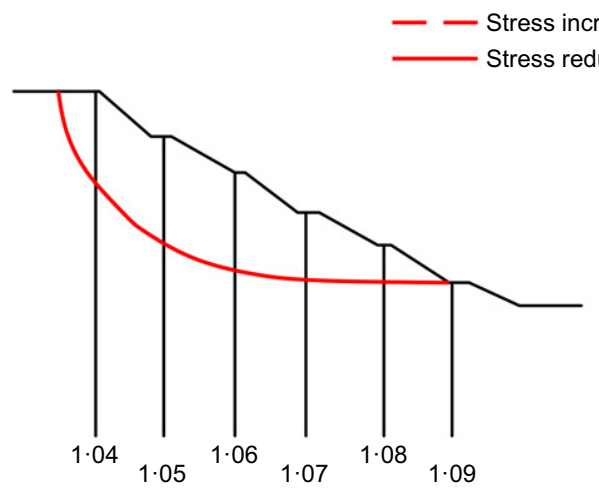

(a)

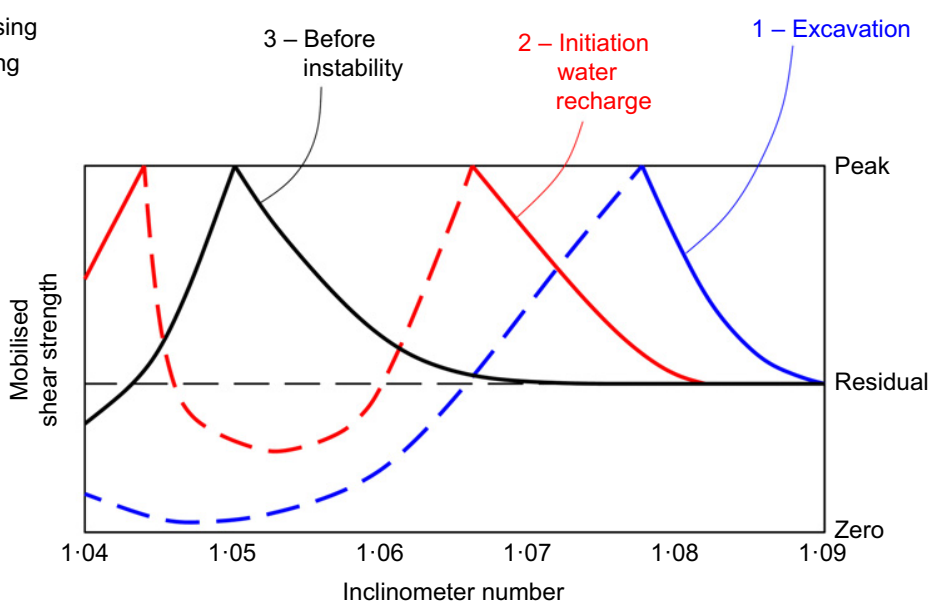

(b)

Fig. 34. (a) Position of inclinometer tubes and (b) interpretation of mobilised shear strength along the failure surface (after Cooper, 1996)
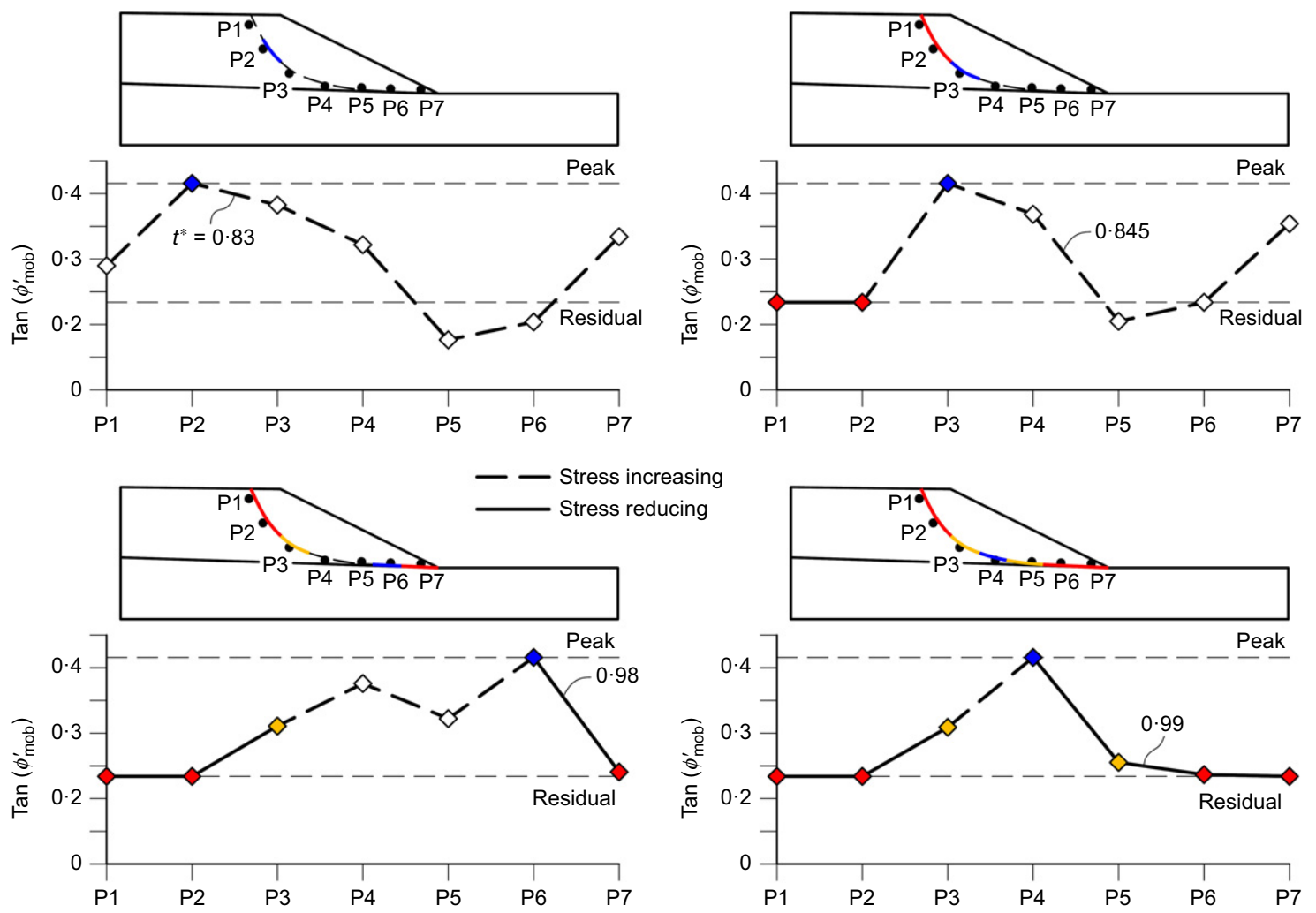

Fig. 35. Calculated evolution of mobilised shear strength along the failure surface for dimensionless times $t^{*}=0.83,0 \cdot 845,0.98$ and 0.99 
manner reproduced in Fig. 34. The slope toe is at residual conditions because of the excavation. Later, as pore water pressures increase, shear strains localise in the upper and lower part of the failure surface. The slip surface develops when a point located in the upper mid-part of the slope reaches peak conditions and evolves towards a residual state.

The MPM simulation results, shown in Fig. 35 for four different times during the interval $t^{*}=0.84$ to 1 , do not predict an initial residual state at the slope toe because excavation was not considered: stresses in the slope are a consequence of self-weight. Nevertheless, the analysis also shows simultaneous strain-softening effects on the upper and lower levels of the failure surface. The final point reaching peak conditions is not located in the lower mid-part of the slip line.

Mirada (2015) describes a similar analysis of the Selborne experiment, considering the excavation and an initial stress state characterised by an at-rest coefficient $K_{0}=2$. In his analysis, the excavation leads to residual conditions in a localised slip length at the slope toe.

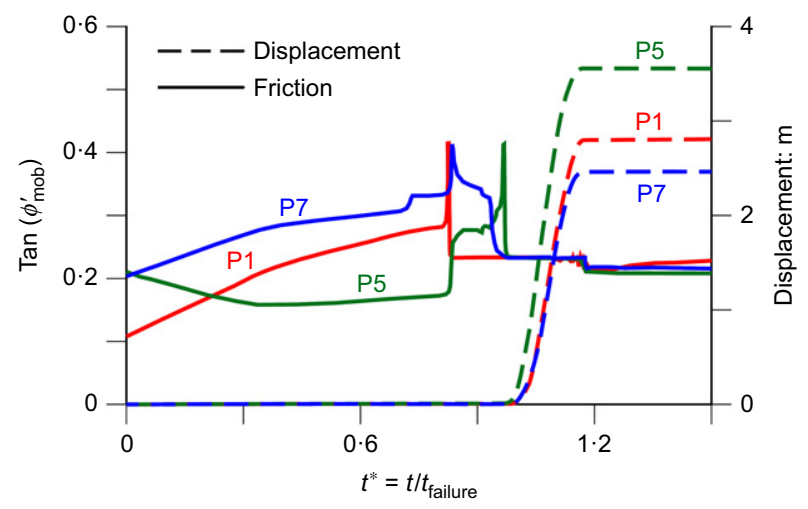

Fig. 36. Evolution of mobilised friction angle at the position of three points belonging to the final failure surface (left scale) and displacements of the same points on the failed soil mass (right scale)
Consider now the failure event and the subsequent dynamic behaviour of the slide in Fig. 36. The figure shows, for three points of the sliding surface, P1 close to the upper surface, $\mathrm{P} 7$ on the toe and P5 in a centred position, the evolution of the mobilised friction angle, defined as $\phi_{\mathrm{mob}}^{\prime}=a \sin \left(q / p^{*}\right) ; p^{*}=p^{\prime}+c^{\prime} / \tan \phi^{\prime}$, where $\left(q, p^{\prime}\right)$ are the deviatoric and effective mean stress, respectively. P1 and P7 reach peak conditions at a similar time, soon after their mobilised friction drops to residual conditions. The last point to evolve from peak to residual state is P5.

The plot also shows (right vertical scale) the calculated total displacement of the three points on the unstable side of the slip line. They accelerate when $\mathrm{P} 5$ reaches residual conditions. This is the start of the motion in practical terms. Before $t^{*}=1$, displacements are calculated but they are hardly visible on the displacement scale of the figure. The change in geometry associated with the motion stabilises the slope. The deceleration of the motion, which eventually comes to a halt, shows this effect. Note that the forward displacement of points P5 and P7, located at a similar level, is different. The overall deformation of the slope explains this result. In fact, the failure is not a rigid body type of motion sliding on a circular slip line, which would result in a kinematically admissible mechanism and a simple displacement pattern of the moving mass. Fig. 37(a) shows the displacement vectors of four points, (C1, C2, C3 and C4) initially located at three different elevations. The figure also shows the runout velocities and accelerations of these points. Maximum calculated acceleration is about $0.35 \mathrm{~m} / \mathrm{s}^{2}(0 \cdot 036 \mathrm{~g})$.

Figure 38 illustrates the stress path of a point near the sliding surface ( point $\mathrm{P} 2$ ). The increase in pore pressure takes the initial stress A to a peak envelope (B) and then to residual conditions. Further increase in pore pressure reduces the mean effective stress and the stress path follows the residual strength envelope. Stress redistribution and changes in geometry induce a reversal in mean effective stress.

Skempton (1964) in his Rankine Lecture addressed the mobilisation of mean friction angle during the process of

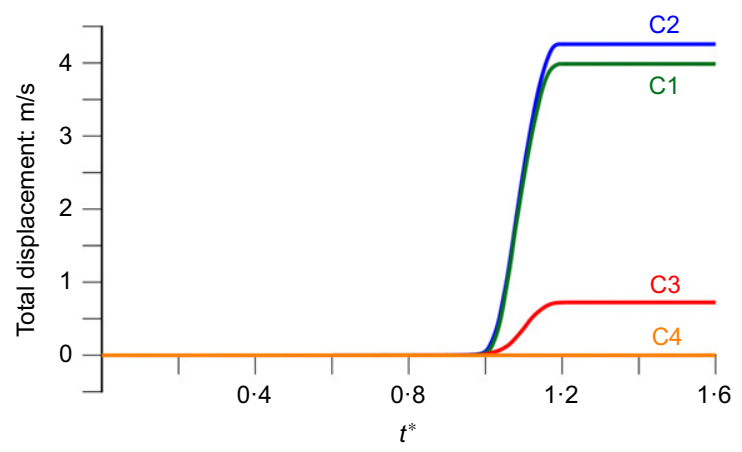

(b)

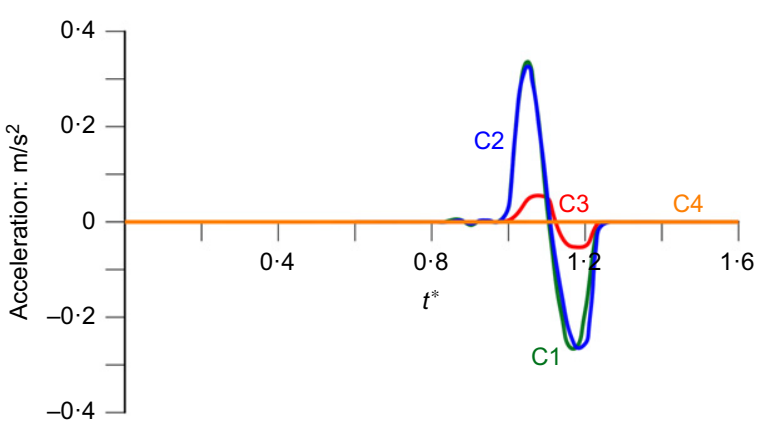

(d)

Fig. 37. (a) Displacement vectors of three points within the Selborne slide; (b) displacement; (c) velocity; and (d) acceleration of the three points 
progressive failure. Stark \& Eid (1994), Potts \& Zdravkovic (2001b) and Gens \& Alonso (2006) (for the Aznalcóllar failure) interpreted failures in brittle clay soils. Often, the mobilised friction at the inception of failure is close to the average value of residual and peak friction angles. This is not a theoretical result and the mobilised friction depends on the aspects controlling the failure.

In the case of Selborne the mobilised friction was calculated by taking the average of 33 points distributed along the failure surface. Fig. 39 shows the result in terms of normalised time. The maximum value $\left(18^{\circ}\right)$ is also in this case close to the average of the peak $\left(24 \cdot 5^{\circ}\right)$ and residual $\left(13 \cdot 5^{\circ}\right)$ of weathered Gault clay.

Figure 40 shows in the vertical axis the magnitude of displacement vectors reported by Grant (1996) of a few surface points of the failed slope. The horizontal axis indicates the original position of the moving point in a scale that represents distance in the direction of the motion. The origin for this scale is the position of the slope crest. The plot shows measurements near the two slope sides, north and south. The runout calculations are close to the north measurements. Apparently, the motion deviated from the intended failure direction because of a restriction offered by the southern side. Boundary conditions of the analysis correspond to the 'free' northern side. The agreement is quite accurate.

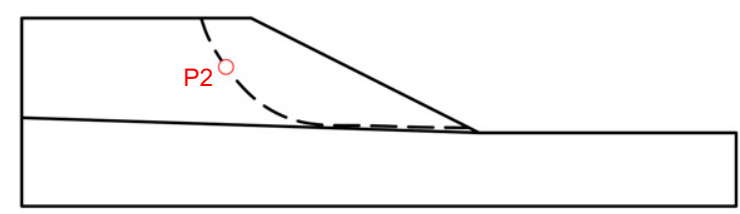

(a)

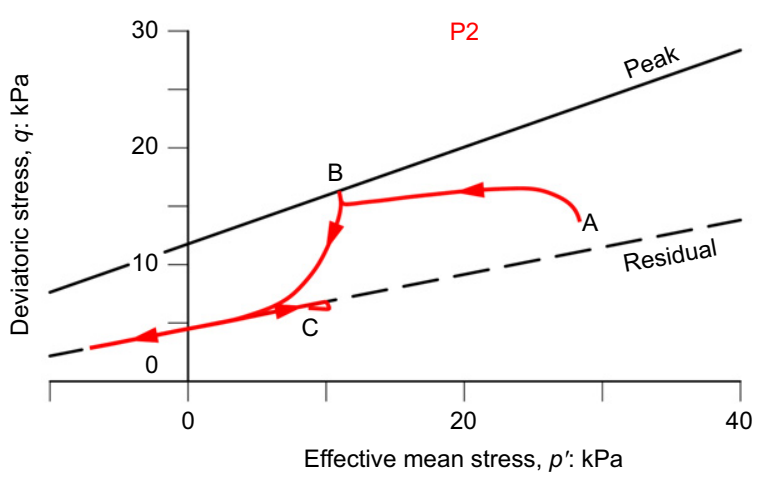

(b)

Fig. 38. Calculated effective stress path of point $P 2$ (a) during the slope overpressure and induced failure (b)

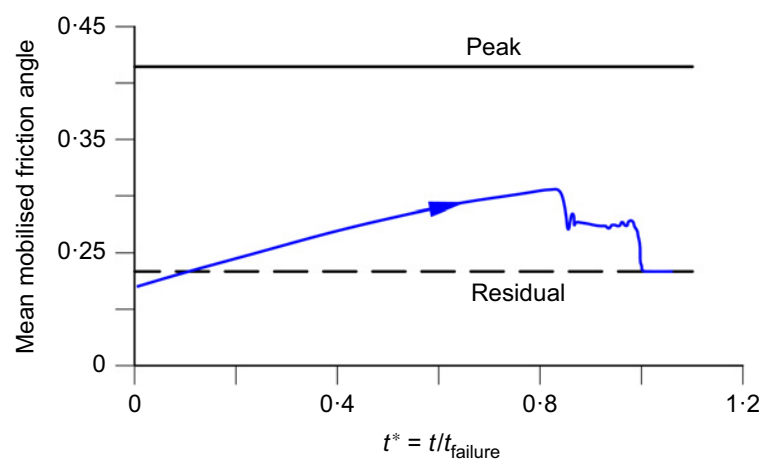

Fig. 39. Evolution of the mean mobilised friction angle along the failure surface

\section{Runout and brittleness}

The Selborne experiment inspired a sensitivity analysis to investigate the relationship between the brittleness index, $I_{\mathrm{B}}=\left(\tau_{\mathrm{p}}-\tau_{\mathrm{r}}\right) / \tau_{\mathrm{p}}$ (Bishop, 1967), and the runout after failure. In the expression for $I_{\mathrm{B}}, \tau_{\mathrm{p}}$ and $\tau_{\mathrm{r}}$ are defined by $\tau_{\mathrm{p}}=$ $c_{\mathrm{p}}^{\prime}+\boldsymbol{\sigma}_{\mathrm{n}}^{\prime} \tan \phi_{\mathrm{p}}^{\prime}$ and $\tau_{\mathrm{r}}=c_{\mathrm{r}}^{\prime}+\boldsymbol{\sigma}_{\mathrm{n}}^{\prime} \tan \phi_{\mathrm{p}}^{\prime} . \boldsymbol{\sigma}_{\mathrm{n}}^{\prime}$ is an average of the effective normal stress on the failure surface. Therefore, $I_{\mathrm{B}}$ is an interpreted measure of the slope brittleness and is calculated for an unstable situation. $I_{\mathrm{B}}$ is not defined in stable slopes.

The reference slope had the dimensions and soil properties indicated in Table 2. As in Selborne, a strain-softening Mohr-Coulomb material describes the soil. Increasing the pore pressure on the lower boundary of the calculation domain triggers failure. The distance between the toe of a slope before failure and after stabilisation defines the runout. Yerro et al. (2016a) describe the details of the MPM modelling of this exercise.

Two triggering 'intensities' were a consequence of varying the water pressure on the lower boundary: either $70 \mathrm{kPa}$ or $40 \mathrm{kPa}$. In a series of parametric analyses, the peak strength remained fixed $\left(c_{\mathrm{p}}^{\prime}=5 \mathrm{kPa} ; \phi_{\mathrm{p}}^{\prime}=35^{\circ}\right)$ and the residual strength parameters changed to examine the effect of $I_{\mathrm{B}}$ varying between $0 \cdot 22$ and $0 \cdot 91$.

The maximum runouts in Fig. 41 reach the lateral boundary of the discretised domain. In addition, for $I_{\mathrm{B}}>$ $0 \cdot 75$, the failure mechanism enters into a rougher calculation mesh and therefore the results become less reliable. However, the relationship between runout and $I_{\mathrm{B}}$ in Fig. 41 is well established. The two triggering boundary pressures lead to essentially the same runout $-I_{\mathrm{B}}$ correlation. Note also that a reduced brittleness index, for the same peak strength conditions, requires an increasing external triggering action (a higher boundary pressure in the current simulation). The figure shows the $\hat{I}_{\mathrm{B}}$ indices required to induce the failure.

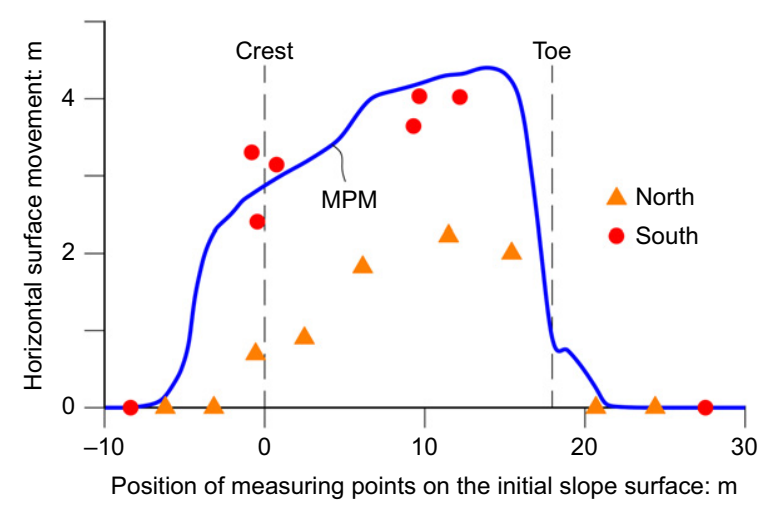

Fig. 40. Measured slide displacements at two cross-sections (north and south) and MPM calculated results

Table 2. Reference slope and soil properties to investigate the relationship between brittleness and runout

\begin{tabular}{l|l}
\hline Slope height: $\mathrm{m}$ & 6 \\
Slope angle: degrees & 37 \\
Porosity & $0 \cdot 2$ \\
Intrinsic permeability: $\mathrm{m}^{2}$ & $10^{-10}$ \\
Young's modulus: $\mathrm{kPa}$ & 20000 \\
Peak cohesion: $\mathrm{kPa}$ & 5 \\
Peak friction angle: degrees & 35 \\
Residual cohesion: kPa & Variable \\
Residual friction angle: degrees & Variable \\
Strain softening rate parameter, $\eta$ & 500 \\
Dilatancy & 0 \\
\hline
\end{tabular}


A given $I_{\mathrm{B}}$ value does not determine the geometry of the failure surface. In fact, changes in residual strength parameters, defining a common $I_{\mathrm{B}}$, lead to significant differences in the failure pattern. Fig. 42 illustrates this result.

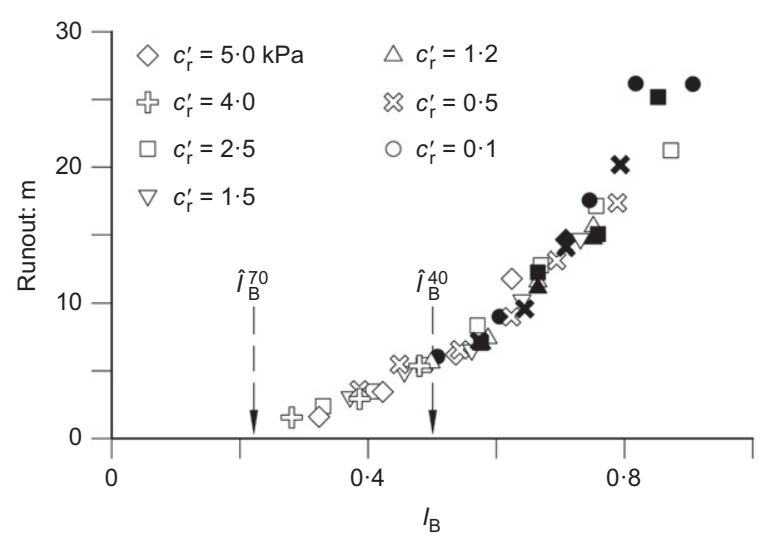

Fig. 41. Relationship between runout and $I_{\mathrm{B}}$. All simulations share the same peak strength $\left(c_{\mathrm{p}}^{\prime}=5 \mathrm{kPa}\right.$ and $\left.\phi_{\mathrm{p}}^{\prime}=35^{\circ}\right) . \Delta P$ indicates the imposed pore water pressure, which induced the failure. Filled symbols: $\Delta p=40 \mathrm{kPa}$. Empty symbols: $\Delta p=70 \mathrm{kPa}$

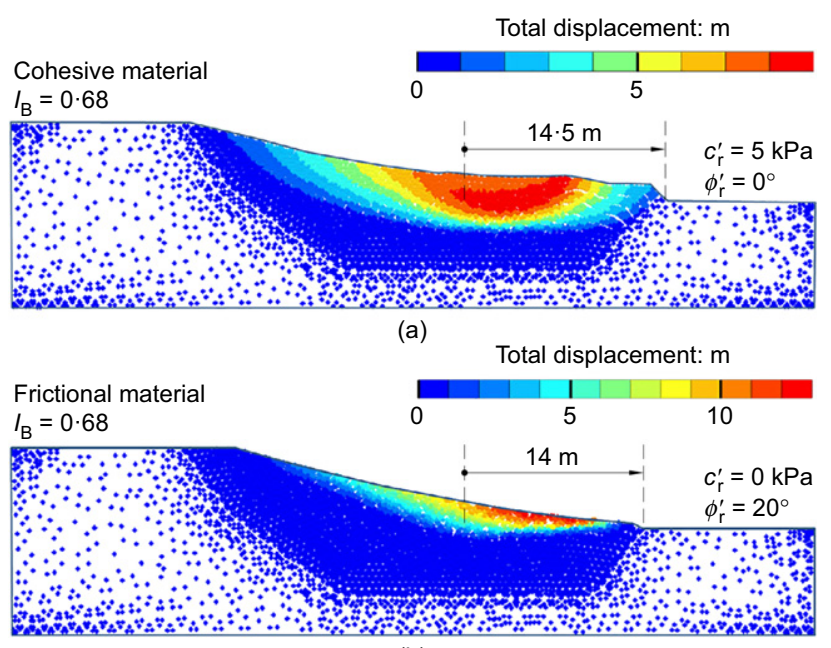

(b)

Fig. 42. Final geometry for two simulations with same $I_{B}$ characterised by common peak strength parameters and different residual strength parameters, indicated in figure

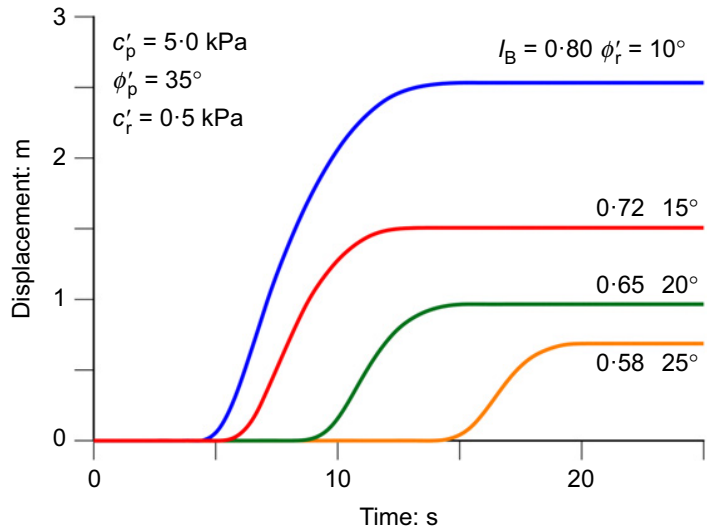

(a)
Displacements of equal locations within the initial stable geometry are different in the two cases represented in Fig. 42, even if the runout (as defined previously) has a common value. The higher residual cohesion case (Fig. 42(a)), if compared with the case in Fig. 42(b), explains the deeper failure mechanism.

Brittleness controls other related aspects of the motion and not only runout. Fig. 43, which represents time histories of displacements, velocities and, indirectly, accelerations for some of the cases included in Fig. 41, shows the results. The time in this figure depends on the transient flow and not on the progressive failure mechanism, which is an instantaneous process. The unstable slope reaches instability for increasing values of $I_{\mathrm{B}}$ earlier. It also undergoes higher accelerations and velocities, if compared with lower brittleness ratios.

Results for the Selborne case discussed previously indicated that the peak strength is directly involved in the triggering mechanism. The last point in the failure surface reaching peak conditions marks the beginning of motion. However, the residual strength defines the runout better. Fig. 44 shows the calculated results for different peak strength envelopes and a few combinations of residual strength parameters. It is also interesting to observe that small changes in $c_{\mathrm{r}}^{\prime}$ for a common $\phi_{\mathrm{r}}^{\prime}$ (for instance $c_{\mathrm{r}}^{\prime}=1.5 \mathrm{kPa}$ and $c_{\mathrm{r}}^{\prime}=0.5 \mathrm{kPa}$ for $\phi_{\mathrm{r}}^{\prime}=20^{\circ}$ in both cases) lead to significant changes in runout.

\section{SLOW-MOVING SLIDES}

Slow-moving or creeping slides are common in nature. In their landslide velocity scale, Cruden \& Varnes (1996) classify as slow or very slow velocity values in the order of $1.6 \mathrm{~m} /$ year and $16 \mathrm{~mm} /$ year, respectively. They add a further class, extremely slow-moving landslides, for an unspecified velocity, probably in the order of a few millimetres per year. Pampaneira landslide, described in the 'Introduction', moves at an extremely low velocity.

Landslide displacements imply a geometric evolution of the sliding mass towards a new dynamic situation, which results in a modification of the creeping rate. A slow-creeping landslide may reactivate by external actions, which lead again to a loss of equilibrium. This is the case of river erosion at the landslide toe, the presence of excavation works and the increase of pore pressure or applied loads.

The classes of landslides examined here are typically translational, rotational, or 'compound' sliding geometries characterised by a basal, well-defined sliding surface. In these slides the moving mass, soil or rock, maintains a certain continuity and preserves, to a significant extent, the original 


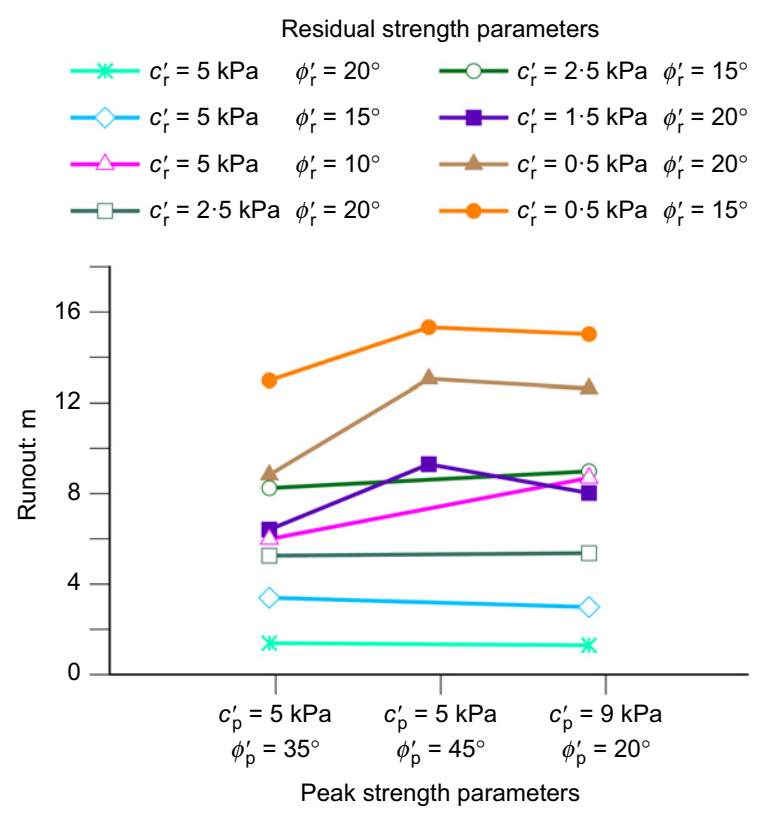

Fig. 44. Influence of residual strength on run-out for three different peak Mohr-Coulomb envelopes

geotechnical properties of the soil above the sliding surface, even if internal shearing is often the case. This is not the case for flow-like slides, which are not considered in this paper.

The concept of safety factor (SF) (ratio of shear and mobilised strength on the sliding surface) is of limited use to analyse the creeping motion. In fact, one may accept that a creeping slide has lost equilibrium and, therefore, its SF is marginally lower than one.

The following simple expression provides the velocity of a planar landslide in terms of SF

$$
v=\boldsymbol{g} \sin \beta(1-\mathrm{SF}) t
$$

which was already advanced by Newmark (1965) in his fifth Rankine Lecture. In equation (4), $\beta$ is the slope of the planar motion. Expression (4) (predicts) a linear increase of velocity with time, for a constant normal effective stress on the failure plane, a situation that is not observed in practice.

In fact, field experience indicates that creeping slides maintain their slow to extremely low velocities for long periods. They exhibit in some cases constant creeping rates. In other cases, they follow periodic changes of velocity as a reaction to varying external actions and, in particular, pore water pressures.

Cascini et al. (2014) investigated the patterns of acceleration and deceleration stages of creeping landslides. Fig. 45 shows the displacement $s$, normalised by the maximum displacement at a given creeping stage, in terms of dimensionless time, $t / t_{\max }, t_{\max }$ being the time interval for the creeping stage. The authors describe the curves in Fig. 45 by simple mathematical expressions, which may be used for forecasting purposes.

Other approaches, purely empirical, prove to be successful to predict the effect of water table changes in sliding velocity. For instance, Comegna et al. (2013) relate creeping velocity and depth of water table, $h$, by the expression $v=a / h^{b}$, where $a, b$ are constants. However, in these approaches the physics of the creeping process are not present explicitly.

A widespread modelling alternative is to introduce viscous resisting forces in the dynamic equilibrium equations. Viscous shearing forces are a function of the shearing velocity (Hungr, 1995; Corominas et al., 2005; Pouya et al., 2007; among many others). Most models that are used

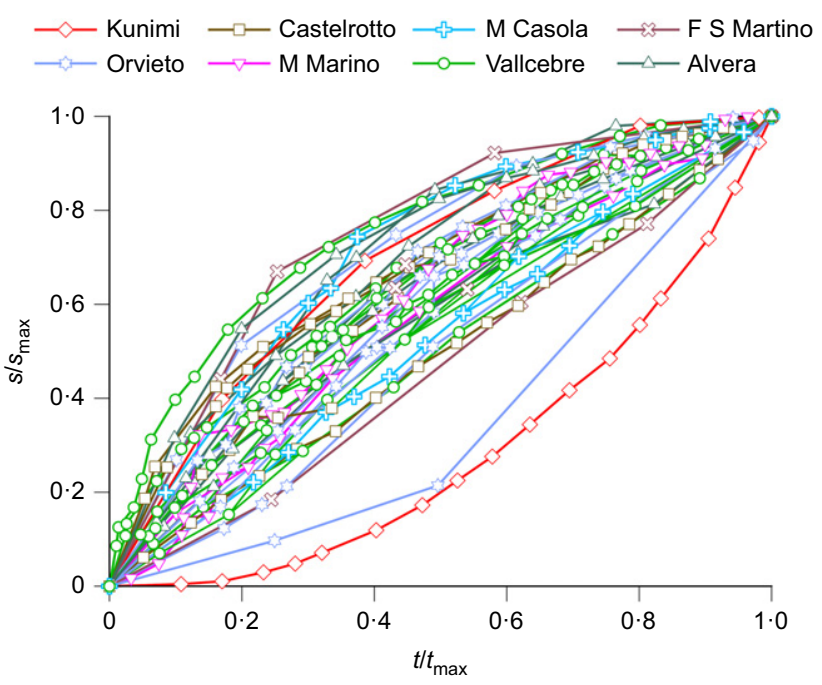

Fig. 45. Normalised displacement-time records in creeping slides collected by Cascini et al. (2014)

describe the viscous resistance as a power function of shearing rate. Van Asch et al. (2007) discuss some difficulties of viscous models: back-analysed viscous parameters from creeping slides are far from experimental results provided by ring shear tests performed at varying strain rates. They report that the field viscosity is several orders of magnitude larger than laboratory values.

Accepting that strength depends on strain rate explains the time-dependent behaviour observed in drained triaxial tests in soils. Leroueil (2001) describes the results of a model that combines a hyperbolic stress-strain model, a linear relationship between $\log$ (shear strength) and $\log$ (strain rate) and a failure criterion controlled by an accumulated critical shear strain. He shows that these hypotheses explain the strain rate-time relationships observed in creep triaxial tests on some clays.

Strain rate observations in this type of tests led to the concepts of 'primary', 'secondary' and 'tertiary' creep. In fact, not only clays, but also granular materials, exhibit similar trends in creeping tests. Fig. 46 compares the timedependent behaviour, under changing deviatoric stress, of two widely different soils: Toyoura sand (Murayama et al., 1984) and San Francisco Bay mud (Lacerda, 1976). For deviatoric stresses, which are a fraction of shear strength, the deviatoric strain rate decreases continuously in time (a linear $\log -\log$ relationship reproduces the experiments). This is a 'primary' creep. For applied deviatoric stresses close to the shear strength, failure (interpreted as a rapid increase of shearing strain rate) takes place after a short time. This is the tertiary creep stage. 'Secondary' creep marks the transition from a stable primary creep to tertiary creep.

Kuhn \& Mitchell (1993) were able to show that this behaviour is a direct consequence of strain rate effects on friction. They simulated a triaxial test on an assembly of 1002 discs by means of a DEM model. The distinct feature of their model was to characterise the friction at the particle contact by a velocity-dependent friction. Their results, reproduced in Fig. 47, capture well the creeping trends for increasing deviatoric stress described previously. Several years later, Kwok \& Bolton (2010) reached the same results, this time by means of a DEM assembly of spherical particles.

These results suggest that strain rate effects on friction at local level are able to explain macroscopic creep observations at a larger scale and under general stress states. Obviously, the microstructural complexity of a soil sample plays 


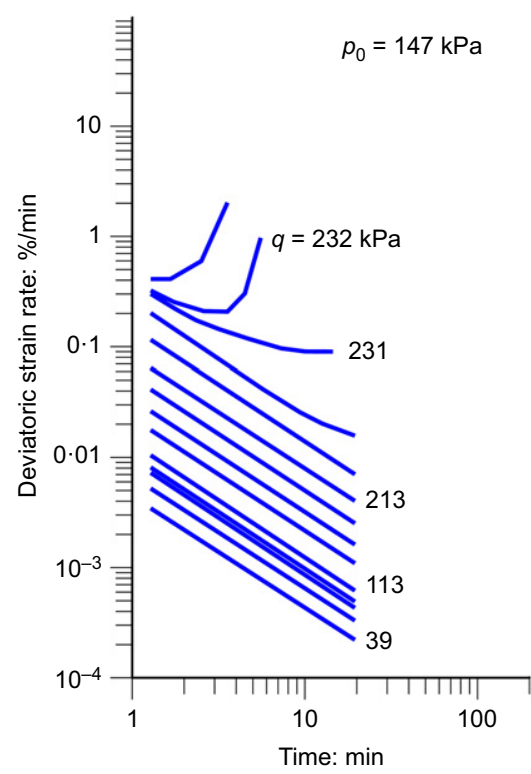

(a)

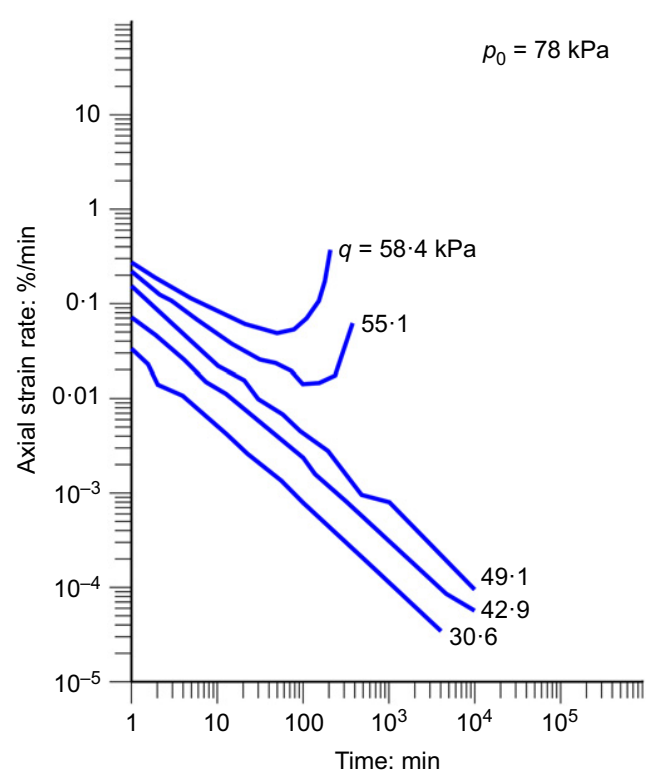

(b)

Fig. 46. Results of triaxial creeping tests reported by (a) Murayama et al. (1984) on Toyoura sand and (b) Lacerda (1976) on San Francisco bay mud (Kuhn \& Mitchell, 1993)

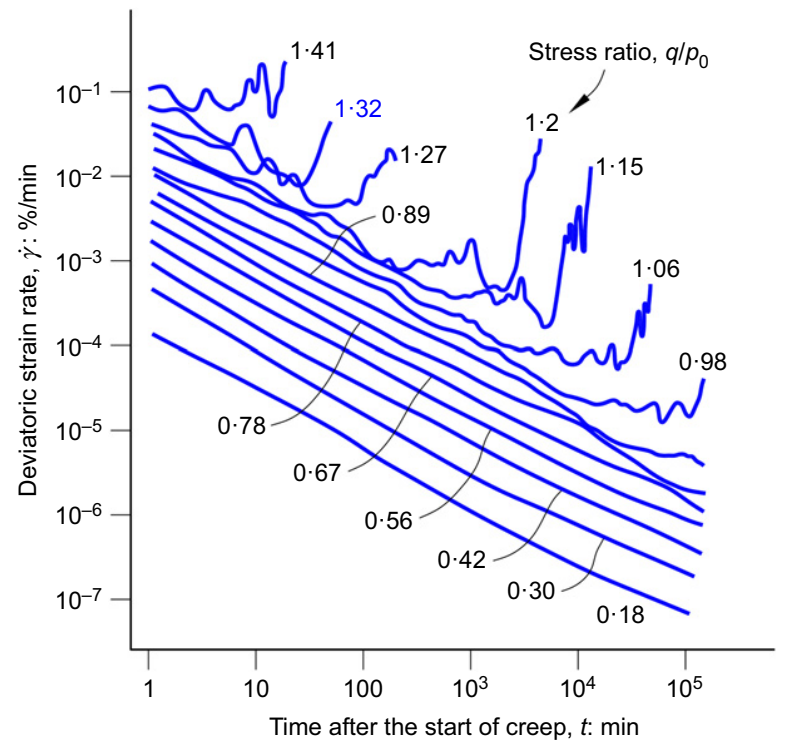

Fig. 47. Calculated deviatoric strain rates for an assembly of discs characterised by a strain rate dependency of contact friction among particles (Kuhn \& Mitchell, 1993)

also a decisive role to explain the observed behaviour. Nevertheless, these results support the relevant role of strain rate effects on friction to interpret creep observations in landslides. Some basic concepts on the nature of friction follow in the next section.

\section{Rate effects on friction}

Bowden \& Tabor (1964), Mitchell (1976) and Rice (2001) describe the nature of friction through the concepts of activation energy, at the local level of contacts between bodies. Consider the situation represented in Fig. 48: the contact between two bodies along a common plane, subjected to a normal stress, $\sigma$, and a shear stress, $\tau$. At a local scale the contact is established through $n$ areas $a_{i}(i=1$ to $n)$. Local values of shear and normal stress $\left(\tau_{\mathrm{c}}, \sigma_{\mathrm{c}}\right)$ act at

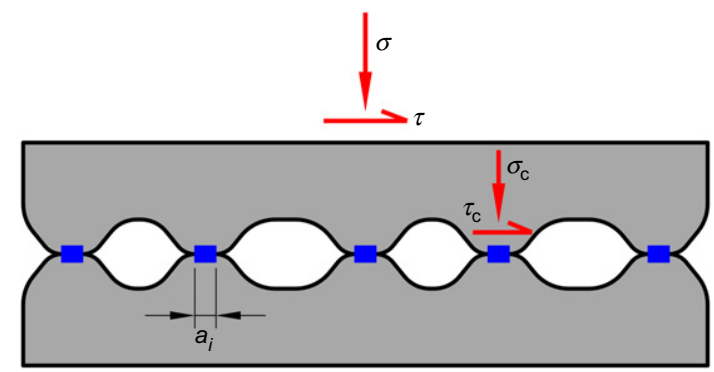

Fig. 48. Scheme to derive the relationship between local and macroscopic friction

these points. Equilibrium leads to the following relationship between the macroscopic stresses

$$
\tau=\sigma \frac{\tau_{\mathrm{c}}}{\sigma_{\mathrm{c}}}
$$

$\tau_{\mathrm{c}}$ and $\sigma_{\mathrm{c}}$ are stresses at a molecular scale. Under shearing, local contact processes are understood as undergoing chemical reactions that may change the $\tau_{\mathrm{c}}$ values. If these reactions follow an Arrhenius rate process, their velocity is

$$
v=v_{\text {ref }} \exp \left(-E_{\mathrm{a}} / R T_{\mathrm{a}}\right)
$$

where $v_{\text {ref }}$ is a reference shearing velocity; $E_{\mathrm{a}}$ is an activation energy; $R$ is the gas constant; and $T_{\mathrm{a}}$ is the absolute temperature.

The energy $E$ is understood as an energy barrier in the sense that a decrease in the energy leads to a velocity increase. Energy $E$ decreases as the energy loss associated with shearing local bonds increases. The following equation

$$
E=E_{\mathrm{a} 1}-\tau_{\mathrm{c}} \Omega
$$

expresses this concept. $E_{\mathrm{a} 1}$ is a reference energy and $\Omega$ is the active volume of contact bonds (the interpretation of stress as energy per unit volume is invoked). Equations (5)-(7) provide the following expression for a shear strength law (Rice et al., 2001)

$$
\tau=\sigma\left[\frac{E_{1}}{\Omega \sigma_{\mathrm{c}}}+\frac{R T}{\Omega \sigma_{\mathrm{c}}} \ln \frac{v}{v_{1}}\right]
$$




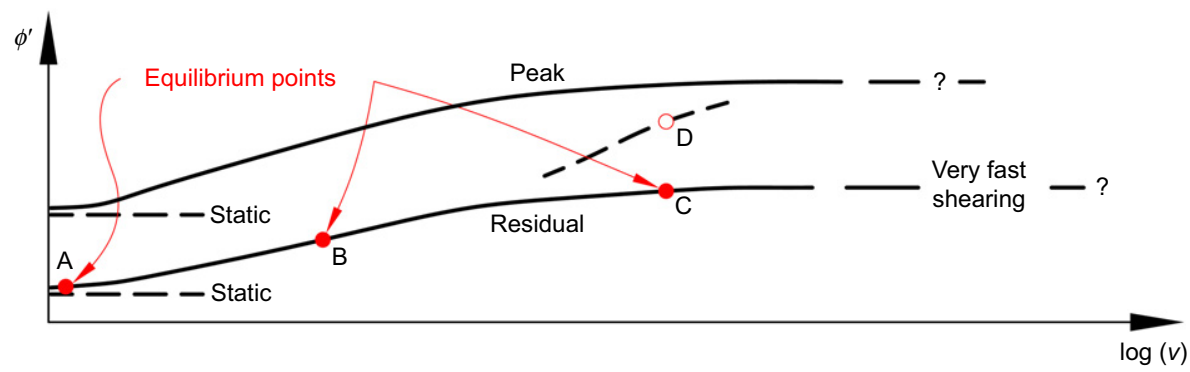

Fig. 49. Expected dependency of friction angle with shearing velocity. Point $D$ illustrates the loss of creeping equilibrium for a landslide resting on a sliding surface at residual conditions

It provides the 'structure' of the friction angle: a 'base' value given by the first term and a second term, proportional to the logarithm of the shearing rate. The basic term is further interpreted as the sum of two terms, a basic friction $f^{*}$ and a 'state' term $\psi$, characterising other aspects controlling friction such as applied stress, relative displacement and healing effects. Therefore

$$
\tau / \sigma=\tan \phi^{\prime}=f^{*}+\psi+A \ln \frac{v}{v_{\text {ref }}}
$$

where the parameter $A$ controls the intensity of rate effects on friction.

Experimental results support equation (9). This is the case of the pioneering tests of Dieterich (1979) and Ruina (1983) testing polished surfaces of rock. Skempton (1985) reported the effect of varying the shear rate four orders of magnitude in ring shear tests on clay. He found an increase of $2 \cdot 5 \%$ in the residual strength per log-cycle of strain rate. Cooper et al. (1998) reported similar tests on high-plasticity Gault clays. Tika et al. (1996) found that some soils exhibit a 'negative' strain rate effect, attributed to an increase of water content in the shearing band because of dilatancy effects. Wedage et al. (1998) found increments of friction coefficient of $0.5 \%$ per log-cycle of shearing strain rate in a highplasticity clay. Wang et al. (2010) report friction angle increments of about $1^{\circ}$ per log-cycle of shear strain rate when testing high-plasticity clay. Wang et al. (2010) found higher increases $\left(2^{\circ}\right.$ to $\left.3^{\circ}\right)$ in the case of low- to mediumplasticity clayey silt.

The shearing velocities applied in the testing programmes mentioned span a wide range: from $10^{-5} \mathrm{~mm} / \mathrm{min}$ to more than $1 \mathrm{~m} / \mathrm{min}$. Shearing velocities in excess of, say, $1 \mathrm{~cm} / \mathrm{min}$ cannot be considered as creeping motions and they enter into a class of moderate to rapid sliding velocities.

For high velocities, physical phenomena on the shearing band become more complex and the friction coefficient tends to reduce (Di Toro et al., 2011). These authors suggested the following friction reducing mechanisms

(a) grinding of minerals into nanoparticles of low friction

(b) dehydration of minerals leading to pore water pressure increase

(c) de-carbonation of calcitic rocks and release of pressurised gas

(d) mineral melting leading to viscous components

(e) thermal pressurisation of water.

These processes require high energy and temperature, which may be present in active faults and, perhaps, in deep landslides. The thermal pressurisation of water, under saturated conditions, will be present for the observed effective normal stresses and sliding velocities found in practice for landslides. This phenomenon is discussed below in more detail.

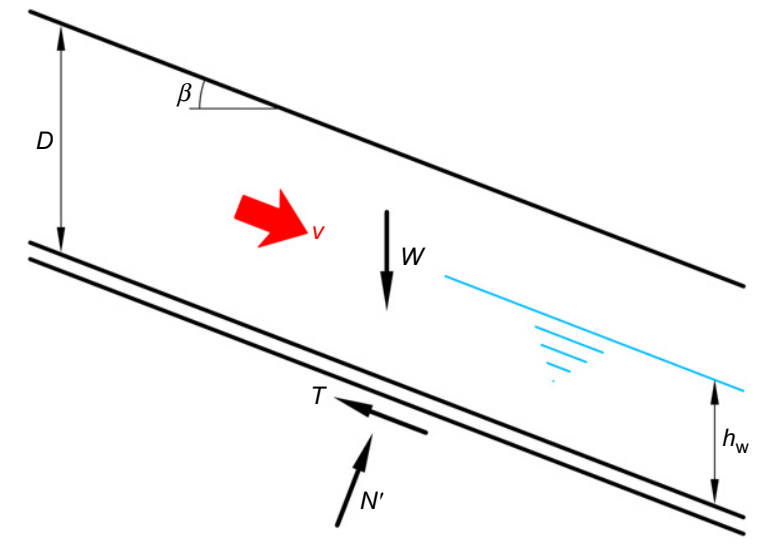

Fig. 50. Scheme for a planar landslide

Returning to the creeping motions, the strain rate effects on friction, characterised by equations (8) and (9), imply, in a dynamic situation, an increasing resistance when the motion accelerates.

Figure 49 shows the implications of strain rate effects for a creeping slide on a sliding surface at residual strength. Once experiencing a slow motion at a constant velocity, the residual friction is in operation at point $A$. If an external 'loading' (i.e. a pore water pressure increase) is applied, dynamic equilibrium conditions will lead to an increased velocity and a parallel increase in residual friction (points $B$ and $\mathrm{C}$ ). Points $\mathrm{B}$ and $\mathrm{C}$ provide the necessary friction angle for an equilibrated creeping stage.

However, if the external loading becomes larger, the necessary friction angle, $\phi_{\mathrm{D}}^{\prime}$, for the slope to remain in a constant creeping stage may be above the rate effect contribution offered by the sliding plane. Then, the slide will accelerate. This evolution corresponds to the notional concept of slope failure. This discussion will be extended in a later section of the paper in the context of an additional phenomenon (water thermal pressurisation) leading to a rapid acceleration.

\section{Dynamic equilibrium of a creeping slide}

Consider the simple planar slide represented in Fig. 50. The equilibrium and friction laws describing the creeping motion are

$$
\begin{aligned}
& W \sin \beta-T=\frac{W}{\boldsymbol{g}} \frac{\mathrm{d} v}{\mathrm{~d} t} \\
& W \cos \beta-N^{\prime}-\gamma_{\mathrm{w}} h_{\mathrm{w}} \cos ^{2} \beta=0 \\
& T=N^{\prime} \tan \phi^{\prime}
\end{aligned}
$$




$$
\begin{aligned}
& \tan \phi^{\prime}=\tan \phi_{0}^{\prime}+f_{\mathrm{v}} \\
& f_{\mathrm{v}}=A \ln \left(\frac{v}{v_{\text {ref }}}\right) \text { for } v>v_{\text {ref }} \\
& f_{\mathrm{v}}=0 \text { for } v \leq v_{\text {ref }}
\end{aligned}
$$

where $W$ is the weight of a reference vertical slice. Fig. 50 and the previous discussion indicate the remaining parameters and variables. Note that no rate effects on friction are considered below a (small) reference velocity $\left(v_{\text {ref }}\right)$, which becomes a model parameter.

The set of equations (10)-(15) were solved numerically for an example defined by $\left(D=25 \mathrm{~m}, \phi^{\prime}=12^{\circ}, \beta=9 \cdot 8^{\circ}\right)$. These parameters lead to strict equilibrium (static safety factor $=1$ ) for a water level, $h_{\mathrm{w}}=11.29 \mathrm{~m}$. The purpose of the example is to find the slope response under a time oscillation in water level given in Fig. 51(a).

Figure 51(b) shows the calculated safety factor during the variation of water level. This information is not particularly relevant if the objective is to find the sliding velocity (Fig. 52). The plot provides the calculated velocity for three values of the parameter $A$, defining the intensity of strain rate effects. In all of the cases, $v_{\text {ref }}=10^{-8} \mathrm{~m} / \mathrm{s}$. Fig. 53 shows the effect of $A$ on the residual friction angle for sliding velocities in the range $0-6 \mathrm{~mm} /$ day. The increase in friction angle with sliding velocity for changes in $A$ is moderate (12 to $13^{\circ}$ ). However, the effect of this change, shown in Fig. 52(b), is outstanding. Sliding velocities become exceedingly large in the absence of rate effects.

There has been an interest in checking the capability of a strain rate approach to explain creeping motions against field

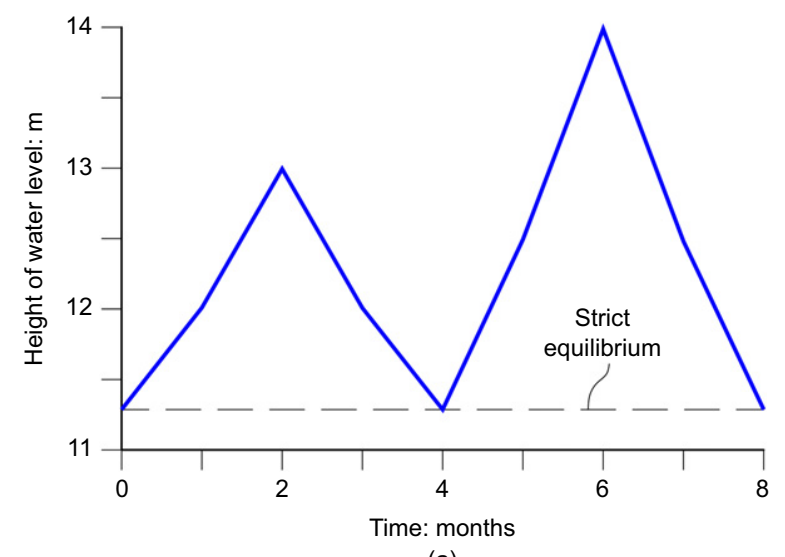

(a)

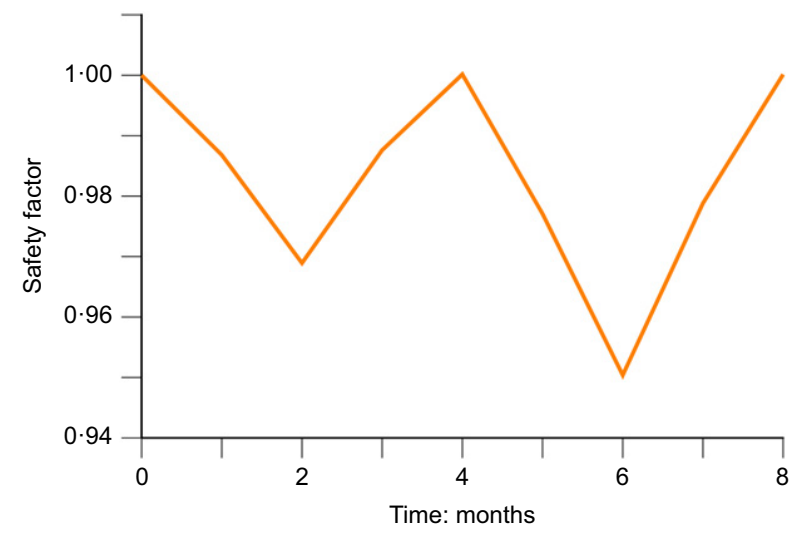

(b)

Fig. 51. Creeping motion of a planar landslide: (a) two cycles of water table change; (b) calculated safety factor observations (Alvarado et al., 2019). Corominas et al. (2005) describe the case selected (Vallcebre creeping slide, eastern Pyrenees, Spain). The lower section of the slide, detached from the upper part, is an almost planar active translational motion (Fig. 54).

An upper layer, $15 \mathrm{~m}$ thick, of clayey siltstone (Upper Cretaceous) slides over a thinner level of fissured shales, which overlie a limestone substratum. The sliding surface is located in the fissured shale. Corominas et al. (2005) describe the field and laboratory work performed to determine the main parameters. With reference to Fig. 54, Vallcebre lower planar slide is described by $\beta=6.5^{\circ}, D=15.5 \mathrm{~m}$ and $\phi_{\mathrm{res}}^{\prime}=7.8^{\circ}$.

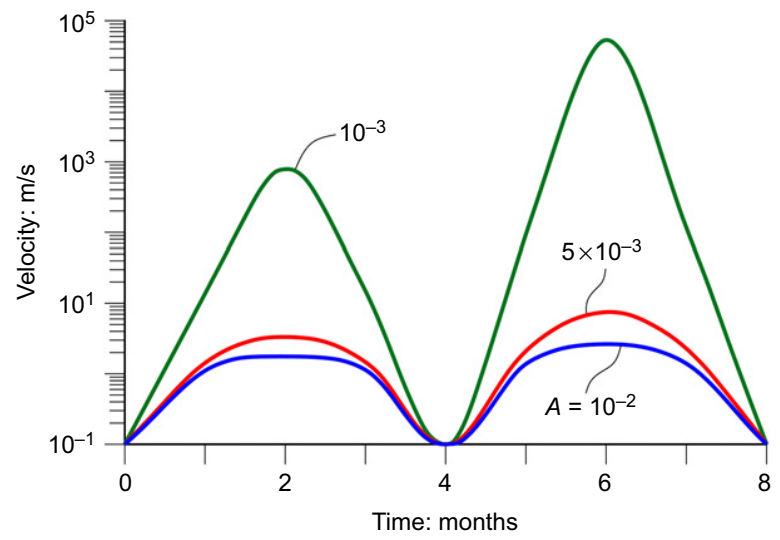

(a)

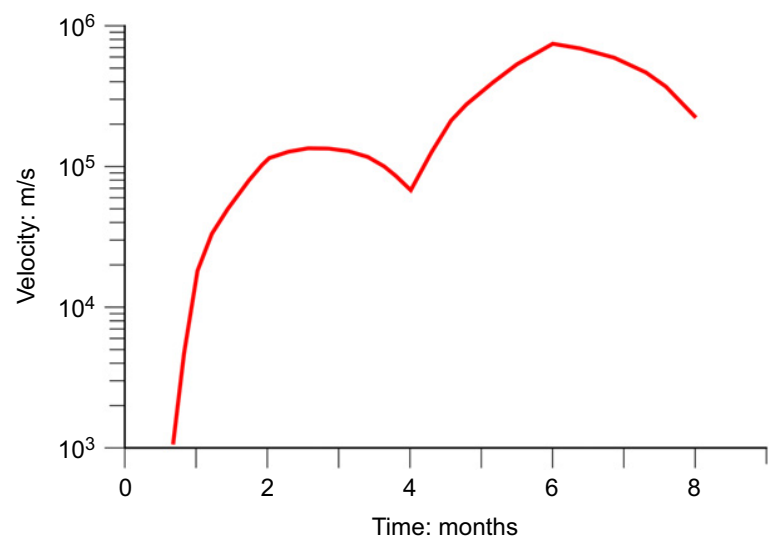

(b)

Fig. 52. (a) Calculated evolution of sliding velocity for a velocity dependent friction at the sliding surface for three values of parameter $A ;$ (b) $A=0$ (no strain rate effects)

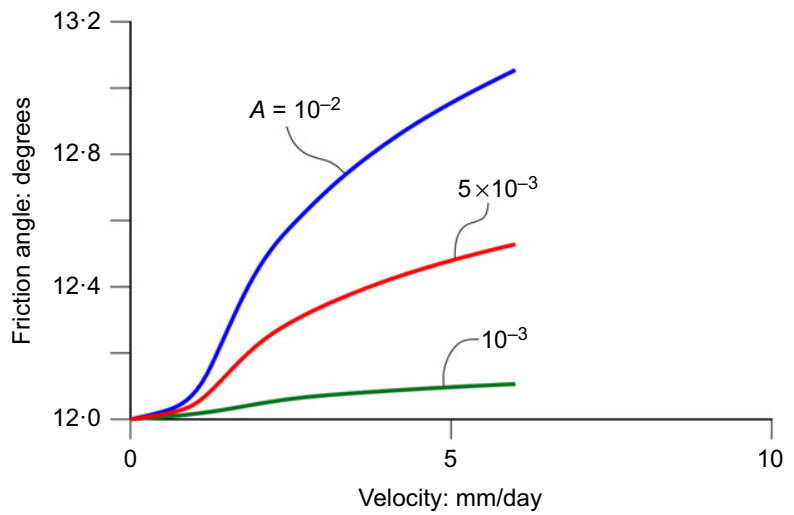

Fig. 53. Variation of friction angle with sliding velocity and parameter $A$ 


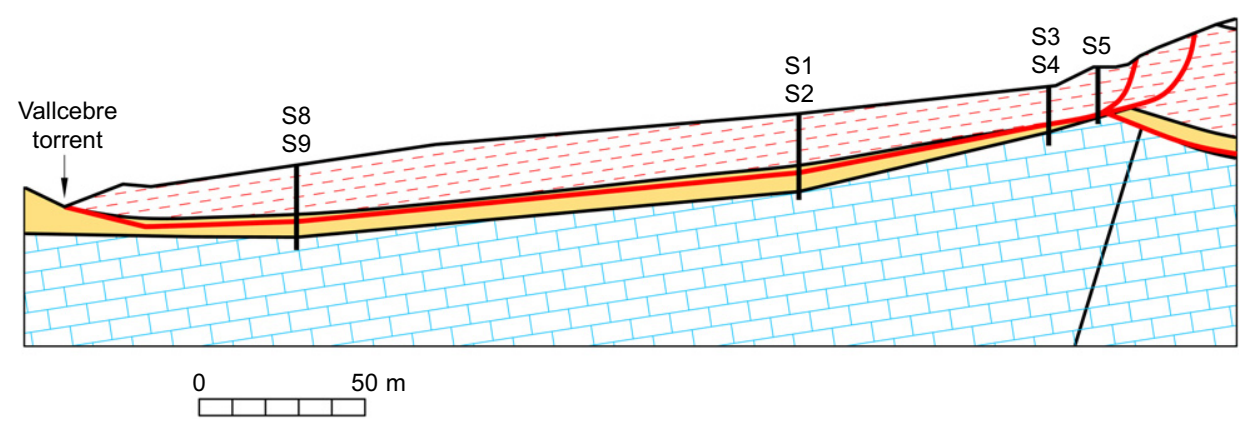

Fig. 54. Lower section of Vallcebre slide

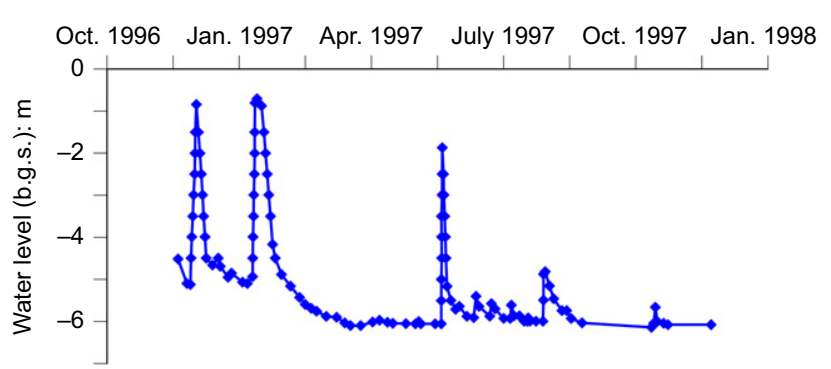

(a)

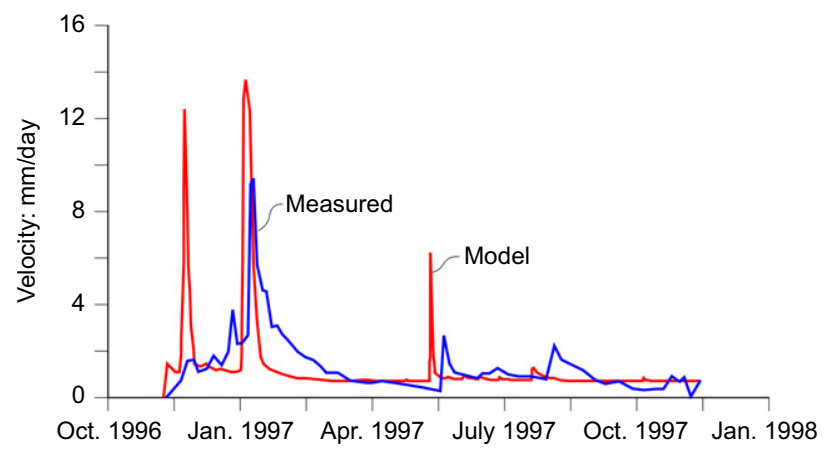

(b)

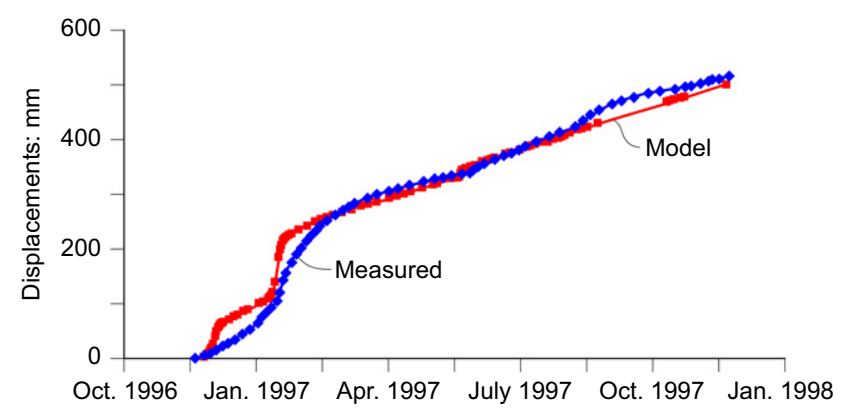

(c)

Fig. 55. Vallcebre landslide: (a) rainfall record (b.g.s., below ground surface); (b), (c) comparison of measured and calculated landslide velocity and displacement

Slide monitoring began in 1996. Fig. 55 shows a rainfall record for the period from October 1996 to December 1997 and the measured velocities and displacements. Also shown in Fig. 55 is the response of the planar model for a value of $A=1.85 \times 10^{-2}$. This parameter results from adjusting measurements and the model, because no tests on the effect of shearing rate on the residual friction were available. However, the $A$ value found is within the range of expected values in view of other laboratory data. In terms of accumulated displacements, the agreement is quite satisfactory. Only one extra parameter, on top of the standard description of sliding variables, leads to a reasonable model for the creeping motion.
Corominas et al. (2005) report also a comparison between two other calculations which introduce viscous resisting forces by means of a Bingham model (one additional parameter: the viscosity), and a power law model requiring two additional parameters. These parameters derive from the minimisation of errors between measured and calculated displacements. Their approximation is no better than the strain rate approach presented here.

The strain rate effect on friction (the function of $f_{\mathrm{v}}$ in equations (13)-(15)) is related to a 'viscous' shear stress, $\tau_{\mathrm{v}}$, through the expression

$$
\tau_{\mathrm{v}}=\sigma_{\mathrm{n}}^{\prime} f_{\mathrm{v}}=\sigma_{\mathrm{n}}^{\prime} A \ln \left(v / v_{\text {ref }}\right)
$$

which is easily found if the equilibrium of a planar slide is formulated under either a viscous or a strain-rate-dependent friction approach. In other words, for a convergence of the two approaches, the viscous formulation should include a linear dependence on effective normal stress to the sliding plane. This condition looks consistent with the frictional character of the shear strength of soils.

\section{Rate effects on friction and failure}

The question of predicting the time to failure has received attention in landslide research. Available procedures investigate measured relationships between accumulated displacement and time, and propose extrapolation techniques to obtain a critical displacement or velocity, selected as an indication of failure.

Saito (1965, 1969), Voight (1978) and Fukuzono (1990) suggested that the sliding velocity is inversely proportional to the time to failure and, therefore, a plot relating the inverse of velocity with time would provide the failure time (for $1 / v=0$ ). This linear relationship implies a continuous non-linear increase of acceleration with time, provided 'external' actions on the landslide do not change in time.

Hungr et al. (2014), in a state-of-the-art report, collected several contributions to this topic and highlighted the implications and limitations of the procedure. For instance, they indicated that Petley et al. (2002) interpreted the continuously increasing acceleration as an indication of shearing planes developing on previously unfailed rock. Fracture in a brittle material is a time-dependent phenomenon, but progressive failure in a strain-softening soil is not. The fact is that these procedures do not explain the physical mechanisms leading to the eventual slope failure.

Helmstetter et al. (2003) analysed the dynamics of a planar slide when friction depends on strain rate and state (equation (9)). Their specific law for friction, $f$, is

$$
f=f_{0}+a \ln v / v_{0}+b \ln \xi / \xi_{0}
$$

where $v$ is the sliding velocity and $\xi$ is a state variable. Subscript 0 indicates a reference value, and $a$ and $b$ are model 

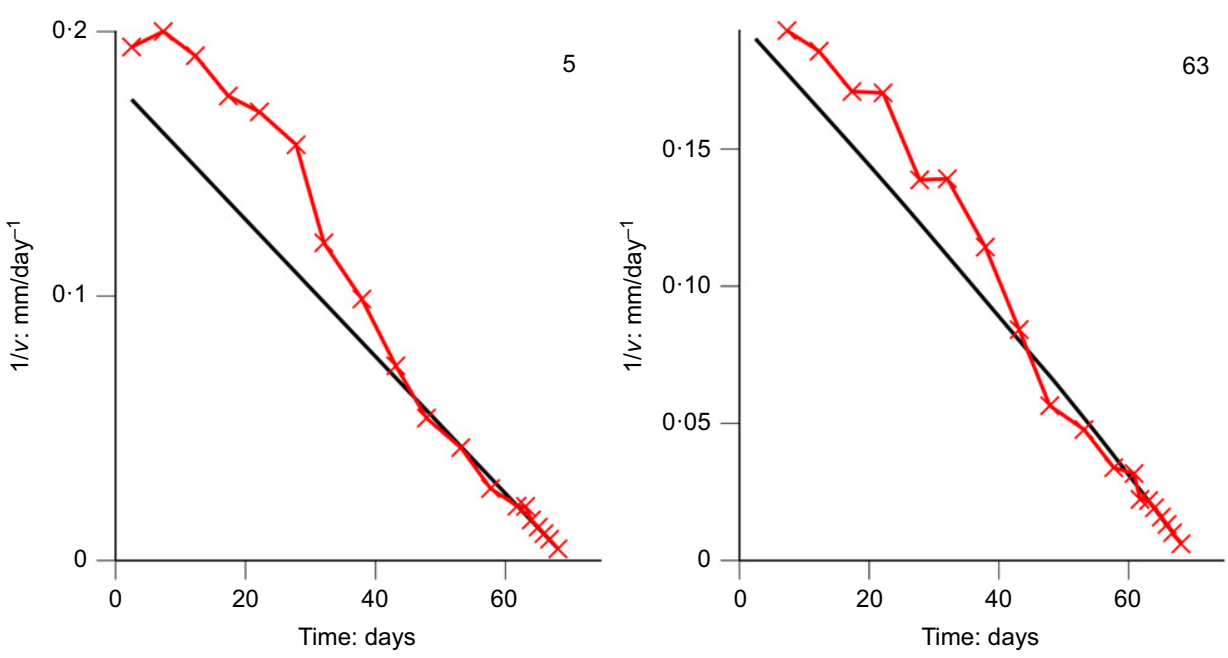

Fig. 56. Measured and predicted evolution of velocities of a simulation of Vajont landslide for two benchmark points (5 and 63$)$ on the surface, according to Helmstetter et al. (2003)

parameters. An evolutionary law further specifies the state variable

$$
\frac{\mathrm{d} \xi}{\mathrm{d} t}=1-\frac{\xi \delta}{D_{\mathrm{c}}}
$$

where $D_{\mathrm{c}}$ is a critical size of asperities of the shearing surface. Variable $\xi$ is capable of modelling weathering effects associated with accumulated shear displacements. In particular, for values $b / a>1$, the slope becomes unstable and the velocity increases continuously with time. The authors suggest that this is the case for the Vajont landslide and examine the known history of Vajont displacements in four benchmarks, in the days before the catastrophic failure. Fig. 56 indicates the time evolution of two of these benchmarks (' 5 ' and ' 63 ') in coordinates $(1 / v$ plottedagainst $t)$.

A planar landslide poorly represents the geometry of Vajont (a compound landslide, better identified as a two-block interacting mechanism). Internal mass shearing, other than the shearing along the basal failure surface, is required for kinematic reasons. In addition, the smoothing of asperities in a sliding surface located in a high-plasticity clay is a doubtful assumption, even if the complexities of the Vajont sliding surface, raised later, may provide support for this idea.

However, in terms of understanding basic mechanisms, the main concern and difficulty offered by Vajont is to explain the sudden acceleration. This is also the main question when risk and damage require quantification.

Final observations in Vajont, before failure, indicate that benchmarks displaced at velocities in the order of $4 \mathrm{~cm} /$ day. This is the velocity of the fitting model in Figs 56 and 57(a) for a time of 60 days, in the scale of the plots. Fig. 57(b) provides, at an enlarged timescale ( $24 \mathrm{~h}$ of a given day), the evolution of creeping velocity in the vicinity of two times, 60 and 65 days, which correspond to landslide velocities of $4 \mathrm{~cm} /$ day and $7.69 \mathrm{~cm} /$ day, respectively.

The final accelerated failure abandoned the creeping stage at some point in time and reached, in a matter of seconds, velocities of the order of several metres per second. This huge change in velocity cannot be represented properly in the velocity scale of Fig. 57(b). This change in velocity is represented by a vertical arrow, pointing upwards, in the figure.

It is concluded that the rate- and state-dependent friction law described does not include the relevant physical process leading to a very rapid acceleration, starting at a creeping stage, even if it can be described as a 'slow to moderate' creeping velocity (in the classification of Varnes (1978)).
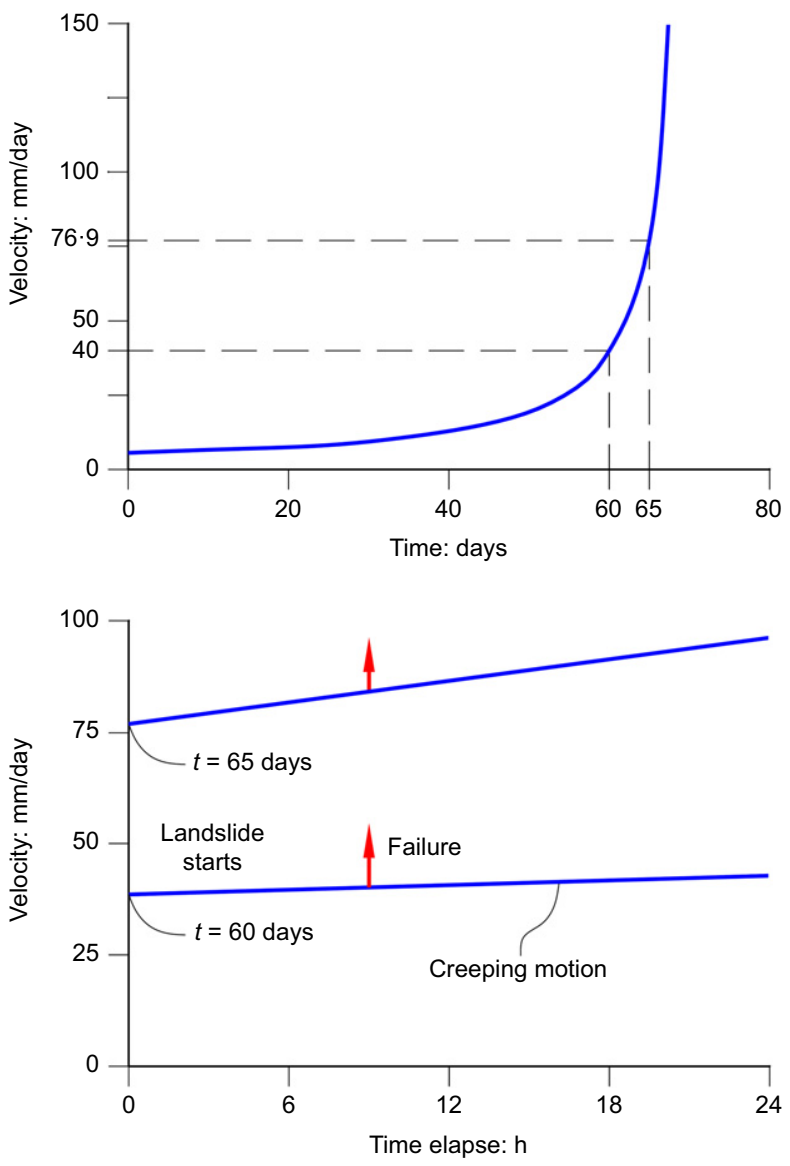

Fig. 57. An interpretation of the velocity of Vajont slide following the simplified model of Helmstetter et al. (2003)

In the next section, the mechanisms and models of fast landslides are discussed from the perspective offered by thermal, hydraulic and mechanical interactions.

\section{FAST LANDSLIDES}

Extreme 'loading' events, namely strong earthquakes and heavy rainfall, result in an immediate response of potentially unstable zones, be they in an undisturbed or creeping stage. However, it is also a common observation that landslides 


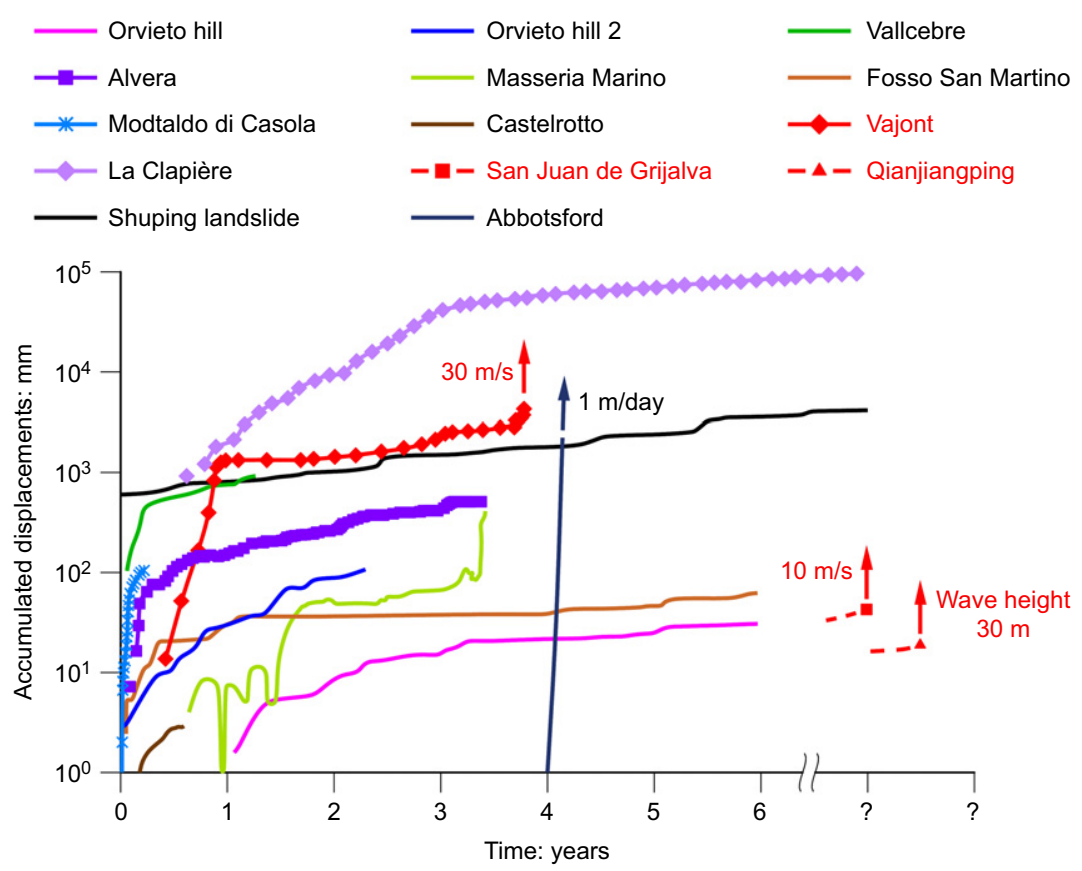

Fig. 58. Observed displacement-time records of creeping landslides. Also shown in the plot are three rapid landslides: Vajont, San Juan de Grijalva and Qianjiangping

remain in a creeping state for years and decades. Fig. 58 shows a few published displacement histories of active landslides. Displacements accumulate in time and experience acceleration or deceleration episodes, controlled by the variability of external actions, often associated with changes of pore water pressure.

The plot includes three cases of a final catastrophic failure. In one of them (Vajont), a known previous period of creeping motion is available (Hendron \& Patton, 1985; MüllerSalzburg, 1987; Nonveiller, 1987). In the cases of San Juan de Grijalva, in México (Hernández-Madrigal et al., 2010) and Qianjiangping, China (Dai et al., 2004; Wang et al., 2004) there is no information on previous slow motions. The plot shows also the estimation of landslide velocity and, in the case of Qianjiangping, the height of gigantic waves generated in the reservoir receiving the failed mass. These are extremely rapid events, which are especially dangerous. These rapid motions are analysed here.

Among the list of physical phenomena explaining a significant reduction of available shear strength on sliding surfaces, given below, this section explores the thermal pressurisation of water in saturated shear bands.

It is useful, in this regard, to examine the limits of conventional kinematic analysis to explain the attainment of high velocities, once the potentially unstable mass loses equilibrium. Vajont landslide is a convenient reference choice, because of the available information and published contributions ever since its failure in 1963.

\section{A 2 D kinematic analysis of Vajont landslide}

Consider, in Fig. 59, a representative cross-section of the slide. The figure is a simplified version of 'cross-section 5' given in the comprehensive Hendron \& Patton (1985) report on the failure. Fig. 59 suggests a simple model for the slide: a large stable block resting on a sub-horizontal sliding surface provides a resistance force to stabilise an upper block sliding on a steep slope (close to $37^{\circ}$ ). Since Vajont was the re-activation of an ancient landslide, the operating friction angle on the sliding surface is close to a

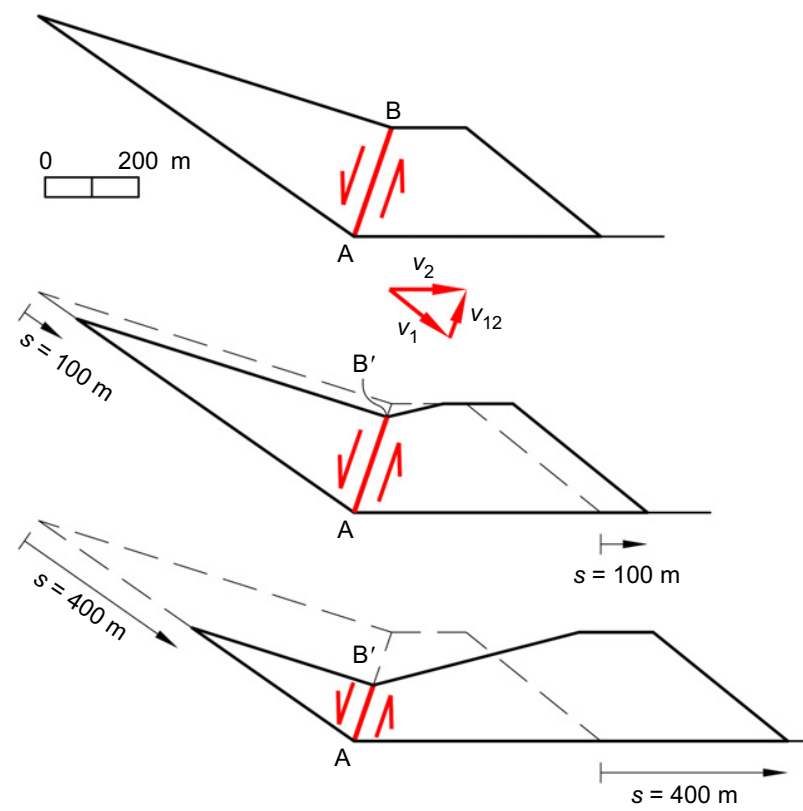

Fig. 59. Interpreted evolution of Vajont landslide for a representative cross-section (Alonso \& Pinyol, 2010)

residual value, $\phi_{\mathrm{r}}^{\prime}=10-12^{\circ}$, according to Hendron \& Patton (1985).

Figure 59 shows the solution adopted to find a kinematically admissible motion of two sliding rigid blocks in contact. The solution allows for large displacements as indicated in the two deformed geometries plotted. At any time during the motion, a common shearing plane $(\mathrm{AB}$ or $\mathrm{AB}^{\prime}$ ) separates the upper and lower wedges.

Note that a necessary condition to reproduce large displacements is to account for a transfer of mass from the upper to the lower block. This mass crosses the 'virtual' shearing plane $\mathrm{AB}^{\prime}$ '. The two failed situations represented in the figure correspond to landslide displacements of $s=100 \mathrm{~m}$ and $s=400 \mathrm{~m}$, respectively. The 
assumption here is that the sliding velocities of upper and lower blocks ( $v_{1}$ and $v_{2}$ ) have equal magnitude, a condition that is justified by measured time records of displacement of surface marks before the failure.

Also shown in the figure is the condition of kinematic compatibility of the sliding mass entering and leaving point A. The change in direction of $v_{2}$ with respect to $v_{1}$ is accommodated by a shearing velocity $v_{12}$ along the shearing plane $\mathrm{AB}^{\prime}$. This is consistent with the shearing plane $\mathrm{AB}$ being the bisector of the angle between the upper and lower sliding planes.

In the period 1960-1963, the water level of Vajont reservoir increased and decreased three times. The landslide velocity measured in some surface marks reacted in the way plotted in Fig. 60. Maximum measured velocities represented in Fig. 60 remain in the range slow to moderate, following the scale proposed by Cruden \& Varnes (1996). Nevertheless, for three times they exhibited a frightening acceleration, which was counteracted in 1960, 1962 and 1963 by reducing the level in the reservoir. This procedure was successful in 1960 and 1962, but not in 1963 .

The increasing ability of the landslide to accept higher reservoir elevations before acceleration is not clear, but reasons for this behaviour may be

(a) the (small) change in geometry of the landslide, which implies an increasing weight of the stable lower block and a parallel decrease of the mass of the upper wedge

(b) an increasing resistance offered by the partially sheared AB plane before the collapse

(c) a variable effect of rainfall history controlling, in part, the water pressures on the sliding plane.

Reason (b) may be the consequence of a progressive failure of the brittle rock layers, sheared along plane AB. Hendron \& Patton (1985) illustrated the third reason in a plot relating reservoir elevation, 30 day accumulated rainfall and rate of slide movement for dates in the period 1960-1963. In the months preceding the failure date (October 1963), the 30 day rainfall did not exceed $350 \mathrm{~mm}$ and the landslide reaction was essentially controlled by the reservoir level. A reasonable assumption is that the phreatic surface remained horizontal and its level coincided with reservoir elevation. The high permeability of the folded limestone layer above the sliding plane suggests this assumption.

The final assumption of the kinematic model concerns the strength along the shearing plane $\mathrm{AB}^{\prime}$. Alonso et al. (2010) proposed a Mohr-Coulomb model

$$
\tau_{\mathrm{f}}=c_{\mathrm{r}}^{\prime}(s)+\sigma^{\prime} \tan \phi_{\mathrm{rock}}^{\prime}
$$

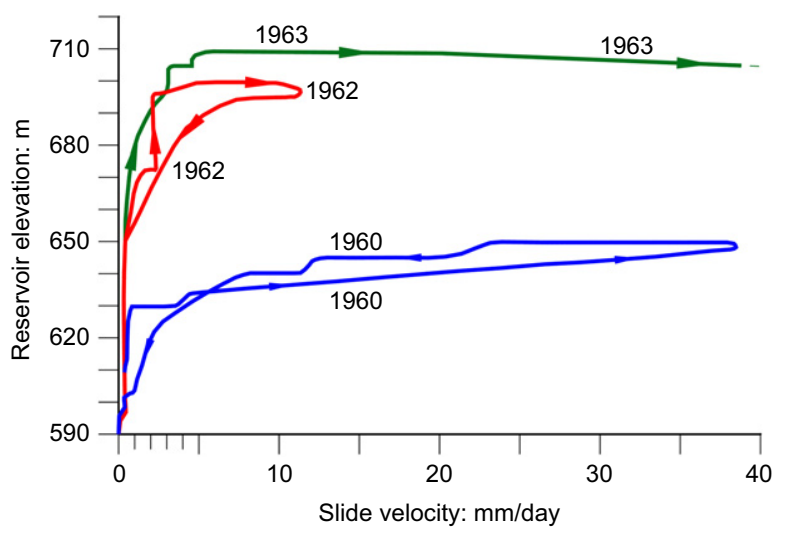

Fig. 60. Observed Vajont sliding velocity plotted in terms of reservoir elevation (Hendron \& Patton, 1985) which introduces the idea that the slide motion could result in a degradation of the rock strength. This is achieved if the rock mass cohesion $c_{\mathrm{r}}^{\prime}(s)$ decreases with the accumulated slide displacement, $s$

$$
c_{\mathrm{r}}^{\prime}=c_{\mathrm{r} 0}^{\prime} \exp \left(-\Gamma_{\mathrm{c}} s\right)
$$

where $\Gamma_{\mathrm{c}}$ is a constant, and $c_{\mathrm{r} 0}^{\prime}$ is the initial $c_{\mathrm{r}}^{\prime}$ value.

Alonso \& Pinyol (2010) suggest values for $c_{\mathrm{r} 0}^{\prime}$ and $\phi_{\mathrm{rock}}^{\prime}$, based on geological descriptions of Vajont rocks.

The formulation of the dynamic equilibrium of the two blocks, the evolving geometry and the force compatibility along plane $\mathrm{AB}^{\prime}$ allows the equation describing the landslide motion to be written. The final compound equation has the following structure

$$
\begin{aligned}
s_{1} \frac{\mathrm{d}\left(M_{1} v\right)}{\mathrm{d} t}+s_{2} \frac{\mathrm{d}\left(M_{2} v\right)}{\mathrm{d} t}= & W_{1} t_{1}+\left(W_{2}-P_{\mathrm{w} 2}-P_{\mathrm{wf}}\right) t_{2} \\
& +c^{\prime}{ }_{\mathrm{r}} A B t_{3}-P_{\mathrm{wint}} t_{4}+P_{\mathrm{w} 1} t_{5}
\end{aligned}
$$

where $M_{1}$ and $M_{2}$ are the current masses of the upper and lower blocks and $W_{1}$ and $W_{2}$ are their weights; $P_{\mathrm{w} 1}$ and $P_{\mathrm{w} 2}$ are the uplift water pressure forces against the upper and lower sliding surfaces; $P_{\mathrm{wf}}$ is the hydrostatic water force of the reservoir against the lower wedge and $P_{w \text { int }}$ is the water pressure force against the shearing plane $\mathrm{AB}^{\prime} ; s_{1}, s_{2}$ and $t_{i}(i=1$ to 5$)$ are functions of the inclination of the upper failure surface and the friction angles of the rock and the sliding surface (plane $\mathrm{AB}^{\prime}$ ) (Alonso et al., 2010).

Vajont failed when the water level above the lower sliding surface reached $120 \mathrm{~m}$. For the rock strength parameters $c_{\mathrm{r} 0}^{\prime}$ $=760 \mathrm{kPa}, \phi_{\text {rock }}^{\prime}=38^{\circ}$ and a residual friction angle of the basal surface of, the landslide was in strict equilibrium. Any increase in water level results in the acceleration of the slope. Then, equation (21) allows the calculation of the resulting motion: landslide velocity in terms of displacement.

Figure 61 shows the calculated landslide motion for no degradation of the rock strength $\left(\Gamma_{\mathrm{c}}=0\right)$ or a moderate degradation $\left(\Gamma_{\mathrm{c}}=0.01\right)$ when the water level increases $1 \mathrm{~m}$. In both cases, the runout and the maximum velocity of the slide are very small if compared with the observed values: $350-400 \mathrm{~m}$ of runout and velocities in excess of $25 \mathrm{~m} / \mathrm{s}$. Even if the rock strength degradation is extreme $\left(\Gamma_{\mathrm{c}}=1\right)$, the calculated maximum velocity is around $4 \mathrm{~m} / \mathrm{s}$. However, a substantial degradation of the shear strength of rock from the upper wedge arriving at the virtual shearing plane $\mathrm{AB}^{\prime}$ is not likely because the moving rock from the upper wedge can be considered reasonably undisturbed.

In fact, introducing a strength degradation in terms of accumulated slide displacements is just a rough and conservative approximation to a complicated phenomenon: the

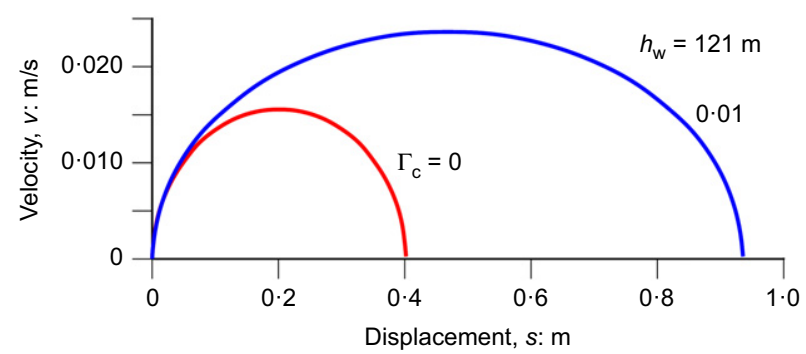

Fig. 61. Calculated velocity-displacement records of Vajont slide for two intensities of rock degradation (no degradation, $\Gamma_{c}=0$ and moderate degradation, $\Gamma_{\mathbf{c}}=0 \cdot 01$ ). Motion is triggered by increasing reservoir water level to $h_{\mathrm{w}}=121 \mathrm{~m}$ 
progressive failure mechanism associated with the angular change in the direction of the motion.

Yerro et al. (2016a, 2016b) analysed the internal progressive failure phenomena in deep-seated landslides, with particular reference to Vajont. The conclusion was that the rock failure starts at the kink of the sharp change of the basal surface dip and progresses upwards along a plane, which was close to the bisector plane $\mathrm{AB}$ in Fig. 59. However, more realistic geometries (a rounded transition between the upper and lower sliding surfaces) leads to a more complex development of the internal strain softening. An interesting finding of this analysis was to confirm that, even if a significant brittleness is specified for the rock mass, the necessary condition to approach the actual runout and velocity of Vajont required a zero-shear strength on the basal sliding surface. Explaining Vajont requires a physically sound explanation to be found for the cancellation of shear strength on the sliding surface.

\section{Thermal pressurisation of saturated shear bands}

Early contributions to explain the Vajont failure, published in the years following the catastrophic event (Jaeger, 1965a, 1965b; Mencl, 1966; Skempton, 1966; Kenney, 1967;
Nonveiller, 1967), present the results of classical limit equilibrium methods. Explaining the triggering of the motion (safety factor $=1$ ) was a simple exercise, which provided an overall friction angle. Back-analysed values of friction angles, given by the authors cited, ranged between $18^{\circ}$ and $28^{\circ}$. These values are not consistent with the low residual friction angle measured in shear tests on the high-plasticity clay found in the sliding surface. However, the mobilisation of the internal rock strength may be compatible with a lower basal friction if the question is limited to the initiation of the slide.

A physical phenomenon capable of explaining the cancellation of effective stress in a shear band is the heat-induced pore water pressurisation. This is a well-known experience, which has received considerable attention in nuclear waste storage in deep repositories because the waste is heat emitting. Fig. 62 shows the results of heating a saturated cylindrical sample of Opalinus clay rock in a special testing cell described in Muñoz et al. (2009).

Figure 62(a) shows the heating power applied to a small heater embedded in the sample, and the evolution of temperature measured in two points. The figure shows also the measured pore water pressures in points that correspond to positions $T_{2}$ and $T_{3}$. Pore pressures increase or decrease when the rate of temperature increases or decreases. If the

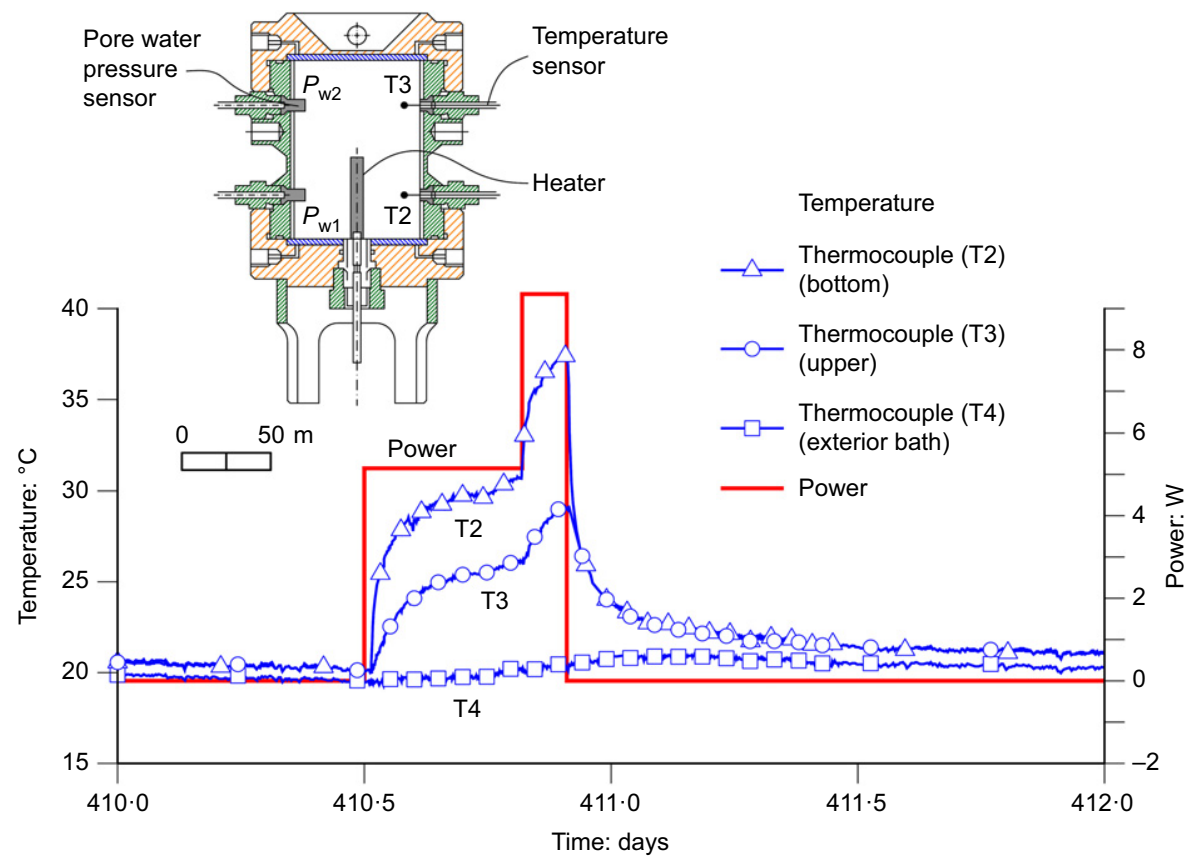

(a)

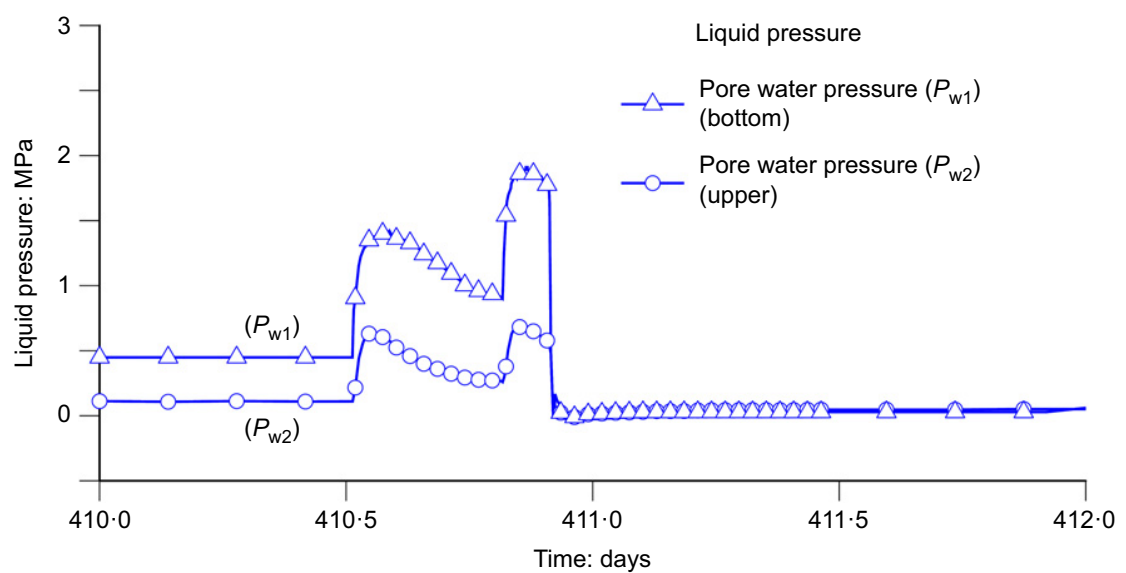

(b)

Fig. 62. Recorded temperatures (a) and pore water pressures (b) in the heating experiment reported by Muñoz et al. (2009) 


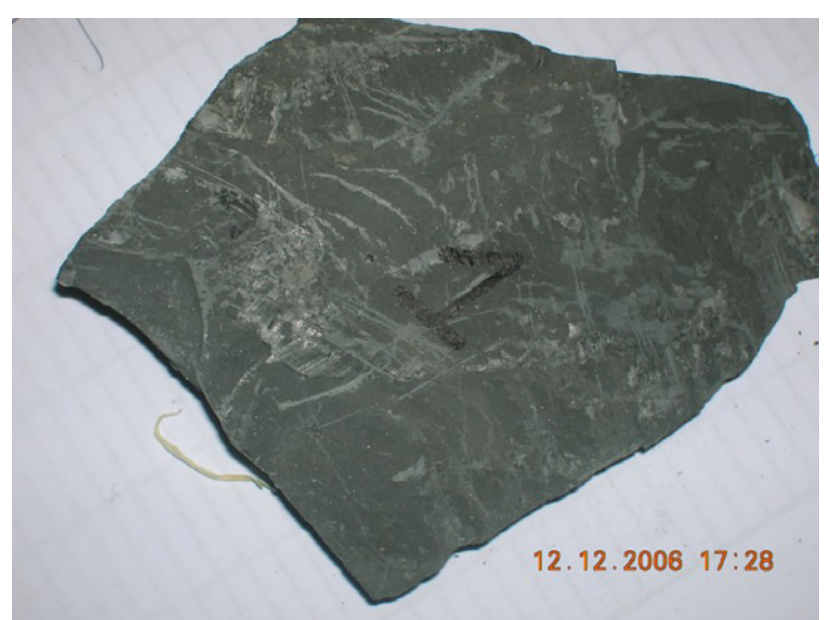

(a)

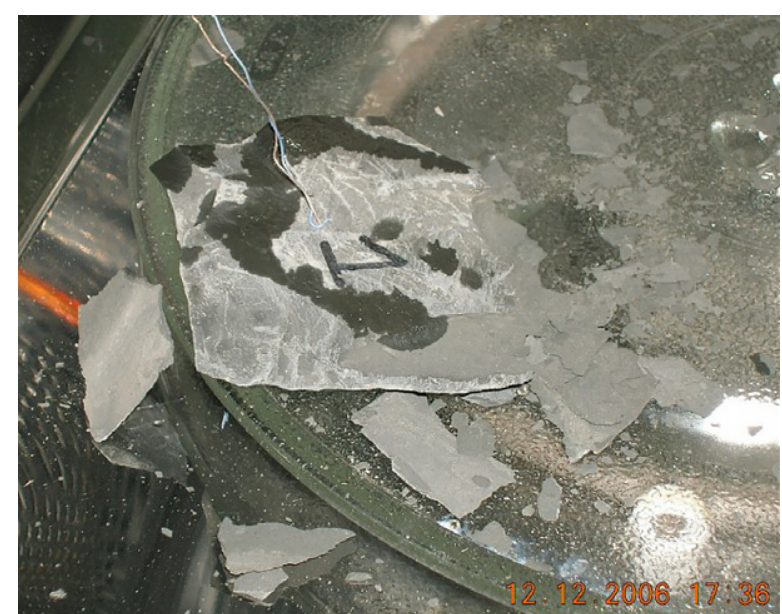

(b)

Fig. 63. Heating a saturated sample of Opalinus clay rock in a microwave oven. Aspect of the sample (a) before and (b) after heating (Puzrin et al., 2010)

rate of temperature change becomes small, the excess pore pressure decreases.

Opalinus clay is a potential host rock for nuclear waste disposal in Switzerland. It is a low-plasticity clay shale of low porosity $(n=0 \cdot 04-0 \cdot 12)$ and very impervious. Unconfined compressive strength ranges between 10 and $16 \mathrm{MPa}$, and its Young's modulus corresponds to a soft to medium rock $(E=1000-7000 \mathrm{MPa})$.

The excess pore pressures measured are very significant. In sensor $P_{w 1}$ the water pressure reaches $1.4 \mathrm{MPa}$ for a total temperature increase of about $10^{\circ} \mathrm{C}$. The test illustrated in Fig. 62 was 'drained'. Pore pressures could dissipate through the top and bottom porous discs in contact with the sample. The generation and dissipation of heat-induced pore pressures are a consequence of the thermal expansion coefficients of water and rock skeleton, the rock permeability, the rate of change of temperature and the test geometry and boundary conditions.

Consider a simpler test in Fig. 63. An irregular piece of saturated Opalinus clay was heated and the temperature was measured in a microwave during a period of a few seconds. A few seconds after the beginning of the application of the thermal pulse, the sample 'exploded' into a several pieces. Fig. 63 shows the intact sample before the test and the aspect of the broken sample after testing. Fig. 64 is the record of measured temperature in the sample by means of an embedded thermocouple sensor.

The figure also shows the recorded temperature in a second test performed on a saturated porous stone, which is a very pervious material. Unlike the Opalinus clay, the porous stone remained intact. The recorded temperature in the porous stone reached a maximum value of $100^{\circ} \mathrm{C}$, a clear indication of water boiling in the pores. However, the temperature in the clay fragment increased continuously during the application of the pulse and reached a maximum temperature of $170^{\circ} \mathrm{C}$. This is an indication of the different nature of the adsorbed water in the clay minerals of the rock.

The sketch of a saturated rock (or soil) pore in Fig. 65(a) and the consideration of thermal expansion of water and quartz (or any other soil or rock mineral) (Fig. 65(b)) helps to explain the previous observations. Water expands more than rock minerals. An increase in temperature results in a dilation of water and minerals and a parallel increase in pressure and its dissipation in real time, controlled by permeability. In an impervious material (Opalinus clay) pressure dissipation will be slow and excess pore pressures will accumulate as

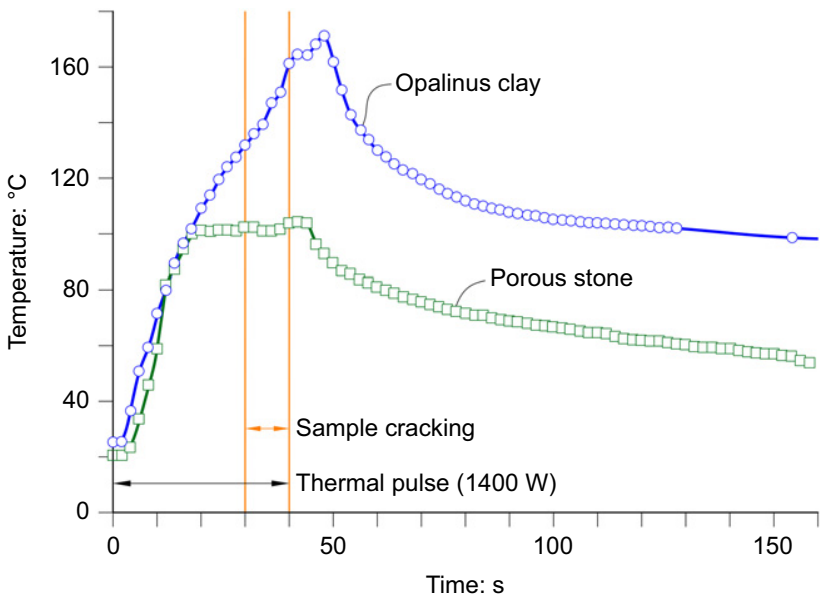

Fig. 64. Recorded temperatures in the microwave oven experiment in the Opalinus clay rock and the porous stone

the temperature increases. Under no confinement (the piece of Opalinus clay rock) the effective stress will become an isotropic tensile stress, which will eventually reach the rock's tensile strength. The high permeability of the porous stone prevents the generation of excess water pressures and the specimen remains intact.

Consider now a point in a sliding surface during the motion of the slide, Fig. 66. At a given velocity, v, shear strains concentrate in the thickness $(2 e)$ of the sliding surface (or shear band). Shear deformations are irreversible and a plastic work $(\dot{W})$ dissipates at a rate per unit volume given by

$$
\dot{W}=\tau_{f} \dot{\gamma}=\frac{\tau_{f} v}{2 e}
$$

in the absence of volumetric strains - a hypothesis that seems reasonable under residual shearing conditions.

This work dissipates in heat and, therefore, excess pore water pressures will generate in the shear band. Then effective stress and shear strength will decrease. The resulting unbalance of forces acting on the slide will result in an increasing landslide acceleration.

The phenomena outlined, which originate at the scale of the thickness of the shear band, are significant in its close 


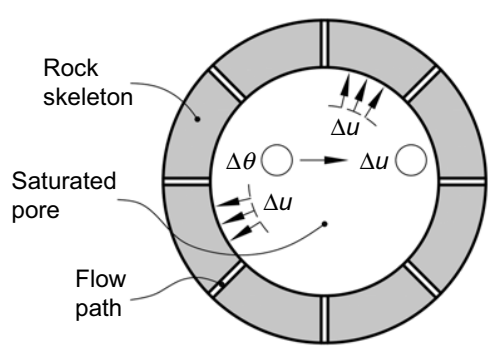

(a)

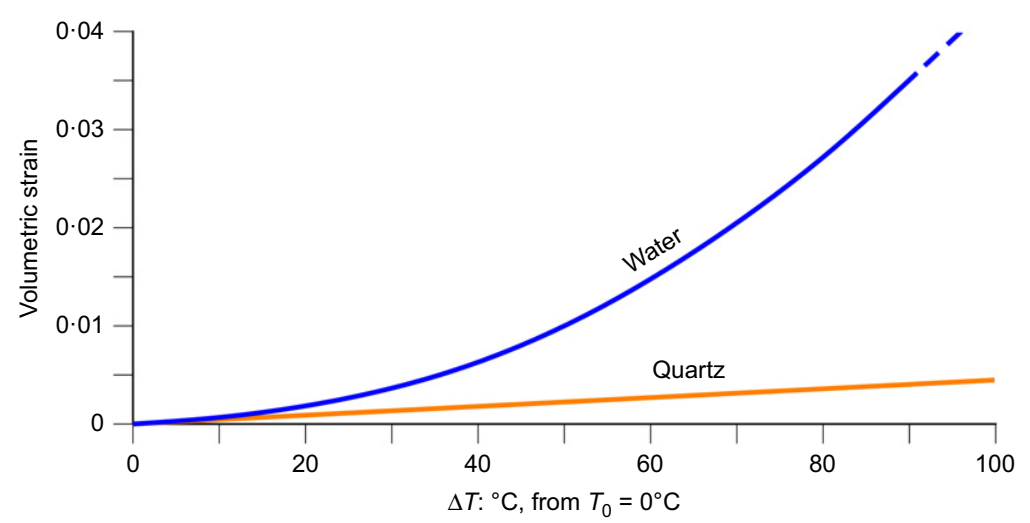

(b)

Fig. 65. (a) Sketch of a pore encircled by a solid skeleton; (b) Volumetric expansion of water and quartz for the indicated increment of temperature
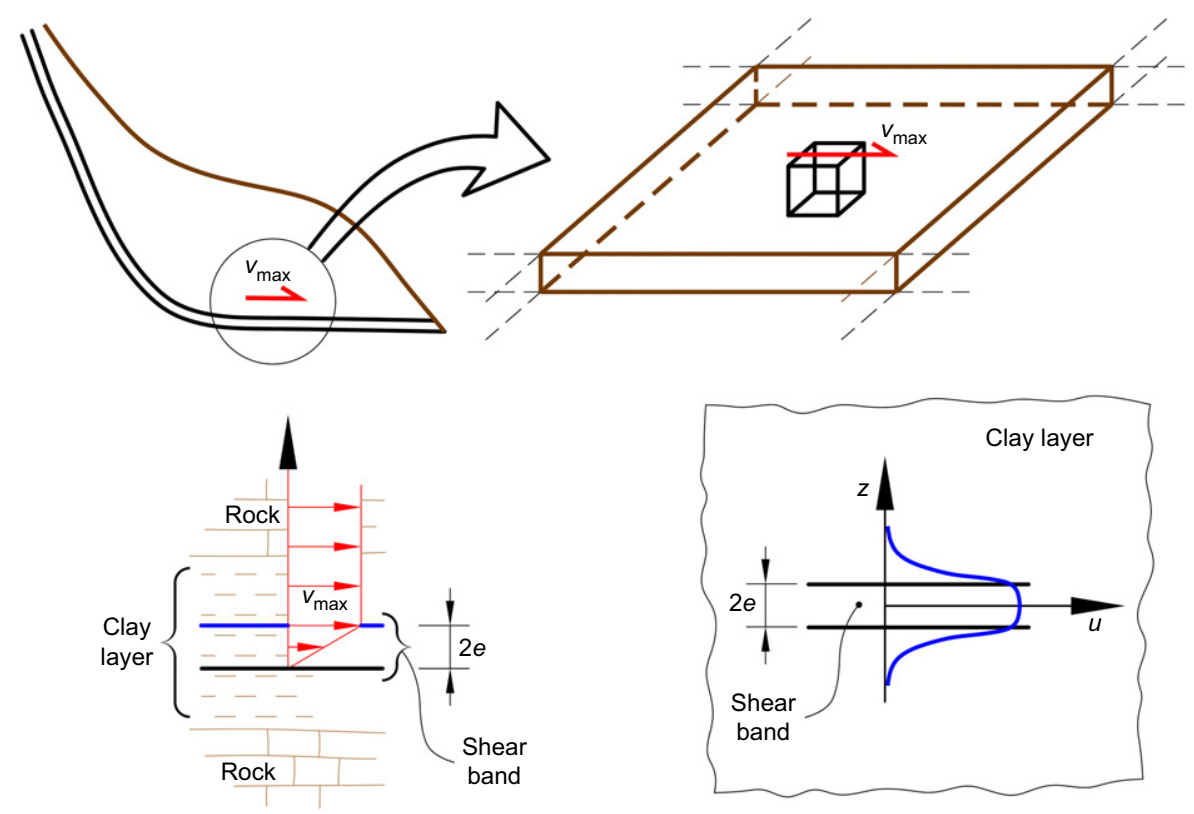

Fig. 66. The mechanism of increasing pore pressure in a shear band subjected to irreversible shear straining due to the sliding motion

vicinity. Therefore, it is probably acceptable to examine them under one-dimensional conditions in a direction perpendicular to the shear band, as shown in Fig. 66.

These are not new ideas. Attempts to explain the high velocity of Vajont landslide by considering the heat dissipated during the rapid motion of the slide go back to the pioneering contribution of Habib (1967), who suggested that the heat induced by friction on the shear band generated water vapour under pressure and a lifting action on the moving rock mass. Uriel Romero \& Molina (1977) formulated the dynamic equations of equilibrium for a realistic cross-section of Vajont, discretised by vertical slices. A vapour-liquid water phase diagram allowed the determination of pore pressures. The calculated velocities matched the observations.

Authors investigating the thermal-induced effects over the next three decades essentially followed the seminal contribution of Voight \& Faust (1982). They concentrated on formulating the mass and energy balance for a planar sliding geometry. Finite elements in one dimension helped to solve the coupled equations. They explained the high velocity of Vajont by the generated water pressures.

A few authors, who have incorporated temperature and rate effects on the friction coefficient and thermally induced volume changes of the shear band material (Vardoulakis, 2000, 2002; Veveakis et al., 2007), have modified the standard Mohr-Coulomb frictional strength model of Voight \& Faust (1982). Cecinato et al. (2011) and Cecinato \& Zervos (2012) introduced thermo-elastoplastic constitutive models. Goren \& Aharonov (2007, 2009) and Goren et al. (2010) performed some sensitivity analyses regarding the triggering factors and constitutive parameters. They also simulated the Heart Mountain landslide in Canada. In all of the cases mentioned, the sliding geometry was fixed 'a priori' and it was geometrically simple: either planar landslides or circular sliding surfaces.

Pinyol \& Alonso (2010a) developed an analytical solution for the case of a planar landslide if advective thermal terms and heat conduction phenomena are negligible, which is a reasonable approximation in fast motions. Pinyol \& Alonso (2010b) introduced a compound geometry, close to the representative 2D cross-sections of Vajont. Mass transfer during the motion was allowed in the manner described in Fig. 59. A small increase in reservoir level, from a situation of strict equilibrium, triggered the motion.

The first step in the derivation of the motion equation for a planar landslide is to formulate the mass balance equations for solids and water in the shear band (Fig. 67). 


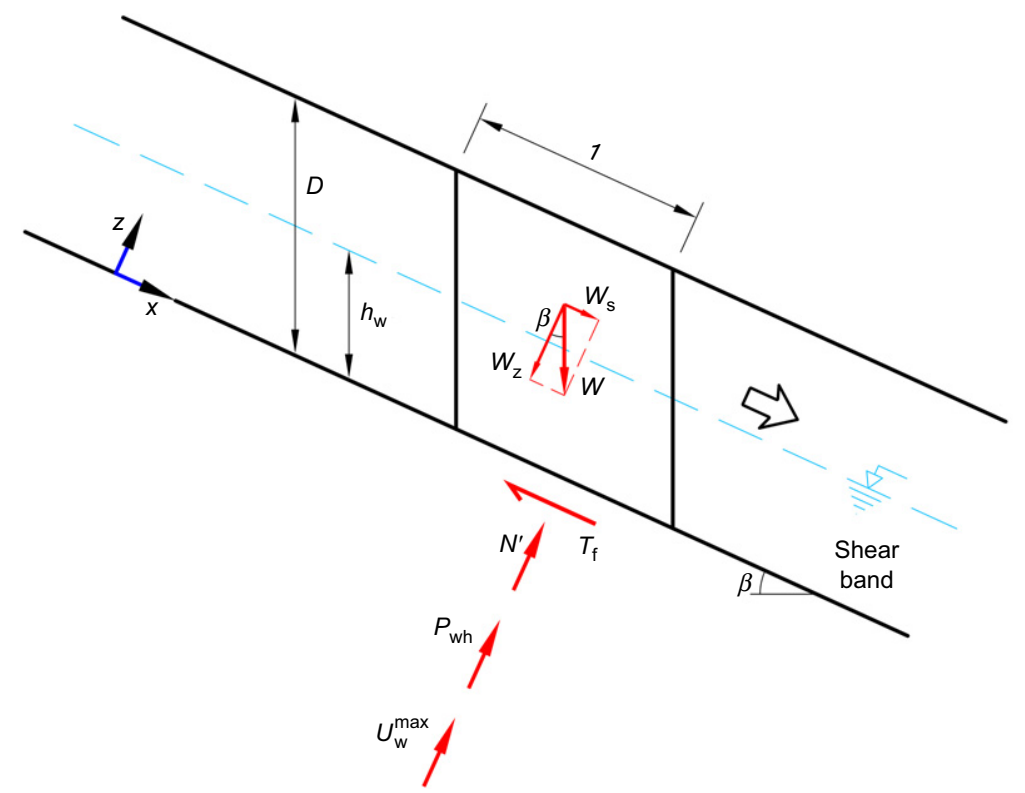

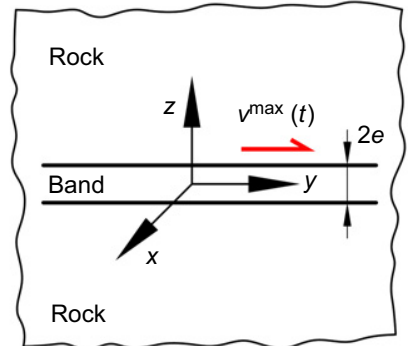

(b)

(a)

Fig. 67. (a) Forces in a planar slide and (b) geometry of the shearing band

The mass conservation in local terms reads

$$
\frac{\partial}{\partial t}\left[\rho_{\mathrm{s}}(1-n)\right]+\operatorname{div}\left[\rho_{\mathrm{s}}(1-n) \boldsymbol{v}_{\mathrm{s}}\right]=0
$$

where $n$ is the porosity, $\rho_{\mathrm{s}}$ the solids density and $\boldsymbol{v}_{\mathrm{s}}$ is the velocity of the solid particles. Equation (23) transforms into

$$
\frac{\mathrm{D} n}{\mathrm{D} t}=\frac{(1-n)}{\rho_{\mathrm{s}}} \frac{\mathrm{D} \rho_{\mathrm{s}}}{\mathrm{D} t}+(1-n) \operatorname{div}\left(\boldsymbol{v}_{\mathrm{s}}\right)
$$

where the material derivative of a property of a material point moving with velocity $\boldsymbol{v}$ is given by

$$
\frac{\mathrm{D}(\cdot)}{\mathrm{D} t}=\frac{\partial(\cdot)}{\partial t}+\boldsymbol{v} \operatorname{grad}(\cdot)
$$

If the compressibility of the solid grains is negligible, equation (24) results in

$$
\frac{\mathrm{D} n}{\mathrm{D} t}=-(1-n) \frac{\partial \varepsilon_{\mathrm{vol}}}{\partial t}
$$

where $\varepsilon_{\mathrm{vol}}$ is the volumetric strain of the soil.

Water mass conservation reads

$$
n \frac{\mathrm{D} \rho_{\mathrm{w}}}{\mathrm{D} t}+\rho_{\mathrm{w}} \frac{\mathrm{D} n}{\mathrm{D} t}+\rho_{\mathrm{w}} n \operatorname{div}\left(\boldsymbol{v}_{\mathrm{s}}\right)+\operatorname{div}\left(\rho_{\mathrm{w}} \boldsymbol{q}\right)=0
$$

where $\rho_{\mathrm{w}}$ is the water density and $\boldsymbol{q}$ is the Darcy flow rate. Equations (24) and (27) combine in an expression for the mass conservation of soil and water

$$
\frac{n}{\rho_{\mathrm{w}}} \frac{\mathrm{D} \rho_{\mathrm{w}}}{\mathrm{D} t}+\frac{(1-n)}{\rho_{s}} \frac{\mathrm{D} \rho_{\mathrm{s}}}{\mathrm{D} t}+\operatorname{div}\left(\boldsymbol{v}_{\mathrm{s}}\right)+\frac{1}{\rho_{\mathrm{w}}} \operatorname{div}\left(\rho_{\mathrm{w}} \boldsymbol{q}\right)=0
$$

The following constitutive relations and hypothesis complete the formulation.

(a) State equation for solid density

$$
\rho_{\mathrm{s}}=-\rho_{\mathrm{s}}^{0} \exp \left[\beta_{\mathrm{s}}\left(\theta-\theta_{0}\right)\right]
$$

where $\beta_{\mathrm{s}}$ is the thermal expansion coefficient of solids and $\theta$ is the temperature. $\rho_{\mathrm{s}}^{0}$ is the solid density value for the reference temperature $\theta_{0}$. (b) State equation for water density

$$
\rho_{\mathrm{w}}=\rho_{\mathrm{w}}^{0} \exp \left[\alpha_{\mathrm{w}}\left(p_{\mathrm{w}}-p_{\mathrm{w}}^{0}\right)-\beta_{\mathrm{w}}\left(\theta-\theta_{0}\right)\right]
$$

where $\beta_{\mathrm{w}}$ is the thermal expansion coefficient of water and $\alpha_{\mathrm{w}}$ is its volumetric compressibility. $\rho_{\mathrm{w}}^{0}$ is the water density value for the reference pressure $p_{\mathrm{w}}^{0}$ and temperature $\theta_{0}$.

(c) The hydrostatic component of water pressure does not change during the (short) time of motion.

(d) Volumetric strains are estimated by a confined compressibility coefficient, $m_{\mathrm{v}}$ ('oedometric' conditions)

$$
\operatorname{div}(\bar{v})=-\frac{\partial \varepsilon_{\mathrm{vol}}}{\partial t}=-m_{\mathrm{v}}\left[\frac{\partial \sigma_{\mathrm{n}}}{\partial t}-\frac{\partial u_{\mathrm{w}}}{\partial t}\right]
$$

where $\sigma_{\mathrm{n}}$ is the normal stress on the shear band and $u_{\mathrm{w}}$ is the excess pore water pressure.

(e) The Darcy's flow rate (in a direction normal to the shear band, $z$ ), is approximated by

$$
\bar{q}=-\frac{K}{\rho_{\mathrm{w}} \boldsymbol{g}} \frac{\partial u_{\mathrm{w}}}{\partial z}
$$

where $K$ is the hydraulic conductivity.

( $f$ ) The expected velocity of solids, $\bar{v}$, is small compared with the time rates of change of the main dependent variables of the problem $\left(\theta, u_{\mathrm{w}}\right)$, which allows the mass balance equation (28) to be written as

$$
\begin{aligned}
& -\left[n \beta_{\mathrm{w}}+(1-n) \beta_{\mathrm{s}}\right] \frac{\partial \theta}{\partial t}+\left(m_{\mathrm{v}}+n \alpha_{\mathrm{w}}\right) \frac{\partial u_{\mathrm{w}}}{\partial t} \\
& -m_{\mathrm{v}} \frac{\partial \sigma_{\mathrm{n}}}{\partial t}-\frac{K}{\gamma_{\mathrm{w}}} \frac{\partial^{2} u_{\mathrm{w}}}{\partial t^{2}}=0
\end{aligned}
$$

where $\gamma_{\mathrm{w}}=\rho_{\mathrm{w}} \boldsymbol{g}$ is the specific weight of the water.

In an impervious soil $(k \rightarrow 0)$, when no changes in external stress are applied, changes in temperature lead to the following changes in excess pore pressure

$$
\frac{\partial u_{\mathrm{w}}}{\partial t}=\frac{n \beta_{\mathrm{w}}+(1-n) \beta_{\mathrm{s}}}{n \alpha_{\mathrm{w}}+m_{\mathrm{v}}} \frac{\partial \theta}{\partial t}
$$


which provides an expression for the heat-induced pressurisation of clay soils discussed previously. Since $\beta_{\mathrm{w}}>\beta_{\mathrm{s}}$ (Fig. 65) the higher the porosity, the higher the pore pressures induced by heating. Also, the stiffer the soil (low $m_{\mathrm{v}}$ values), the higher the water pressures. In the limit (a very stiff soil: $m_{\mathrm{v}} \rightarrow 0$ ), the temperature-induced water pressures are controlled by the water compressibility. Finally, thermal dilations of both solid and water contribute to the development of water pressures.

The local balance of heat follows a similar structure

$$
\begin{aligned}
& \frac{\mathrm{D}\left(\rho c_{\mathrm{m}} \theta\right)}{\mathrm{D} t}+\operatorname{div}[\Gamma \operatorname{grad} \theta]+\operatorname{div}\left[\rho_{\mathrm{w}} c_{\mathrm{w}} \theta\left(\boldsymbol{q}+n \boldsymbol{v}_{\mathrm{s}}\right)\right. \\
& \left.\quad+(1-n) \rho_{\mathrm{s}} c_{\mathrm{s}} \theta \boldsymbol{v}_{\mathrm{s}}\right]=\dot{H}
\end{aligned}
$$

where $c_{\mathrm{m}}$ is the specific heat of the saturated soil and $\rho$ is the saturated soil density. In terms of the specific heat of solid and water $\left(c_{\mathrm{w}}, c_{\mathrm{s}}\right)$ and their density $\left(\rho_{\mathrm{w}}, \rho_{\mathrm{s}}\right)$

$$
\rho c_{\mathrm{m}}=(1-n) \rho_{\mathrm{s}} c_{\mathrm{s}}+n \rho_{\mathrm{w}} c_{\mathrm{w}}
$$

The first term in equation (35) is the rate of heat stored per unit volume of soil, the second accounts for the heat transfer in a conduction mode ( $\Gamma$ is the Fourier heat conduction coefficient) and the third term quantifies the heat transported by the moving mass of water and solid particles (advective conduction). The term on the right is a heat source term. This term is equal to the plastic work dissipated in the band $(\dot{H}=\dot{W})$, given in equation (22).

In a fast landslide, conductive and advective heat flows out of the shearing band will be small compared with the accumulated heat. Therefore, with minor error, the heat balance inside the shear band reduces to

$$
\dot{H}=\dot{W}=\frac{\tau_{\mathrm{f}} v}{2 e}=\rho c_{\mathrm{m}} \frac{\partial \theta}{\partial t}
$$

Finally, the motion equation in the direction of sliding (see Fig. 67) is

$$
M \frac{\mathrm{d} v}{\mathrm{~d} t}=W \sin \beta-\left(W \cos \beta-p_{\mathrm{w}}\right) \tan \phi^{\prime}
$$

where $M=\rho D \cos \beta, W=\gamma D \cos \beta$.

Summarising, the set of equations describing the mass and heat balance inside the shear band and the motion equations of the planar landslide are equations (35), (37) and (38). Solving the coupled thermo-hydro-dynamic problem requires a similar set of equations, formulated for points outside the shear band, and the definition of boundary conditions specifying the temperature and water pressure at a certain distance (in the $z$ direction).

Some simplifying assumptions allow closed-form expressions to be obtained that help to highlight the main controlling variables and physical phenomena governing the problem. Two simple cases are given below.

First case - thermal-induced response of the shear band at constant shearing velocity.

The sketch in Fig. 68 shows the case. A rigid weightless block under a vertical stress $\sigma_{\mathrm{n}}$ displaces at a velocity $v$, suddenly applied at $t=0^{+}$over a clayey shear band of thickness $2 e$ and very low permeability $(K \approx 0)$.

Under these assumptions, equations (35) and (37) became a first-order differential equation for the excess pore pressure. The solution is

$$
u_{\mathrm{w}}=\sigma_{\mathrm{n}}\left[1-\exp \left(-\frac{\beta_{\text {soil }} \tan \phi^{\prime} v}{m_{\text {soil }}\left(\rho c_{\mathrm{m}}\right) 2 e} t\right)\right]
$$

under the condition $u_{\mathrm{w}}=0$ for $t=0$. In equation (39), $\beta_{\text {soil }}=$ $n \beta_{\mathrm{w}}+(1-n) \beta_{\mathrm{s}}, m_{\text {soil }}=m_{\mathrm{v}}+\alpha_{\mathrm{w}}$ and $\rho c_{\mathrm{m}}$ is indicated in equation (36). Fig. 69 shows the effect of shear band thickness on the development of thermally induced normalised excess pore pressure. The plotted curves correspond to a $25 \mathrm{~m}$ high planar slide travelling at a constant velocity of $0 \cdot 1 \mathrm{~m} / \mathrm{s}$ for the set of parameters indicated in Table 3 .

The plot shows the relevant effect of shear band thickness: the thinner the band, the stronger the generated pore pressure. All the curves plotted reach asymptotically, for infinite time, a condition of zero effective normal stress $\left(u_{\mathrm{w}}=\right.$ $\left.\sigma_{\mathrm{n}}\right)$. However, the rate of pressure accumulation increases

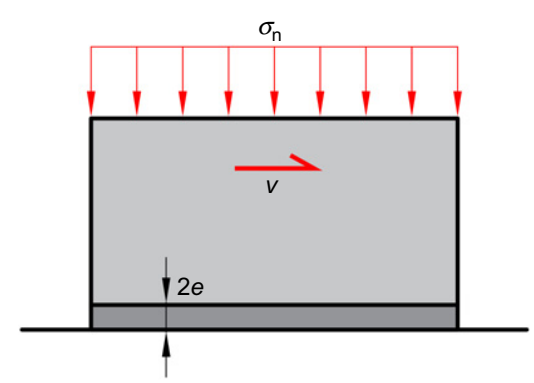

Fig. 68. A loaded weightless block sliding at a constant velocity on a

\begin{tabular}{|c|c|c|c|}
\hline Parameter & Symbol & Value & Units \\
\hline \multicolumn{4}{|l|}{ Water } \\
\hline Density & $\rho_{\mathrm{w}}$ & 1000 & $\mathrm{~kg} / \mathrm{m}^{3}$ \\
\hline $\begin{array}{l}\text { Coefficient of } \\
\text { compressibility }\end{array}$ & $\alpha_{\mathrm{w}}$ & $5 \times 10^{-10}$ & $1 / \mathrm{Pa}$ \\
\hline $\begin{array}{l}\text { Thermal expansion } \\
\text { coefficient }\end{array}$ & $\beta_{\mathrm{w}}$ & $3 \cdot 42 \times 10^{-4}$ & $1 /{ }^{\circ} \mathrm{C}$ \\
\hline Specific heat & $c_{\mathrm{W}}$ & $4 \cdot 19 \times 10^{-3}$ & $\mathrm{~J} /\left(\mathrm{kg}^{\circ} \mathrm{C}\right)$ \\
\hline Thermal conductivity & $\Gamma$ & $0 \cdot 580$ & $\mathrm{~J} /\left(\mathrm{m} \mathrm{s} \mathrm{s}^{\circ} \mathrm{C}\right)$ \\
\hline \multicolumn{4}{|l|}{ Solid particles } \\
\hline Density & $\rho_{\mathrm{s}}$ & 2700 & $\mathrm{~kg} / \mathrm{m}^{3}$ \\
\hline $\begin{array}{l}\text { Thermal expansion } \\
\text { coefficient }\end{array}$ & $\beta_{\mathrm{s}}$ & $3 \cdot 0 \times 10^{-5}$ & $1 /{ }^{\circ} \mathrm{C}$ \\
\hline Specific heat & $c_{\mathrm{S}}$ & $8.37 \times 10^{2}$ & $\mathrm{~J} /\left(\mathrm{kg}{ }^{\circ} \mathrm{C}\right)$ \\
\hline Thermal conductivity & $\Gamma$ & $0 \cdot 375$ & $\mathrm{~J} /\left(\mathrm{m} \mathrm{s}^{\circ} \mathrm{C}\right)$ \\
\hline \multicolumn{4}{|l|}{ Soil } \\
\hline Porosity & $N$ & $0 \cdot 2$ & - \\
\hline Friction angle & $\phi^{\prime}$ & 12 & degrees \\
\hline $\begin{array}{l}\text { Constrained compressibility } \\
\text { coefficient }\end{array}$ & $m_{\mathrm{V}}$ & $1.5 \times 10^{-9}$ & $1 / \mathrm{Pa}$ \\
\hline Permeability & $K$ & $10^{-11}$ & $\mathrm{~m} / \mathrm{s}$ \\
\hline Shear band thickness & $2 e$ & 10 & $\mathrm{~mm}$ \\
\hline
\end{tabular}
shear band of thickness $e$

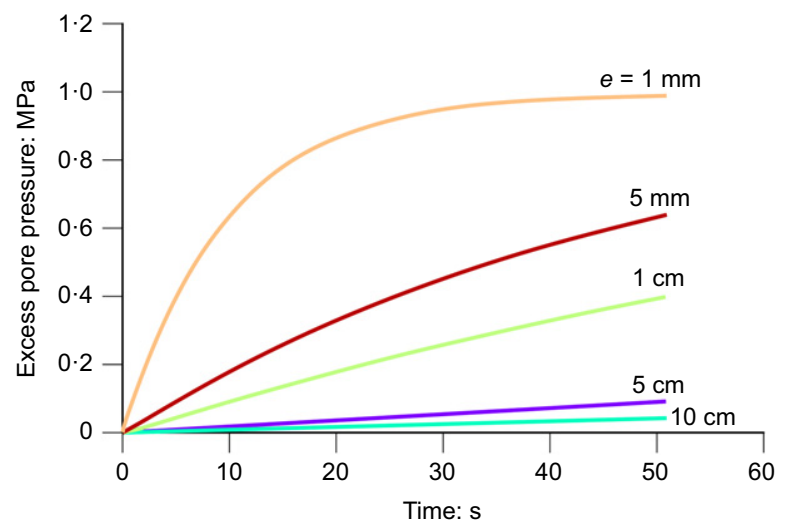

Fig. 69. Effect of shear band thickness on the pore pressure development for a sliding block at constant velocity

Table 3. Water and soil parameters for the planar landslide example 
also when the shear band thickness decreases. In this simple case, excess pore pressures and temperature do not dissipate because of the assumptions made. The distinctive effect of the shear band thickness is the result of the decreasing dissipation work, per unit volume, as the shear band thickness increases.

The problem defined is a velocity-controlled or strainrate-controlled case. As argued before, landslides are stresscontrolled phenomena. The following case illustrates this significant difference.

Second case - thermally induced response of a planar landslide.

The balance equation for water flow outside the shear band is now necessary if flow out of the band is accepted. The soil/rock outside the band will be in most cases similar to the band material, at least in its vicinity, and it receives the same properties. Flow due to excess pore water pressures will be directed perpendicular to the band, but in two opposite directions. Since no heat generates outside the band, the balance equation outside the band becomes (with reference to the coordinate axis in Fig. 67(b))

$$
\begin{aligned}
& \left(m_{\mathrm{v}}+n \alpha_{\mathrm{w}}\right) \frac{\partial u_{\mathrm{w}}}{\partial t}-m_{\mathrm{v}} \frac{\partial \sigma_{\mathrm{n}}}{\partial t}-\frac{K}{\gamma_{\mathrm{w}}} \frac{\partial^{2} u_{\mathrm{w}}}{\partial z^{2}}=0 \\
& \quad \text { for } z \in(-\infty,-e] \cup[e, \infty)
\end{aligned}
$$

where $K$ is the permeability outside the band.

No heat advection or convection are considered because of the short time of a rapid landslide. The plane $z=0$ in Fig. 67(b) is a symmetry plane in the case of water flow induced by excess pore pressure gradients. Therefore, there will be no flow across the $z=0$ plane

$$
-\frac{K}{\gamma_{\mathrm{w}}} \frac{\partial^{2} u_{\mathrm{w}}}{\partial z^{2}}=0
$$

At the $z=e$ boundary, pressures and flow rates are continuous functions

$$
\begin{aligned}
& \left.u_{\mathrm{w}}\right|_{z=e^{-}}=\left.u_{\mathrm{w}}\right|_{z=e^{+}} \\
& \left.K \frac{\partial u_{\mathrm{w}}}{\partial z}\right|_{z=e^{-}}=\left.K \frac{\partial u_{\mathrm{w}}}{\partial z}\right|_{z=e^{+}}
\end{aligned}
$$

At a large distance from the band, excess pore pressure will vanish.

The set of equations (35), (37), (38) and (40)-(43) define the planar landslide problem. The solution required a finite-difference procedure.

Consider a planar slope defined by the geometry given in Fig. 50. A standard equilibrium analysis with the purpose of finding its safety factor (SF) requires information regarding geometry $(D, \beta)$, position of water table $\left(h_{\mathrm{w} 0}\right)$, soil unit weight and friction angle $\left(\phi_{0}^{\prime}\right)$. Given $D=25 \mathrm{~m}$ and $\beta=9 \cdot 8^{\circ}$, the slope is in strict equilibrium, for a shear band friction of $12^{\circ}$, if a water table parallel to the slope has a height $h_{\mathrm{w} 0}=11.05 \mathrm{~m}$. A small increase in $\Delta h_{\mathrm{w}}=10 \mathrm{~cm}$ triggers the landslide. Table 3 shows the necessary water and soil parameters to analyse the coupled THM phenomena developing in the shear band and the soil above it. The assumed initial temperature, $\theta_{0}$, is $10^{\circ}$.

The slide reached a displacement of $50 \mathrm{~m}$ in $12 \mathrm{~s}$ after the initial triggering. The results shown in the figures correspond to this time interval.

Figure 70 shows the parallel development of temperatures and pore pressures in the shear band and its vicinity. Maximum pore pressures, of around $0.45 \mathrm{MPa}$, occur in the centre of the band. The evolution in time of maximum temperature and pore pressures follow the pattern indicated

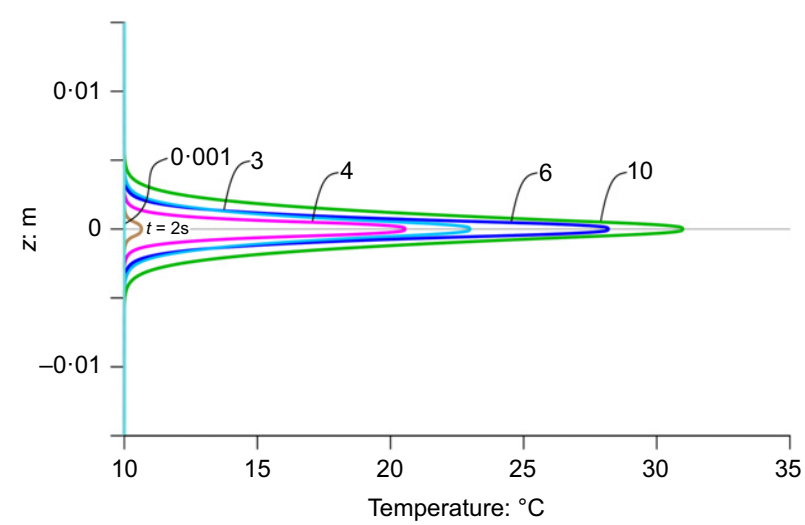

(a)

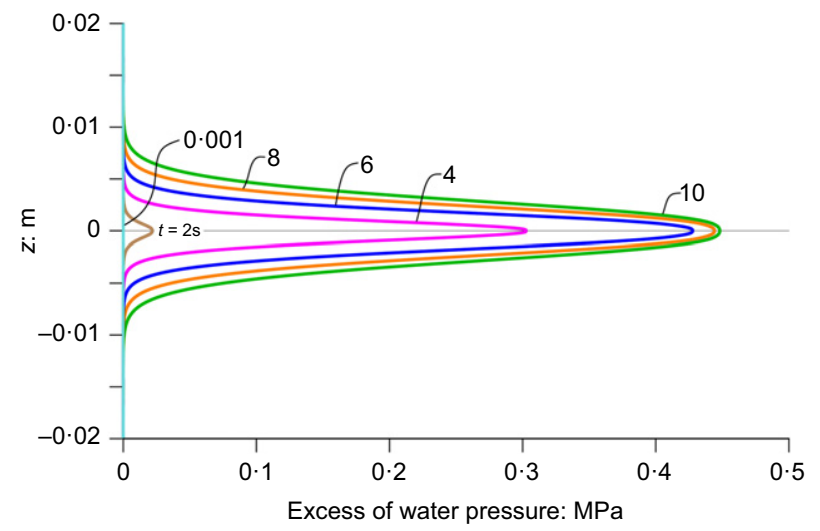

(b)

Fig. 70. Planar slide example. Temperature and excess pore pressures calculated in the shear band and its vicinity for different times since the triggering of the motion

in Fig. 71. After a short period, pore pressures and temperature increase fast, but level off at about $8 \mathrm{~s}$ after the triggering instant. Fig. 72(a) shows the reason: the available shear strength on the shearing plane drops to a very small value because of the drastic reduction in normal effective stress. The heat input into the band reduces accordingly. Fig. 72(b) shows the calculated evolution of landslide displacement.

The maximum velocity for a given displacement depends on the soil permeability, which mainly controls the dissipation of pore pressures in the shear band, and the shear band thickness, because it controls the pressure dissipation and the heat input per unit volume of shear band material. Fig. 73 shows, for the reference example defined in Table 3 and a maximum displacement of $50 \mathrm{~m}$, this dependence. The plotted continuous relationship is the average of five different shear band thicknesses in the range $0 \cdot 5-10 \mathrm{~mm}$. Differences in the calculated velocity are small for this range in shear band thickness. Also included in the plot is the limiting case of zero band thickness, which fits nicely within the range of bands analysed. The formulation of the MPM problem for a zero band thickness requires some changes in the equations. Alonso et al. (2016) describe this limiting case.

An infinite slope made unstable will eventually reach an infinite displacement and an infinite velocity in the absence of thermal effects. However, it accelerates extremely slowly if compared with the THM solution for the same problem. Fig. 73 includes this case ('no heat') to illustrate this comment.

Figure 73 highlights the dominant effect of permeability. Two $k$-controlled regions are distinguished. An 'unsafe' region for low $K$ values and a 'safe' region for high $K$ values. Unsafe means high velocity. Interestingly, high 


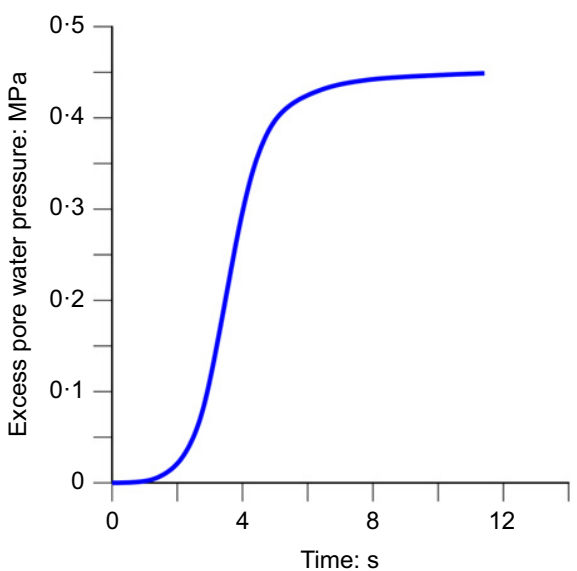

(a)

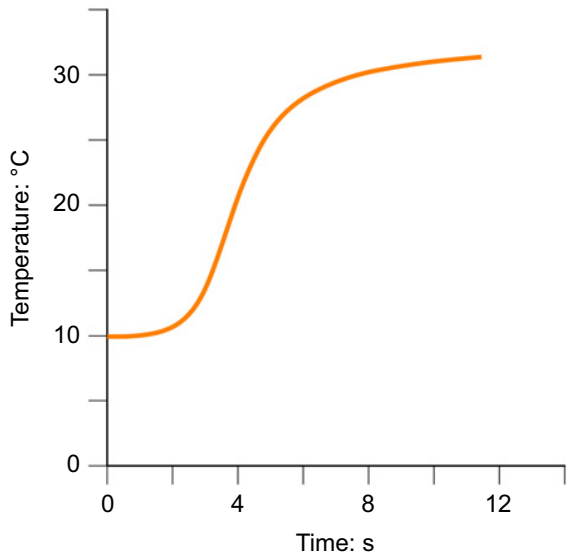

(b)

Fig. 71. Planar slide example. Development of maximum excess pore pressure and temperature at the shear band axis

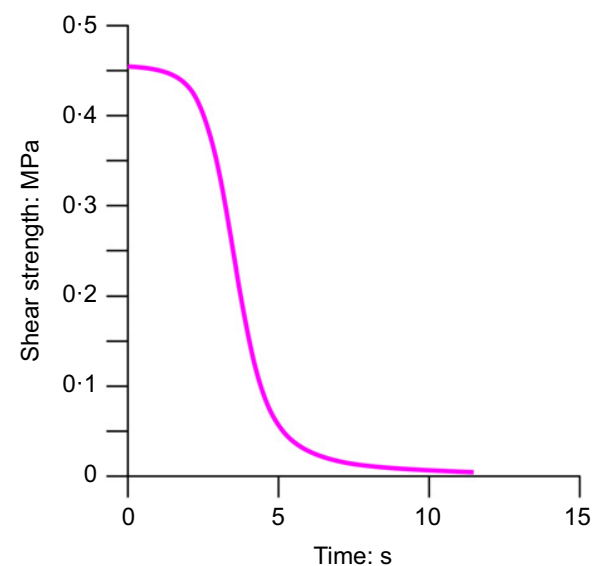

(a)

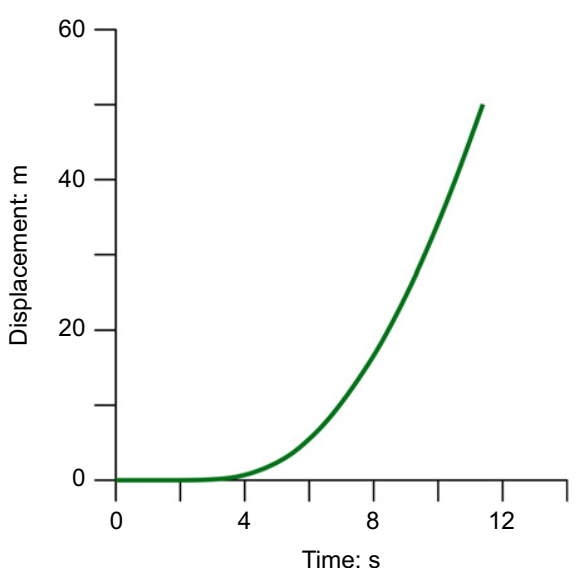

(b)

Fig. 72. Planar slide example. Reduction on available (a) shear band strength and (b) evolution of slide displacement

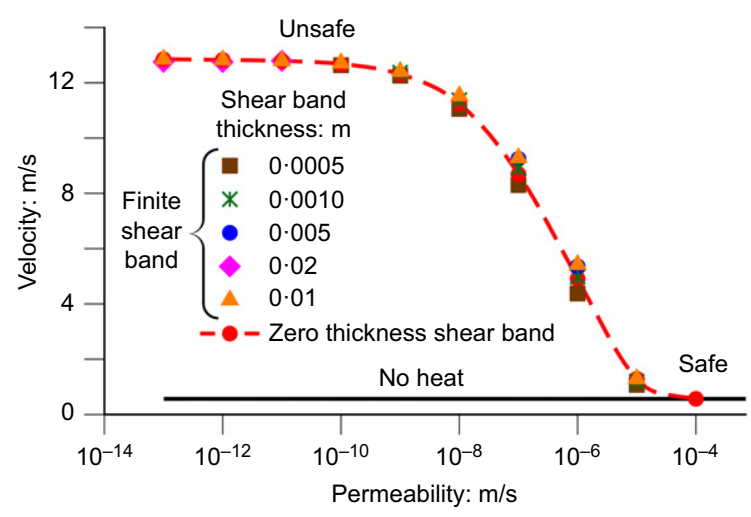

Fig. 73. Planar slide example. Relationship between the maximum velocity and shear band permeability for a runout of $50 \mathrm{~m}$. The plot includes results for six cases characterised by varying band thickness. Also shown is the non-thermal case

landslide velocities are predicted for a wide range of permeability (from $10^{-13} \mathrm{~m} / \mathrm{s}$ to $10^{-8} \mathrm{~m} / \mathrm{s}$ ). The safe region (no thermally induced effects) requires permeabilities in excess of $10^{-4} \mathrm{~m} / \mathrm{s}$ in the example described. In a transition region, $\left(10^{-8} \mathrm{~m} / \mathrm{s}<K<10^{-5} \mathrm{~m} / \mathrm{s}\right)$ the predicted landslide velocity decreases continuously.

The next step in this discussion is to analyse the behaviour of a compound landslide.

\section{Compound landslides}

Consider the simplified geometry of Vajont landslide plotted in Fig. 59. Two blocks (upper and lower), which interchange mass, and a common shear plane $\mathrm{AB}^{\prime}$ characterise the idealisation. No thermally induced excess pore pressures are considered in plane $\mathrm{AB}^{\prime}$ because of the high permeability of the rock above the sliding surface.

The formulation of the dynamic model is as follows

(a) sliding surface under the upper block

(i) balance equations inside the shear band for solid, water and heat (equations (35) and (37))

(ii) balance equations outside the shear band for solid and water (equation (35))

(b) sliding surface under the lower block

(i) balance equations inside the shear band for solid, water and heat (equations (35) and (37))

(ii) balance equations outside the shear band for solid and water (equation (35))

(c) the overall dynamic equilibrium for the two interacting wedges (equation (21)).

The solution of the system of equations required the development of a finite-difference program. Fig. 59 and the associated discussion described the Vajont case and the 2D dynamic analysis in the absence of heat generation. Rapid 
motions may be thought to be associated with large landslides. A relevant issue was whether or not there is a scale effect in rapid landslides. To answer this question, the Vajont geometry was scaled in this example by $1: 10$ (the analysis of the full-scale Vajont landslide is presented below within the framework of the MPM). Rock and soil properties remained as in the previous section. The water level is located in a position that guarantees strict equilibrium, and a small increase of the water level $(10 \mathrm{~cm})$ triggers the motion. The shear band has a uniform thickness $(2 \cdot 5 \mathrm{~mm})$.

It was found that the reduced scale Vajont geometry led to a fast acceleration and high velocities within a few seconds, because of the rapid cancellation of normal effective stress on the sliding surface. Initial accelerations are similar when the scale changes. However, if a landslide size is reduced, the displacement required to modify substantially the slide geometry to mechanisms not contemplated in the assumptions reduces accordingly. As a result, the expected maximum velocities and runout decrease when the landslide size reduces.

Having in mind the behaviour of a planar landslide, there was also an interest in examining the effect of changing the permeability in the shear band and its vicinity. Fig. 74 shows the calculated velocity-displacement plot for varying permeability within a relatively reduced range (from $10^{-11} \mathrm{~m} / \mathrm{s}$ to $5 \times 10^{-9} \mathrm{~m} / \mathrm{s}$ ). However, its effect is very significant.

Unlike the planar case, in which the maximum velocity corresponds to the maximum displacement, in the selected 2D Vajont's geometry, the slide may stop at a smaller runout because of its self-stabilising evolutionary geometry. Therefore, the maximum velocity may occur before the maximum specified (or actual) runout.

Figure 75 shows the maximum landslide velocity in terms of the permeability of the sliding surface for a maximum runout of $50 \mathrm{~m}$ and several shear band thicknesses in the range $0-20 \mathrm{~mm}$. Also shown in the plot, for a comparison, is the previously analysed planar case, again for a maximum run-out of $50 \mathrm{~m}$. The two plots show similar trends. The transition permeability from the unsafe to the safe region is significantly smaller for the compound landslide. This reduction is a consequence of the major differences of an evolutionary geometry if a self-stabilisation mechanism is compared with the planar case. The figure suggests that a simple criterion to decide if a fast landslide may develop is to check if the soil permeability in the expected position of the sliding surface is 'high enough'. High enough means a permeability larger than $10^{-5} \mathrm{~m} / \mathrm{s}$ in the case of a planar landslide, and larger than $10^{-8} \mathrm{~m} / \mathrm{s}$ for the compound cases.

In the cases represented, the effect of shear band thickness was negligible provided it remained within a small range $(0-20 \mathrm{~mm})$. However, this result changes dramatically if the shear band thickness increases to a large value. For instance,

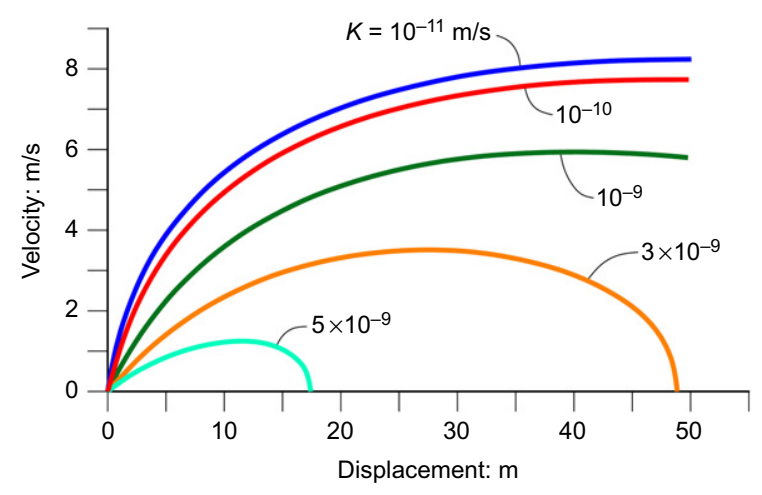

Fig. 74. Velocity-displacement relationship for the compound slide. Effect of permeability of the sliding surface

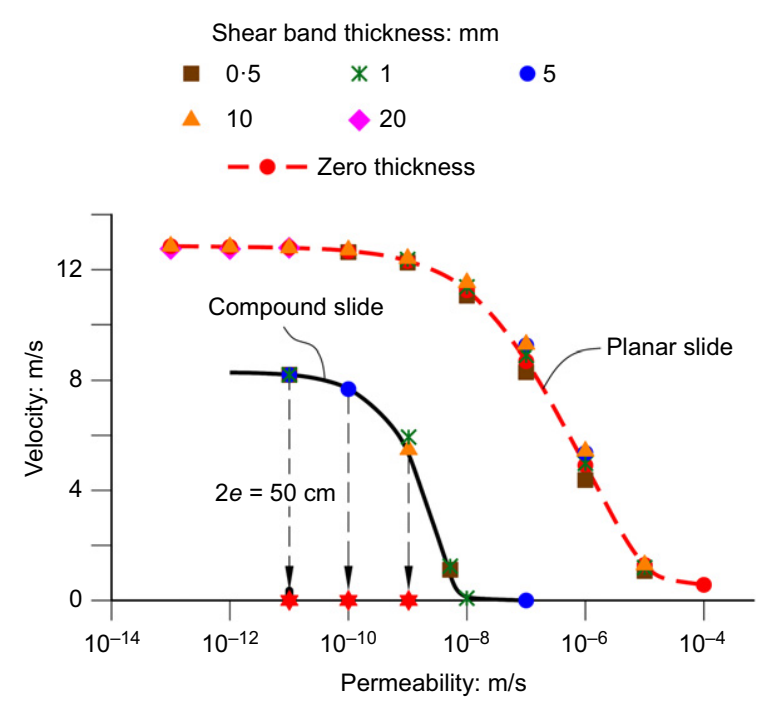

Fig. 75. Effect of permeability of sliding surface on the maximum velocity for the planar and compound slides

$2 e=50 \mathrm{~cm}$. The compound slide case was run again for this value of $2 e$ and the result is indicated in Fig. 75. At the velocity scale of the plot, the calculated velocities are negligible for the full range of soil permeability. This is due to the small value of the input energy per unit volume in the shear band. Then, pore pressures increase slightly and the slide requires a small and slow displacement to become stable again. A shear band thickness of $50 \mathrm{~cm}$ in clay does not make sense, but the reason for checking the effect of increasing band thickness will be clear when dealing with a continuum analysis in the next section.

\section{THM analysis of landslides in a continuous medium}

This section is a generalisation of the calculation procedures discussed before. The generalisation concerns the geometry of the problem. The geometry of the sliding surfaces becomes a part of the solution. It is also fair to say that geological considerations also remain as key information in practice to predict the location and shape of the failure surface.

The MPM code developed for the THM formulation solves the balance equations already mentioned: the balance of solid and water (equations (27) and (24)) and the heat transfer (equation (35)). Now the heat source term $\dot{H}$ develops on the entire domain by the dissipated rate of plastic work

$$
\dot{H}=\boldsymbol{\sigma}^{\prime}: \dot{\boldsymbol{\varepsilon}}^{\mathrm{p}}=\left(\boldsymbol{\sigma}-u_{\mathrm{w}} \mathbf{m}\right): \dot{\boldsymbol{\varepsilon}}^{\mathrm{p}}
$$

where $\boldsymbol{\sigma}^{\prime}$ is the effective stress tensor; $\dot{\boldsymbol{\varepsilon}}^{\mathrm{p}}$ is the rate of plastic strains; and $\mathbf{m}$ is the unit matrix.

In addition, the momentum balance equations for the water and the mixture (the saturated soil) complete the formulation.

The objective was to reproduce the dynamic motion of Vajont landslide (Pinyol et al., 2018). The consistency of the procedures developed requires checking against simplified academic examples.

Figure 76 illustrates the selected benchmark. A simple uniform and saturated slope with an increasing density of discretisation (reducing the cell size of the computational mesh) becomes unstable by reducing soil strength. The water surface is located at the upper boundary and every material point has an initial water pressure equivalent to the vertical distance between the point and the slope surface. A zero water pressure at the surface of the slope table is maintained 

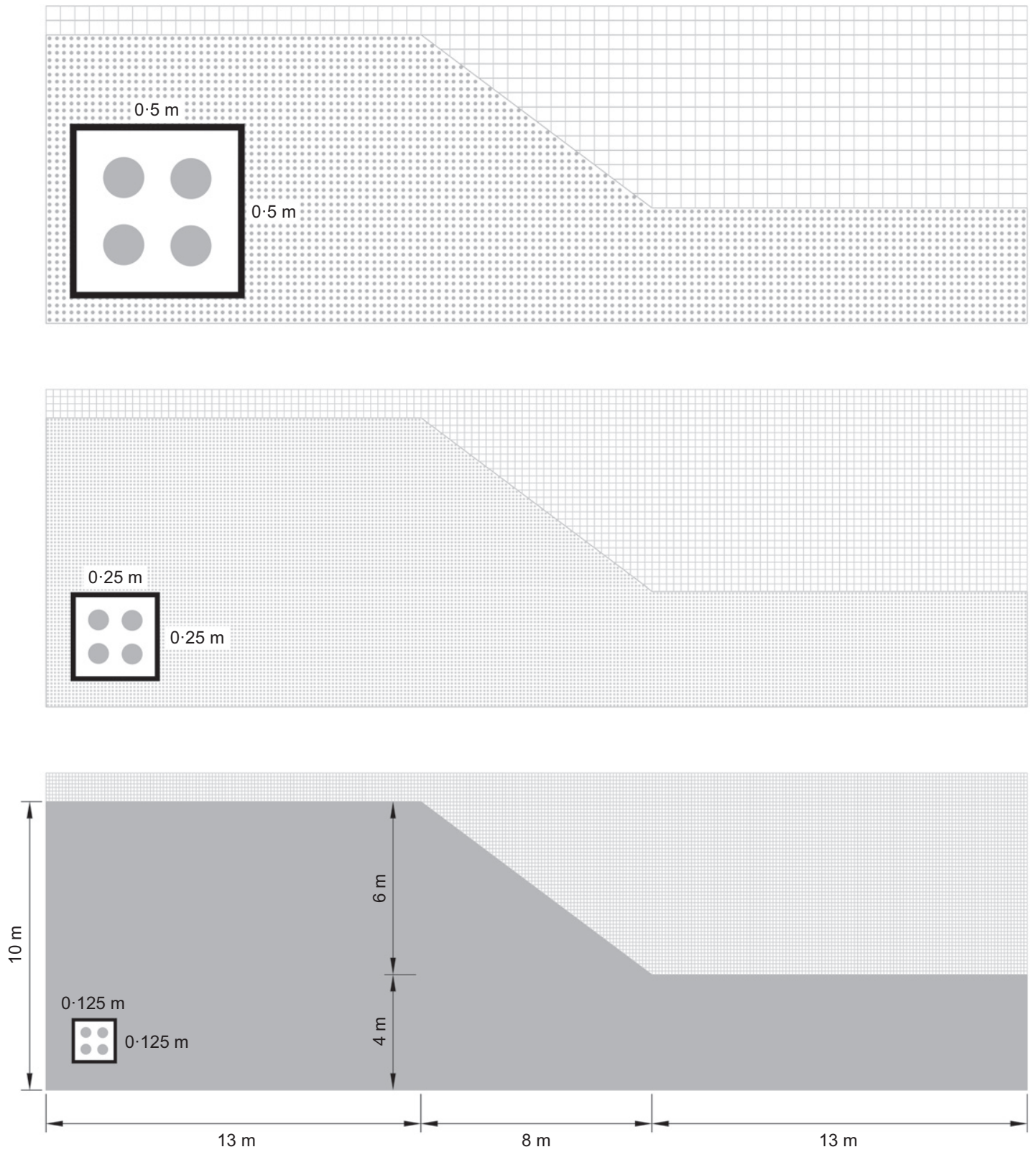

Fig. 76. A simple slope selected to validate the MPM approach. The figure shows three computational meshes of increasing detail

during the analysis. The remaining mesh contours are impervious. The upper boundary of the slope is stress free. Displacements of the mesh are prevented on the bottom and lateral boundaries. The initial state of stress results from the application of gravity (density of soil particles, $27 \mathrm{kN} / \mathrm{m}^{3}$; porosity, 0.4). A Mohr-Coulomb elastoplastic constitutive model $\left(c^{\prime}=20 \mathrm{kPa} ; \phi^{\prime}=28^{\circ}\right)$ defines the soil.

Failure is triggered by reducing $c^{\prime}$ from $2 \mathrm{kPa}$ to $1 \mathrm{kPa}$. Table 3 indicates the water and solid thermal properties for the THM analysis of the motion after failure. A Young's modulus $E=20 \mathrm{MPa}$ and a Poisson's ratio $v=0.33$ completes the model. The soil is rather impervious $\left(K=10^{-11} \mathrm{~m} / \mathrm{s}\right)$. With reference to Fig. 75 , this permeability belongs to the 'unsafe' domain.

Note that the formulation of this problem does not specify the thickness of the shear band. However, shear deformations localise in shear bands and the plastic work dissipation concentrates naturally in shear bands, in the present case in the sliding surface.

Figures 77 and 78 show the calculated excess pore water pressures and the slide displacements once the landslide reaches a new equilibrium after the initiation of the motion. Fig. 77 indicates that the excess pore water pressures in the shear band increase as the mesh size decrease. Since the thickness of the 'numerical' shear band depends directly on the cell size, the heat dissipated in the band per unit volume increases as the cell size decreases. Fig. 78 shows the consequence in terms of calculated displacements: they increase as the computational mesh becomes finer. This strong mesh dependency of results is not acceptable.

On the other hand, the shear band thickness is a material property very much related to grain size distribution. This information, which was present in the simplified theoretical models described previously, requires specific attention in the numerical analysis.

Figure 79 shows the procedure devised to achieve this goal. In addition to the MPM representation of the soil matrix, the idea is to embed shear bands in material points. They activate whenever deviatoric plastic strain develops. The thickness of these shear bands is a material property, not related to the size of mesh discretisation. Heat, equivalent to the plastic work, generates in the shear bands, as well as 


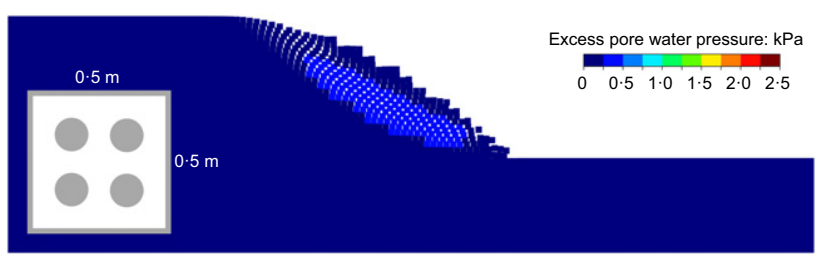

(a)

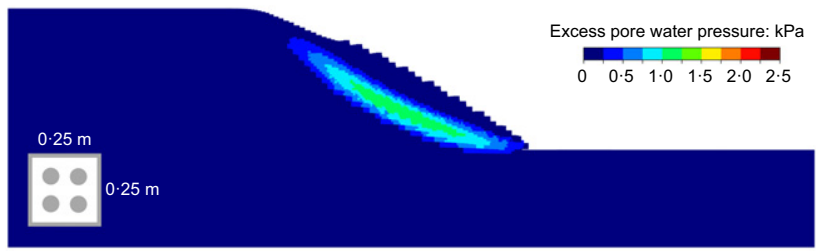

(b)

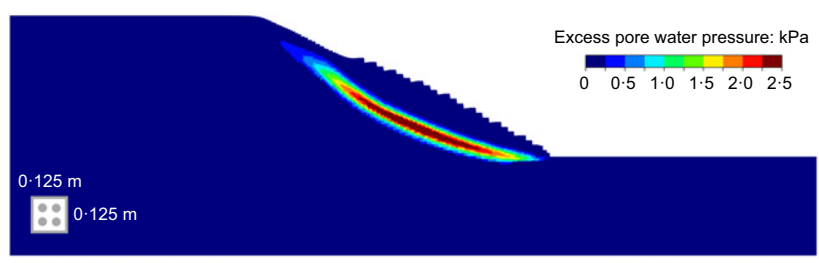

(c)

Fig. 77. Calculated excess pore pressures, after slide stabilisation for the three computational meshes

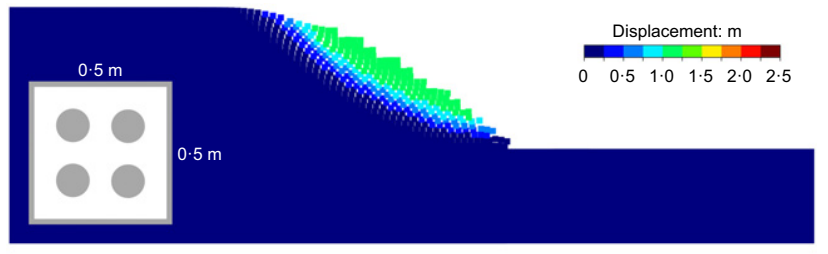

(a)

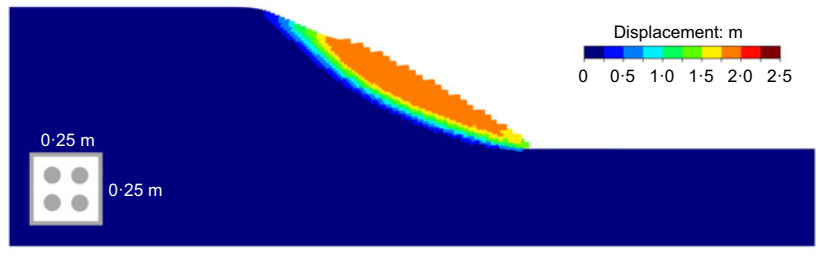

(b)

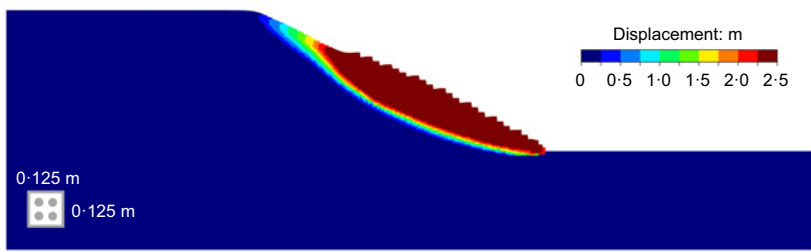

(c)

Fig. 78. Calculated displacement after slide stabilisation for the three computational meshes

excess pore water pressures. Heat and pore pressures will dissipate towards the soil matrix. This dissipation requires a local formulation of balance equations.

Shear bands may generate anywhere within the soil domain. The MPM model developed handles two interacting continua, which are described below in more detail. No attempt is made to orient the shear bands developing locally at a given material point. The set of activated shear bands will define the geometry of the sliding surface.

Figure 79 indicates the main variables involved in the dissipation process: temperature and liquid pressure for the matrix $\left(\theta^{\mathrm{M}}, p_{\mathrm{L}}^{\mathrm{M}}\right)$ and the shear bands $\left(\theta^{\mathrm{B}}, p_{\mathrm{L}}^{\mathrm{B}}\right)$.

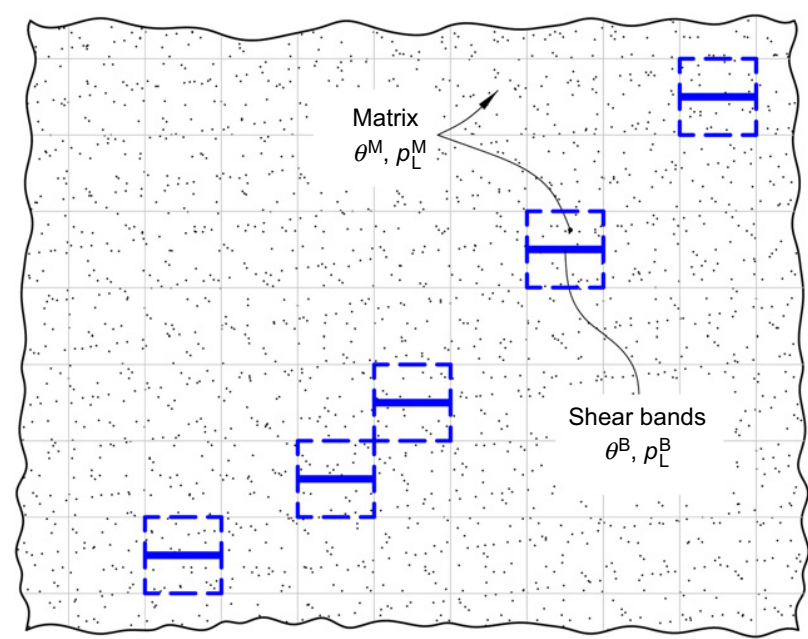

Fig. 79. Embedded shear bands in a soil matrix

Consider in Fig. 80(a) a soil element subjected to a shear strain rate. The reference length of this element is $L_{\text {ref }}$, which defines the size of the cell of the computational mesh. The figure indicates the deformed shape, in simple shear, of this element (Fig. 80(b)). However, if strains localise in a (thin) shear band of thickness $L_{\mathrm{B}}$, the actual deformation will look like Fig. 80(c). This sketch shows the two interacting continua defined - matrix and shear band.

Integrating the plastic work per unit volume (equation (44)) along the length $L_{\text {ref }}$ allows the heat dissipated in a sheared soil mass of thickness $L_{\text {ref }}$ to be found. This calculation is equal to $\dot{H} L_{\text {ref }}$. However, this plastic work is concentrated in the real shear band, with a thickness $L_{\mathrm{B}}$. Therefore, the work dissipated in shear bands, per unit volume, is

$$
\dot{H}^{\mathrm{B}}=\frac{L_{\mathrm{ref}}}{L_{\mathrm{B}}}\left(\bar{\sigma}^{\prime}: \dot{\varepsilon}^{\mathrm{p}}\right)
$$

Heat and water pressure will dissipate from the bands towards the matrix (Fig. 80(d)). The difference in temperature and water pressure between the shear band and the soil matrix drives the local flow rates. A linear relationship

$$
\begin{aligned}
& f_{\theta}^{\mathrm{B}-\mathrm{M}}=\psi_{\theta}\left(\theta^{\mathrm{B}}-\theta^{\mathrm{M}}\right) \\
& f_{\mathrm{L}}^{\mathrm{B}-\mathrm{M}}=\psi_{\mathrm{L}}\left(p_{\mathrm{L}}^{\mathrm{B}}-p_{\mathrm{L}}^{\mathrm{M}}\right)
\end{aligned}
$$

is an approximation. Heat transfer rates will to increase with the Fourier's coefficient $\Gamma$ (units: energy rate per unit length and temperature). Therefore, a suitable expression for $\psi_{\theta}$ is

$$
\psi_{\theta}=\frac{\Gamma}{A_{\text {ref }}}
$$

where $A_{\text {ref }}$ is a reference area for the heat flow, which was made equal to the cell area contributing to a material point. A sensitivity analysis indicated that varying $A_{\text {ref }}$ between $A_{\text {ref }} / 4$ and $4 A_{\text {ref }}$ led to minimum changes in results.

Likewise, the following equation provides a reasonable approximation to coefficient $\psi_{\mathrm{L}}$ in terms of the matrix permeability

$$
\psi_{\mathrm{L}}=\frac{\rho_{\mathrm{L}} k}{\mu_{\mathrm{L}} A_{\text {ref }}}
$$

where $k$ is the intrinsic permeability and $\rho_{\mathrm{L}}$ and $\mu_{\mathrm{L}}$ are the water density and viscosity.

The local energy balance for the matrix and embedded shear band follows equation (35). 


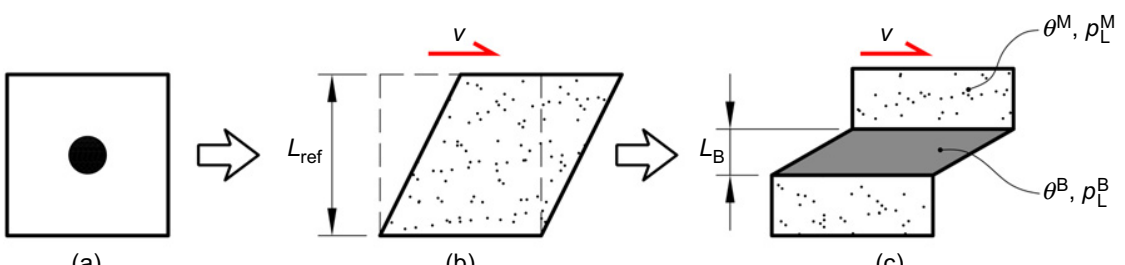

(a)

(b)

(c)

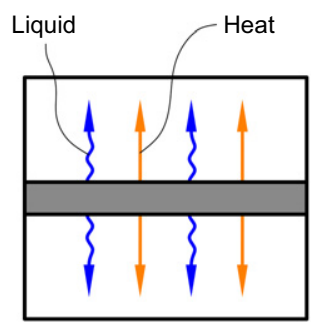

(d)

Fig. 80. Sketch showing a soil element, represented by (a) a material point; (b) when subjected to simple shear rate; (c) when shear strains localise a shear band of thickness $L_{\mathrm{B}}$ develops; (d) excess temperature and pore pressures generated in the shear band dissipate towards the soil matrix

$$
\begin{aligned}
& \text { Matrix } \\
& \begin{array}{l}
\frac{\mathrm{D}}{\mathrm{D} t}\left(\rho c_{\mathrm{m}} \theta^{\mathrm{M}}\right)+\operatorname{div}\left[-\Gamma \operatorname{grad} \theta^{\mathrm{M}}\right] \\
\quad+\operatorname{div}\left[\rho_{\mathrm{w}} c_{\mathrm{w}} \boldsymbol{q} \theta^{\mathrm{M}}+\rho c_{\mathrm{m}} \boldsymbol{v}_{\mathrm{s}} \theta^{\mathrm{M}}\right]=\psi_{\theta}\left(\theta^{\mathrm{B}}-\theta^{\mathrm{M}}\right)
\end{array}
\end{aligned}
$$

Shear band

$$
\frac{\mathrm{D}}{\mathrm{D} t}\left(\rho c_{\mathrm{m}} \theta^{\mathrm{B}}\right)=-\psi_{\theta}\left(\theta^{\mathrm{B}}-\theta^{\mathrm{M}}\right)+\dot{H}^{\mathrm{B}}
$$

Note that this expression disregards advective and convective terms inside the shear band. The temperature in the shear band is only explained by the plastic work and the heat conducted away.

Balance equations for the liquid read (see equation (28)) as follows.

Matrix

$$
\begin{aligned}
& \frac{\mathrm{D}}{\mathrm{D} t}\left(\beta_{\mathrm{m}} \theta^{\mathrm{M}}\right)+n \alpha_{\mathrm{L}} \frac{\mathrm{D} P_{\mathrm{L}}^{\mathrm{M}}}{\mathrm{D} t}+\operatorname{div}\left[\boldsymbol{v}_{\mathrm{s}}\right]+\operatorname{div}\left[\boldsymbol{q}_{\mathrm{L}}\right] \\
& \quad=\frac{1}{\rho_{\mathrm{L}}} \psi_{\mathrm{L}}\left(p_{\mathrm{L}}^{\mathrm{B}}-p_{\mathrm{L}}^{\mathrm{M}}\right)
\end{aligned}
$$

Shear band

$$
\frac{\mathrm{D}}{\mathrm{D} t}\left(\beta_{\mathrm{m}} \theta^{\mathrm{B}}\right)+n \alpha_{\mathrm{L}} \frac{\mathrm{D} P_{\mathrm{L}}^{\mathrm{B}}}{\mathrm{D} t}=-\frac{1}{\rho_{\mathrm{L}}} \psi_{\mathrm{L}}\left(p_{\mathrm{L}}^{\mathrm{B}}-p_{\mathrm{L}}^{\mathrm{M}}\right)
$$

which neglects advective and convective flow terms inside the bands.

A modified MPM code incorporated equations (50)-(53) instead of the standard balance relationships for the liquid and energy. A formal modification of the effective stress equation ensures that effective stresses are calculated at the location exhibiting the maximum pore pressure

$$
\boldsymbol{\sigma}^{\prime}=\boldsymbol{\sigma}-\max \left(p_{\mathrm{L}}^{\mathrm{B}}, p_{\mathrm{L}}^{\mathrm{M}}\right) \mathbf{m}
$$

where the maximum refers to the matrix and the shear band continua and $\mathbf{m}$ is a unit diagonal matrix.

Figures 81 and 82 illustrate the revision of the benchmark case using the new formulation. $L_{\mathrm{B}}$ is defined as equal to $1 \mathrm{~cm}$. The coarseness of the computational mesh again controls the numerical width of the shear bands. However, the maximum excess pore pressures now exhibit (Fig. 81) higher values, if compared with Fig. 77. They develop in the inner regions of shear bands. The pressure scale indicates that

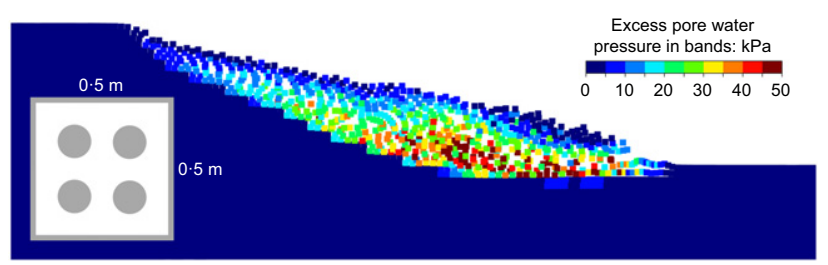

(a)

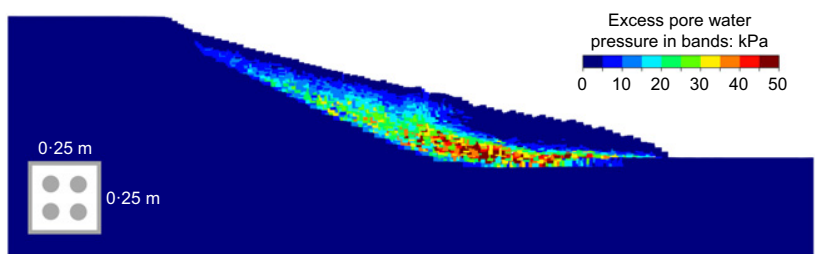

(b)

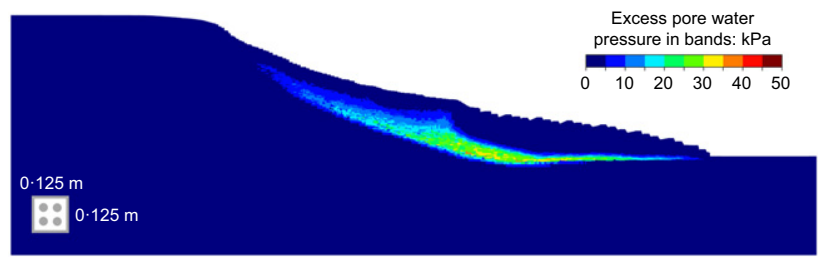

(c)

Fig. 81. Excess pore pressures at slide stabilisation for the reference example in the case of embedded shear bands

the maximum values in the three plots are essentially equal. The consequence is a common runout in the three cases (Fig. 82). The consequence (Fig. 83) is that the calculated runout becomes essentially independent of the calculation mesh size.

There was an interest in investigating, in this academic example, the effect of the main variables controlling the thermal interactions, as described in previous sections with the help of simplified models. The soil permeability is a dominant variable, and the reference slope was again calculated for varying values of permeability without changing soil properties and triggering action. A common value, $L_{\mathrm{B}}=10 \mathrm{~mm}$, defines the band thickness in all cases. Permeability changed between $10^{-3} \mathrm{~m} / \mathrm{s}$ and $10^{-11} \mathrm{~m} / \mathrm{s}$. Fig. 84 shows the results. Excess pore pressures are plotted in a centred point in the sliding surface (Fig. 84(a)), during the motion. Fig. 84(b) shows the evolution of displacements 


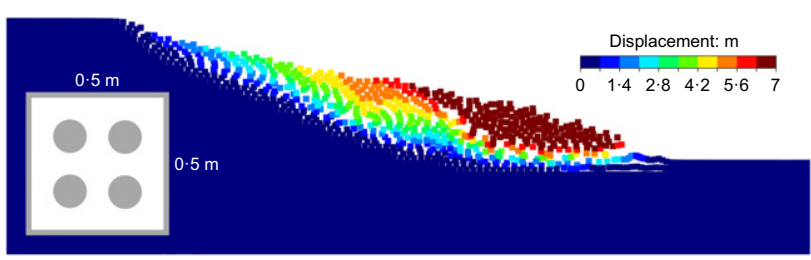

(a)

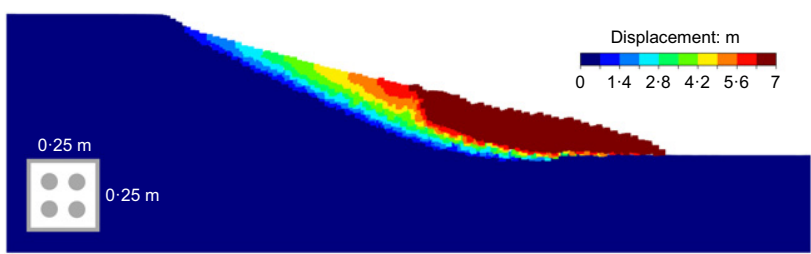

(b)

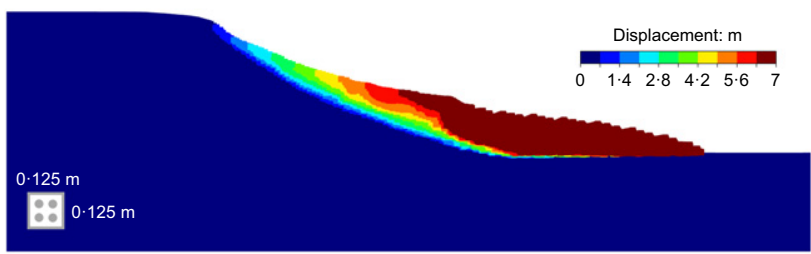

(c)

Fig. 82. Displacements at slide stabilisation for the reference example in the case of embedded shear bands

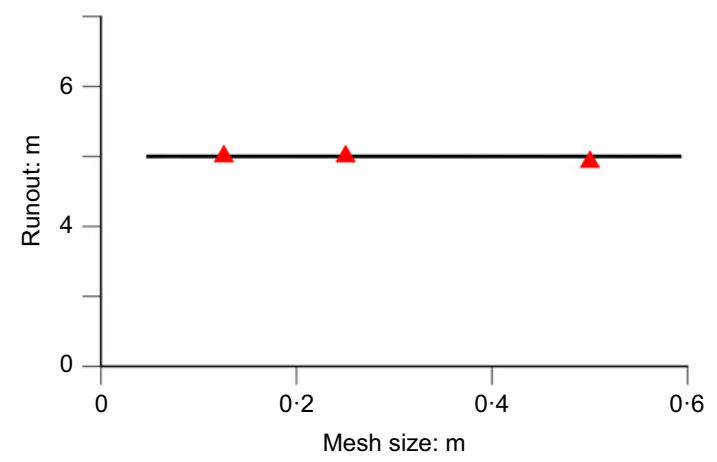

Fig. 83. A constant maximum runout, for a varying size of the computational mesh, in the case of embedded shear bands in time. The results are consistent with previous findings. Permeability values in the range $10^{-11}-10^{-7} \mathrm{~m} / \mathrm{s}$ lead to a rapid acceleration of the slope, and small variations in final runout, calculated for a centred point on the slope surface. The range $10^{-11}-10^{-7} \mathrm{~m} / \mathrm{s}$ belongs to the 'unsafe zone' in the terminology introduced previously (see Figs 73 and 75). The transition towards a safe zone spans the permeability values of $10^{-6}$ to $10^{-4} \mathrm{~m} / \mathrm{s}$.

Calculated maximum increments of temperature in the sliding plane are small $\left(0.02^{\circ} \mathrm{C}\right)$ in this example, which mobilises a shallow slide (around $2 \mathrm{~m}$ thick in the central part) and, therefore, a relatively small dissipation of plastic work during the runout. However, it is enough to bring pore pressures to values close to the total stress acting on the sliding surface for the 'unsafe' range of soil permeability.

Vajont landslide. The improved capabilities of the MPM model developed and the technique to eliminate the pathological dependence on the computational mesh required validation against a real case. Vajont was the target because of the accumulated data and the increasing understanding offered by the continuous research work performed during the past decades. The continuum MPM model allowed some limitations of the one-dimensional THM analysis described before to be removed.

The shear band thickness is now a constitutive parameter and the actual sliding surface is not defined, except for the geological constraints. In addition, the THM analysis provided additional information on the internal shearing mechanism on the rock mass above the sliding surface. In the simplified analysis reported by Alonso \& Pinyol (2010) and Pinyol \& Alonso (2010b) kinematic compatibility required the introduction of a bisector shearing plane fixed in space during the entire motion (Fig. 59). However, a strain-softening model now characterises the rock mass. In this way, a progressive failure mechanism, which plays a role in the triggering and runout of the landslide, could be included in the analysis.

Since Vajont is a case of a reactivation of an ancient landslide, the available friction on the clayey sliding plane corresponds to residual conditions. Tests collected by Hendron \& Patton (1985) indicate that the high-plasticity clay found in the sliding surface has a residual friction angle in the range $10-12^{\circ}$

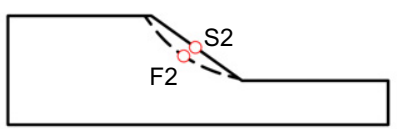

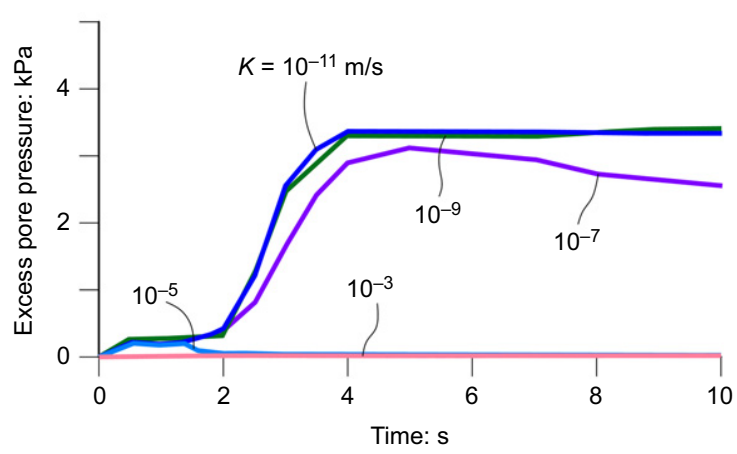

(a)

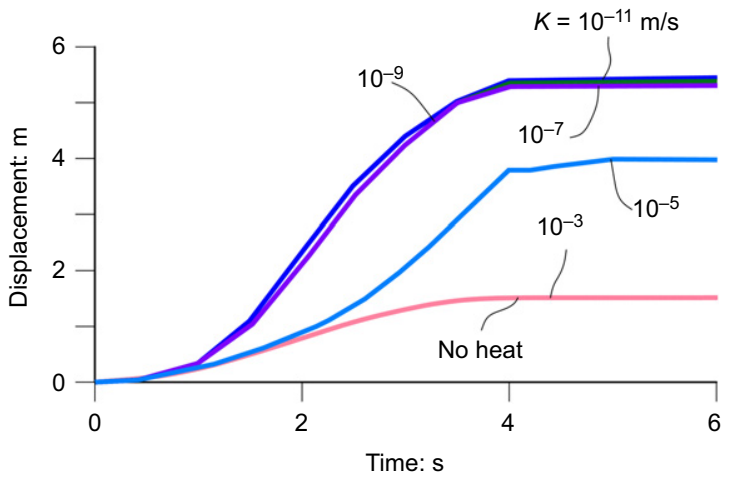

(b)

Fig. 84. (a) Evolution of excess pore pressures in point $F 2$ of the sliding surface and (b) displacement of point $S 2$ at the surface of the slope, after slope stabilisation, for different values of soil permeability 
The strength of the rock overlying the failure surface is more uncertain. Müller-Salzburg (1987: p. 432) provided a qualitative description of the rock as follows.

The part of the stratigraphic column exposed in the slide mass consists of beds of partially crystalline limestones, limestones with hard siliceous inclusions, marly limestones and marls. Many beds are strongly folded and show indications of slope tectonics. Its geological structure but also its geological sequence has remained essentially unchanged. The entire rock mass remained intact and the sediment facies is nearly unchanged. Apart from some newly formed faults, the only other effects of the slide were the opening of existing joints and the development of new joints, resulting in an overall volume increase of 4-6\% and an associated reduction of the mechanical coherence of the rock mass.

It conveys the notion of a reasonably sound sequence of folded limestone and marl layers. It also points out the apparent small damage suffered by the moving rock mass.

Alonso et al. (2010) discuss the strength of the rock by examining the equilibrium conditions of a representative 2D section of the landslide and accepting a residual basal friction of $12^{\circ}$. In terms of a Mohr-Coulomb strength criterion, the pair $c_{\text {rock }}^{\prime}=0.78 \mathrm{MPa}$ and $\phi_{\text {rock }}^{\prime}=38.8^{\circ}$ leads to strict equilibrium for the water level at the time of failure. These are 'average' values in the sense of classical limit equilibrium. However, there was an interest in introducing a strain-softening behaviour of the rock mass. The peak and residual strength parameters selected are upper and lower bounds of the average pair mentioned.

In a recent contribution to the geology of Vajont, Paronuzzi \& Bolla (2012: p. 169) describe the sliding surface in the following terms

field evidence has clearly demonstrated that the basal detachment surface was characterized by a stepped pattern involving various materials (limestone and marl limestone strata, clay interfaces, clay lenses, angular gravel, etc.).

When describing the sliding surface, Hendron \& Patton (1985) also mention the existence of areas in which shearing was across bedding planes, the presence of sections not having clay and others in which the clay was squeezed into rock voids and brecciated rock fragments within the clay beds. Wolter et al. (2014), in their photogrammetric-based description of the exposed failure, also describe its rough pattern.

These descriptions indicate that the sliding surface could not be interpreted as a continuous and regular shearing band, which developed entirely into a clay stratum. A precise representation of the sliding surface is not a real possibility and the approach for the analysis was to adopt an idealised representation combining clay stretches and a few rock bridges (Fig. 85).

Two materials describe the sliding mass in Fig. 85: a homogeneous strain-softening rock and a discontinuous clay band, which defines the position of the sliding surface. In addition, an elastic material of negligible shear modulus and water bulk compressibility represents the reservoir. This representation reproduces the dynamic water resistance to the slide entering the reservoir. The figure shows a thin layer of rock under the clayey band, which extends to the opposite side of the valley.

Table 4 collects the soil properties used in the analysis. The physical properties of water and solid particles are indicated in Table 3.

The relatively thick value selected for the clay layer reflects its heterogeneous nature, as described in previous comments. The value selected for the rock is a rough approximation. However, it has no effect on the results because of the high rock permeability $\left(10^{-5} \mathrm{~m} / \mathrm{s}\right)$, Fig. 85 shows also the computational mesh: a uniform grid of $5 \times 5 \mathrm{~m}$ cells. Four material points per cell define the material properties and field variables.

In an initial stage, with no water in the reservoir, the weight load is applied to define the initial stress conditions. The water level in the reservoir increased in steps and water pressures in the rock correspond to a horizontal water level that follows the reservoir surface elevation. The water 'material' applies the corresponding hydrostatic pressure

Table 4. Material properties for the MPM analysis of Vajont landslide

\begin{tabular}{|c|c|c|c|c|}
\hline Property & Rock & $\begin{array}{l}\text { Basal } \\
\text { clay layer }\end{array}$ & Water & Units \\
\hline Porosity & $0 \cdot 2$ & $0 \cdot 12$ & - & - \\
\hline Elastic modulus & 5000 & 500 & & MPa \\
\hline Poisson's coefficient & $0 \cdot 33$ & $0 \cdot 33$ & & - \\
\hline Shear modulus & - & - & 1 & $\mathrm{kPa}$ \\
\hline Bulk modulus & - & - & 2200 & MPa \\
\hline Peak effective cohesion & 2800 & - & - & $\mathrm{kPa}$ \\
\hline $\begin{array}{l}\text { Residual effective } \\
\text { cohesion }\end{array}$ & 200 & 1 & - & $\mathrm{kPa}$ \\
\hline $\begin{array}{l}\text { Peak effective friction } \\
\text { angle }\end{array}$ & 43 & 一 & - & degrees \\
\hline $\begin{array}{l}\text { Residual effective } \\
\text { friction angle }\end{array}$ & 34 & 11 & - & degrees \\
\hline Shear band thickness & 50 & 25 & - & $\mathrm{mm}$ \\
\hline Permeability & $10^{-5}$ & $10^{-11}$ & - & $\mathrm{m} / \mathrm{s}$ \\
\hline
\end{tabular}

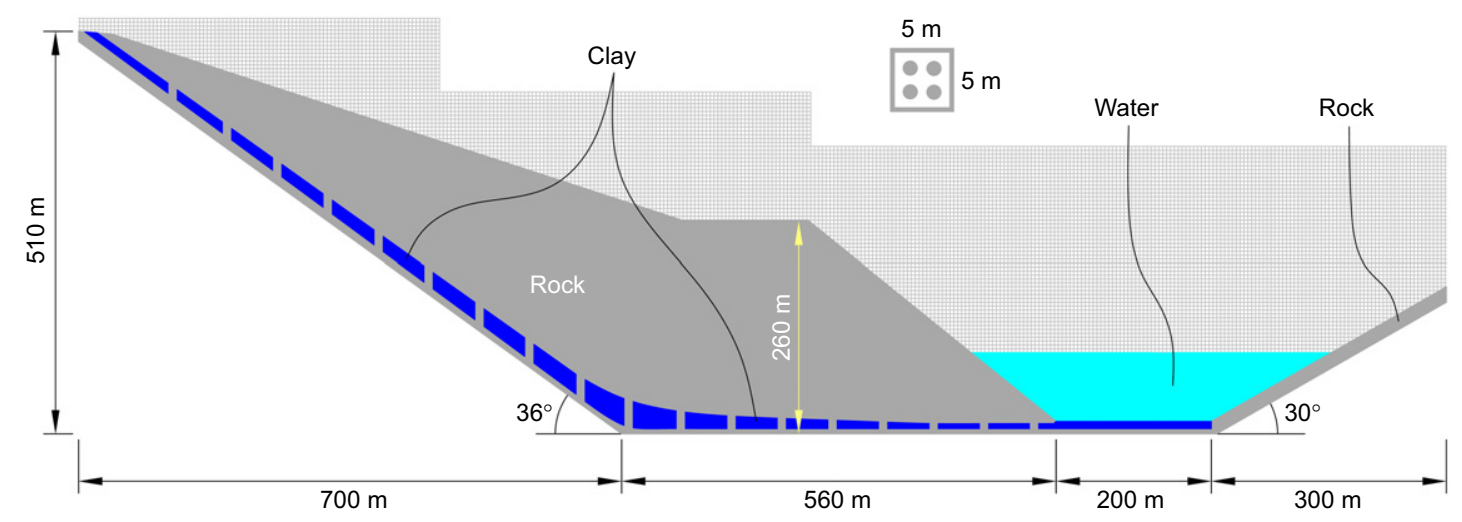

Fig. 85. Details of the computational mesh for the MPM analysis of a central section of Vajont landslide 
against the slope. Later, during the motion after failure, the water develops hydrodynamic forces against solid surfaces in contact. Failure occurred when the reservoir reached a water level $100 \mathrm{~m}$ above the elevation of the lower horizontal section of the failure surface.

The discretised cross-section in Fig. 85 follows the geometry of cross-section 5 in Hendron \& Patton (1985). The narrow valley of the river was not included in the model.

The simplified analytical two-wedge model described before is kinematically admissible because of the assumed planar failure surface along the bisector direction $\mathrm{AB}$ (Fig. 59). However, the geometry of the basal failure surface determines strongly the development of internal shearing surfaces. They evolve during the motion. Fig. 86 shows the intensity of plastic shearing in internal rupture surfaces that developed $9 \mathrm{~s}$ and $40 \mathrm{~s}$ after the initiation of the motion. Plastic shear strains reach maximum values on the main sliding surface on the lower clay level, but the massive rock overlying the clay layer experiences significant shearing, even if large rock volumes remain intact. This result is consistent with a previous description of the rock mass after failure (Müller-Salzburg, 1987).

The discontinuous curve of Fig. 87 shows the motion (velocity plotted against displacement) of one particle located to the toe of the slope. An average of a few material

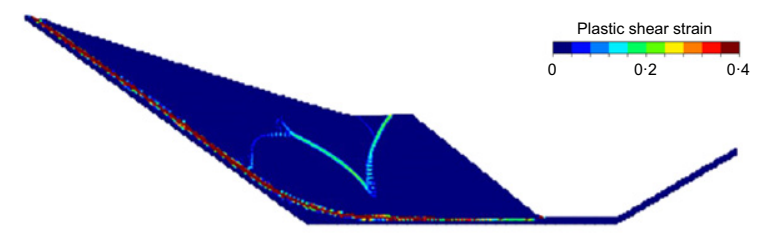

(a)

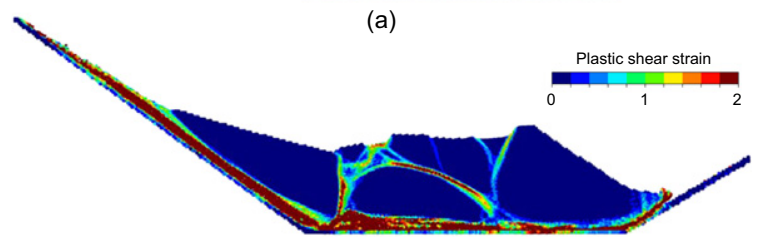

(b)

Fig. 86. Plastic shearing strains developing in Vajont landslide: (a) $9 \mathrm{~s}$ and (b) $40 \mathrm{~s}$ after the initiation of the motion

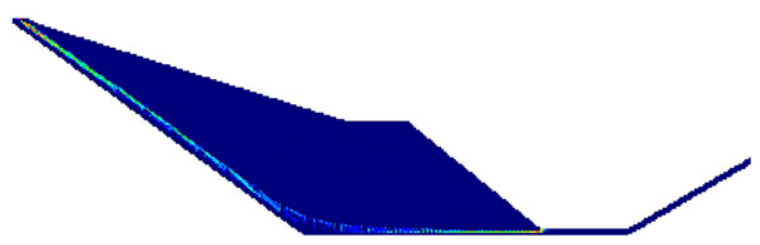

(a)

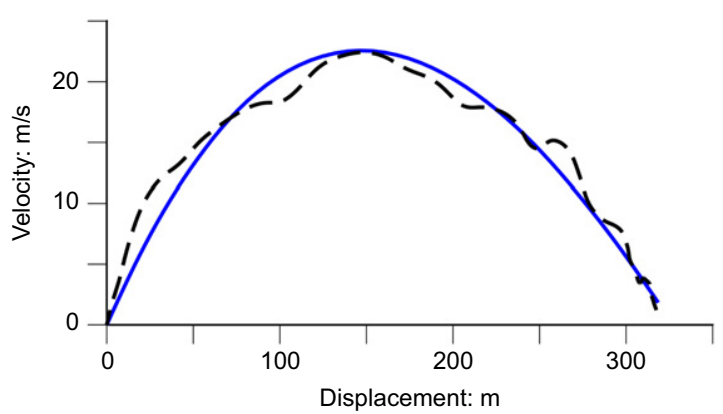

(b)

Fig. 87. (a) Initial state of Vajont central section. Plastic shearing strains due to self-weight (scale as in Fig. 86). (b) Velocity of the toe of Vajont landslide for increasing displacement. Discontinuous curve for one material point. Continuous line is an average value of a few materials points points located at the slope toe provide the representative velocity-displacement relationship indicated by the continuous line. The analysis performed shows a maximum velocity of $22.5 \mathrm{~m} / \mathrm{s}$ and a runout of $320 \mathrm{~m}$. Hendron \& Patton (1985) estimate the maximum velocity as $20-25 \mathrm{~m} / \mathrm{s}$, and a runout close to the value calculated here.

Some of the model assumptions mentioned are difficult to justify, in particular, the thickness of the sliding surface on the clay layer. However, the main purpose of the analysis described is to show that the thermal interactions provide a satisfactory explanation for the after-failure Vajont dynamic behaviour with a geometry close to actual conditions, defined by a reasonable set of material properties.

Figure 88 shows the calculated temperatures and excess pore water pressures at the end of the motion $(t=40 \mathrm{~s})$. The maximum temperature increment in the clay layer is close to $50^{\circ} \mathrm{C}$. This value depends on the assumed shear band thickness. It may look to be a relatively low value in view of the high total vertical stress expected on the sliding surface and the sliding velocity. However, this temperature increase is capable of increasing pore water pressures to values (7-8 MPa; Fig. 88(b)) that bring the effective normal stress on the shear band to near-zero values. This is the case even if the assumed pervious rock bridges have a non-negligible effect to drain quickly the excess pore pressures in the clay.

Calculated shear strains in Fig. 86(b) suggest that the violent motion led to the penetration of basal clayey material into the overlying rock. An examination of the position of the material points describing the clay confirmed this interpretation. This result is reminiscent of the description made by Paronuzzi \& Bolla (2012) of the sliding surface.

The next step in the analysis of the motion of landslides is to examine the question of the expected evolution of a creeping landslide towards a generalised failure, which may be a fast event. The approach followed is to combine the ideas and models for creeping phenomena and thermal interactions into a unified framework.

\section{TRANSITION FROM CREEPING TO FAST SLIDING MOTION}

First-time failures may reach relatively high velocities during the subsequent runout. In Aznalcóllar failure, the maximum calculated velocity was $5.6 \mathrm{~m} / \mathrm{s}$. The failure surface was sub-horizontal and the measured runout allowed the calibration of the model. In other known high-velocity landslides, no information on slide motions before the catastrophic failure is available.

Creeping records are abundant (Figs 45 and 58) because of the marginal safety often found in displaced landslide

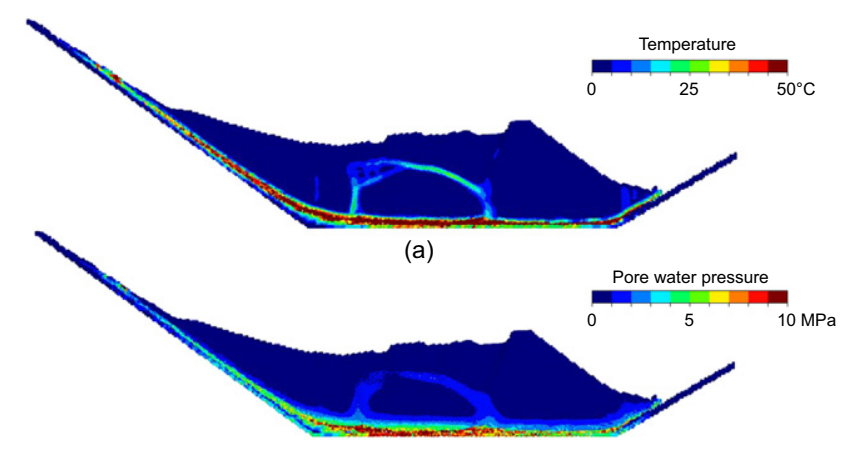

(b)

Fig. 88. (a) Increments of temperature and (b) pore water pressure when landslide stabilised 


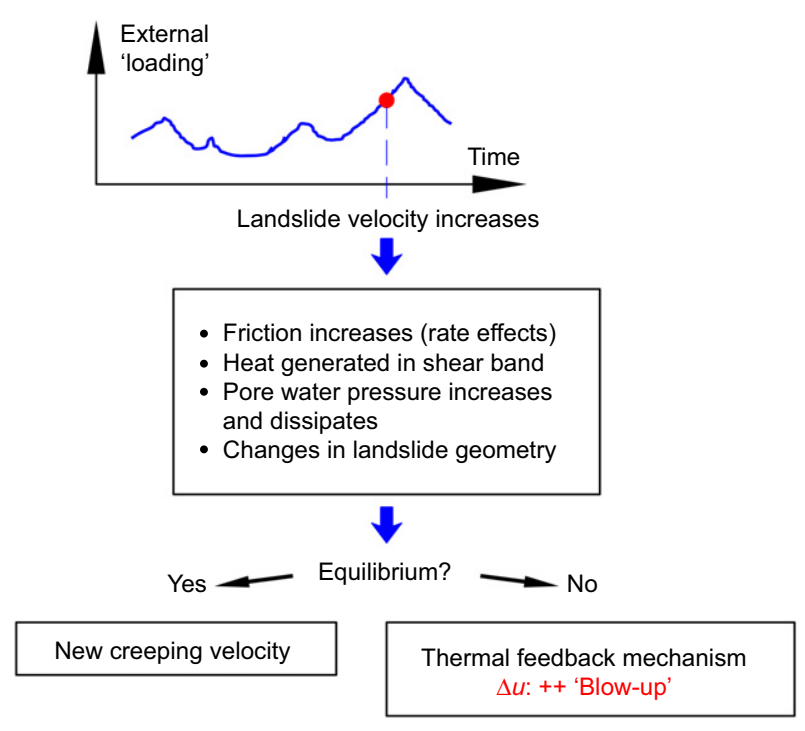

Fig. 89. A scenario to interpret the interaction between creeping and failure of landslides

masses, especially if external actions modify equilibrium conditions by reducing resisting forces or increase the loading.

Figure 89 describes the problem addressed here. The sketch on top represents a creeping situation. An 'external loading', for example, a change in water pressure, follows a given time history. In a situation of increasing water pressure, the creeping velocity of the landslide will increase. The expected physical phenomena are

(a) rate effects on friction induce a (small) increase in friction because of the increase in velocity

(b) the rate of work input into the sliding surface results in a temperature increase of the shear band and the immediate neighbourhood (by heat conduction)

(c) pore water pressure increases in the band

(d) the landslide displacement leads to an updated geometry.

A check of equilibrium conditions of the landslide at this last stage may lead to a new creeping stage at an increasing velocity. However, there is a second possibility: rate effects are no longer capable of maintaining a new creeping stage and the slide accelerates. This acceleration increases the work input into the sliding surface, the rise of pore pressures, the reduction of available strength and the triggering of a feed-back mechanism leading to a fast motion. This triggers a 'blow-up' condition (Fig. 89).

Formulating a model for this scenario is not particularly complicated. The THM coupled formulation already described should now include the provision for rate effects. This is simply done by expressing friction angle in terms of shearing velocity (equations (13)-(15)).

The implications of such a model were first explored for a planar landslide (Fig. 67) and then for a compound two-block geometry.

\section{Planar landslide}

A dimensionless formulation of the THM model helps to generalise the main results and, more usefully, it provides a set of coefficients, which control the phenomenon. There is some freedom to derive a dimensionless version of the problem because the selection of basic reference variables is a matter of convenience.
In the planar motion, a reference distance is the depth of the sliding surface. Then, a reasonable proposal for dimensionless coordinates, time, excess pore pressures and sliding velocity is as follows:

$$
\hat{z}=z / D ; \hat{t}=\frac{t \sqrt{\boldsymbol{g} D}}{D} ; \hat{u}_{\mathrm{w}}=\frac{u_{\mathrm{w}}(z, t)}{\rho \boldsymbol{g} D} ; \hat{v}(t)=\frac{v(t)}{\sqrt{\boldsymbol{g} D}}
$$

where $\boldsymbol{g}$ is the gravity acceleration.

A reference temperature, the initial value, $\theta_{0}$, allows a dimensionless temperature to be written as the ratio between the actual temperature field $\theta(z, t)$ and $\theta_{0}$.

A straightforward re-formulation of the THM differential equations leads to the following set of governing dimensionless coefficients (Alonso et al., 2016), given by equations (56)-(59).

$$
\Theta=\frac{\Gamma}{(\rho c)_{\mathrm{m}} D \sqrt{\boldsymbol{g} D}}
$$

is a thermal dissipation coefficient associated with heat flow. It combines heat conduction $(\Gamma)$, heat storage $(\rho c)_{\mathrm{m}}$, a reference dimension and a reference velocity. $\Theta$ is essentially a fixed coefficient if compared with the others, because $\Gamma$ and $(\rho c)_{\mathrm{m}}$ do not change much for different soils and rocks.

$$
\Psi=\frac{\rho D(\sqrt{\boldsymbol{g} D})^{2}}{(\rho c)_{\mathrm{m}} \theta_{0} 2 e}
$$

is the ratio between the kinetic energy of the moving mass and the initial heat stored in the shear band. Its value varies between 30 and 1800 .

$$
\Pi=\frac{\beta_{\text {soil }} \theta_{0}}{m_{\text {soil } \rho} \rho D}
$$

is the ratio between the thermal expansion of the saturated porous medium and its mechanical compressibility. It may range between, say, $0 \cdot 1$ and 10 . Note that the band stiffness is characterised by a confined elastic coefficient, $m_{\text {soil }}$.

$$
\Sigma=\frac{K}{\gamma_{\mathrm{w}} m_{\text {soil }} D \sqrt{\boldsymbol{g} D}}
$$

has the structure of a consolidation coefficient. It combines the soil permeability, its confined compressibility and the depth of the sliding plane. Mainly because of the large variability of permeability when considering different soils, the expected range of $\Sigma$ covers many orders of magnitude: $10^{-12}$ to $10^{-1}$.

Coefficient $\Sigma$ includes the fundamental information to describe the THM interactions in a planar landslide. Next in the scale of relevance are coefficients $\Psi$ and $\Pi$. Their maximum range of variation is 'only' two orders of magnitude.

The following example illustrates the bifurcation in behaviour outlined in Fig. 89. Consider the same planar slide analysed above (see section entitled 'Fast landslides'), whose geometry and water level are given in Fig. 67: $D=25 \mathrm{~m}$, $\beta=9 \cdot 8^{\circ}$. Strict equilibrium requires a shear band friction of $12^{\circ}$ when the water table, parallel to the slope, has a height $h_{\mathrm{w} 0}=11.05 \mathrm{~m}$. The slope may find a dynamic equilibrium at a constant velocity if friction depends on rate effects. Incorporating thermal effects requires additional information (indicated in Table 3): shear band thickness (2e), permeability $(K)$, confined stiffness of the shear band $\left(m_{\mathrm{v}}\right)$, a few thermal parameters and the initial temperature (taken as) of the shear band. The set of parameters introduced describe a planar landslide in equilibrium, potentially creeping if initial conditions change, in which thermal effects are activated. The frictional rate effects are defined by means of equations (13)-(15) for $A=0 \cdot 014$ and $v_{\text {ref }}=10^{-5} \mathrm{~m} / \mathrm{s}$. 
The slope becomes unstable if the water table increases to $h_{\mathrm{w}}=12 \mathrm{~m}$. The objective of this exercise is to predict the slide response under a history of water table fluctuations given in Fig. 90(a). The answer comes from the solution of the balance equations (for the motion of solids, water and energy) inside and outside the shear band, and the dynamic equation of equilibrium. In addition, rate effects modify the friction angle. An additional assumption was that the shear band was in the mid-plane of a $2 \mathrm{~m}$ thick clay layer bounded by pervious rock, which maintains the initial pore pressure and temperature.

Figure 90 shows the calculated response of the slide. The slide velocity for the first three different water levels maintained a creeping motion. Note that under a water level, $h_{\mathrm{w}}=$ $13 \mathrm{~m}$ (Fig. 90(b)), there is a small increase in creeping rate. This is also the case for the slide behaviour during the first creeping stage $\left(h_{\mathrm{w}}=12 \mathrm{~m}\right)$ even if the velocity increase is rather small to be noticed because of the scale of the plot. A heat-driven slow accumulation of excess pore water pressures in the shear band, which reduce the available resisting force (Fig. 90(c)), explains this result. A relevant question here is to ask for the long-term behaviour of the slide for a constant water level. This issue is discussed below.

The final rapid increase of water level (from $h_{\mathrm{w}}=12.5 \mathrm{~m}$ to $h_{\mathrm{w}}=14 \mathrm{~m}$ ) leads to a fundamental change in the sliding regime. Fig. 90(c) illustrates the calculated rapid change in pore water pressure. After a transient period, which looks similar in shape to the previous excess water pressures in the shear band, there is a sudden and very rapid increase in pore pressure, a situation identified as 'blow-up' in the figure. The sliding velocity also increases rapidly and evolves from a creeping value of around $1 \mathrm{~mm} / \mathrm{s}$ to $10 \mathrm{~m} / \mathrm{s}$ in a few seconds. Shear band temperature (Fig. 90(d)) and friction angle (Fig. 90(e)) also increase fast. Interestingly, the increase in temperature is very moderate, a fraction of one degree, but enough to explain a significant increase in pore pressures because of the low permeability assumed for the shear band and surrounding clay matrix. The friction angle increases because of the assumed rate effect on friction. The increase is again small (about $1^{\circ}$ ) because of the logarithmic expression relating shearing velocity and friction angle. Blow-up conditions develop when rate effects on friction are no longer

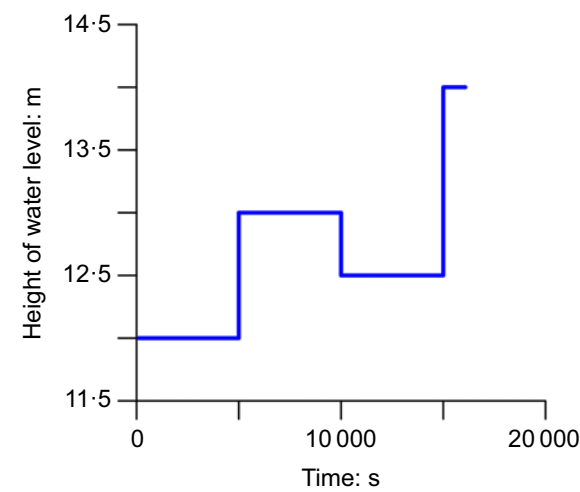

(a)

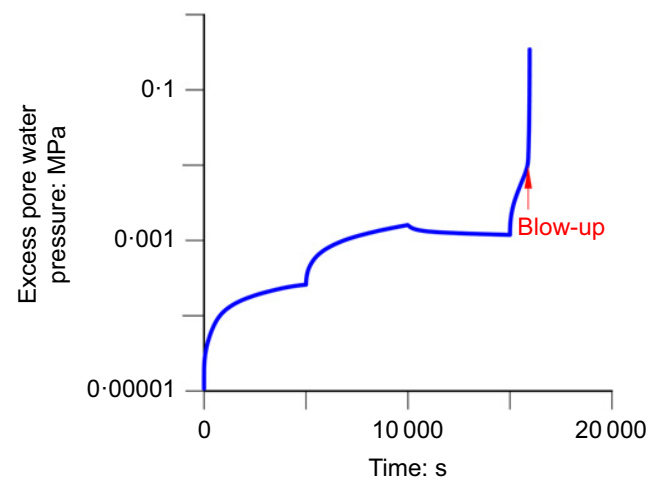

(c)

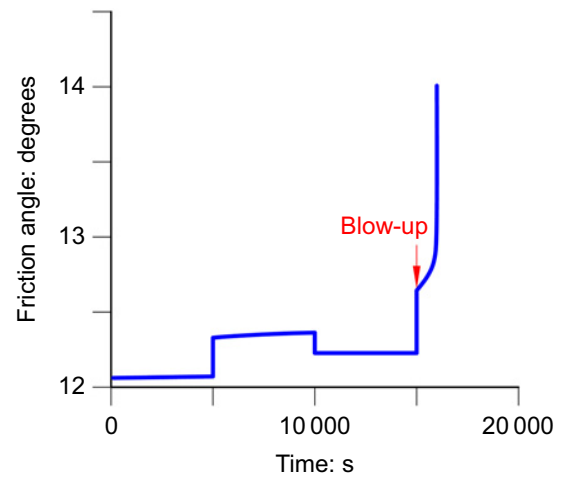

(e)

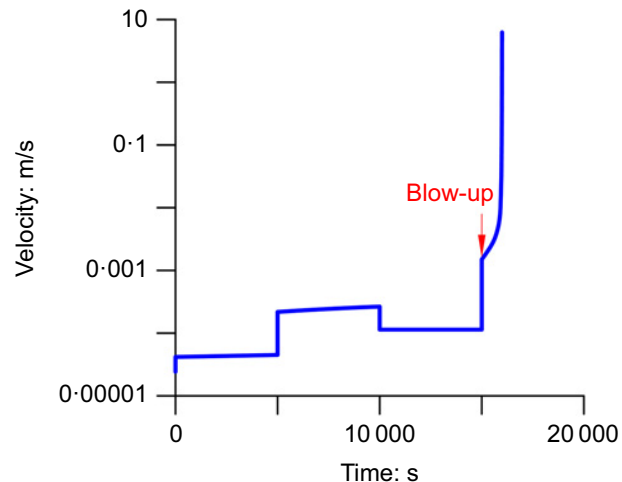

(b)

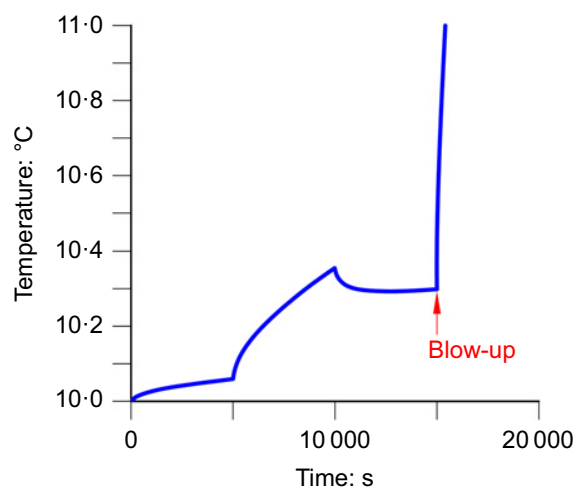

(d) 
capable of counteracting the loss of resistance forces associated with thermally induced excess pore water pressures.

This example is further extended to examine the combined effect of permeability, a dominant parameter, and the intensity of rate effects (explained by parameter $A$ ) on the transition from creeping to blow-up regimes. Consider the following $A$ values: $A=0$ (no rate effects) and two more values $\left(A=4 \cdot 7 \times 10^{-3}\right.$ and $\left.A=9 \cdot 4 \times 10^{-3}\right)$, whose effect on friction angle is given in Fig. 91 for a reference velocity equal to $6.4 \times 10^{-7}$. In both cases, rate effects are moderate. For the maximum $A$ value, friction angle increases $4 \%$, with respect to the static value, for a two orders of magnitude increase of shearing velocity.

The landslide is destabilised by imposing an increment of the dimensionless pore water pressure equal to $0 \cdot 0016$, equivalent to increasing the water level by $10 \mathrm{~cm}$. This involves a reduction of the safety factor from $\mathrm{SF}=1$ to $\mathrm{SF}=0.9978$. The calculated dimensionless sliding velocity varies with rate effect $(A)$ and the consolidation coefficient $(\Sigma)$ in the manner indicated in Fig. 92. This plot is conceptually similar to Fig. 73, which introduced the 'safe' and 'unsafe' states of the slope. When rate effects increase, the transition between the two conditions moves towards decreasing values of $\Sigma$. This is a positive consequence of rate effects. Even if their contribution to increase friction is small, they have a profound effect in reducing the scenarios for blow-up occurrence. $\Sigma$ is dominated by band permeability. Fig. 92 shows that a moderate rate effect $\left(A=4 \cdot 7 \times 10^{-3}\right)$ reduces in five orders of magnitude the critical permeability for the safe-unsafe transition.

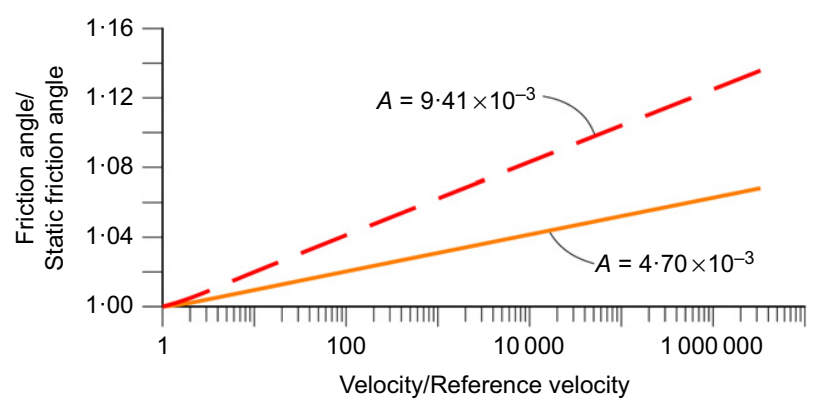

Fig. 91. Effect of parameter $A$ on the increase of friction angle with sliding velocity $\left(\right.$ reference velocity $=6.4 \times 10^{-7}$ )

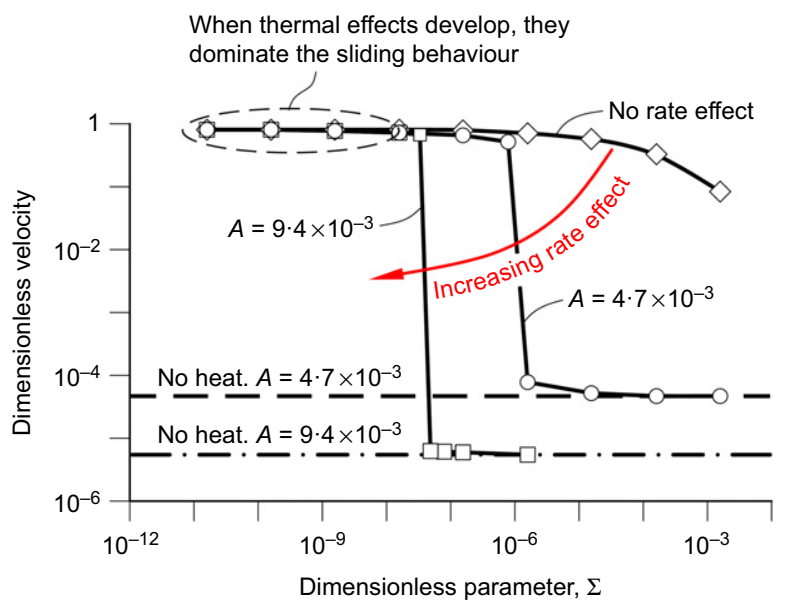

Fig. 92. Effect of the consolidation coefficient, $\Sigma$, on dimensionless sliding velocity for different values of the strain rate coefficient $\boldsymbol{A}$. Also indicated is the creeping velocity in the absence of heat effects
Once the slide enters the safe area, a creeping regime develops, which is close, in terms of velocity, to the case of no thermal interactions because excess pore pressures in the shear band dissipate sufficiently rapidly.

The question of when a creeping slide evolves towards blow-up conditions, raised above, is now considered. The answer remains in the adopted formulation for the problem, which explains the creep, thermal and mechanical interactions.

Consider now this calculated interaction for a large planar slide whose dimensions are inspired by the Vajont case. It is convenient to present results in terms of the dimensionless parameters controlling the coupled interactions.

The slope inclination $\left(9-8^{\circ}\right)$ and the friction angle $\left(12^{\circ}\right)$ are equal to the values adopted for the previous case. The slope is in strict equilibrium for a water surface position, $h_{\mathrm{w} 0}=106.08 \mathrm{~m}$. Now the depth of the failure surface is $D=240 \mathrm{~m}$. Calculations stop for a maximum runout of $2 D=480 \mathrm{~m}$. The landslide is triggered by a small increase in the water height, $h_{\mathrm{w}}$, which brings the safety factor down to $\mathrm{SF}=0.99$. In the absence of rate effects, the slide accelerates to a very high velocity within seconds.

Figure 93 highlights the effect of rate parameter $A$ on the creeping velocity and blow-up time of the slope for the same triggering conditions applied previously. Consider first the calculated creeping velocity in the absence of thermal interactions ('no heat'). The figure shows (right vertical axis) a decreasing creeping velocity after the trigger of the motion as $A$ increases. If thermal interactions are activated, the calculated creeping velocities increase by one or two orders of magnitude (their magnitude depends on the $A$ value considered in Fig. 93). This creeping velocity refers to the time immediately after the start of the instability.

However, one may suspect that blow-up conditions will develop in some cases if time increases. This situation is obviously more likely the smaller the value of $A$.

Figure 93 shows a number of points, along the 'THM creep velocity' curve, in which calculations were extended in time in search of blow-up conditions. They are more likely for low $A$ values (reduced rate effects). The figure shows (left vertical axis) the calculated time interval for the initiation of blow-up conditions. This interval increases fast as $A$ increases. The plot shows the position of an asymptotic $A$ value which may be accepted as a limiting value that separates the creeping behaviour from blow-up conditions.

A similar result could be expected if the attention is focused on parameter $\Sigma$, and therefore, on permeability. Permeability controls the development and dissipation of excess pore water pressures in the shear band for a given work input and rate effect on friction. A few runs of the coupled problem for a fixed value, $A=5.75 \times 10^{-4}$, and varying $\Sigma$, provided the results summarised in Fig. 94, which has the

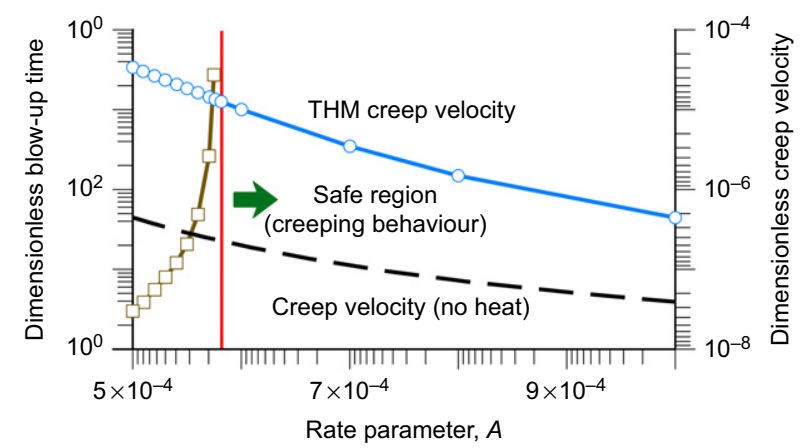

Fig. 93. Effect of rate parameter $A$ on dimensionless creeping velocity and blow-up time 


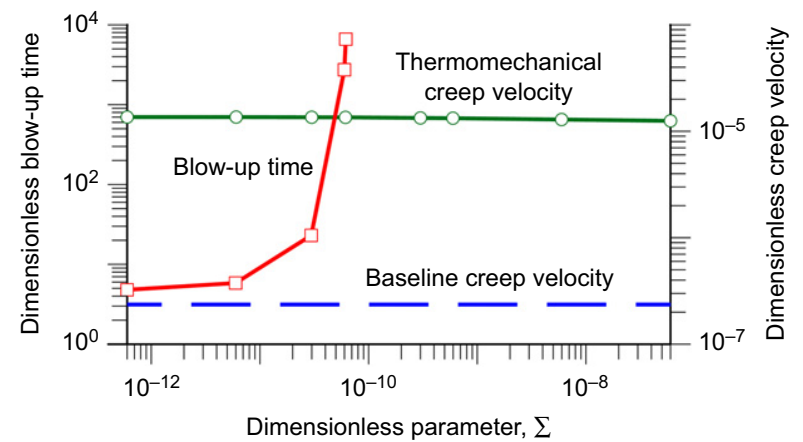

Fig. 94. Effect of consolidation parameter, $\Sigma$, on dimensionless creeping velocity and blow-up time

same structure as Fig. 93. The figure shows the calculated creeping velocities (right vertical scale) if thermal interactions are absent or activated. Changes in $\Sigma$ have essentially no effect on the creeping velocity. This is true for the initial stages of creep in the case when thermal effects are present. However, if the motion is followed in time, some values of $\Sigma$, associated with low permeability, lead to blow-up conditions. The relationship of blow-up time (right vertical scale) against $\Sigma$ is highly non-linear and tends to reach an asymptotic behaviour for a critical value of $\Sigma$ close to $\Sigma=6 \times 10^{-11}$. To the right of this critical value, the slide will remain in a creeping mode.

\section{Compound slides}

Compound geometries are common in nature. The cases of Cortes and Vajont landslides, described in the paper, are examples that could conceptually be interpreted as selfstabilising mechanisms because of the mass transfer between upper unstable and lower stabilising rock wedges. Rotational slides also share this property because of the decreasing driving moment during the motion.

Unlike planar motions, which never stop after the initial triggering, 'convex' compound slides should come to rest for some displacement. This section explores the combined effect of compound geometry, thermal interactions and rate effects on friction.

Figure 95 defines the simple compound geometry used in the analysis. The mechanical interaction between the upper and lower blocks is reduced to a hinged bar. There is, however, a water level active on the lower block and a provision for a mass transfer between the two blocks.

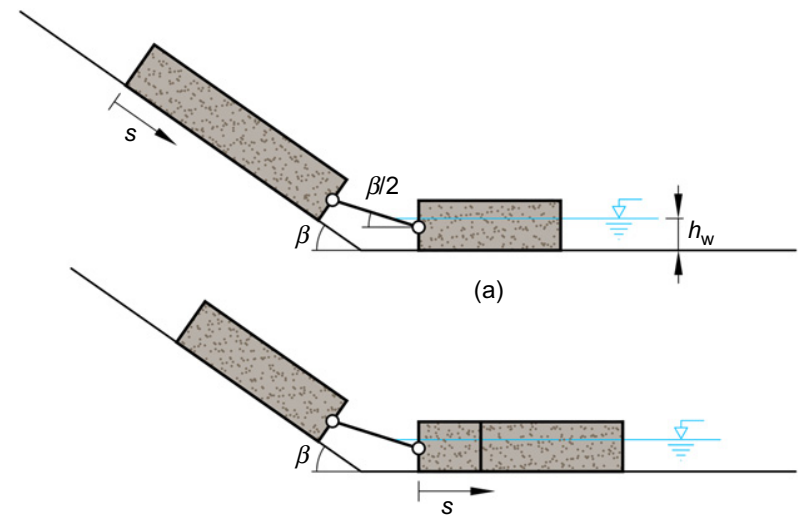

(b)

Fig. 95. A simplified two-block sliding mechanism for a selfstabilising compound landslide
Alonso et al. (2010) describe this simple mechanical approximation to Vajont landslide. Table 5 summarises the geometry and Table 4 provides the remaining parameters, with the exception of shear band thickness, which is now zero.

Modelling this case follows previous steps. The solution now requires the mass and energy balance in a normal direction to the sliding surfaces of the two blocks as well as the dynamic equilibrium of the entire mechanism. A $1 \mathrm{~m}$ increase $\left(\Delta \hat{p}_{\mathrm{wh}}=0.04\right)$ of the water level acting on the lower block triggers the landslide. Fig. 96 summarises the calculated response of the slide for two cases: no rate effects and $A=4 \cdot 7 \times 10^{-3}$ (Fig. 91 provides its effect on friction).

The maximum runout considered in calculations is $2 D=50 \mathrm{~m}$. In the absence of rate effects (Fig. 96(a)), $\Sigma$ values below $1.6 \times 10^{-5}$ result in blow-up conditions. At higher $\Sigma$ values the slide is able to stop because of the changing geometry. When rate effects on friction are present in the formulation (Fig. 96(b)), the slide stops even if the $\Sigma$ coefficient is rather low $\left(1.6 \times 10^{-5}\right)$. A comparison of Figs 96(a) and 96(b) shows the relevant role of rate effects

Table 5. Geometry of the compound slide (Fig. 95)

\begin{tabular}{l|l}
\hline & Value \\
\hline Upper block & \\
$L_{10}$ & $60 \mathrm{~m}$ \\
$D$ & $25 \mathrm{~m}$ \\
$\beta$ & $37^{\circ}$ \\
Lower block & \\
$L_{20}$ & $120 \mathrm{~m}$ \\
$D$ & $25 \mathrm{~m}$ \\
Height of water for strict equilibrium, $h_{\mathrm{w} 0}$ & $15 \mathrm{~m}$ \\
\hline
\end{tabular}

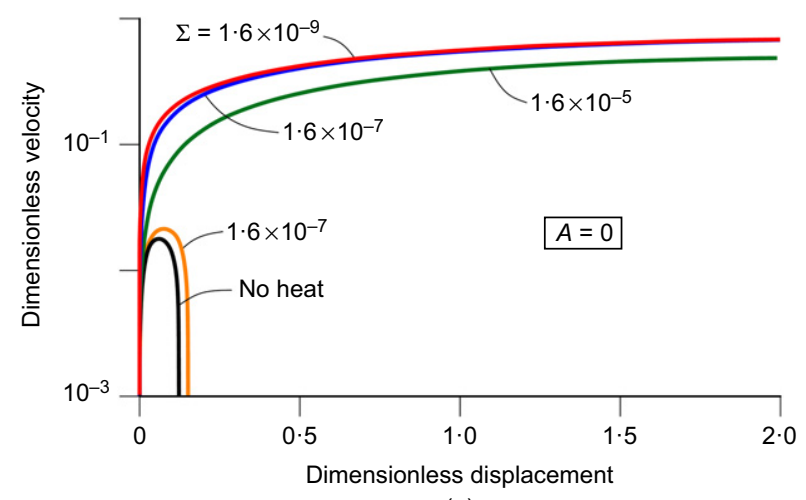

(a)

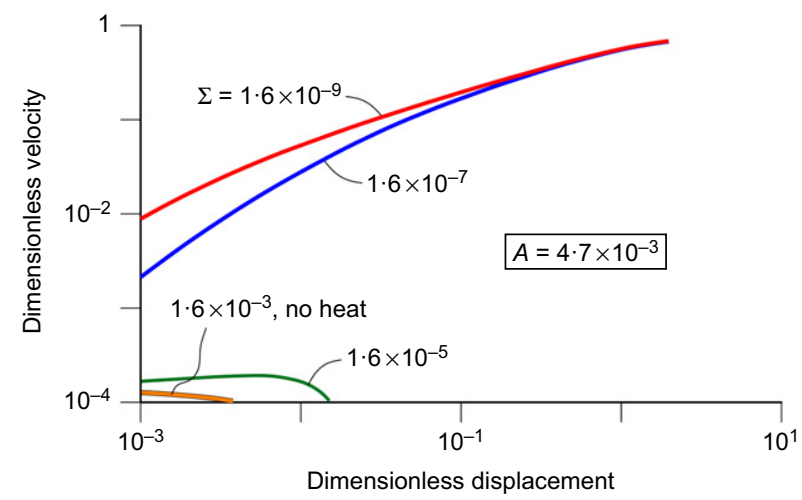

(b)

Fig. 96. The motion of the compound for different coefficients of consolidation, $\Sigma$ : (a) no rate effects on friction and (b) rate parameter $A=4.7 \times 10^{-3}$ 
to restrict blow-up conditions to a narrower range of the consolidation coefficient.

Figure 96 also indicates that once blow-up conditions develop, the slide geometry and rate effects on friction are not capable of avoiding large velocities and runouts.

A final point concerns the preservation of rate effects on friction when shearing velocity increases to high values. The logarithmic law adopted in this work rapidly reduces the rate of friction increase as shearing velocity increases. However, experimental results, namely, on rock contacts (Di Toro et al., 2011) indicate the presence of mechanisms reducing basic shearing resistance (including thermal pressurisation of water). A physical mechanism reducing friction is the 'flash heating' or thermally induced melting of micro-contacts. In the case of saturated clays, thermal pressurisation of water is present at relatively high shearing rates, and this makes it difficult to isolate other mechanisms, whether enhancement or reduction of basic drained friction.

The next step in the analysis of creep-fast landslide interaction is the generalisation of the formulation for arbitrary geometries and dynamics of the motion. The next section describes this interaction.

\section{Creep and thermal interactions in landslide analysis. Canelles landslide (Spain)}

In the summer of 2006 a large landslide $\left(4.0 \times 10^{6} \mathrm{~m}^{3}\right)$ reactivated on the left bank of Canelles reservoir. A long continuous tension crack ( 5 to $10 \mathrm{~cm}$ wide) limited the landslide on the land side. The toe of the slide remained under the reservoir water level. A rapid drawdown of reservoir water level, following a 4 year period of high water levels, triggered the instability. Fig. 97 shows a central cross-section of the landslide. The sliding surface was located in a continuous high-plasticity clay layer of Garumnian age (the transition from Secondary to Tertiary geological ages). Above and below this layer, sequences of hard but folded limestones and sandstones complete the geological profile. The figure also shows the very large drawdown $(72 \mathrm{~m})$ experienced in the period from April 2004 to August 2005.

The slide reactivation raised the question of a possible rapid motion of the landslide mass and an associated reservoir tsunami. Pinyol et al. (2012) describe the case and the procedure followed to provide an answer.

Piezometers installed in the clay layer, below and above the sliding surface, provided a useful record of pore pressures for one and a half years following their installation at the end of 2007. During this period, the water level in the reservoir experienced significant changes, which allowed good validation of a finite-element hydraulic model of the reservoir. A back-analysis of the fast drawdown of August 2005, and subsequent evolution of pore water pressures, by means of the finite-element code Code-Bright (Olivella et al., 2019), provided relevant information on the field permeability of the Garumnian clay.

Calculated pore pressures along the sliding surface allowed an MPM THM analysis of the landslide (Alvarado et al., 2019). The conclusion was that the landslide could accelerate and invade the reservoir at a calculated maximum speed of $8 \mathrm{~m} / \mathrm{s}$. Fig. 98 shows the calculated motion (velocity plotted against displacement of the landslide toe).

Figure 99 shows contours of calculated displacement, deviatoric strains, temperature and water pressure increments at the end of the runout. Canelles is also an example of self-stabilising geometry.

However, Canelles never failed! It is a case located in the 'unsafe region' in Fig. 75 because of the high plasticity $\left(w_{\mathrm{L}}=54-57 \%\right.$; PI $\left.=26-31 \%\right)$, low permeability $\left(10^{-10} \mathrm{~m} / \mathrm{s}\right)$, consistent with oedometer tests results, and the high continuity of the Garumnian clay.

The next step to interpret Canelles landslide response was to incorporate strain rate effects in the analysis.

Wedage et al. (1998) describe a strain-rate-dependent elastoplastic Mohr-Coulomb constitutive model, which is

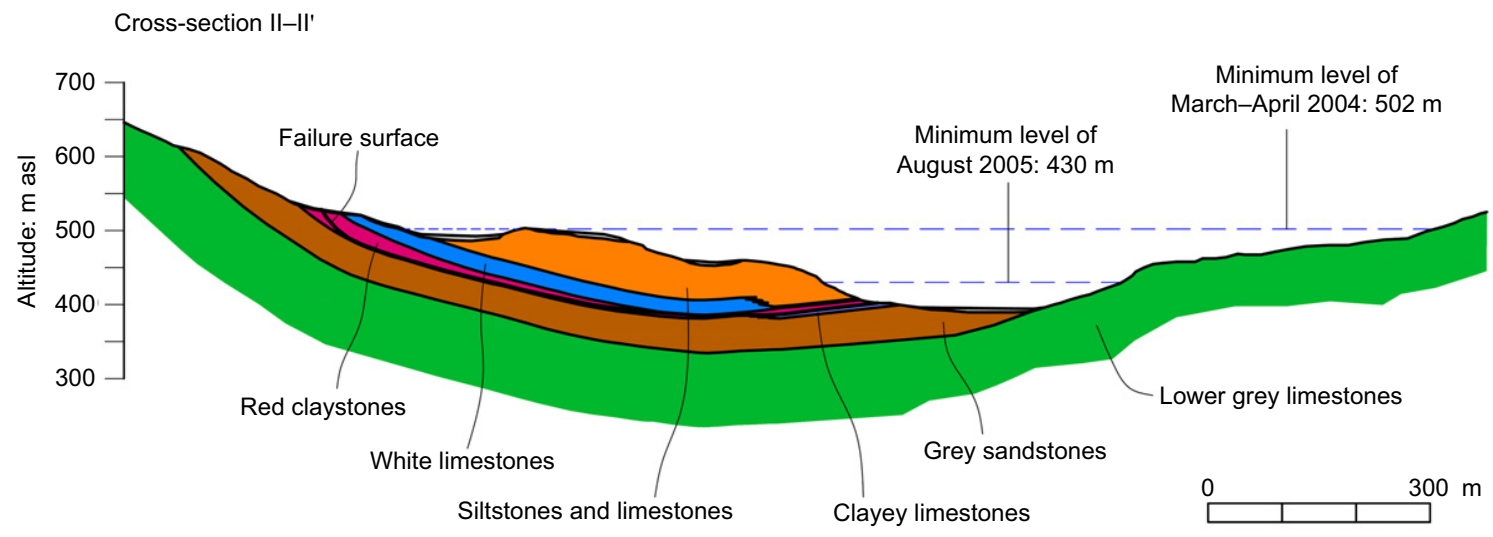

(a)

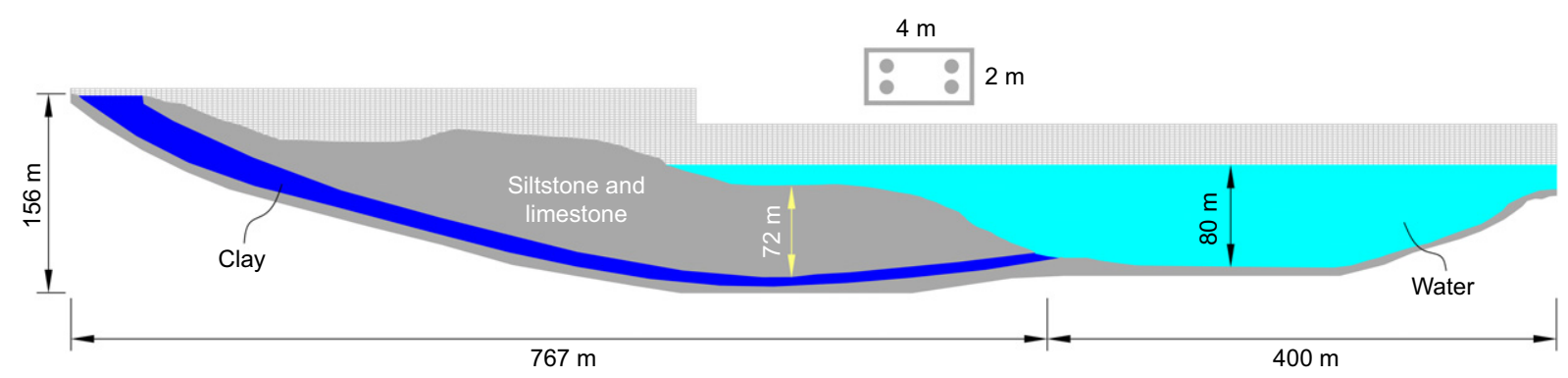

(b)

Fig. 97. (a) Central cross-section of Canelles landslide and (b) MPM model 
applicable for clays in its residual state. The authors define the rate-dependent field function and derive an incremental stress-strain relationship. This model was included in the MPM Geopart code.

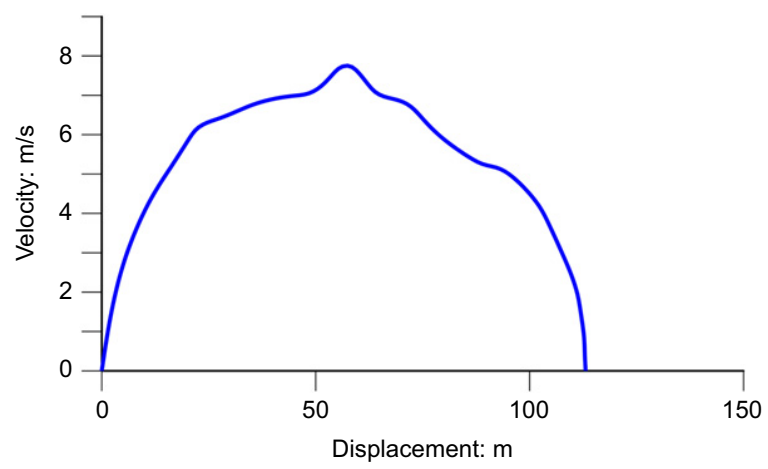

Fig. 98. The calculated motion of Canelles landslide after reactivation by a rapid drawdown

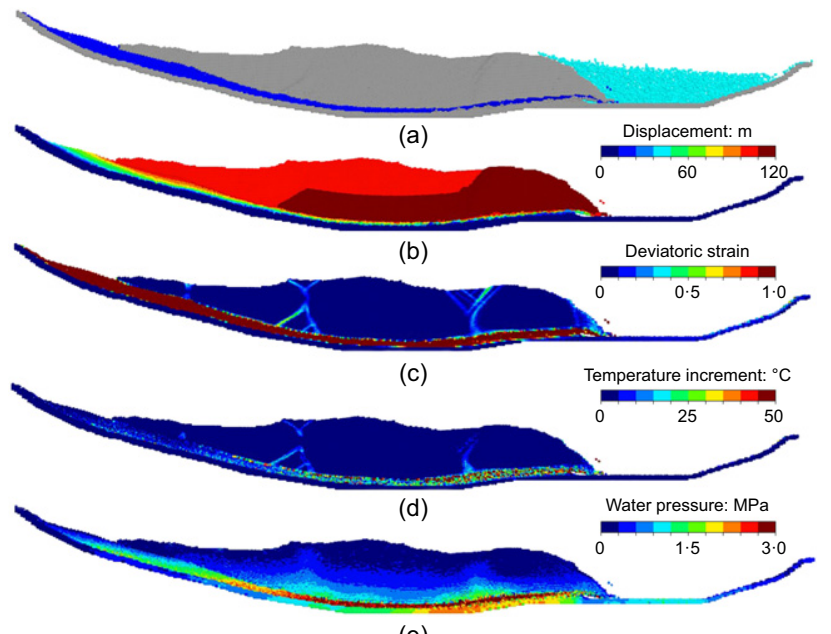

(e)

Fig. 99. THM analysis of Canelles landslide. Results given at the end of the motion: (a) geometry; (b) contours of displacement; (c) deviatoric plastic strain; (d) temperature increment; and (e) excess pore pressures
The relationship adopted here for the effective friction angle, $\phi^{\prime}$, in terms of a residual friction angle, $\phi_{\text {res }}^{\prime}$, for static or low strain rate and an additional term accounting for rate effects, is

$$
\phi^{\prime}=\phi_{\mathrm{res}}^{\prime}+\bar{\phi}^{\prime}\left(1-\mathrm{e}^{-\alpha \dot{\varepsilon}_{\mathrm{d}}^{\mathrm{p}}}\right)
$$

where $\bar{\phi}^{\prime}$ is the maximum increase in friction angle due to rate effects; $\dot{\varepsilon}_{\mathrm{d}}^{\mathrm{p}}$ is the deviatoric plastic strain rate; and $\alpha$ is a parameter. Equation (60) deviates from equations (13)-(15) discussed previously because it bounds the maximum increase in strain rate effects. It is probably better adapted to deal with high shearing rates, present in landslides, because of the lack of reliable information on rate effects on friction for fast shearing velocities.

Ring shear tests for relatively low confining stresses $(100-250 \mathrm{kPa})$ provided a residual friction in the range $12-13^{\circ}$. Normal effective stresses confining the sliding surface reach much higher values (around $800 \mathrm{kPa}$ ), which suggested a lower value $\phi_{\text {res }}^{\prime}=11^{\circ}$ in calculations. Fig. 100 shows the strain rate effects on $\phi^{\prime}$ for varying $\bar{\phi}^{\prime}$ and $\alpha$.

The analysis performed describes the situation at the end of the rapid drawdown triggering the instability. Pore water pressures calculated by the Code-Bright finite-element code provided an initial distribution for the MPM analysis. The water level in the reservoir reproduced actual field conditions at that time. Table 6 summarises the clay and rock parameters for the MPM analysis.

Table 3 lists the thermal properties for water and solid particles of clay or rock. An elastic material having a bulk modulus $K=2200 \mathrm{MPa}$ and a negligible shear stiffness simulates the reservoir water.

\section{Results}

The back-analysis of the landslide reactivation by means of a limit equilibrium procedure led to a residual friction angle of the sliding surface of $11.5^{\circ}$. The drawdown of August 2006 resulted in a lack of equilibrium for this residual friction.

Strain rate effects on friction provide a resisting force increasing non-linearly with the sliding velocity. If, for a given change in boundary conditions, a new dynamic equilibrium exists for a new creeping velocity, 'failure' is prevented. Otherwise, there will be an initial stage of slide acceleration followed by a propagation of the motion, dictated by inertia forces and changes in geometry. The consideration

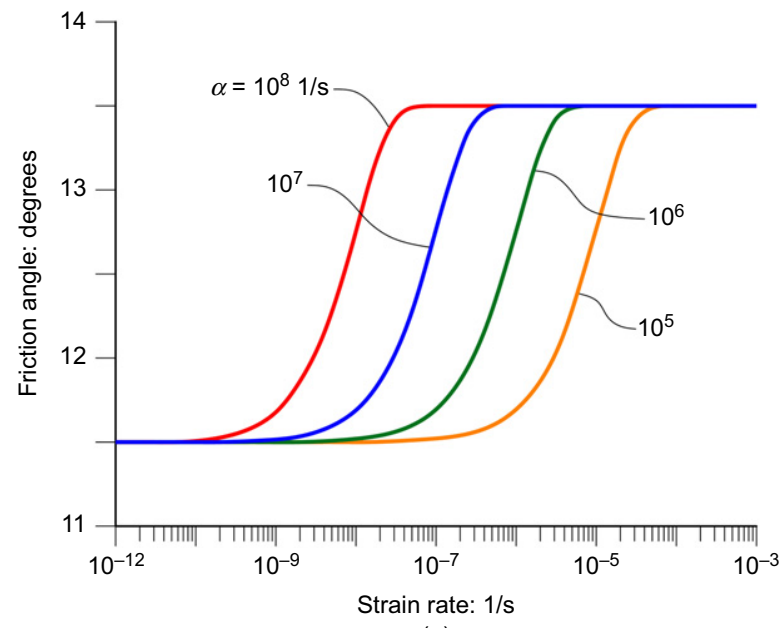

(a)

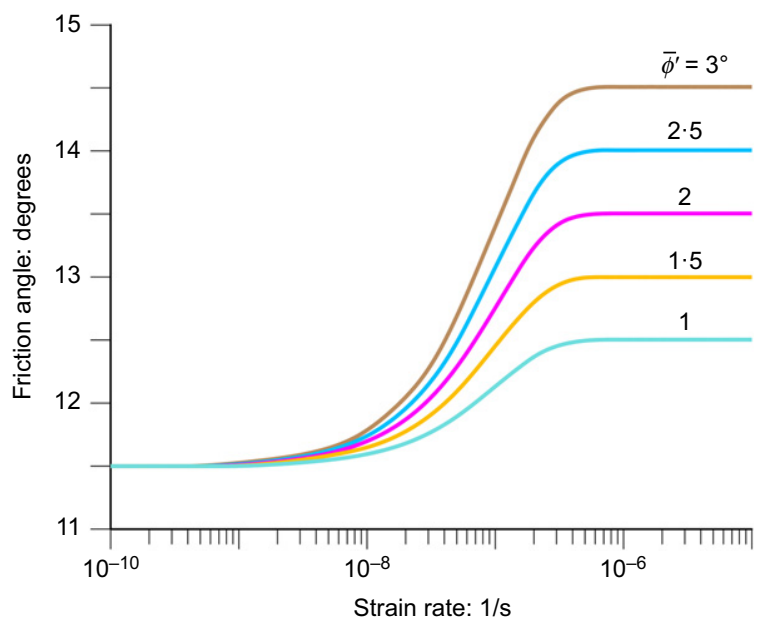

(b)

Fig. 100. Increase of residual friction angle with strain rate: effect of parameters $\alpha$ (a) and $\bar{\phi}^{\prime}$ (b) (equation (60)) 
Table 6. Soil/rock parameters for the analysis of Canelles landslide

\begin{tabular}{|c|c|c|c|}
\hline Property & Symbol & Value & Units \\
\hline \multicolumn{4}{|l|}{ Garumnian clay } \\
\hline Porosity & $n_{\mathrm{c}}$ & $0 \cdot 2$ & - \\
\hline Permeability & $K_{\mathrm{c}}$ & $10^{-10}$ & $\mathrm{~m} / \mathrm{s}$ \\
\hline Young's modulus & $E_{\mathrm{c}}$ & 50000 & $\mathrm{kPa}$ \\
\hline Poisson's ratio & $v_{\mathrm{c}}$ & $0 \cdot 3$ & - \\
\hline Static residual friction angle & $\phi_{\text {res }}^{\prime}$ & $11 \cdot 5$ & degrees \\
\hline $\begin{array}{l}\text { Rate effects. Maximum } \\
\text { increase of friction }\end{array}$ & $\phi^{\prime}$ & 2 & degrees \\
\hline $\begin{array}{l}\text { Controls rate of increase of } \\
\text { friction with plastic } \\
\text { shearing rate }\end{array}$ & $\alpha$ & $10^{7}$ & $1 / \mathrm{s}$ \\
\hline Shear band thickness & $L_{\mathrm{Bc}}$ & 10 & $\mathrm{~mm}$ \\
\hline \multicolumn{4}{|l|}{ Rock } \\
\hline Porosity & $n_{\mathrm{r}}$ & $0 \cdot 3$ & - \\
\hline Permeability & $K_{\mathrm{r}}$ & $10^{-6}$ & $\mathrm{~m} / \mathrm{s}$ \\
\hline Young's modulus & $E_{\mathrm{c}}$ & 250000 & $\mathrm{kPa}$ \\
\hline Poisson's ratio & & $0 \cdot 3$ & - \\
\hline Peak/residual friction angle & $\phi_{\text {peak }}^{\prime} / \phi_{\text {res }}^{\prime}$ & $35 / 30$ & degrees \\
\hline Peak/residual cohesion & $c_{\text {peak }}^{\prime} / c_{\text {res }}^{\prime}$ & $1 / 0 \cdot 2$ & $\mathrm{MPa}$ \\
\hline Shear band thickness & $L_{\mathrm{Br}}$ & 100 & $\mathrm{~mm}$ \\
\hline
\end{tabular}

Table 7. Cases to analyse the interaction between strain rate effects on friction (creep mechanism) and the thermal pressurisation of the sliding surface (THM)

\begin{tabular}{l|l|l|l}
\hline Case & Creep & THM & Observations \\
\hline 1 & No & No & $\begin{array}{l}\text { Triggering action, changes in } \\
\text { geometry and strain softening (if } \\
\text { present) define the dynamics of the } \\
\text { motion } \\
\text { As in case 1, but creep is an added } \\
\text { effect, which restrains the landslide } \\
\text { motion prior to failure (if other } \\
\text { causes allow it) } \\
\text { Explains a rapid failure once strict } \\
\text { equilibrium is lost. Rapid failure is } \\
\text { mainly a consequence of the low } \\
\text { permeability of the sliding surface } \\
\text { and its vicinity in the case of thin } \\
\text { shear bands (a possibility in clays) } \\
\text { Two physical phenomena acting in } \\
\text { opposite directions. Creep effects } \\
\text { tend to prevent the development of } \\
\text { 'blow-up' conditions }\end{array}$ \\
\hline
\end{tabular}

of thermal water pressurisation in the sliding surface adds a potential mechanism for very rapid sliding, because of the rapid drop of effective confining stress. If the available shear strength reduces to zero or very small values, geometric changes of the landslide have a very limited effect to restrict the motion.

The interaction between the creep/strain rate effect phenomena and the development of blow-up conditions is not straightforward and it is convenient to analyse it in the light of modelling results.

Consider the four combinations described in Table 7 . Previous analyses described in the paper belong to a particular case defined in Table 7. The specific landslides and simplified examples are grouped in Table 8. The table indicates the name of the landslide, the academic examples, the figures which illustrate the cases and the calculation procedure. The academic examples were formulated in analytical terms and the resulting dynamic equations were solved by finite-difference techniques. In most of the field cases analysed by the MPM (Aznalcóllar, Selborne, Vajont, Canelles) the clay formation or the rock masses involved were described by a strain-softening elastoplastic MohrCoulomb material. In the last landslide analysed (Canelles), the effect of alternative hypotheses is compared in the following paragraphs.

Figure 101 shows the calculated response of Canelles landslide after the sudden drawdown, which triggered the initiation of the motion. In case 1, the landslide stabilises because of the mass transfer between the upper zones of the slide, resting on a steep failure surface, and the lower ones. If creeping effects add to the previous case, the 'viscous-like' additional resisting force reduces the final displacement to a small amount. In both cases, the final displacement is small $(4-5 \mathrm{~cm})$, which is close to the observed opening of the surface crack developed after the rapid drawdown.

Case 3 shows blow-up conditions after the initiation of failure. This is an expected result because of the low permeability of the Garumnian clay layer, which hosts the failure surface. Case 4 is the most interesting one. In short, strain rate effects are capable of counteracting the selffeeding mechanism of heat-induced pore pressures in the sliding surface and therefore the slide comes to rest after $6 \mathrm{~cm}$ of final displacement.

In case 3 (blow-up conditions), the calculated displacements eventually stop after a runout of about $65 \mathrm{~m}$ (Fig. 102). The geometrical evolution of the landslide, which implies the mass transfer towards a more stable

Table 8. A classification of landslide cases and stability analysis described in the paper

\begin{tabular}{|c|c|c|c|}
\hline Case & Landslide/example analysed & Figures & Method of analysis \\
\hline $\begin{array}{ll}1 & \\
& \text { No creep } \\
& \text { No THM } \\
& \\
2 & \\
& \text { Creep } \\
& \text { No THM } \\
3 & \\
& \text { No creep } \\
& \text { THM }\end{array}$ & $\begin{array}{l}\text { - Aznalcóllar landslide } \\
\text { - Selborne slide } \\
\text { - Sensitivity analysis (Selborne based) } \\
\text { - Vajont landslide } \\
\text { - Example. Planar slide } \\
\text { - Vallcebre landslide } \\
\text { - Example. Planar slide } \\
\text { - Vajont geometry (scale:1/10) } \\
\text { - Example. Simple slope } \\
\text { - Vajont landslide } \\
\text { - Canelles landslide } \\
\text { - Example. Planar slide } \\
\text { - Example. Compound slide } \\
\text { - Canelles landslide }\end{array}$ & $\begin{array}{l}28 \text { to } 30 \\
32 ; 35 \text { to } 40 \\
41 \text { to } 44 \\
59 ; 61 \\
50 ; 52 \\
54 ; 55 \\
67 ; 70 \text { to } 73 \\
59 ; 74 \text { to } 75 \\
76 \text { to } 78 ; 81 \text { to } 84 \\
86 \text { to } 88 \\
97 \text { to } 99 \\
67 ; 90 \text { to } 94 \\
95 ; 96 \\
97 ; 100 \text { to } 106\end{array}$ & $\begin{array}{l}\text { MPM } \\
\text { MPM } \\
\text { MPM } \\
\text { Analytical/FD } \\
\text { Analytical/FD } \\
\text { Analytical/FD } \\
\text { Analytical/FD } \\
\text { Analytical/FD } \\
\text { MPM } \\
\text { MPM } \\
\text { MPM } \\
\text { Analytical/FD } \\
\text { Analytical/FD } \\
\text { MPM }\end{array}$ \\
\hline
\end{tabular}

MPM, material point method; FD, finite difference. 
configuration, explains the final runout. Fig. 102(b) also shows the calculated velocity. A peak velocity close to $1.5 \mathrm{~m} / \mathrm{s}$ is reached $7 \mathrm{~s}$ after the instant of triggering. At the scale of displacements and velocities of Fig. 102, cases 1, 2 and 4 are not distinguishable in any detail.

It is also interesting to examine the pore pressures developed at the sliding surface for cases 3 and 4 , which incorporate the thermal pressurisation (Fig. 103). Under full blow-up conditions, high excess pore pressures develop (Fig. 103(a), case $3)$. The intensity of pore pressures at points along the failure surface (P1, P2, P3) reflect the intensity of confining stress and, therefore, the rate effect of work input into the shearing band. At point $\mathrm{P} 2$, which has a significant rock cover, pore pressures reach higher values compared with the crest and toe positions. This is also true in case 4 (creep + THM activated), in relative terms. Now, the intensity of the excess pore pressure developed is much smaller because the landslide velocity and, therefore,

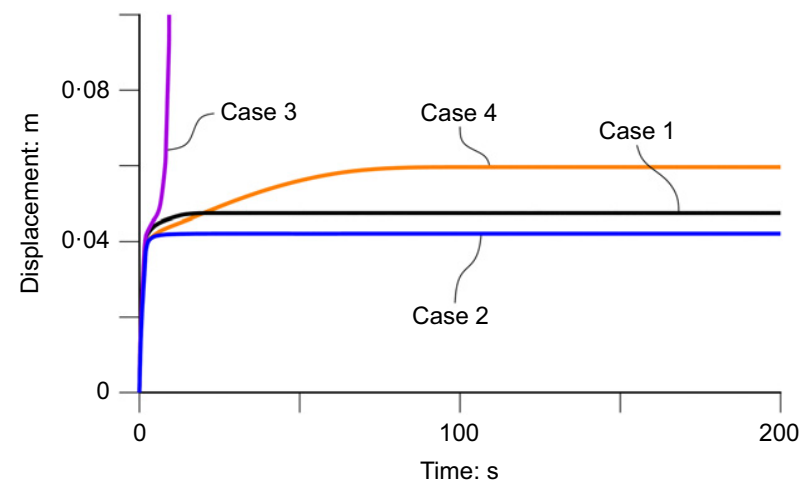

Fig. 101. MPM analysis of Canelles landslide. Runout for the cases defined in Table 7

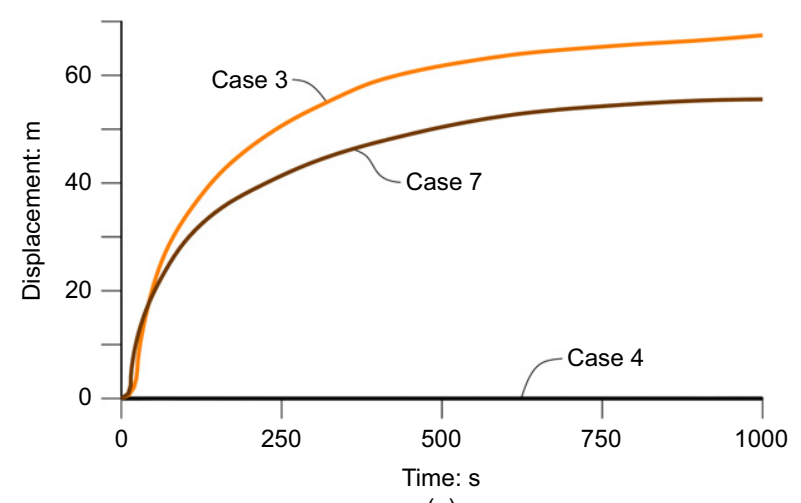

(a)

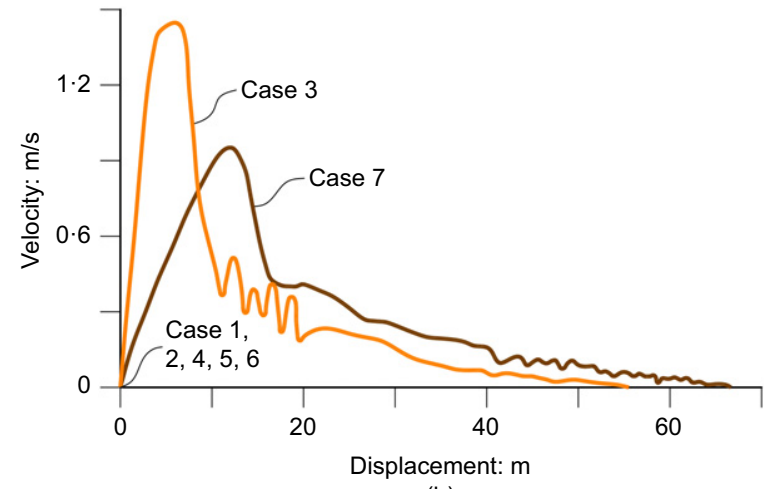

(b)

Fig. 102. MPM analysis of Canelles landslide: (a) calculated runout and (b) velocities for all the cases explored the dissipated plastic work is small, compared with the previous case.

Figure 104 shows the deformation of the landslide after failure and runout for cases 3 and 4 . Note that in case 3 (no creep, THM) the landslide does not displace as a solid body, but internal straining is a consequence of the rock stiffness/strength and the roughness of the sliding surface.

Some limited strain softening on strength is suspected in a landslide that has remained non-active during a long (but unknown) time. A friction angle described as follows

$$
\phi^{\prime}=\phi_{\text {res }}^{\prime}+\left(\phi_{\text {peak }}^{\prime}-\phi_{\text {res }}^{\prime}\right) \mathrm{e}^{-\eta \varepsilon_{\mathrm{d}}^{\mathrm{p}}}+\bar{\phi}^{\prime}\left(1-\mathrm{e}^{\alpha \varepsilon_{\mathrm{d}}^{\mathrm{p}}}\right)
$$
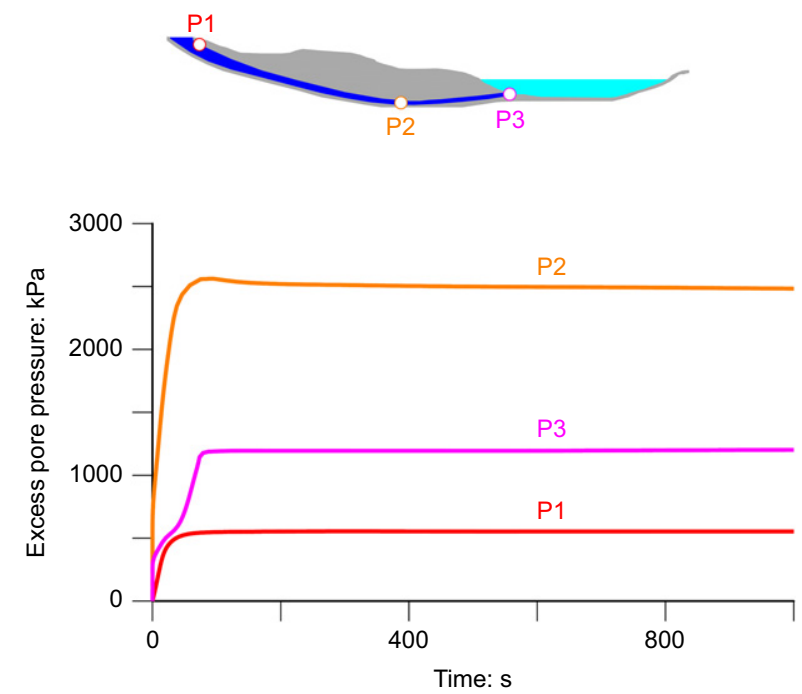

(a)

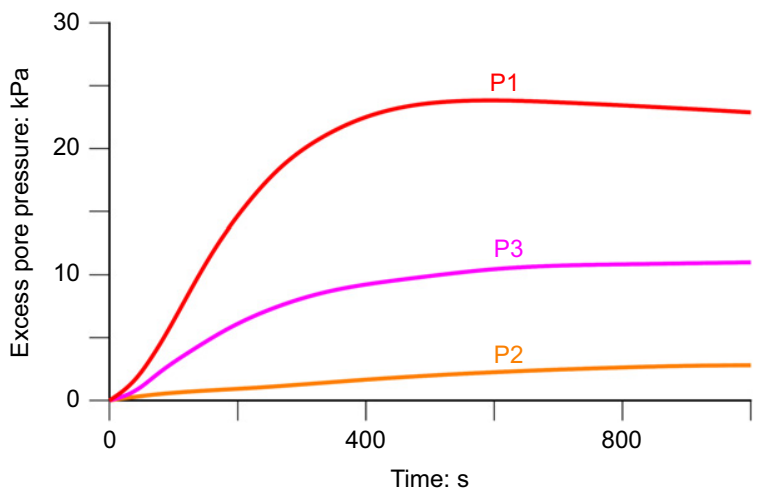

(b)

Fig. 103. Excess pore water pressure at three points located in the sliding surface for (a) case 3 and (b) case 4

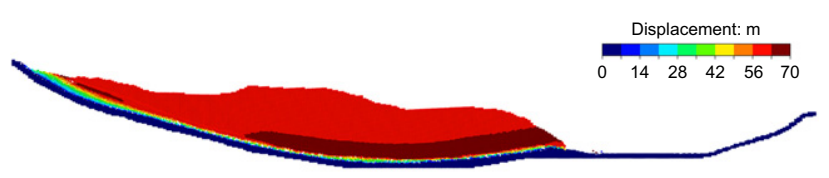

(a)

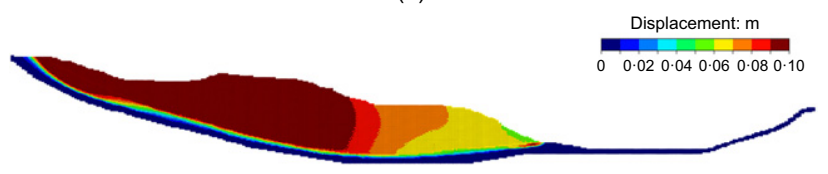

(b)

Fig. 104. Accumulated displacement and deformed geometry at the end of the motion: (a) case 3 and (b) case 4 
introduces the combined effect of strain softening and rate effects on friction. Parameter $\eta$ defines the rate of friction reduction with accumulated plastic deviatoric strain.

Three new cases provide additional information. The idea was to explore the effect of a limited friction strain softening around the average, as indicated below. All of them correspond to case 4 (creep and THM interaction)

(a) case 5: $\phi^{\prime}=12-11^{\circ}$ (peak-residual)

(b) case 6: $\phi^{\prime}=13-10^{\circ}$

(c) case 7: $\phi^{\prime}=12-10^{\circ}$

In all cases, a common strain-softening parameter $\eta=50$ describes the rate of decrease of strength from peak to residual friction.

Figure 105 completes the previous Fig. 101 with the three new cases. It provides the calculated displacements in time for the strain-softening cases. Cases 5 and 6 lead to the smallest runout. However, case 7 develops a blow-up situation. The final run-out for case 7 is shown in Fig. 102(a). The slide accelerates in the manner indicated in Fig. 102(b) and reaches a maximum velocity of $0.92 \mathrm{~m} / \mathrm{s} 12 \mathrm{~s}$ after landslide triggering. Note that in all cases the maximum increase of friction, induced by strain rate effects, is $2^{\circ}$. The actual friction developing depends on the combined effect of strain rate and strain softening. Both act in opposite senses.

Observing the evolution of operating friction angle (Fig. 106) provides a clue for the different behaviour of cases 7 and 5 . In case 5 the initial increase in sliding velocity mobilises the strain rate effects and the effective friction reaches a maximum of around $13 \cdot 5^{\circ}\left(1 \cdot 5^{\circ}\right.$ above the peak friction angle). As time increases, the maximum friction

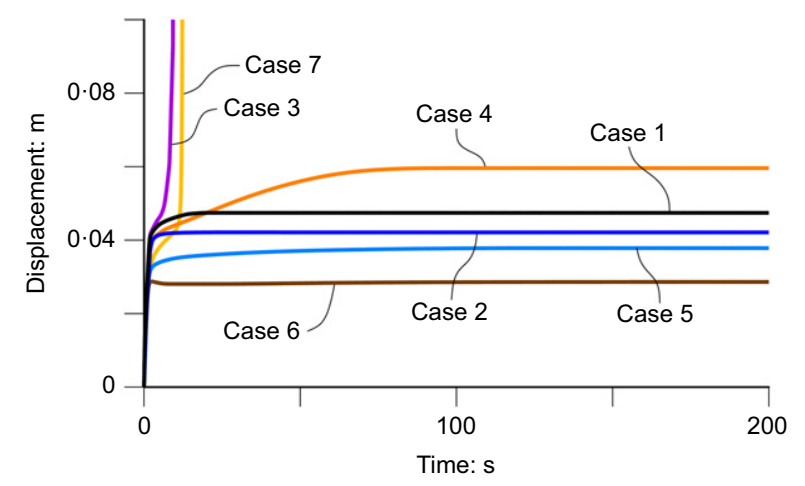

Fig. 105. MPM analysis of Canelles landslide. Evolution of displacement for all cases defined

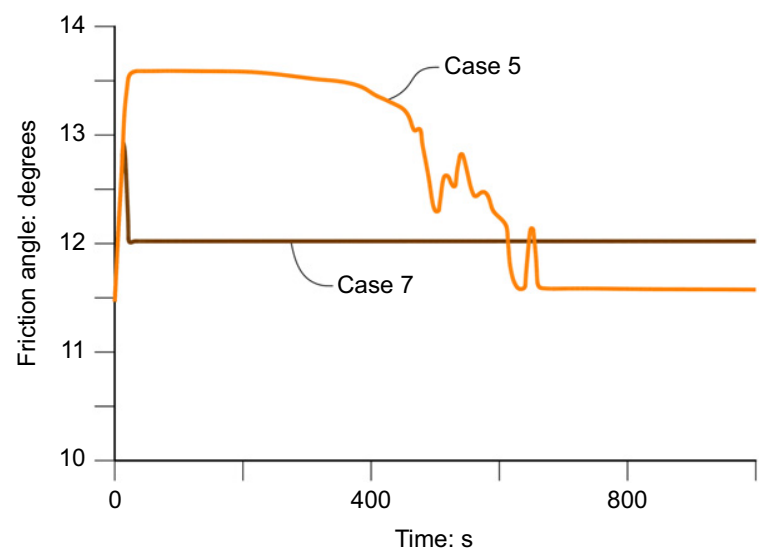

Fig. 106. Friction angle evolution for cases 5 and 7 decreases progressively because of the reduction of the landslide velocity, which is a consequence of a more stable configuration of the landslide. It eventually reaches a constant value of $11.5^{\circ}, 0.5^{\circ}$ above the residual strength.

In case 7 the initial stage is similar to the previous case: an increase in effective friction above the peak, because of strain rate effects. However, the strain-softening effect is now more pronounced $\left(12^{\circ}\right.$ drops to $10^{\circ}$ in case 7 , compared with a reduction from $12^{\circ}$ to $11^{\circ}$ in case 5) and the effective friction drops fast to $12^{\circ}, 2^{\circ}$ above the residual. This friction is now unable to prevent the fast development of excess pore pressures and the rapid acceleration of the slide. The rate effect on friction is limited to a maximum value of $2^{\circ}$, when velocity increases, and this effect explains the operating friction of $12^{\circ}$ during the fast motion of the slide.

Case 7 illustrates, at the scale of the landslide, the intricate relationships among the physical phenomena controlling the available strength on the failure surface: strain rate, thermal interactions and strain softening.

\section{CONCLUSIONS AND MAIN CONTRIBUTIONS}

The paper sets out the problem of determining the evolution of soil or rock masses once static stability conditions are lost. This scenario is a widespread occurrence in nature but it is also the result of construction works.

More specifically, the main issues to be concerned about are the mass, velocity and runout of landslides. This information contributes directly to expected damage of utilities, civil engineering infrastructure and living creatures.

Landslide phenomena and morphological features are extensive. Modern landslide classifications help also to understand the deformation mechanisms (Hungr et al., 2014).

The work reported here refers to a class of motions explained by the presence of sliding surfaces where shear strains concentrate. Shear strain localisation is a general mode of failure of pressure-sensitive elastoplastic materials, such as soils and rocks. Among the features of the shear band, in particular, their thickness is a property associated with the material microstructure and, therefore, it has been accepted as a material property. Phenomena taking place in shear bands during the motion of a landslide provide a starting point for the analysis reported here.

Field observations of landslides (a term used in its widest sense) indicate that mechanisms other than shear strain localisation are present. Major re-working of moving soil or rock masses result in flow-like motions. This category of landslides is outside the scope of the paper.

In geotechnical practice, but also from a theoretical perspective, it is useful to distinguish first-time failures from re-activation of ancient slides. Slow, creeping motions are often the result of a reactivation.

In the first case, the issue of progressive failure is often unavoidable because of the strain-softening behaviour, after a peak strength, observed in strain-controlled tests. This behaviour is also a consequence of the development of shear banding.

In slow-moving, creeping slides, a key issue is the expected evolution of the landslide and the prospects of a catastrophic destructive event. Explaining the sudden acceleration and high velocities of some landslides is not an easy task from the perspective and understanding offered by classical soil mechanics. However, a detailed analysis of physical phenomena taking place in shear bands offers an explanation and the possibility of developing predictive models.

The paper covers the dynamic behaviour of landslides at the start of the motion and during the post-failure event. The discussion follows two steps: (a) simple geometries (planar, interacting wedges) and (b) a generalisation to arbitrary 
geometries. This part relies on the capabilities offered by the MPM. Whenever possible, model predictions are compared against observations in real cases.

\section{First failures}

Landslides are essentially stress-controlled events. Under these circumstances, the failure of a brittle material results in an accelerated deformation. This is true in a stressed 'point'. In a larger domain, strain-softening behaviour leads to a progressive failure mechanism, which terminates also in an accelerated motion.

Two documented landslides, the Aznalcóllar dam failure and the Selborne experiment, provided field data to investigate the triggering mechanism and the subsequent runout of the unstable soil mass. In both cases, the failure involved the progressive failure of overconsolidated, brittle, high-plasticity clays of tertiary age. Laboratory tests provided peak and residual strength parameters.

Clay brittleness and the forward construction method adopted for Aznalcóllar dam explain the planar geometry of the failure surface and its position. The MPM analysis matched the after-failure runout. Also shown in the paper is the good correspondence between the measured and calculated complex shearing banding developed in the passive zone of the slide.

In Selborne, the strain-softening MPM model provided a reasonably good representation of the interpreted progressive failure, by means of inclinometer data, of the rotational slide. The model also went into the after-failure accelerated motion. The model reproduced correctly the available information of the runout of a few points distributed on the slope surface.

A relevant conclusion of the two cases is that a single set of constitutive parameters determined in standard geotechnical tests explains the static pre-failure development of progressive failure and the subsequent dynamic behaviour.

The relationship between runout and soil brittleness was explored by conducting a series of parametric exercises involving the simple geometry of an excavated slope. In this sensitivity analysis, the Selborne slope geometry and the triggering mechanism (an increase in pore water pressure) inspired the analysis performed. A strain-softening elastoplastic Mohr-Coulomb model defined the soil brittleness. The slide runout, defined as the distance between the toe of the original slope and the toe of the slope once equilibrium is restored, correlates well with the brittleness index of Bishop (1967) when a common peak strength is adopted. In a general case, both the peak and the residual strength control the failure and its dynamic behaviour.

\section{Creeping landslides}

Strain rate effects on friction explain the slow creeping motion of landslides once static equilibrium is lost. The relationship between friction and shearing strain rate derives from theoretical results, which explains friction, at the local scale of yielding points in contact, by means of the chemical reaction process. Strain rate effects are capable of explaining creep at the small scale of sample testing, as well as at the large scale of creeping slides. A simple dynamic formulation of a planar slide and a logarithmic dependence of residual friction on sliding velocity explained the time history of observed displacements of Vallcebre creeping slide.

Rate effects on friction introduce a 'viscous' resisting force on the shearing plane. Viscous forces formulated directly in terms of landslide velocity are a common procedure to explain and model creeping phenomena. Rate effects on friction are preferred because of the theoretical background justifying their origin, the simplicity of the approach, which can be introduced directly in existing models, and the automatic dependence of 'viscous' resisting forces on confining effective stress, which appears to be a desirable feature.

A generalisation of the dependence of friction angle on rate effects is to add a 'state' component to account for other phenomena such as healing effects. This assumption offers the possibility of predicting the evolution of sliding velocity and the failure time. The discussion centred on one case, formulated for a planar landslide. However, known cases of fast landslide acceleration require a major and sudden change in velocity, which is not accounted for by rate- and statedependent friction laws. Matching the sudden acceleration observed in Vajont landslide, for instance, requires the rapid cancellation of available shear strength on the failure surface.

\section{Fast sliding}

The preferred explanation for the cancellation of shearing strength in shearing bands in clays is the thermally induced pressurisation of the clay pore water and the parallel decrease of effective confining stress. Plastic work, which accumulates in the sliding surface during the landslide motion, provides the heating.

The original formulation of this physical phenomenon in the context of THM interactions developing in a deforming shear band is attributable to Voight \& Faust (1982). Many authors in the years that followed adopted this framework in their analysis of fast landslides, very often inspired by Vajont landslide.

A compound geometry, simplified by two interacting wedges, which accounts for mass transfer between the blocks, allows the generalisation of previous developments for planar slides. The solution of this case captures the high velocity estimated for Vajont landslide when a two-wedge model approximates a representative $2 \mathrm{D}$ cross-section of the slide. The permeability of the shearing band and the nearby clay layer emerged as the main controlling variable to determine the danger of fast landsliding. Shear band thickness is also a key parameter in this regard. However, the stress-controlled nature of landslides and the small thickness of shear bands in clay contribute to minimise the relevance of shear band thickness in practice.

The paper presents a generalisation of the dynamic THM approach to arbitrary landslide geometries, by way of an MPM numerical procedure.

The thickness of strain localisation bands in MPM depends on the size of the cells of the computational mesh. The implication is that numerical band thickness is exceedingly large if compared with reality, especially in clays. Then, the calculated input work per unit volume of the band decreases, as well as the calculated excess pore pressures. This unacceptable result led to solution of the problem by superimposing two interacting continua: the 'shear band' continuum and the remaining soil/rock matrix.

The shear band thickness becomes a material parameter, which is not related to the numerical calculation procedure. The new formulation was ultimately applied to simulate Vajont landslide successfully. Calculated excess temperatures in the basal Vajont failure surface were close to $50^{\circ} \mathrm{C}$. This excess temperature was capable of increasing pore pressures and reducing effective stress to nil values during the landslide motion.

\section{Transition from creeping to fast motion}

The dynamic THM approach developed for simple geometries (planar, two wedges) was enhanced by adding a 
rate-dependent component of friction. This simple addition provides an interesting framework to analyse the slow-fast transition of creeping landslides. In straightforward descriptive terms, rate effects work to avoid the feeding back mechanism leading to the 'blow-up' phenomenon, which is responsible for the fast accumulation of excess pore pressures in shearing bands.

The positive result is the reduction of the permeability-related area for unsafe conditions (risk of high sliding velocity). Further parametric studies led to the identification of 'safe' and 'unsafe' regions in terms of the intensity of shearing rate effects.

The method was also generalised for continuous domains. It was applied to the reactivated Canelles landslide, which was initially judged as a landslide prone to fast landsliding mainly because of the low permeability of the clay layer that includes the sliding surface. Even a moderate strain rate effect on the residual clay strength was enough to avoid the risk of rapid sliding under conditions leading to the slide re-activation: a strong reservoir drawdown.

\section{ACKNOWLEDGEMENTS}

Dr Núria M. Pinyol (UPC) has maintained a close and wide-ranging cooperation with the author, during the last decade, in the discussion of concepts and development of models for landslide mobility. Dr Francisco Zabala (Universidad de San Juan, Argentina) and Dr Alba Yerro (Virginia Tech) pioneered the development of material point methods at UPC and contributed enthusiastically to apply these methods to landslide phenomena. They deserve the credit for most of the examples given in the paper. Dr Mauricio Alvarado continued the UPC effort to develop MPM methods and contributed to the modelling of Vajont and Canelles landslides. Professor Sebastiá Olivella (UPC) helped decisively to resolve the ill-conditioned mesh dependence of THM analysis in the presence of shearing bands. Dr Antonio Zervos (University of Southhampton) provided critical help to resolve numerical difficulties for the interaction between slow and rapid motion landslides. Dr Alex Rohe (Deltares) provided permanent support and advice for the use of the MPM code Anura3D. The code was developed at the initiative of the MPM research community, which include, at present, the following institutions: Deltares, University of Cambridge, Technical University of Hamburg, UPC, University of Padova, University of California, Technical University of Delft, Virginia Tech and University of Salerno. Eng. Mercedes Sondon helped to solve the complicated soil-structure problem posed by the Pampaneira landslide. Many colleagues from UPC collaborated with the author to analyse and understand slope stability and landslide cases of widely different nature. Their support covers field work, modelling, instrumentation, calculations and laboratory work: Professor J. Corominas, Professor A. Gens, Professor J. Gili; Professor A. Lloret, Professor E. Romero, Dr J. Moya and Dr A. Ramon. The first serious attempt to understand the rapid acceleration of compound landslides, such as Vajont, was done during the preparation of the books on the geomechanics of failures. Professor Alexander Puzrin, a co-author of the books, helped much with his discussions and rigour. Professor Luciano Picarelli and Professor Leonardo Cascini with their permanent determination and enthusiasm to promote landslide research under any conceivable perspective and their generous friendship have been an enduring incentive to the author's work. The author expresses his gratitude and deep thanks to all of them.

\section{NOTATION}

$A$ coefficient quantifying the intensity of rate effects on friction

$A_{\text {ref }} \quad$ reference area for heat transfer

$B$ parameter quantifying effect of state on friction

$c_{\mathrm{m}} \quad$ specific heat of saturated soil

$c_{\mathrm{r}}^{\prime} \quad$ effective cohesion of rock

$c_{\mathrm{r} 0}^{\prime} \quad$ reference rock effective cohesion

$c_{\mathrm{S}}$ specific heat of solid

$c_{\mathrm{w}} \quad$ specific heat of water

$D$ depth of failure surface in planar slides

$D_{\text {c }} \quad$ critical size of asperities

$E \quad$ Young's modulus

$E_{\text {a }}$ activation energy

$E_{\mathrm{a} 1}$ reference activation energy

$e$ half thickness of shear band

$e^{\mathrm{p}} \quad$ deviatoric plastic strain tensor

$f$ friction coefficient

$f^{*} \quad$ basic friction coefficient

$f_{\mathrm{v}}$ frictional term accounting for strain rate effects

g gravitational constant

$\stackrel{g}{H}$ rate of heat dissipation

$\dot{H}_{\mathrm{B}} \quad$ work dissipated in shear band

$h_{\mathrm{w}}$ height of water surface

$I_{\mathrm{B}} \quad$ Bishop's brittleness index

$K$ coefficient of permeability (Darcy)

$k$ intrinsic permeability

$L_{10}, L_{20}$ lengths of sliding blocks 1 and 2

$L_{\mathrm{B}} \quad$ reference length for shear band thickness $\left(L_{\mathrm{B}}=2 e\right)$

$L_{\text {ref }}$ reference length for computational mesh

$M_{1}, M_{2}$ mass of wedges 1 and 2

m unit matrix

$m_{\text {soil }} \quad$ compressibility coefficient of soil

$m_{\mathrm{v}} \quad$ confined compressibility coefficient

$N^{\prime}$ effective normal force

$n$ porosity

$P_{\text {w1 }}, P_{\text {w2 }}, P_{\text {wint }} \quad$ water pressure forces

$p_{0} \quad$ effective isotropic confining stress in tests reported in Fig. 46

$p^{\prime}$ effective mean stress

$p^{*} \quad p^{\prime}+c^{\prime} / \tan \phi^{\prime}$

$p_{\mathrm{L}}^{\mathrm{B}} \quad$ liquid pressure in shear band

$p_{\mathrm{L}}^{\mathrm{M}} \quad$ liquid pressure in soil matrix

$p_{\mathrm{w}} \quad$ water pressure

$p_{\mathrm{w}}^{0} \quad$ reference water pressure

$q$ deviatoric stress

$q$ Darcy flow rate

$\boldsymbol{q}_{\mathrm{L}}$ local liquid flow rate between shear band and soil matrix

$R$ gas constant

$R_{\mathrm{f}} \quad$ residual factor

$s$ displacement

$s_{i}(i=1,2) \quad$ geometric and frictional coefficients in equation (21) for dynamic equilibrium

$T$ shear force

$T_{\mathrm{a}} \quad$ absolute temperature

$t$ time

$t * \quad$ ratio of time to time to failure

$\hat{t}$ dimensionless time

$t_{\text {failure }}$ time to failure

$t_{i}(i=1$ to 5$) \quad$ geometric and frictional coefficients in equation (21) for dynamic equilibrium

$u_{\mathrm{w}} \quad$ excess pore water pressure

$\hat{u}_{\mathrm{w}} \quad$ dimensionless excess pore pressure

$v$ velocity

$\hat{v}$ dimensionless velocity

$v_{\text {ref }}$ reference velocity

$\boldsymbol{v}_{\mathrm{S}}$ velocity of solid particles

$W \quad$ weight of a vertical slice

$\dot{W}$ rate of plastic work per unit volume

$W_{1}, W_{2} \quad$ weight of wedges 1 and 2

$\hat{z}$ dimensionless $z$ coordinate

$\alpha$ parameter controlling rate of change in effective friction with plastic shear strain rate

$\alpha_{\mathrm{w}} \quad$ volumetric compressibility of water 
$\beta$ slope angle

$\beta_{\mathrm{s}}$ thermal expansion coefficient of solids

$\beta_{\text {soil }}$ thermal expansion coefficient of soil

$\beta_{\mathrm{w}}$ thermal expansion coefficient of water

$\Gamma$ thermal conductivity

$\Gamma_{c}$ constant to describe decay of effective rock cohesion with slide displacement

$\dot{\gamma}$ shear strain rate

$\gamma_{\mathrm{w}}$ specific weight of water

$\varepsilon_{\mathrm{a}}$ axial deformation

$\varepsilon_{\mathrm{ef}}^{\mathrm{p}}$ equivalent plastic strain

rate of plastic strain

$\varepsilon_{\mathrm{vol}}$ volumetric deformation

$\eta$ parameter controlling softening rate when deviatoric strains accumulate

$\Theta$ dimensionless thermal dissipation coefficient

$\theta$ temperature

$\theta_{0} \quad$ reference temperature

$\theta^{\mathrm{B}} \quad$ shear band temperature

$\mu_{\mathrm{L}} \quad$ liquid (water) viscosity

$v$ Poisson's ratio

$\xi$ state variable

$\xi_{0}$ reference state variable

$\Pi$ dimensionless coefficient associated with thermal expansion and compressibility

$\rho_{\mathrm{L}} \quad$ liquid density

$\rho_{\mathrm{S}} \quad$ solids density

$\rho_{\mathrm{s}}^{0} \quad$ reference solids density

$\rho_{\mathrm{w}} \quad$ water density

$\rho_{\mathrm{w}}^{0} \quad$ reference water density

$\Sigma$ dimensionless consolidation coefficient

$\sigma$ normal stress

$\bar{\sigma} \quad$ stress tensor

$\bar{\sigma}^{\prime}$ effective stress tensor

$\sigma_{\mathrm{a}}^{\prime} \quad$ axial effective stress

$\sigma_{\mathrm{c}}$ local normal stress (molecular scale)

$\sigma_{\mathrm{n}}$ normal stress

$\sigma_{\mathrm{n}}^{\prime} \quad$ normal effective stress

$\bar{\sigma}_{\mathrm{n}}^{\prime} \quad$ average normal effective stress on a failure surface

$\tau$ shear stress

$\bar{\tau}$ average shear stress on a failure surface

$\tau_{\mathrm{c}}$ local shear stress (molecular scale)

$\tau_{\mathrm{f}} \quad$ failure shear strength

$\tau_{\mathrm{p}}, \tau_{\text {peak }}$ peak shear strength

$\tau_{\mathrm{r}}, \tau_{\text {res }}$ residual shear strength

$\tau_{\mathrm{v}} \quad$ viscous shear stress

$\phi^{\prime}$ effective friction angle

$\phi_{0}^{\prime} \quad$ basic friction angle

$\phi_{\text {mob }}$ mobilised friction angle

$\phi_{\mathrm{p}}^{\prime}, \phi_{\text {pak }}^{\prime}$ effective peak friction angle

$\phi_{\mathrm{r}}^{\prime}, \phi_{\mathrm{res}}^{\prime}$ effective residual friction angle

$\phi_{\text {rock }}^{\prime}$ effective friction angle of rock

$\phi^{\mathrm{T}}$ maximum increase in friction angle due to rate effects

$\Psi \quad$ dimensionless coefficient associated with kinetic energy and heat stored in shear band

$\psi \quad$ state friction term

$\psi_{\mathrm{L}} \quad$ coefficient for liquid transfer from shear bands to soil matrix

$\psi_{\theta} \quad$ coefficient for heat transfer from shear bands to soil matrix

$\Omega \quad$ active volume of contact bonds

\section{REFERENCES}

Alonso, E. E. (2000). General report: cuttings and natural slopes. In The geotechnics of hard soils-soft rocks (eds A. Evangelista and L. Picarelli), vol. 3, pp. 1557-1588. Rotterdam, the Netherlands: Balkema.

Alonso, E. E. \& Gens, A. (2006a). Aznalcóllar dam failure. Part 1: field observations and material properties. Géotechnique 56, No. 3, 165-183, https://doi.org/10.1680/geot.2006.56.3.165.

Alonso, E. E. \& Gens, A. (2006b). Aznalcóllar dam failure. Part 3: dynamics of the motion. Géotechnique 56, No. 3, 203-210, https://doi.org/10.1680/geot.2006.56.3.203.
Alonso, E. E. \& Pinyol, N. M. (2010). Criteria for rapid sliding I. a review of vaiont case. Engng Geol. 114, No. 3-4, 198-210.

Alonso, E. E. \& Zabala, F. (2012). Failure mechanisms in brittle soils: a dam failure revisited with the material point method. In Computer methods for geomechanics: frontiers and new applications. Proceedings of international conference of IACMAG (International Association for Computer Methods and Advances in Geomechanics), Melbourne, Australia (eds N. Khalili and M. Oeser ), vol. 1, pp. 377-380. Sydney, Australia: Centre for Infrastructure Engineering and Safety.

Alonso, E. E., Gens, A. \& Lloret, A. (1993). The landslide of Cortes de Pallás, Spain. A case study. Géotechnique 43, No. 4, 507-521, https://doi.org/10.1680/geot.1993.43.4.507.

Alonso, E. E., Pinyol, N. M. \& Puzrin, A. (2010). Geomechanics of failures. Dordrecht, the Netherlands: Springer.

Alonso, E. E., Zervos, A. \& Pinyol, N. M. (2016). Thermo-poro-mechanical analysis of landslides: from creeping behaviour to catastrophic failure. Géotechnique 66, No. 3, 202-219, https://doi.org/10.1680/jgeot.15.LM.006.

Alvarado, M., Pinyol, N. M. \& Alonso, E. E. (2019). Landslide motion assessment including rate effects and thermal interactions: revisiting the Canelles landslide. Can. Geotech. J. 56, No. 9, 1338-1350.

Anura3D (2020). www.anura3d.com (accessed 21/09/2020).

Bazant, Z. P. \& Jirásek, M. (2002). Nonlocal integral formulations of plasticity and damage: survey of progress. J. Engng Mech. 128, No. 11, 1119-1149.

Bishop, A. W. (1967). Progressive failure - with special reference to the mechanism causing it. In Proceedings of the geotechnical conference, vol. 2, pp. 142-150. Oslo, Norway: Norwegian Geotechnical Institute.

Bowden, F. \& Tabor, D. (1964). The friction and lubrication of solids. New York, NY. USA: Oxford University Press.

BSI (2004) BS EN 1977-1:2004: Eurocode 7: Geotechnical design Part 1: General rules. London, UK: BSI.

Cascini, L., Calvello, M. \& Grimaldi, G. M. (2014). Displacement trends of slow moving landslides: classification and modelling. J. Mountain Sci. 11, No. 3, 592-606.

Cecinato, F. \& Zervos, A. (2012). Influence of thermomechanics in the catastrophic collapse of planar landslides. Can. Geotech. J. 49, No. 2, 207-225.

Cecinato, F., Zervos, A. \& Veveakis, E. (2011). A thermomechanical model for the catastrophic collapse of large landslides. Int. J. Numer. Methods Engng 35, No. 14, 1507-1535.

Comegna, L., Picarelli, L., Bucchignani, E. \& Mercogliano, P. (2013). Potential effects of incoming climate changes on the behaviour of slow active landslides in clay. Landslides 10, No. 4, 373-391.

Cooper, M. (1996). The progressive development of a failure slip surface in over-consolidated clay at Selborne, UK. In Proceedings of the 7th international symposium on landslides (ed. K. Senneset), pp. 683-688. Rotterdam, the Netherlands: Balkema.

Cooper, M. R., Bromhead, E. N., Petley, D. J. \& Grant, D. I. (1998). The Selbourne cutting stability experiment. Géotechnique 48, No. 1, 83-101, https://doi.org/10.1680/geot. 1998.48.1.83.

Corominas, J., Moya, J., Ledesma, A., Lloret, A. \& Gili, J. A. (2005). Prediction of ground displacements and velocities from groundwater level changes at the Vallcebre landslide (Eastern Pyrenees, Spain). Landslides 2, No. 2, 83-96.

Cruden, D. M. \& Varnes, D. J. (1996). Landslide types and processes. In Landslide: investigation and mitigation, special report 247, pp. 36-75. Washington, DC, USA: Transportation Research Board.

Dai, F. C., Deng, J. H., Tham, L. G., Law, K. T. \& Lee, C. F. (2004). A large landslide in Zigui County, Three Gorges area. Can. Geotech. J. 41, No. 6, 1233-1240.

Desrues, J. \& Viggiani, G. (2004). Strain localization in sand: an overview of the experimental results obtained in Grenoble using stereophotogrammetry. Int. J. Numer. Analyt. Meth. Geomec. 28, No. 4, 279-321.

Di Carluccio, G., Pinyol, N. M. \& Alonso, E. E. (2019). Liquefaction-induced large displacements of caisson quay wall: Barcelona harbor, Spain. In Proceedings of 2nd international conference on the material point method for modelling 
soil-water-structure interaction (eds D. Liang, K. Kumar and A. Rohe), pp. 234-239. Beijing, China: China Ocean Press.

Di Toro, G., Han, R., Hirose, T., De Paoloa, N., Nielsen, S., Mizoguchi, K., Ferri, F., Cocco, M. \& Shimamoto, T. (2011). Fault lubrication during earthquakes. Nature 471, No. 7339, 494-498. https://doi.org/10.1038/nature09838.

Dieterich, J. (1979). Modeling of rock friction 1. Experimental results and constitutive equations. J. Geophys. Res. 84, No. 5B, 2161-2168.

Dounias, G. T., Potts, D. M. \& Vaughan, P. R. (1996). Analysis of progressive failure and cracking in old British dams. Géotechnique 46, No. 4, 621-640, https://doi.org/10.1680/ geot. 1996.46.4.621.

Fern, E. J. \& Soga, K. (2016). The role of constitutive models in MPM simulations of granular column collapses. Acta Geotechnica 11, No. 3, 659-678, https://doi.org/10.1007/ s11440-016-0436-x.

Fern, J. Rohe, A., Soga, K. \& Alonso, E. E. (2019). The material point method for geotechnical engineering: a practical guide. Boca Raton, FL, USA: CRC Press.

Fukuzono, T. (1990). Recent studies on time prediction of slope failure. Landslide News 4, 9-12.

Gens, A. \& Alonso, E. E. (2006). Aznalcóllar dam failure. Part 2: stability conditions and failure mechanism. Géotechnique 56, No. 3, 185-201, https://doi.org/10.1680/ geot. 2006.56.3.203.

Ghasemi, P., Martinelli, M., Cuomo, S. \& Calvello, M. (2018). MPM modelling of static liquefaction in reduced-scale slope. In Numerical methods in geotechnical engineering IX (NUMGE 2018) (eds A. S. Cardoso, J. L. Borges, P. A. Costa, A. T. Gomes, J. C. Marques and C. S. Vieira), vol. 1, pp. 1041-1046. Leiden, the Netherlands: CRC Press/Balkema.

Giridharan, S., Stolle, D. \& Moormann, C. (2019). Modelling liquefaction using the material point method - an evaluation using two constitutive models. In Proceedings of 2nd international conference on the material point method for modelling soil-water-structure interaction (eds D. Liang, K. Kumar and A. Rohe), pp. 82-89. Beijing, China: China Ocean Press.

Goren, L. \& Aharonov, E. (2007). Long runout landslides: the role of frictional heating and hydraulic diffusivity. Geophys. Res. Lett. 34, No. 7, L07301.

Goren, L. \& Aharonov, E. (2009). On the stability of landslides: a thermo-poro-elastic approach. Earth Planet. Sci. Lett. 277, No. 3-4, 365-372.

Goren, L., Aharonov, E. \& Anders, M. H. (2010). The long runoutof the heart mountain landslide: heating, pressurization, andcarbonate decomposition. J. Geophys. Res.: Solid Earth 115, No. B10, B10210.

Grant, D. (1996). Instrumentation systems for and failure mechanisms of an induced slope failure project. $\mathrm{PhD}$ thesis, University of Southampton, Southampton, UK.

Habib, P. (1967). Sur un mode de glissement des massifs rocheux. Comptes Rendus de l'Académie des Sciences Paris 264, Serie A, 151-153 (in French).

Helmstetter, A., Sornette, D., Grasso, J. R., Andersen, J. V., Gluzman, S. \& Pisarenko, V. (2003). Slider-block friction model for landslides: application to Vajont and La Clapiere landslides. J. Geophys. Res.: Solid Earth 109, No. B2, B02409.

Hendron, A. \& Patton, F. D. (1985). The Vajont slide, a geotechnical analysis based on new geologic observations of the failure surface, Technical Report GL-85-5. Washington, DC, USA: Department of the Army, US Army Corps of Engineers.

Hernández-Madrigal, V., Mora-Chaparro, J. \& Garduño-Monroy, V. (2010). Large block slide at San Juan Grijalva, northwest, Chiapas, Mexico. Landslides 7, No. 3, $109-115$.

Hungr, O. (1995). A model for the runout analysis of rapid flow slides, debris flows and avalanches. Can. Geotech. J. 32, No. 4, $610-623$.

Hungr, O., Leroueil, S. \& Picarelli, L. (2014). The Varnes classification of landslide types, an update. Landslides 11, No. 2, 167-194.

Jaeger, C. (1965a). The Vaiont rockslide. Part I. Water Power March, $110-111$.

Jaeger, C. (1965b). The Vaiont rockslide. Part II. Water Power April, $142-144$
Kenney, T. C. (1967). Stability of the Vajont valley slope, discussion of a paper by L. Müller (1964) on the rock slide in the Vajont valley. Rock Mech. Engng Geol. 5, No. 1, 10-16.

Kuhn, M. R. \& Mitchell, J. K. (1993). New perspectives on soil creep. J. Geotech. Engng 119, No. 3, 507-524.

Kwok, C. Y. \& Bolton, M. D. (2010). DEM simulations of thermally activated creep in soils. Géotechnique 60, No. 6, 425-433, https://doi.org/10.1680/geot.2010.60.6.425.

Lacerda, W. A. (1976). Stress-relaxation and creep effects on soil deformation. PhD thesis, University of California, Berkeley, CA, USA.

Leroueil, S. (2001). Natural slopes and cuts: movement and failure mechanisms. Géotechnique 51, No. 23, 197-243, https://doi. org/10.1680/geot.2001.51.3.197.

Li, X. \& Zienkiewicz, O. C. (1992). Multiphase flow in deforming porous media and finite element solutions. Comput. Structs 45, No. 2, 211-227.

Mencl, V. (1966). Mechanics of landslides with non-circular slip surfaces with special reference to the Vaiont landslide. Géotechnique 19, No. 4, 329-337, https://doi.org/10.1680/geot. 1966.16.4.329.

Mirada, F. (2015). The material point method in slope stability analysis. MSc thesis, Universitat Politècnica de Catalunya, Barcelona, Spain.

Mitchell, J. K. (1976). Fundamentals of soil behaviour. New York, NY, USA: John Wiley \& Sons.

Moya, J. (2000). Geological survey of Aznalcóllar tailings deposit. Annex 3, of expert witness report for the court of Sanlúcar la Mayor, Sevilla, Spain. Barcelona, Spain: Department of Geotechnical Engineering and Geosciences, Universitat Politècnica de Catalunya.

Müller-Salzburg, L. (1987). The Vajont catastrophe - a personal review. Engng Geol. 24, No. 1-4, 423-444. https://doi.org/ 10.1016/0013-7952(87)90078-0.

Muñoz, J., Alonso, E. E. \& Lloret, A. (2009). Thermo-hydraulic characterisation of soft rock by means of heating pulse tests. Géotechnique 59, No. 4, 293-306, https://doi.org/10.1680/geot. 2009.59.4.293.

Murayama, S., Michihiro, K. \& Sakagami, T. (1984). Creep characteristics of sands. Soils Found. 24, No. 2, 1-15.

Newmark, N. M. (1965). Effects of earthquakes on dams and embankments. Géotechnique 15, No. 2, 139-160, https://doi.org/ 10.1680/geot.1965.15.2.139.

Nonveiller, E. (1967). Shear strength of bedded and jointed rock as determined from the Zalesina and Vaiont slides. In Proceedings of the geotechnical conference, vol. 1, pp. 289-294. Oslo, Norway: Norwegian Geotechnical Institute.

Nonveiller, E. (1987). The Vajont reservoir slope failure. Engng Geol. 24, No. 1-4, 493-512.

Olivella, S., Vaunat, J. \& Rodríguez-Dono, A. (2019). Code_Bright user's guide. Version 9. Barcelona, Spain: Division of Geotechnical Engineering and Geosciences, Universitat Politècnica de Catalunya. See https://deca.upc.edu/en/ projects/code_bright (accessed 25/09/2020).

Paronuzzi, P. \& Bolla, A. (2012). The prehistoric Vaiont rockslide: an updated geological model. Geomorphology 169-170, 165-191.

Petley, D. N., Bulmer, M. H. \& Murphy, W. (2002). Patterns of movement in rotational and translational landslides. Geology $\mathbf{3 0}$, No. 8, 719-722.

Pinyol, N. M. \& Alonso, E. E. (2010a). Fast planar slides. a closed-form thermo-hydro-mechanical solution. Int. J. Numer. Analyt. Methods Geomech 34, No. 1, 27-52.

Pinyol, N. M. \& Alonso, E. E. (2010b). Criteria for rapid sliding II. Thermo-hydro-mechanical and scale effect in vaiont case. Engng Geol. 114, No. 3-4, 211-227.

Pinyol, N. M., Alonso, E. E., Corominas, J. \& Moya, J. (2012). Canelles landslide. Modelling rapid drawdown and fast potential sliding. Landslides 95, No. 1, 33-51.

Pinyol, N. M., Alvarado, M., Alonso, E. E. \& Zabala, F. (2018). Thermal effects in landslide mobility. Géotechnique 68, No. 6, 528-546, https://doi.org/10.1680/jgeot. 17.P.054.

Potts, D. M. \& Zdravkovic, L. (2001a). Finite element analysis in geotechnical engineering: theory. London, UK: Thomas Telford Ltd. 
Potts, D. M. \& Zdravkovic, L (2001b). Finite element analysis in geotechnical engineering: application. London, UK: Thomas Telford.

Potts, D. M., Dounias, G. T. \& Vaughan, P. R. (1990). Finite element analysis of progressive failure of Carsington embankment. Géotechnique 40, No. 1, 79-101, https://doi.org/10.1680/geot. 1990.40.1.79.

Pouya, A., Léonard, C. \& Alfonsi, P. (2007). Modelling a viscous rock joint activated by rainfall: application to the la Clapière landslide. Int. J. Rock Mech. Min. Sci. 44, No. 1, 120-129.

Puzrin, A. M., Alonso, E. E. \& Pinyol, N. M. (2010). Geomechanics of failures. Dordrecht, the Netherlands: Springer.

Rice, J. R. (2001). New perspectives in crack and fault dynamics. Mechanics for a new millennium. In Proceedings of the 20th international congress on theoretical and applied mechanics (eds H. Aref and J. W. Phillips), pp. 1-23. Chicago, IL, USA: Kluwer Academic Publishers.

Rice, J. R., Lapusta, N. \& Ranjith, K. (2001). Rate and state dependent friction and the stability of sliding between elastically deformable solids. J. Mech. Phys. Solids 49, No. 9, 1865-1898.

Rots, J., Nauta, P., Kuster, G. \& Blaauwendraad, J. (1985). Smeared crack approach and fracture localization in concrete. HERON 30, No. 1, 3-48.

Ruina, A. (1983). Slip instability and state variable friction laws. $J$. Geophys. Res. 8, No. B12, 10359-10370.

Saito, M. (1965). Forecasting the time of occurrence of a slope failure. In Proceedings of the 6th international conference on soil mechanics and foundation engineering, vol. 2, pp. 315-318. Toronto, Canada: University of Toronto Press.

Saito, M. (1969). Forecasting time of slope failure by tertiary creep. In Proceedings of the 7th international conference on soil mechanics and foundation engineering, vol. 2, pp. 677-683. Mexico City, Mexico: Sociedad Mexicana de Mecanica.

Sibille, L. (2016). Erosion interne et rupture dans les sols grenus. Thèse d'Habilitation à diriger des recherches, Universite Grenoble Alpes, Grenoble, France (in French).

Skempton, A. W. (1964). Long term stability of clay slopes. Géotechnique 14, No. 2, 77-101, https://doi.org/10.1680/geot. 1964.14.2.77.

Skempton, A. W. (1966). Bedding-plane slip, residual strength and the Vaiont landslide. Correspondence. Géotechnique 16, No. 1, 82-84, https://doi.org/10.1680/geot.1966.16.1.82.

Skempton, A. W. (1985). Residual strength of clays in landslides, folded strata, and the laboratory. Géotechnique 35, No. 1, 3-18, https://doi.org/10.1680/geot.1985.35.1.3.

Soga, K., Alonso, E., Yerro, A., Kumar, K. \& Bandara, S. (2016). Trends in large-deformation analysis of landslide mass movements with particular emphasis on the material point method. Géotechnique 66, No. 3, 248-273, https://doi.org/10.1680/jgeot. 15.LM.005.

Stark, T. D. \& Eid, H. T. (1994). Drained residual strength of cohesive soils. J. Geotech. Engng 120, No. 5, 856-871.

Tika, T. E., Vaughan, P. R. \& Lemos, L. (1996). Fast shearing of pre-existing shear zones in soil. Géotechnique 46, No. 2, 197-233, https://doi.org/10.1680/geot.1996.46.2.197.

Uriel Romero, S. \& Molina, R. (1977). Kinematic aspects of Vaiont slide. In Proceedings of the 3rd international conference of the ISRMR, pp. 865-870. Denver, CO, USA: National Academy of Sciences 2B.

Van Asch, T. W. J., Van Beek, L. P. H. \& Bogaard, T. A. (2007). Problems in predicting the mobility of slow-moving landslides. Engng Geol. 91, No. 1, 46-55.

Vardoulakis, I. (2000). Catastrophic landslides due to frictional heating of the failure plane. Mech. Cohesive-frict. Mater. 5, No. 6, 443-467.

Vardoulakis, I. (2002). Dynamic thermo-poro-mechanical analysis of catastrophic landslides. Géotechnique 52, No. 3, 157-171, https://doi.org/10.1680/geot.2002.52.3.157.

Vardoulakis, I. (2006). Localization in geomechanics. In Proceedings of the 16th international conference on soil mechanics and geotechnical engineering, pp. 3663-3668. Rotterdam, the Netherlands: IOS Press/Millpress.

Varnes, D. J. (1978). Slope movement types and processes. In Landslides, analysis and control (eds R. L. Schuster and R.
J. Krizek), special report 176, pp. 11-33. Washington, DC, USA: Transportation Research Board, National Academy of Sciences.

Vaughan, P. R. \& Walbancke, H. J. (1973). Pore pressure changes and delayed failure of cutting slopes in overconsolidated clay. Géotechnique 23, No. 4, 531-539, https://doi.org/10.1680/geot. 1973.23.4.531.

Veveakis, E., Vardoulakis, I. \& Di Toro, G. (2007). Thermoporomechanics of creeping landslides: the 1963 Vaiont slide, northern Italy. J. Geophys. Res. 112, No. F3, F03026.

Voight, B. (1978). Rockslides and avalanches, vol. 1. New York, NY, USA: Elsevier.

Voight, B. \& Faust, C. (1982). Frictional heat and strength loss in some rapid landslides. Géotechnique 32, No. 1, 43-54, https:// doi.org/10.1680/geot.1982.32.1.43.

Wang, F. W., Zhang, Y. M., Huo, A. T., Matsumoto, T. \& Huang, B. T. (2004). The July 14, 2003 Qianjiangping landslide, Three Gorges reservoir, China. Landslides 1, No. 2, 157-162.

Wang, G., Suemine, A. \& Schulz, W. H. (2010). Shear-rate-dependent strength control on the dynamics of rainfall-triggered landslides, Tokushima prefecture, Japan. Earth Surf. Processes Landforms 35, No. 4, 407-416.

Wedage, A., Morgenstern, N. R. \& Chan, D. H. (1998). A strain rate dependent constitutive model for clays at residual strength. Can. Geotech. J. 35, No. 2, 364-373.

Wolter, A., Stead, D. \& Clague, J. J. (2014). A morphologic characterisation of the 1963 Vajont slide. Italy, using long-range terrestrial photogrammetry. Geomorphology 206, 147-164. https://doi.org/10.1016/j.geomorph.2013.10.006.

Yerro, A., Alonso, E. E. \& Pinyol, N. M. (2015). The material point method for unsaturated soils. Géotechnique 65, No. 3, 201-217, https://doi.org/10.1680/geot.14.P.163.

Yerro, A., Alonso, E. E. \& Pinyol, N. M. (2016a). Run-out of landslides in brittle soils. Comput. Geotech. 80, 427-439. https://doi.org/10.1016/j.compgeo.2016.03.001.

Yerro, A., Pinyol, N. M. \& Alonso, E. E. (2016b). Internal progressive failure in deep-seated landslides. Rock Mech. Rock Engng 49, No. 6, 1-16. https://doi.org/10.1007/s00603015-0888-6.

Zabala, F. \& Alonso, E. E. (2011). Progressive failure of aznalcóllar dam using the material point method. Géotechnique 61, No. 9, 795-808, https://doi.org/10.1680/geot.9.P.134.

Zabala, F., Rodari, R. \& Oldecop, L. (2004). Localización de deformaciones en estructuras utilizando el método del punto material. Revista Engenharia Estrutural 1290, No. 5400, 11-29 (in Spanish).

\section{VOTE OF THANKS}

ALEXANDER M. PUZRIN, ETH Zurich, Zurich, Switzerland

My Lord, Mr Chairman, ladies and gentlemen: It is an honour and great pleasure to deliver a vote of thanks to the 57th Rankine lecturer, Professor Eduardo Alonso.

I met Eduardo 15 years ago in Atlanta, where he gave us a presentation on Aznalcóllar dam collapse. Someone asked him if chemistry played a role there. Eduardo's answer surprised me. He said that he always starts with simple mechanics, and if it works, he does not look for more exotic explanations. This was unusual, because we often go straight for exotic explanations before even trying simple mechanics.

In his Rankine Lecture, Eduardo remained faithful to himself. He started with simple mechanics, successfully explaining slow landslides, and 'turned on the heat' only after this simple approach failed to predict landslide acceleration. Eduardo mentioned today that he was not the first one to make this connection. But the truth is that most of the previous attempts required a bit of magic to make this work.

Today we saw an elegant THM framework based on solid experimental evidence, thermodynamically consistent theory 
and impressive case study validations. The most important outcome of this approach is that it allows the critical transition between the slow and fast landslide phases to be predicted using basic soil properties. There is no magic here, except perhaps the magic of human brilliance.

And when he comes to the limits of what this analytical framework can do, Eduardo turns to the numerical analysis, but again in his own way. Instead of abusing finite elements, he joins the pioneers of the material point method in developing a more appropriate framework for his theory. This is even more admirable, considering that many people miraculously forget how to program the moment they become full professors.

There are many reasons for us to be grateful to Eduardo. I will just mention three of them. The first one is the choice of this topic. We know his many contributions to soil mechanics and geotechnical engineering. He could easily have turned this lecture into a life tribute to himself. Instead he chose to show us his latest development, his 'baby', giving us an opportunity to learn something new. Thank you, Eduardo, for that.

To explain the second reason, I shall have to remind you that this topic of landslides we share with geologists who would prefer not to share it. I remember the major International Landslide Symposium in Canada in 2012. Geotechnical engineers had a lonely session somewhere in the basement. Suddenly there came an announcement of the new lecture dedicated to Albert Heim, one of the fathers of engineering geology. And whom do you think the geologists decided to honour with delivering the inaugural Albert Heim lecture? Yes, it was Eduardo, and this was a moment of pride for all of us in the basement. Thank you.

Finally, I have been trying for many years to understand the secret of Eduardo's success, and I think today I got it. The hint was hidden in his list of acknowledgements. Eduardo was the first one to tap into the enormous reservoir of Spanish and Catalonian female geotechnical talent. Nuria Pinyol, Anna Ramon, Alba Yerro, are just some of those he mentored to become outstanding young researchers, who helped him in his investigations. Thank you, Eduardo, for this valuable hint.

On behalf of the British Geotechnical Association and all of the rest of us I would like to thank Professor Eduardo Alonso for his inspiring Rankine Lecture, and to wish him many productive years, interesting problems and talented young disciples. Please, join me in a round of applause. 